Editora Poisson

\section{Estudos sobre Transporte Volume 1}

1a Edição

Belo Horizonte

Poisson

2021 
Editor Chefe: Dr. Darly Fernando Andrade

\section{Conselho Editorial}

Dr. Antônio Artur de Souza - Universidade Federal de Minas Gerais Msc. Davilson Eduardo Andrade

Dra. Elizângela de Jesus Oliveira - Universidade Federal do Amazonas

Msc. Fabiane dos Santos

Dr. José Eduardo Ferreira Lopes - Universidade Federal de Uberlândia

Dr. Otaviano Francisco Neves - Pontifícia Universidade Católica de Minas Gerais

Dr. Luiz Cláudio de Lima - Universidade FUMEC

Dr. Nelson Ferreira Filho - Faculdades Kennedy

Msc. Valdiney Alves de Oliveira - Universidade Federal de Uberlândia

\begin{tabular}{l} 
Dados Internacionais de Catalogação na Publicação (CIP) \\
E82 \\
Estudos sobre Transporte - Volume 1/ \\
Organização Editora Poisson - Belo \\
Horizonte - MG: Poisson, 2021 \\
Formato: PDF \\
ISBN: 978-65-5866-111-5 \\
DOI: 10.36229/978-65-5866-111-5 \\
Modo de acesso: World Wide Web \\
Inclui bibliografia \\
1. Engenharia 2. Educação.I. Título. \\
\hline Sônia Márcia Soares de Moura - CRB 6/1896
\end{tabular}

O conteúdo deste livro está licenciado sob a Licença de Atribuição Creative Commons 4.0.

Com ela é permitido compartilhar o livro, devendo ser dado o devido crédito, não podendo ser utilizado para fins comerciais e nem ser alterada.

O conteúdo dos artigos e seus dados em sua forma, correção e confiabilidade são de responsabilidade exclusiva dos seus respectivos autores.

www.poisson.com.br contato@poisson.com.br 


\section{SUMÁRIO}

Capítulo 1: Avaliação do desempenho de pavimento semirrígido: Segmento monitorado da SC-390, trecho Orleans - Pedras Grandes 6

Fernanda Mattos Deucher, Glicério Trichês

DOI: 10.36229/978-65-5866-111-5.CAP.01

Capítulo 2: Avaliação da resistência à ação da água em misturas asfálticas modificadas por nanoargila e polímero SBS. 18

Gabriela Ceccon Carlesso, Glicério Trichês, João Victor Staub de Melo, Matheus Felipe Marcon, Liseane Padilha Thives, Adosindro Joaquim de Almeida

DOI: $10.36229 / 978-65-5866-111-5 . C A P .02$

Capítulo 3: Análise da aplicação de dados planialtimétricos obtidos com Aeronave Remotamente Pilotada (ARP) para execução de projetos de terraplenagem.

Maelckson Bruno Barros Gomes, André Luís Silva dos Santos, Paulo Afonso Lopes da Silva, Maria da Anunciação Rodrigues Araújo

DOI: 10.36229/978-65-5866-111-5.CAP.03

Capítulo 4: Logística de última milha de bens e serviços essenciais durante a pandemia COVID-19: 0 caso das favelas brasileiras. 43

Joaquim José Guilherme de Aragão, Yaeko Yamashita, Lucas Cezar Santana Ferreira

DOI: $10.36229 / 978-65-5866-111-5 . C A P .04$

Capítulo 5: Identificando segmentos latentes de usuários em função dos atributos do Serviço de Transporte Público de Goiânia 57

Ronny Marcelo Aliaga Medrano, Willer Luciano Carvalho

DOI: $10.36229 / 978-65-5866-111-5 . C A P .05$

Capítulo 6: Entre os planos e a realidade: Até que ponto os planos diretores de Fortaleza determinaram as alterações na malha viária da cidade?. 68

Rebeca Froés de Assis, Camila Bandeira Cavalcante, André Soares Lopes, Luádyna Almeida Bezerra, Gabriel Sato Feitosa Arrais

DOI: $10.36229 / 978-65-5866-111-5 . C A P .06$

Capítulo 7: Caracterização de pedestres obedientes e oportunistas em travessias semaforizadas de Fortaleza.

Kaio Gefferson de Almeida Mesquita, Francisco Altanízio Batista de Castro Júnior, Moisés Gomes de Holanda Cunha

DOI: $10.36229 / 978-65-5866-111-5 . C A P .07$ 


\section{SUMÁRIO}

Capítulo 8: Diagnóstico técnico-operacional para implementação de Postos de Pesagem Veicular (PPVs) com Agente Remoto.

Leonardo Perim Guerson, Vanessa Espíndola, Valter Zanela Tani, Amir Mattar Valente, Marcelo Bavier Marcos

DOI: $10.36229 / 978-65-5866-111-5 . C A P .08$

Capítulo 9: Análise do transporte de minério: Uma abordagem financeira utilizando o método de Black \& Scholes em opções reais 103

Rodrigo Rodrigues de Freitas, Diego Manoel Enedino Gonçalves, Thiago de Souza Cardoso Mayrink Paiva DOI: 10.36229/978-65-5866-111-5.CAP.09

Capítulo 10: Seleção de sítios aeroportuários - Estudo de caso para o aeroporto de Balsas (MA)

Teotonio Ko Freitag, José dos Santos de Magalhães, Anderson Schmitt, Rafael Cardoso Cunha, Amir Mattar Valente

DOI: 10.36229/978-65-5866-111-5.CAP.10

Autores: 


\section{Capítulo 1}

\section{Avaliação do desempenho de pavimento semirrígido: Segmento monitorado da SC-390, trecho Orleans - Pedras Grandes}

\section{Fernanda Mattos Deucher}

Glicério Trichês

Resumo: Os solos saprolíticos de origem granítico-gnáissica são materiais abundantes no litoral de Santa Catarina e frequentemente empregados na construção de rodovias de baixo e médio volume de tráfego. Apresentam Índices de Suporte Califórnia (ISC) que podem atingir valores acima de $20 \%$, porém apresentam grau resiliente de intermediário a elevado. Nesta pesquisa, apresenta-se a avaliação do desempenho de um segmento monitorado da rodovia SC-390, a qual foi construída com base de solo saprolítico melhorado com $3 \%$ de cimento. 0 monitoramento do desempenho tem como objetivo contribuir para o entendimento do comportamento deste tipo de material nos pavimentos e fornecer parâmetros e diretrizes para o dimensionamento deste tipo de estrutura. A rodovia tem um $\mathrm{N}_{8,2 \mathrm{t}}$ previsto de projeto de $6,4 \times 10^{6}$ e foi aberta ao tráfego em 2015. 0 desempenho do pavimento foi avaliado através de levantamentos estruturais e funcionais realizados entre os anos de 2016 e 2018. Foram realizados ensaios de laboratório para a caracterização do solo natural e ensaios para caracterização do comportamento mecânico e à fadiga da mistura com $3 \%$ de cimento. Tanto os levantamentos estruturais quanto os funcionais mostraram um bom desempenho da estrutura ao longo do período de análise, observando-se apenas o surgimento de trincas isoladas de retração, representando menos de $1 \%$ de área trincada. Na retroanálise de bacias de deflexão, a camada de base estabilizada atingiu módulos entre 900 a $1040 \mathrm{MPa}$, enquanto que a sub-base, composta pelo solo natural, atingiu módulos próximos a $130 \mathrm{MPa}$. 


\section{INTRODUÇÃO}

Os solos saprolíticos com origem de granitos e gnaisses são materiais abundantes no litoral de Santa Catarina, onde predomina o domínio de rochas do escudo cristalino, preponderantemente constituído por rochas metamórficas como granulitos e gnaisses (MARCON, 1996). Estes solos possuem baixo custo de exploração, baixas distâncias de transporte e valores satisfatórios de Índice de Suporte Califórnia (ISC), sendo frequentemente empregados na construção de rodovias de baixo e médio volume de tráfego como reforço do subleito ou sub-base (VALLE, 1994). Entretanto, Valle (1994), ao realizar um estudo em pavimentos onde o solo saprolítico granítico-gnáissico foi empregado na camada de reforço de subleito e camada de sub-base, constatou que este apresenta grau de resiliência de intermediário a elevado, ocasionando o trincamento precoce por fadiga da camada de revestimento asfáltico.

Neste contexto, a estabilização química do solo saprolítico granítico-gnáissico com cimento surge como uma alternativa para o seu emprego racional na pavimentação de rodovias assentes em regiões de rochas do escudo cristalino em Santa Catarina. A adição de cimento confere ao solo melhorias como a redução na plasticidade, redução na expansibilidade e compressibilidade e aumento de resistência e rigidez (MAKUSA, 2013). No que diz respeito às vantagens ambientais e econômicas, a exploração dos solos lindeiros à rodovia reduz os custos de compra, transporte e distribuição de agregados e os impactos ambientais causados pela instalação de pedreiras e pelo processo de britagem (DO MONTE, 2012).

As bases de solo estabilizado com cimento são propensas ao desenvolvimento de trincas, sendo que as duas principais causas deste trincamento são a retração hidráulica e a fadiga (AUSTSTAB, 2012). Enquanto que a retração hidráulica pode ser controlada principalmente durante o processo construtivo, o trincamento por fadiga é um fenômeno que resulta da atuação das cargas dinâmicas sobre o pavimento, as quais induzem tensões e deformações críticas de tração na parte inferior da camada estabilizada. A resistência à fadiga destas camadas é muito sensível à sua espessura e rigidez, sendo o trincamento por fadiga o principal critério de dimensionamento de pavimentos com camadas cimentadas (SOLANKI E ZAMAN, 2014).

No Brasil, embora o solo-cimento tenha sido amplamente empregado até meados de 1990 (com destaque para o estado de São Paulo, que até a década de 1990 apresentava cerca de vinte mil quilômetros de rodovias com bases ou sub-bases de solo-cimento), atualmente o seu emprego encontra limitações, especialmente devido ao conservadorismo dos métodos de projeto e dimensionamento vigentes no Brasil, que dificultam e desmotivam o emprego do material na pavimentação de rodovias (SENÇO, 1995; SPECHT, 2000).

A implantação do novo método brasileiro de dimensionamento de pavimentos flexíveis (MeDiNa) resultará em pavimentos dimensionados com maiores espessuras de revestimento asfáltico, aumentando os custos de construção das rodovias. Além disso, a incompatibilidade de rigidez dos materiais que compõem as camadas das estruturas poderá ocasionar o trincamento precoce do revestimento. Neste contexto, as bases estabilizadas quimicamente passarão a adquirir uma maior importância na escolha da alternativa de pavimentação.

Com o objetivo de reduzir o custo de implantação de rodovias na região de embasamento cristalino, o então Departamento Estadual de Infraestrutura do Estado de Santa Catarina (DEINFRA/SC), atual Secretaria de Estado da Infraestrutura e Mobilidade (SIE/SC), concluiu, em julho de 2015, a execução de um trecho de rodovia da SC-390 cuja camada de base foi executada com solo saprolítico melhorado com adição de 3\% cimento. 0 solo empregado, pertencente ao horizonte saprolítico de granito, é proveniente de uma jazida localizada na faixa de domínio da rodovia.

O projeto original deste trecho da SC-390 previa a construção da camada de base com o emprego de brita graduada, mas a solução final adotada foi a utilização da mistura de solo melhorado com cimento. Entretanto, no início da construção, o comportamento à fadiga desta mistura não era conhecido e tampouco se conseguiu apurar como foi realizado o dimensionamento da estrutura, uma vez que houve readequação do projeto original.

Sendo assim, tendo como abrangência a região de embasamento cristalino do território Catarinense, a presente pesquisa buscou avaliar o desempenho do pavimento executado através da realização de ensaios de laboratório e do monitoramento sistemático das suas condições funcionais e estruturais. 


\section{MATERIAIS E MÉTODOS}

\subsection{CARACTERIZAÇÃO DO SEGMENTO}

O segmento monitorado da SC-390 possui uma extensão de 700 metros e seu início está localizado no km 442+346. A estrutura do pavimento é apresentada na Figura 1.

Figura 1: Estrutura do pavimento executado

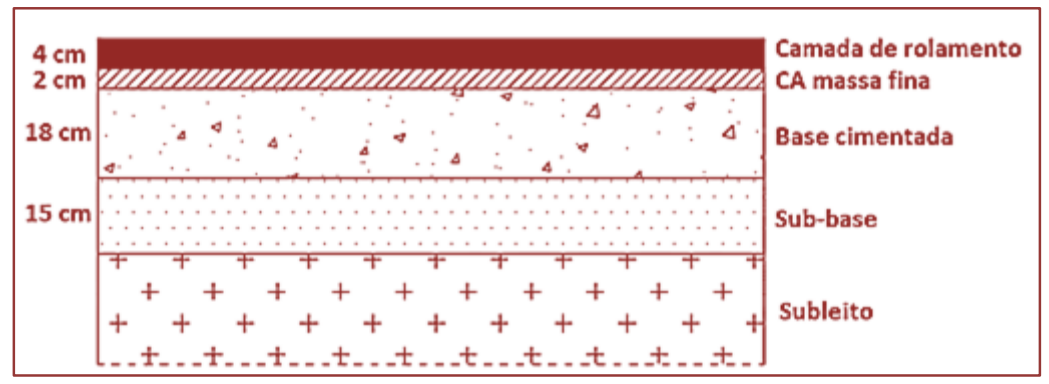

\subsection{CARACTERIZAÇÃO DO SOLO MELHORADO COM CIMENTO}

Para a caracterização da mistura solo melhorado com cimento empregada na camada de base, coletou-se material da mesma jazida explorada durante a execução do trecho. Inicialmente foram realizados ensaios de granulometria (ABNT NBR 7181:2016), limite de liquidez (ABNT NBR 6459:2016), limite de plasticidade (ABNT NBR 7180:2016), compactação do solo natural (ABNT NBR 7182:2016) e do solo com 3\% de cimento (ABNT NBR 12023:2012). Em ambos foi aplicada a energia do Proctor modificado (a mesma utilizada na obra).

Posteriormente, foram moldados corpos de prova de 5,0 x 10,0 cm para a determinação da resistência à compressão simples (ABNT NBR 12025:2012), nas idades de 7, 14 e 28 dias, e teores de 1,5\%, 3,0\% e 4,5\% de cimento (em relação à massa específica aparente seca máxima de solo). Os teores de cimento foram definidos com base no valor utilizado em campo (3\%), com variação de 1,5\% para mais e para menos, com objetivo de avaliar a influência do teor de cimento na resistência da mistura.

Na sequência, foram moldadas vigotas com dimensões de 5,0 cm de altura, 6,3 cm de largura e 40,0 cm de comprimento para determinação da resistência à tração na flexão e ensaios de fadiga da mistura com $3 \%$ de cimento. A resistência à tração na flexão foi determinada aos 7 e aos 28 dias de cura. A caracterização do comportamento à fadiga foi realizada em corpos de prova com 28 dias de cura e empregando-se o equipamento "Pneumatic 4 Point Bending Apparatus" da empresa australiana IPC Global@. Durante o ensaio de fadiga, as vigotas foram envoltas por plástico filme para evitar a formação de um gradiente de umidade a partir das superfícies para o interior dos corpos de prova, o que poderia induzir o desenvolvimento de tensões de tração na superfície e impactar na interpretação dos resultados dos ensaios de longa duração. A Figura 2 mostra o molde metálico desmontável desenvolvido para a moldagem dos corpos de prova e uma vigota rompida no terço médio central envolta no filme plástico. 
Figura 2: (a) Molde metálico desmontável desenvolvido; (b) Vigota rompida no terço médio.
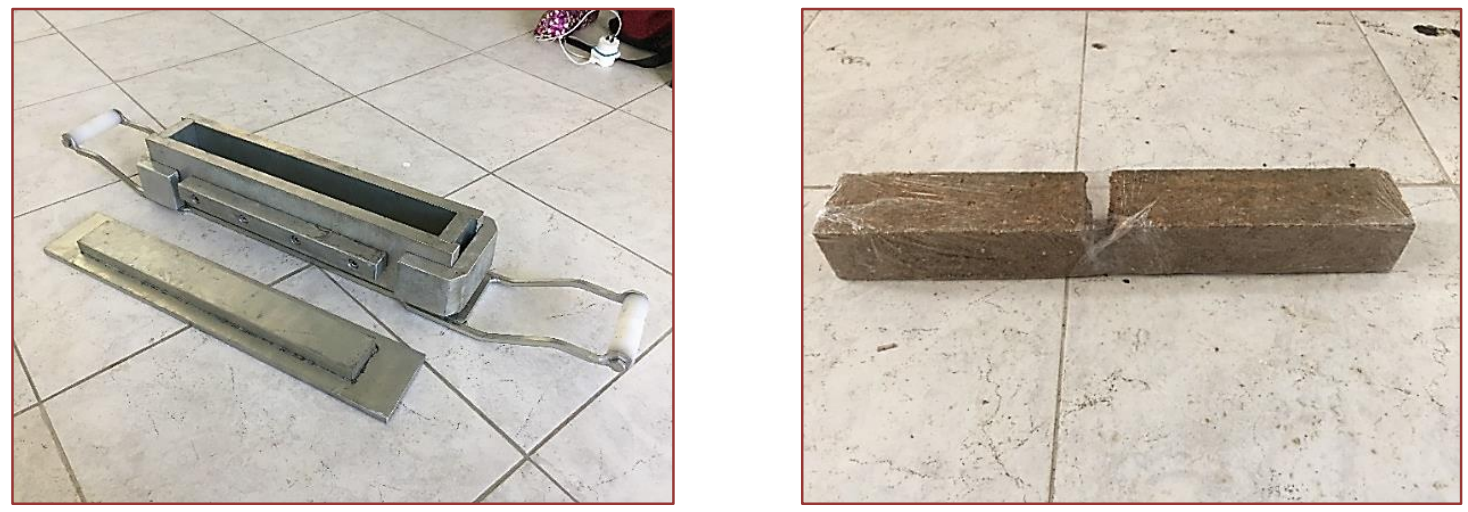

A Tabela 1 resume as condições empregadas na realização dos ensaios de fadiga.

Tabela 1: Resumo das condições de ensaio

\begin{tabular}{|l|c|}
\multicolumn{2}{|c|}{ Condições de ensaio } \\
\hline Modo de carregamento & Tensão controlada \\
\hline Forma de carregamento & Sinusoidal \\
\hline Tensão aplicada & SR* entre 0,6 e $0,9^{*}$ \\
\hline Frequência & $5 \mathrm{~Hz}$ \\
\hline Temperatura fixada & $21^{\circ} \mathrm{C}$ \\
\hline Critério de fadiga & Número de repetições até a ruptura \\
\hline
\end{tabular}

*Relação entre a tensão de tração aplicada e a resistência à tração média aos 28 dias da mistura.

\subsection{ATUALIZAÇÃO DO TRÁFEGO}

Em outubro de 2019 realizou-se uma contagem volumétrica de veículos para atualização do tráfego. A partir da contagem realizada, foram utilizadas as taxas de crescimento do Produto Interno Bruto (PIB) do Brasil, entre os anos de 2015 a 2018, para a estimativa do número $\mathrm{N}_{8,2 t}$ acumulado até o ano de 2019. Para a estimativa do $\mathrm{N}_{8,2 \mathrm{t}}$ acumulado até o ano de 2025, período de projeto para o qual a rodovia foi projetada, utilizou-se a taxa de crescimento de $2,4 \%$, que corresponde à média das taxas de crescimento do PIB brasileiro previstas pelo Banco Mundial para os anos de 2020 e 2021 (BANCO MUNDIAL, 2019), antes da pandemia da Covid19.

\subsection{LEVANTAMENTO DAS CONDIÇÕES ESTRUTURAIS E FUNCIONAIS DO PAVIMENTO}

O levantamento das condições funcionais e estruturais do pavimento ao longo do tempo foi realizado empregando-se os procedimentos conforme mostrado na Tabela 2.

Tabela 2: Levantamento das condições estruturais e funcionais do pavimento

\begin{tabular}{|c|c|c|}
\hline 2016 & $\begin{array}{l}\text { Levantamentos realizados por ano } \\
\qquad 2017\end{array}$ & 2018 \\
\hline $\begin{array}{l}\text { Levantamento de defeitos (DNIT } \\
\text { PRO 006/2003) }\end{array}$ & $\begin{array}{l}\text { Levantamento de defeitos } \\
\text { (DNIT PRO 006/2003) }\end{array}$ & $\begin{array}{l}\text { Levantamento de defeitos } \\
\text { (DNIT PRO 006/2003) }\end{array}$ \\
\hline $\begin{array}{l}\text { Afundamentos de trilha de roda } \\
\text { (treliça e perfilômetro a laser) }\end{array}$ & $\begin{array}{l}\text { Afundamentos de trilha de roda } \\
\text { (perfilômetro a laser) }\end{array}$ & $\begin{array}{l}\text { Afundamentos de trilha de roda } \\
\text { (treliça) }\end{array}$ \\
\hline $\begin{array}{l}\text { Irregularidade longitudinal } \\
\text { (perfilômetro a laser) }\end{array}$ & $\begin{array}{l}\text { Irregularidade longitudinal } \\
\text { (perfilômetro a laser) }\end{array}$ & 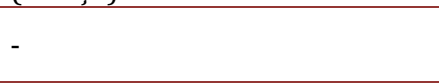 \\
\hline $\begin{array}{l}\text { Levantamento deflectométrico } \\
\text { (FWD - DNER PRO 273/96) }\end{array}$ & $\begin{array}{l}\text { Levantamento deflectométrico (FWD } \\
\text { - DNER PRO 273/96) }\end{array}$ & - \\
\hline
\end{tabular}




\subsection{ANÁLISE DAS CONDIÇÕES ESTRUTURAIS E FUNCIONAIS AO LONGO DO TEMPO}

A análise temporal das condições estruturais e funcionais do pavimento foi realizada a partir dos dados obtidos nos levantamentos de 2016, 2017 e 2018, como detalhado na Tabela 3.

Tabela 3: Análise das condições estruturais e funcionais ao longo do tempo

\begin{tabular}{|l|l|}
\multicolumn{2}{|c|}{ Condição funcional } \\
\hline Evolução da porcentagem de área trincada & Evolução das deflexões \\
\hline Evolução do IGG & Evolução dos raios de curvatura das bacias deflectométricas \\
\hline Evolução dos afundamentos de trilha de roda & Variação dos módulos obtidos por retroanálise (BAKFAA) \\
\hline Evolução do IRI & \\
\hline
\end{tabular}

Para a retroanálise das bacias de deflexão, estabeleceu-se uma metodologia conforme detalhado na Tabela 4.

Tabela 4: Procedimentos adotados para a retroanálise das bacias

Retroanálise com bacia média representativa de cada faixa, testando-se diferentes considerações de aderência entre as camadas (todas as camadas aderidas, todas as camadas não aderidas, apenas revestimento aderido e apenas base não aderida).

Definição da condição de aderência mais adequada através dos valores de raiz quadrática média (RMS), coerência dos módulos conforme as características das camadas e semelhança dos módulos entre as duas faixas de rolamento.

Comparação dos módulos obtidos a partir de duas abordagens de análise das bacias: retroanálise com uma bacia média representativa de cada faixa; e retroanálise estaca por estaca, seguida de análise estatística e média dos módulos de cada camada.

4 Escolha da melhor abordagem e aplicação em todos os dados.

\subsection{ESTIMATIVA DE VIDA ÚTIL}

Utilizando-se o software ELSYM5, foi realizada a estimativa de vida útil do pavimento a partir dos módulos obtidos por retroanálise e da equação de fadiga resultante do ensaio de flexão a quatro pontos. Com o objetivo de aproximar a deflexão calculada pelo programa da deflexão medida em campo, a análise foi realizada utilizando-se uma carga de $4.100 \mathrm{Kgf}$ aplicada em um único ponto (similar à aplicação de carga do FWD) e com pressão de enchimento dos pneus de $820 \mathrm{kPa}$. Segundo Fernandes Júnior et al. (2007 apud RÉUS et al., 2014), esta é a pressão de enchimento média utilizada no Brasil.

\section{APRESENTAÇÃO E DISCUSSÃO DOS RESULTADOS}

\subsection{CARACTERIZAÇÃO GEOTÉCNICA E MECÂNICA DO SOLO MELHORADO}

\subsubsection{CARACTERIZAÇÃO GEOTÉCNICA}

O solo residual saprolítico foi caracterizado como não plástico (NP) e pertencente ao grupo A-1-A pela classificação Transport Research Board (TRB). A curva granulométrica do solo é apresentada na Figura 3 (a). Para o solo puro, a massa específica aparente seca máxima e a umidade ótima obtidas foram de 2,068 $\mathrm{g} / \mathrm{cm}^{3}$ e $7,2 \%$, respectivamente (energia do Proctor modificado). Para o solo com adição de 3\% de cimento, a massa específica aparente seca máxima e a umidade ótima obtidas foram de 2,098 g/ $\mathrm{cm}^{3}$ e 7,4\%, respectivamente. Como pode ser observado, a adição de $3 \%$ de cimento exerceu pouca influência nos valores de massa específica aparente seca e umidade ótima. Sendo assim, optou-se por utilizar a mesma curva de compactação obtida para a mistura com 3\% de cimento para as demais misturas ensaiadas (teores de $1,5 \%$ e $4,5 \%$ de cimento). 


\subsubsection{RESISTÊNCIA À COMPRESSÃO SIMPLES}

A Figura 3 (b) mostra os resultados obtidos no ensaio de resistência à compressão simples para os diferentes teores de cimento e idades de cura.

Figura 3: (a) Curva granulométrica do solo; (b) RCS média para diferentes teores e idades de cura
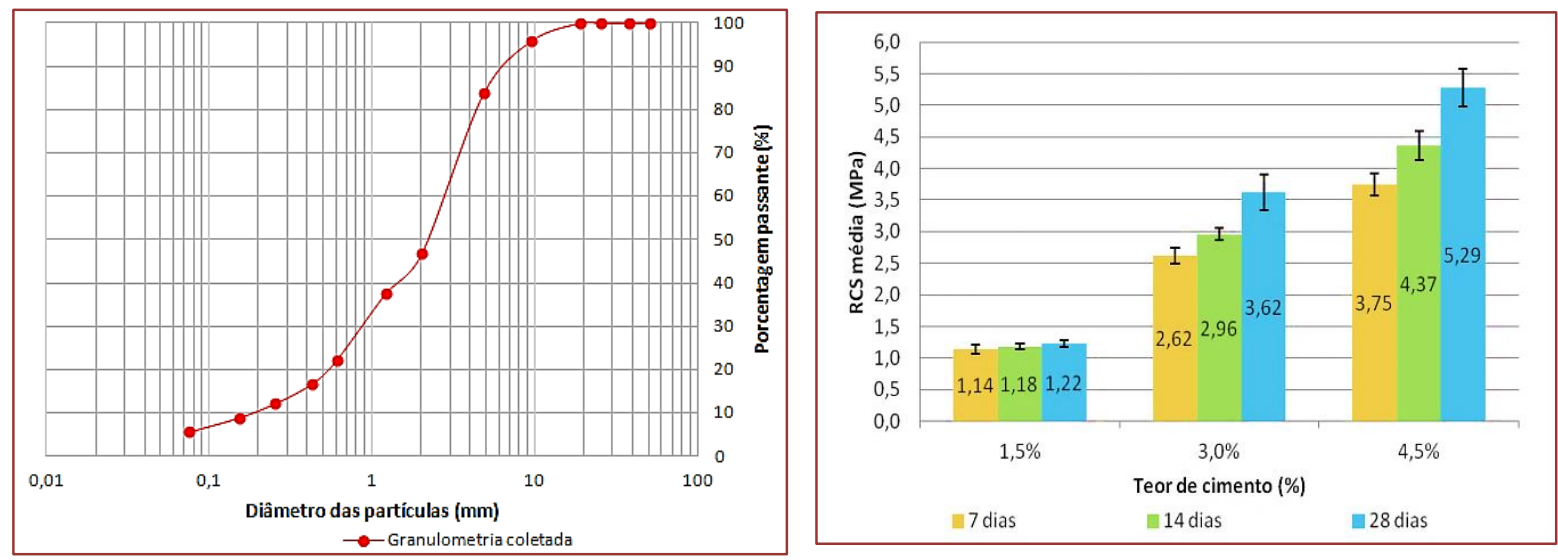

\subsubsection{RESISTÊNCIA À TRAÇÃo NA FLEXÃo}

A Tabela 5 mostra os resultados obtidos. Aos 7 dias de cura, as vigotas chegaram a 59,30\% do valor da resistência à tração na flexão atingido aos 28 dias. Isto demonstra que deve haver uma melhor avaliação dos possíveis danos causados à camada cimentada com a abertura ao tráfego aos 7 dias de idade. Uma alternativa seria a limitação ao tráfego de veículos pesados por períodos maiores, respeitando-se um período de cura de 28 dias.

Tabela 5: Resultado dos ensaios de tração na flexão

\begin{tabular}{|c|c|c|c|}
\hline \multirow{2}{*}{ Teor de cimento } & Idade & $\begin{array}{c}\text { Média da resistência à } \\
\text { tração na flexão (MPa) }\end{array}$ & \begin{tabular}{c} 
Desvio padrão (MPa) \\
\hline $3 \%$
\end{tabular} \\
\hline $3 \%$ & 28 dias & 0,51 & 0,064 \\
\hline & 28 dias & 0,86 & 0,085 \\
\hline
\end{tabular}

\subsubsection{RESISTÊNCIA À FADIGA}

Os ensaios de fadiga foram realizados somente para idade de cura das vigotas de 28 dias. Isto exigiu uma compatibilização entre moldagem dos corpos de prova, tempo de cura e tempo de duração de cada ensaio. A Tabela 6 contém um resumo dos resultados obtidos. Para os corpos de prova que compõem a curva de fadiga, observou-se um módulo de flexão médio (medido nos 100 primeiros ciclos de carregamento) de 4.636 MPa e desvio padrão de 1.167 MPa. Constata-se que estes valores são muito superiores aos obtidos por retroanálise das bacias deflectométricas (vide item 3.3.5), indicando que, salvo melhor entendimento, estes valores não são indicados para o dimensionamento deste tipo de estrutura. Provavelmente, o mais indicado para a obtenção do módulo deste tipo de mistura seria a realização de ensaios triaxiais de carregamento repetido.

Fedrigo et al. (2019) compararam os módulos na flexão obtidos em vigotas moldadas em laboratório e em vigotas retiradas do pavimento para uma mistura de solo de origem xistosa com 3\% de cimento. Eles constataram que os módulos das amostras de laboratório foram quatro vezes superiores aos das amostras de campo. Neste estudo, o módulo médio obtido através da retroanálise das bacias de deflexão foi de, aproximadamente, 4,8 vezes inferior ao módulo na flexão obtido em laboratório, o que corrobora com os achados do presente estudo. 
Tabela 6: Resumo dos ensaios de fadiga

\begin{tabular}{|c|c|c|c|c|}
\hline № CP & SR & et inicial $\left(10^{-6}\right)$ & Módulo na flexão (MPa) & $\mathrm{N}$ ruptura \\
\hline 1 & 0,93 & - & - & 1 \\
\hline 2 & 0,86 & 140 & 3791 & 8 \\
\hline 3 & 0,85 & 90 & 4064 & 839 \\
\hline 4 & 0,66 & 109 & 3289 & 1811 \\
\hline 5 & 0,81 & 101 & 3602 & 4169 \\
\hline 6 & 0,84 & 68 & 5284 & 4299 \\
\hline 7 & 0,69 & 55 & 6666 & 8233 \\
\hline 8 & 0,69 & 93 & 3906 & 32735 \\
\hline 9 & 0,69 & 67 & 5259 & 170260 \\
\hline 10 & 0,67 & 56 & 5863 & 1646547 \\
\hline
\end{tabular}

A Figura 4 mostra a curva de fadiga obtida em função da relação de tensões inicial. Também foram plotadas as curvas obtidas por Ceratti (1991), para uma mistura de solo não arenoso A-1-B com 6\% de cimento, por Luvizão (2014) para mistura reciclada (trituração do revestimento mais base) com 3\% de cimento, e por Sounthararajah et. al (2018) para mistura de material granular (granítico) melhorado com 3\% de cimento.

Conforme pode ser observado na Figura 4, em comparação aos demais modelos, a mistura estudada apresentou uma grande sensibilidade quanto ao número de solicitações para a ruptura dos corpos de prova frente a pequenas variações da relação de tensões SR, demonstrada através da menor inclinação da reta. A Equação 1 representa o modelo de fadiga obtido em função da relação de tensões SR.

em que: $\quad N f$ : vida de fadiga;

$$
\begin{gathered}
N_{f}=10(15,732-16,229 S R) \\
R^{2}=0,66
\end{gathered}
$$

SR: relação entre a tensão de tração aplicada e a resistência à tração da mistura obtida aos 28 dias de cura.

Embora o ensaio tenha sido realizado à tensão controlada, a Figura 5 mostra a curva de fadiga obtida em termos de deformação específica de tração inicial medida após 100 ciclos de aplicação do carregamento. Na figura também foram plotadas as curvas de fadiga obtidas por Ceratti (1991) para uma mistura de solo não arenoso A-1-B com 6\% de cimento e por Sounthararajah et al. (2018), para mistura de material granular (granítico) estabilizado com $3 \%$ de cimento. A três misturas apresentaram intervalos semelhantes de deformação, que foram de, aproximadamente, $55 \times 10^{-6}$ a $140 \times 10^{-6}$, mostrando que os materiais cimentados não são capazes de suportar grandes deformações e que, portanto, o intervalo de variação das deformações é relativamente pequeno. A Austroads (2014) recomenda um intervalo de deformações entre $50 \times 10^{-6} \mathrm{e}$ $120 \times 10^{-6}$ para caracterização de misturas cimentadas no ensaio de fadiga a 4 pontos. A Equação 2 representa o modelo de fadiga obtida em termos de deformação específica de tração inicial.

em que $\quad N f$ : vida de fadiga;

$$
\begin{gathered}
N_{f}=10\left(7,529-4,307 \times 10^{4} \times \varepsilon t\right) \\
R^{2}=0,65
\end{gathered}
$$

$\varepsilon t$ : deformação específica de tração inicial (entrada no modelo como $\varepsilon t$ x $10^{-6}$ ). 
Figura 4: Curva de fadiga: $\mathrm{N}$ versus relação de tensões.

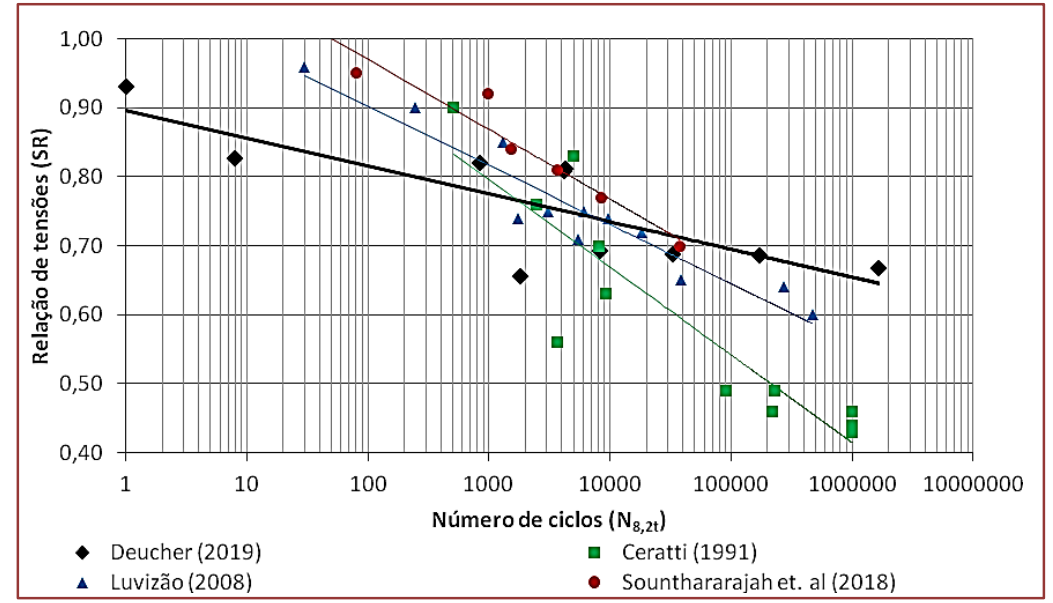

Figura 5: Curva de fadiga: N versus deformação específica de tração inicial.

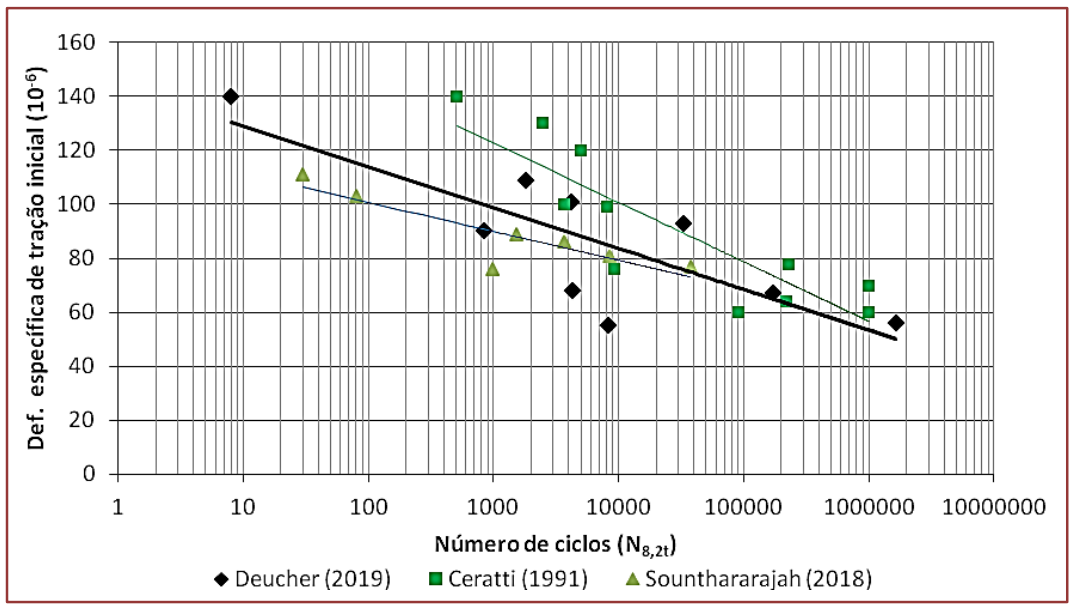

\subsection{ATUALIZAÇÃO DO TRÁFEGO}

A partir da contagem volumétrica realizada em 2019 (antes da pandemia da COVID19), o N8,2t estimado para o ano de 2019 pela metodologia do Corpo de Engenheiros do Exército Americano (USACE) foi de 3,83 x 1066, o que corresponderia a $59,8 \%$ do $\mathrm{N}_{8,2 \mathrm{t}}$ estabelecido em projeto (final do período de projeto em 2025), que era de $6,40 \times 10^{6}$. Ou seja, decorridos $42 \%$ do período de projeto, aproximadamente, o tráfego atuante foi de $59,8 \%$ do tráfego previsto, indicando que ele estaria acima do que foi estimado para o projeto. Segundo a contagem realizada, o $\mathrm{N}_{8,2 t}$ estimado para o ano de 2025 seria de $1,0 \times 10^{7}$ (USACE), ou seja, cerca de $36 \%$ superior ao $\mathrm{N}_{8,2 \mathrm{t}}$ de projeto, considerando-se um crescimento do VMDA de 2,4\% ao ano entre 2019 e 2025 (antes da pandemia).

\subsection{LEVANTAMENTO E ANÁLISE DAS CONDIÇÕES ESTRUTURAL E FUNCIONAL DO PAVIMENTO AO LONGO DO TEMPO}

\subsubsection{LEVANTAMENTO DE DEFEITOS DE SUPERFÍCIE}

Nos três levantamentos de defeitos (2016, 2017 e 2018) foram constatadas apenas trincas do tipo FC-1, transversais e longitudinais (nas trilhas de roda). A hipótese para o surgimento das trincas longitudinais estaria relacionada ao processo construtivo, mais precisamente na região onde ocorre a superposição das faixas de passagem do caminhão distribuidor de cimento e da recicladora. Nesta região, é possível que tenha ocorrido a aplicação de uma maior taxa de cimento e também um maior teor de umidade. A combinação destas duas condições teria potencializado a formação das trincas longitudinais. Com relação às trincas 
transversais, algumas estão associadas ao final de jornada de trabalho (estas não apresentam uma continuidade na transversal da pista) enquanto que outras estariam associadas à retração hidráulica da mistura (se manifestam em toda a largura da pista de rolamento).

Também foi constatada a presença de trincas transversais de retração com início no acostamento, sendo que algumas delas já haviam atingido a região da trilha de roda externa. A hipótese é de que estas trincas sejam resultantes do fenômeno de retração da mistura devido ao seu ressecamento a partir dos bordos do acostamento.

Conforme observado na Figura 6 (a), após 39 meses de atuação do tráfego, o IGG calculado para as duas faixas de rolamento permaneceu abaixo do valor recomendado pela ARTESP (2018) como indicativo de intervenção no pavimento. As duas faixas seriam classificadas como ótimas segundo o DNIT (DNIT, 2003).

\subsubsection{AFUNDAMENTOS NAS TRILHAS DE RODA}

Conforme apresenta a Figura 6 (b), Após 39 meses de atuação do tráfego, os afundamentos permaneceram abaixo do limite recomendado pela ARTESP (2018), como indicativo de intervenção no pavimento (7 mm). Ressalta-se que este limite recomendado pela a ARTESP refere-se a pavimentos flexíveis. A faixa Pedras Grandes - Orleans, a qual manifestou a maior quantidade de seções amostrais com trincas, apresentou menores afundamentos de trilha de roda do que a faixa Orleans - Pedras Grandes. Portanto, pode-se afirmar que a presença de trincas não é um fator determinante no desenvolvimento dos afundamentos. Todavia, até o momento não se conseguiu uma explicação clara para esta diferença de comportamento entre as faixas.

Figura 6: (a) Evolução do IGG; (b) Evolução dos afundamentos nas trilhas de roda externa
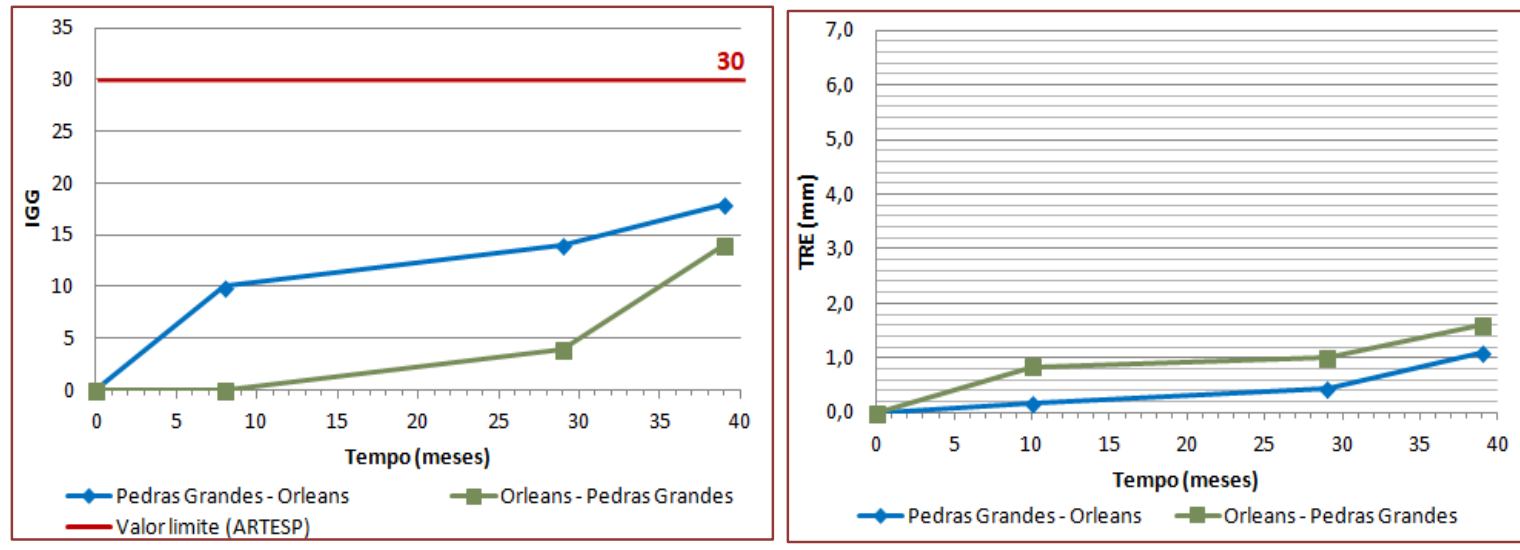


\subsubsection{IRREGULARIDADE LONGITUDINAL}

A Figura 7 (a) mostra que praticamente não houve evolução do IRI ao longo de um intervalo de 19 meses entre duas medições (levantamentos realizados no mês 10 e no mês 29, após a abertura ao tráfego). Também mostra que as duas faixas de rolamento apresentaram valores bastante próximos de IRI, tanto em 2016 quanto em 2017. Portanto, é possível afirmar que as trincas desenvolvidas não afetaram a superfície do pavimento no quesito irregularidade. As duas faixas permaneceram dentro do limite de 2,69 m/km recomendado pela ARTESP (2018) para a necessidade de intervenção, e mantiveram-se classificadas como excelentes quanto à condição de superfície do pavimento em função do IRI (BRASIL, 2006). Ressalta-se que este limite recomendado pela a ARTESP refere-se a pavimentos flexíveis.

\subsubsection{DEFLEXÕES MÁXIMAS}

A Figura 7 (b) apresenta a evolução das deflexões máximas. Observa-se que a faixa Pedras Grandes - Orleans apresentou um aumento de 8,8\% no valor da deflexão máxima média entre 2016 e 2017. Enquanto que para a faixa Orleans - Pedras Grandes, foi observada uma redução de, aproximadamente, 1\% (atribuída a variações inerentes ao levantamento deflectométrico). Para a faixa Orleans - Pedras grandes pode-se afirmar que não houve mudança na condição estrutural do pavimento entre as duas medições. Entretanto, para a faixa Pedras Grandes - Orleans, a maior porcentagem de área trincada pode estar indicando o início de uma perda da capacidade estrutural do pavimento nesta faixa, retratada pelo aumento da sua deflexão.

Figura 7: (a) Evolução do IRI; (b) Evolução das deflexões máximas.
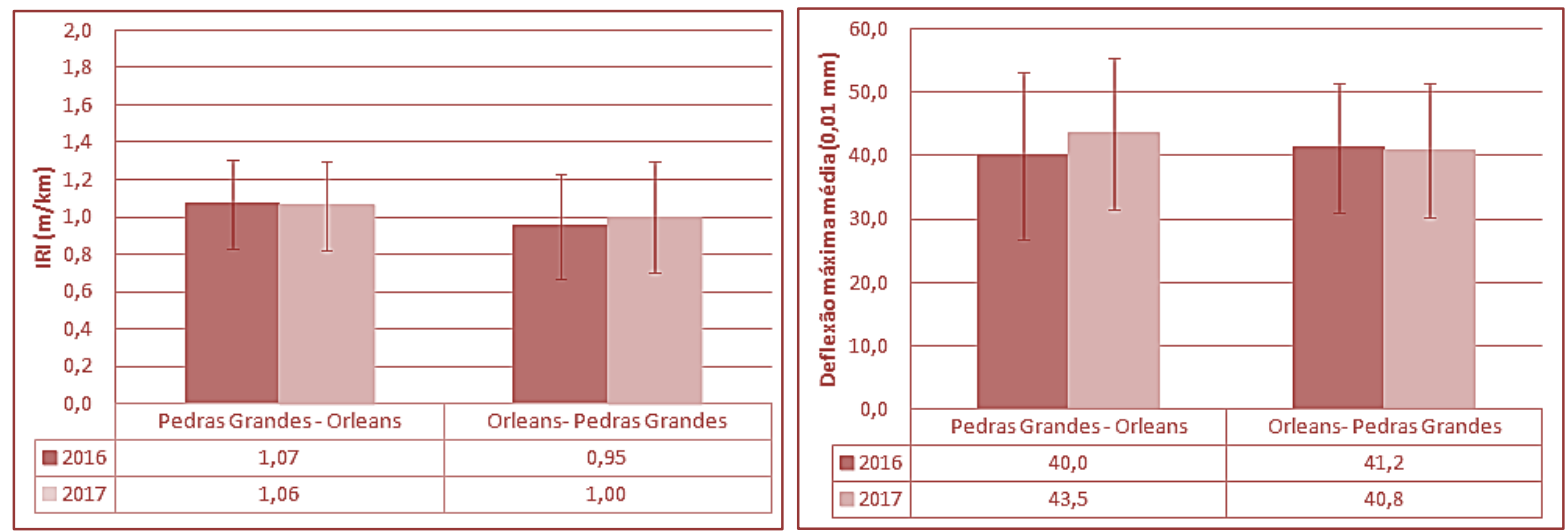

\subsubsection{MÓDULOS OBTIDOS POR RETROANÁLISE}

Quanto às diferentes considerações de aderência entre as camadas ao se realizar a retroanálise das bacias, a melhor condição verificada foi "apenas base não aderida", pois além de ser plausível de ocorrência em campo, resultou em módulos condizentes com as características das camadas, com pouca variação entre as duas faixas de rolamento e com valores de RMS inferiores a 10. A retroanálise estaca por estaca é uma alternativa morosa e apresentou resultados bastante semelhantes aos obtidos apenas com a retroanálise da bacia média representativa de cada faixa de rolamento. Sendo assim, adotou-se esta última condição para a retroanálise das bacias medidas nos dois levantamentos realizados. A Tabela 7 apresenta os resultados obtidos com a retroanálise pela bacia média de cada faixa de rolamento, considerando-se a camada de base não aderida. 
Tabela 7: Evolução dos módulos obtidos por retroanálise

\begin{tabular}{|c|c|c|c|c|}
\hline \multicolumn{1}{|c}{ Módulo (MPa) } & Revestimento & Base & Sub-base & Subleito \\
\hline Pedras Grandes - Orleans (2016) & 4881 & 1014 & 134 & 122 \\
\hline Pedras Grandes - Orleans (2017) & 4566 & 903 & 136 & 117 \\
\hline Orleans - Pedras Grandes (2016) & 4622 & 937 & 128 & 123 \\
\hline Orleans - Pedras Grandes (2017) & 4631 & 1037 & 131 & 120 \\
\hline
\end{tabular}

Como esperado, na faixa Pedras Grandes - Orleans, na qual há uma maior área trincada e onde se constatou um aumento da deflexão, há uma redução no módulo de rigidez das camadas, indicando a perda de capacidade estrutural do pavimento. Entretanto, com base nos valores destes módulos, da área trincada e IRI, pode-se afirmar que a estrutura ainda se encontra na fase elástica de comportamento estrutural. Quanto à faixa Orleans - Pedras Grandes, o fato das deflexões permanecerem estáveis também se reflete nos valores de módulo das camadas.

\subsection{ESTIMATIVA DE VIDA ÚTIL}

A partir dos módulos retroanalisados, curva de fadiga obtida e programa utilizado, a estimativa de vida útil obtida foi de $5,33 \times 10^{9}$, a qual está cerca de 500 vezes acima do tráfego estimado para o período de projeto. Até a data do último levantamento visual (dezembro de 2018), o tráfego acumulado calculado foi de 2,34 x $10^{6}$, sendo que até este levantamento não foram constatadas trincas por fadiga (FC-2 e FC-3) no segmento monitorado. Deste modo, pela baixa porcentagem de área trincada não se pode estimar, no momento, um fator laboratório/campo (ou função de transferência) relacionado à porcentagem de área trincada por fadiga na superfície do pavimento e o tráfego atuante.

\section{CONSIDERAÇÕES PARCIAIS}

A partir dos resultados obtidos no monitoramento do segmento pode-se afirmar que, quanto às condições funcionais do pavimento, as trincas isoladas existentes podem ser atribuídas ao processo executivo e ao fenômeno de retração. Quanto às condições estruturais, não houve mudança significativa entre os levantamentos de 2016 e 2017. Na retroanálise das bacias deflectométricas, a consideração de perfeita aderência entre as camadas pode alterar significativamente o valor dos módulos obtidos. Nesta pesquisa, a situação que se mostrou mais adequada foi a condição onde a camada de base não estaria aderida à camada subjacente.

A adição de um teor de 3\% de cimento ao solo saprolítico de origem granítica melhorou significativamente o seu comportamento mecânico. Porém, uma diferença muito significativa no valor do módulo entre a camada cimentada e a camada subjacente resulta em maiores deformações específicas de tração na face inferior da camada cimentada, podendo conduzir ao surgimento de trincas com certa intensidade antes do final do período de projeto.

A respeito do estudo de tráfego, é de fundamental importância um monitoramento contínuo do tráfego na rodovia já implantada, com o objetivo de avaliar como o tráfego está se comportando com relação ao $\mathrm{N}$ de projeto estimado e, se necessário, reavaliar premissas e metodologias utilizadas em projeto. Além da contagem de tráfego, dados de pesagem são essenciais para retratar da forma mais aproximada possível as solicitações às quais o pavimento está submetido.

A adequação do modelo de fadiga obtido nesta pesquisa ao desempenho observado em campo se dará ao longo dos anos de utilização do pavimento, através da continuidade do acompanhamento do seu desempenho no decorrer da vida de serviço. Até o último levantamento realizado (outubro de 2018), o pavimento apresentava apenas trincas isoladas, não indicando a existência de um processo de fadiga da mistura estabilizada com cimento. Futuramente, com a evolução do trincamento por fadiga, será possível a obtenção de um fator laboratório/campo (ou função de transferência) para porcentagens maiores de área trincada, que possam ser representativas do fim da vida útil da estrutura. 


\section{AGRADECIMENTOS}

Agradeço à Universidade Federal de Santa Catarina e ao Programa de Pós-Graduação em Engenharia Civil.

Agradeço à Rede Temática de Tecnologia do Asfalto pelos investimentos realizados no Laboratório de Pavimentação da UFSC.

O presente trabalho foi realizado com apoio da Coordenação de Aperfeiçoamento de Pessoal de Nível Superior - Brasil (CAPES) - Código de Financiamento 001.

\section{REFERÊNCIAS}

[1] Artesp (2018) Editais e contratos de concessão. Disponível em:

<http://www.artesp.sp.gov.br/Style\%20Library/extranet/transparencia/contratos-de-concessao.aspx>.

[2] Austroads (2014) Cemented materials characterization - Final report. Research Report AP-R462-14, 2014.

Auststab (2012) Auststab technical note - no 5. Pavement Recycling and Stabilisation Association, Austrália.

Banco Mundial (2019) Perspectivas econômicas globais. Disponível em:

<https://www.worldbank.org/en/publication/global-economic-prospects>.

Brasil (2006) Manual de restauração de pavimentos asfálticos. 2 ed. Rio de Janeiro

[3] Ceratti, J. P. A (1991). Estudo do comportamento à fadiga de solos estabilizados com cimento para utilização em pavimentos. Tese. Universidade Federal do Rio de Janeiro, Coordenação dos Programas de Pós Graduação de Engenharia, Rio de Janeiro.

[4] DNIT (2003) Norma DNIT 006/2003 - PRO - Avaliação objetiva da superfície de pavimentos flexíveis e semirígidos: procedimento. Departamento Nacional de Infraestrutura de Transportes, Rio de Janeiro.

[5] Do Monte, M. A. V. (2012) Aplicação de solo-cimento em pavimentos flexíveis. Dissertação (Mestrado). Faculdade de Engenharia da Universidade do Porto, Porto, Portugal.

[6] Fedrigo W.; Visser A. T.; Steyn J. W.; Núnez W. P (2019) Flexural behaviour of lightly cement stabilised materials: South Africa and Brazil. Road Materials and Pavement Design.

[7] Fernandes Junior, J. L.; Paes, J. C.; Pereira, P. A. A (2007). Avaliação dos efeitos das solicitações do tráfego sobre o desempenho de pavimentos flexíveis portugueses e brasileiros. Revista Pavimentação, Ano II, n. 5, pp. 28-38. Associação Brasileira de Pavimentação - ABPv, Rio de Janeiro.

[8] Luvizão G. (2014) Avaliação do desempenho da reciclagem na rodovia SC-355: caracterização da mistura reciclada e avaliação estrutural de segmentos monitorados executados. Dissertação. Universidade Federal de Santa Catarina, Florianópolis.

[9] Makusa, G. P. (2012) Soil stabilization methods and materials in engineering practice, In: State of the art review. Department of Civil, Environmental and Natural Resources Engineering, Division of Mining and Geotechnical Engineering, Luleå University of Technology, Luleå, Suécia.

[10] Marcon, A. F. (1996) Contribuição ao desenvolvimento de um sistema de gerência de pavimentos para a malha rodoviária estadual de Santa Catarina. Tese. Pós Graduação do Curso de Engenharia Aeronáutica, Instituto de Aeronáutica, São José dos Campos.

[11] Réus, T. F.; Junior, C. A. P. S.; Fontenelle, H. B (2014). Análise empírico-mecanística do efeito do excesso de carga de veículos comerciais. Revista Eletrônica de Engenharia Civil, v. 9, n. 2, p. 57-70.

[12] Senço, W (1995). O solo-cimento no estado de São Paulo. In: 39a Reunião Anual de Pavimentação. Anais da 39a Reunião Anual de Pavimentação, v. 3, p. 502-516. Cuiabá.

[13] Solanki P., Zaman M. (2014) Behavior of stabilized subgrade soils under indirect tension and flexure. Journal of Materials in Civil Engineering, v. 26, n. 5, p. 833-844.

[14] Sounthararajah, A. et al. (2018) Early-age fatigue damage assessment of cement-treated bases under repetitive heavy traffic loading. Journal of Materials in Civil Engineering, v. 30, n. 6, p. 04018079.

[15] Specht, L. P (2000). Comportamento de misturas solo-cimento-fibra submetidas a carregamentos estáticos e dinâmicos visando à pavimentação. Dissertação. Universidade Federal do Rio Grande do Sul. Porto Alegre.

[16] Valle, N. (1994) Utilização de solos residuais saprolíticos na pavimentação rodoviária em Santa Catarina. Dissertação. Universidade Federal de Santa Catarina, Florianópolis. 


\section{Capítulo 2}

Avaliação da resistência à ação da água em misturas asfálticas modificadas por nanoargila e polímero SBS1

\section{Gabriela Ceccon Carlesso}

\section{Glicério Trichês}

João Victor Staub de Melo

Matheus Felipe Marcon

Liseane Padilha Thives

Adosindro Joaquim de Almeida

Resumo: A ação da água nas misturas asfálticas é capaz de acelerar a formação de defeitos no revestimento, aumentando a necessidade de manutenções e reduzindo a segurança dos usuários das rodovias. Visando a busca por maior resistência aos efeitos negativos da umidade, sobretudo diante do possível emprego de um nanomaterial para este fim, a pesquisa avaliou a resistência à ação da água em quatro misturas asfálticas: (1) com ligante convencional (CAP 50-70); (2) com ligante modificado por nanoargila (3\%NA); (3) com ligante modificado por polímero SBS (SBS 60/85E); e (4) com ligante modificado por nanoargila e SBS (3\%NA + 2\% SBS). A avaliação foi realizada por meio de ensaios de Lottman modificado. Como resultado, observou-se que a nanoargila e o polímero SBS podem atuar, de maneira isolada ou conjunta, como melhoradores da resistência à ação deletéria da água, sendo o melhor comportamento observado para a mistura 3\% NA + 2\% SBS. 


\section{INTRODUÇÃO}

Em regiões tropicais e subtropicais úmidas, a elevada temperatura, combinada com frequentes chuvas, faz com que o revestimento asfáltico fique submetido a repetitivos ciclos de secagem e molhagem. A ação da água nas misturas asfálticas pode ser responsável pela separação ou descolamento da película de ligante asfáltico da superfície do agregado. Como resultado da possível ação negativa da presença de umidade, na prática, tem-se a perda de resistência do revestimento asfáltico, culminando, por exemplo, na aceleração dos processos de trincamento e/ou formação de trilhas de roda, na desagregação das misturas e na formação de buracos (Bernucci et al., 1999). Isto reduz, de modo considerável, a vida útil dos pavimentos rodoviários, aumentando-se a necessidade de manutenções e reduzindo a segurança dos usuários. Desta forma, torna-se mandatório que, na fase de projeto da mistura asfáltica, a adesividade entre ligante e agregado seja avaliada.

A suscetibilidade das misturas asfálticas à ação da água depende, normalmente, das propriedades dos agregados, mas também pode ser influenciada pelas propriedades dos ligantes, características das misturas, clima, tráfego, práticas construtivas e considerações do projeto do pavimento (Seebaly et al., 2007). Nesta direção, os efeitos da presença de umidade são mais intensos em rodovias sujeitas a tráfego elevado, em misturas asfálticas com elevada porcentagem de vazios e baixos teores de ligante, submetidas a processos de compactação falhos, com sistemas de drenagem de pavimento insuficientes, e nas situações em que haja elevados teores de argila e pó aderidos à superfície dos agregados (Ceratti e Reis, 2011).

Para evitar a degradação precoce dos revestimentos devido à ação deletéria da água, costumam ser adicionados às misturas asfálticas e/ou aos ligantes produtos que contribuem para aumentar a afinidade entre agregado e ligante, como a cal hidratada e os "dopes" (Silva, 2009). Outros produtos, como o cimento Portland, as cinzas e escórias, também podem servir como melhoradores da resistência em presença de umidade (Seebaly et al., 1998). Além destes, estudos têm demonstrado que ligantes asfálticos modificados também implementam a melhoria da resistência das misturas ao efeito deletério da água. Anitelli (2007), por exemplo, constatou o aumento da resistência da mistura à ação da umidade quando do uso de ligante modificado por polímero SBS (Styrene-Butadiene-Styrene). 0 mesmo autor apresentou resultados positivos quando da adição de cal à mistura.

Em termos de modificadores dos ligantes, com a ascensão da nanotecnologia, os nanomateriais passaram a receber especial interesse da comunidade científica nos últimos anos. Diversos estudos já demonstraram as melhorias no desempenho das misturas asfálticas modificadas com nanoprodutos (Yu et al., 2009; You et al., 2011; Goh et al., 2011; Jahromi et al., 2010; Jahromi e Khodaii, 2009; Zare-Shahabadi et al., 2010; Leite et al., 2012; Cavalcanti et al., 2010), notadamente quando combinados com outros modificadores (Pamplona et al., 2012; Farias et al., 2016; Merusi et al., 2014; Galooyak et al., 2010; Golestani et al., 2012; Golestani et al., 2015). Contudo, uma grande parcela dos estudos se restringe a ensaios com apenas os ligantes.

Neste contexto, nesta pesquisa avaliou-se a possibilidade de melhorar o comportamento das misturas asfálticas diante da ação deletéria da água por meio da adição de um nanomaterial ao ligante asfáltico, estudando-se concomitantemente os efeitos da adição de um polímero. Para tanto, foi avaliada a resistência à ação da água das quatro misturas asfálticas apresentadas a seguir: (1) uma mistura de referência, produzida com ligante convencional (CAP 50-70) (Melo, 2014); (2) uma mistura com ligante modificado somente por nanoargila (3\% NA), produzido em laboratório (Melo, 2014); (3) uma mistura com ligante modificado somente por polímero SBS (Styrene-Butadiene-Styrene) (SBS 60/85E), produzido industrialmente (Marcon, 2016); e (4) uma mistura com ligante modificado simultaneamente por nanoargila e por SBS (3\% NA + 2\% SBS), produzido em laboratório (Carlesso, 2017).

\section{MATERIAIS E MÉTODO DA PESQUISA}

\subsection{MATERIAIS}

\subsubsection{AGREGADOS E COMPOSIÇÃO GRANULOMÉTRICA}

As misturas asfálticas foram produzidas com agregados de origem basáltica, cuja caracterização encontrase relacionada na Tabela 1. Como é possível observar, as propriedades listadas atendem aos critérios estabelecidos pela metodologia Superpave (quando aplicáveis), mostrando que os agregados são adequados para a formulação das respectivas misturas. 
Na Tabela 2 é apresentada a caracterização da cal hidratada empregada na pesquisa, que é correspondente ao tipo $\mathrm{CH}-1$ dolomítica.

Tabela 1: Caracterização dos agregados (Melo, 2014)

\begin{tabular}{|l|c|c|c|}
\hline \multicolumn{1}{|c}{ Propriedade } & Norma & Resultado & Critério \\
Massa específica real do agregado graúdo & ASTM C 127 & $2,953 \mathrm{~g} / \mathrm{cm}^{3}$ & $\mathrm{n} / \mathrm{a}$ \\
\hline Massa específica aparente do agregado graúdo & ASTM C 127 & $2,880 \mathrm{~g} / \mathrm{cm}^{3}$ & $\mathrm{n} / \mathrm{a}$ \\
\hline Absorção do agregado graúdo & ASTM C 127 & $0,8 \%$ & $\mathrm{n} / \mathrm{a}$ \\
\hline Massa específica real do agregado miúdo & DNER-ME 084 & $2,974 \mathrm{~g} / \mathrm{cm}^{3}$ & $\mathrm{n} / \mathrm{a}$ \\
\hline Massa específica real do material pulverulento & DNER-ME 085 & $2,804 \mathrm{~g} / \mathrm{cm}^{3}$ & $\mathrm{n} / \mathrm{a}$ \\
\hline Angularidade do agregado graúdo & ASTM D 5821 & $100 \% / 100 \%$ & $100 \% / 100 \%$ \\
mín.1
\end{tabular}

Tabela 2: Caracterização da cal hidratada (Melo, 2014)

\begin{tabular}{|l|c|}
\hline \multicolumn{1}{|c|}{ Propriedade } & Resultado \\
\hline Perda ao fogo & $18,6 \%$ \\
\hline Resíduo insolúvel & $1,9 \%$ \\
\hline Anidrido carbônico $\left(\mathrm{CO}_{2}\right)$ & $2,5 \%$ \\
\hline Óxido de cálcio (CaO) & $45,1 \%$ \\
\hline Óxido de magnésio (MgO) & $33,5 \%$ \\
\hline $\begin{array}{l}\text { Óxidos totais não voláteis (CaO + } \\
\text { MgO) }\end{array}$ & $96,5 \%$ \\
\hline Óxidos totais não hidratados & $27,6 \%$ \\
\hline Óxidos de CaO não hidratados & $0,0 \%$ \\
\hline Cálcio (Ca) & $32,2 \%$ \\
\hline Magnésio (Mg) & $20,2 \%$ \\
\hline Densidade & 3,0 \\
\hline
\end{tabular}

Para a formulação das misturas asfálticas, foi adotada uma curva granulométrica correspondente à faixa $\mathrm{B}$ do DNIT (Figura 1), sendo composta por 43\% de brita 3/4", 15,5\% de pedrisco, 40\% de pó de pedra e 1,5\% de cal. Esta composição foi previamente definida pelo Centro de Pesquisas e Desenvolvimento Leopoldo Américo Miguez de Mello (CENPES/Petrobras), e teve como objetivo a obtenção de misturas com elevada resistência à deformação permanente. 
Figura 1: Curva granulométrica da composição de agregados

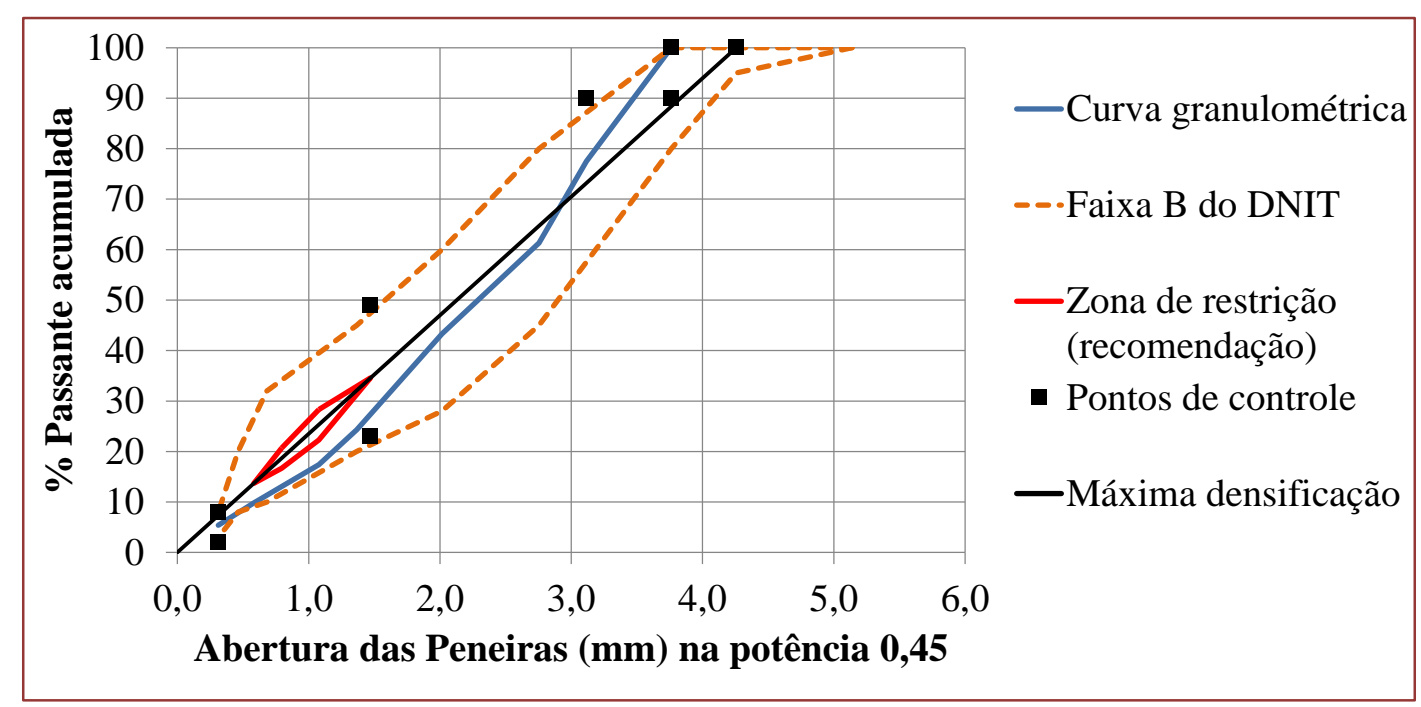

Cabe ressaltar que os agregados e a composição granulométrica empregados neste estudo correspondem aos mesmos aplicados na execução dos Segmentos Monitorados do Contorno de Araranguá, BR-101 Sul, no estado de Santa Catarina, e fazem parte de um Projeto de Pesquisa coordenado pela Rede Temática de Tecnologia do Asfalto, patrocinado pela Petrobras.

\subsubsection{LIGANTE ASFÁLTICO CONVENCIONAL}

O ligante asfáltico convencional utilizado para a produção da mistura asfáltica de referência e como matriz para a modificação dos ligantes 3\% NA e 3\% NA + 2 \% SBS corresponde a um CAP 50-70, de PG 58-22. A caracterização deste material é apresentada na Tabela 3.

Tabela 3: Caracterização do ligante asfáltico convencional (CAP 50-70)

\begin{tabular}{|c|c|c|c|}
\hline Propriedade & Unidade & Norma & Resultado \\
\hline Penetração & $0,1 \mathrm{~mm}$ & ASTM D 5 & 57 \\
\hline Ponto de amolecimento & ${ }^{\circ} \mathrm{C}$ & ASTM D 36 & 47,9 \\
\hline $\begin{array}{l}\text { Índice de Susceptibilidade } \\
\text { Térmica }\end{array}$ & - & - & $-1,44$ \\
\hline Viscosidade Brookfield & \multirow{4}{*}{$\mathrm{cP}$} & \multirow{4}{*}{ ASTM D 4402} & \\
\hline a $135^{\circ} \mathrm{C}$ (spindle $\left.21,20 \mathrm{rpm}\right)$ & & & 290 \\
\hline a $150^{\circ} \mathrm{C}$ (spindle $\left.21,50 \mathrm{rpm}\right)$ & & & 150 \\
\hline a $175^{\circ} \mathrm{C}$ (spindle $\left.21,100 \mathrm{rpm}\right)$ & & & 60 \\
\hline
\end{tabular}

\subsubsection{LIGANTE ASFÁLTICO MODIFICADO POR POLÍMERO SBS}

A Tabela 4 apresenta a caracterização do ligante modificado por polímero SBS (60/85E). 
Tabela 4: Caracterização do ligante asfáltico modificado por polímero SBS (SBS 60/85E)

\begin{tabular}{|l|c|c|c|}
\hline \multicolumn{1}{|c|}{ Propriedade } & Unidade & Norma & Resultado \\
\hline Penetração & $0,1 \mathrm{~mm}$ & ABNT NBR 6576 & 50 \\
\hline Ponto de amolecimento & ${ }^{\circ} \mathrm{C}$ & ABNT NBR 6560 & 73,0 \\
\hline Recuperação elástica & $\%$ & ABNT NBR 15086 & 90 \\
\hline Viscosidade aparente & & & \\
\cline { 1 - 3 } $135^{\circ} \mathrm{C}$ (spindle 21, $\left.20 \mathrm{rpm}\right)$ & \multirow{2}{*}{ cP } & ABNT NBR 15184 & 1910 \\
\hline a $150{ }^{\circ} \mathrm{C}$ (spindle 21, $\left.50 \mathrm{rpm}\right)$ & & & 640 \\
\hline a $175{ }^{\circ} \mathrm{C}$ (spindle 21, $\left.100 \mathrm{rpm}\right)$ & & & 290 \\
\hline
\end{tabular}

\subsubsection{MODIFICADORES}

A nanoargila organofílica empregada para a modificação do CAP 50-70 possui tamanho de partícula (seco) de 7-9 $\mu \mathrm{m}$, tamanho de partícula após a dispersão de $1 \times 500 \mathrm{~nm}$ e massa específica igual a $1,7 \mathrm{~g} / \mathrm{cm}^{3}$. É composta por carbono (45,50\%), silício (33,42\%), alumínio (16,08\%), ferro $(3,60 \%)$, cloro $(0,80 \%)$, titânio $(0,31 \%)$, potássio $(0,27 \%)$ e estrôncio $(0,02 \%)$. Conforme resultados de ensaios de termogravimetria, é termicamente estável em temperaturas abaixo de $262,4^{\circ} \mathrm{C}$ (Melo, 2014).

O polímero SBS utilizado como modificador possui estrutura linear, com porcentagem de poliestireno entre $30 \%$ e $32 \%$, sendo fornecido e empregado na forma de grânulos.

\subsection{MÉTODO DA PESQUISA}

\subsubsection{ETAPA 1: MODIFICAÇÃO E CARACTERIZAÇÃO DOS LIGANTES MODIFICADOS}

A Etapa 1 consistiu na modificação do ligante convencional e posterior caracterização dos ligantes modificados. Nesta etapa, foram produzidos, em laboratório, os ligantes 3\% NA (modificado por 3\% de nanoargila em relação ao peso de CAP 50-70) e 3\% NA + 2\% SBS (modificado por 3\% de nanoargila e $2 \%$ de polímero SBS). 0 teor de 3\% de nanoargila foi adotado a partir dos resultados de um estudo de otimização realizado previamente, no qual foi avaliada a resistência à deformação permanente de misturas asfálticas produzidas com ligantes modificados por 1\%, 2\% e 3\% de nanoargila (Melo, 2014).

No caso do ligante 3\% NA + 2\% SBS, a adição simultânea de $2 \%$ de SBS teve como objetivo conferir recuperação elástica ao ligante asfáltico modificado somente com 3\% NA, o qual apresentava recuperação elástica menor do que $10 \%$. Além disso, ao se adotar um teor reduzido de polímero, buscou-se aliar um aumento significativo no desempenho do ligante a um baixo incremento no custo final, baseando-se nos resultados obtidos por Pamplona et al. (2012), que estudaram a modificação com 2,5\% de nanoargila e 2,5\% de SBS.

A nanoargila e o polímero SBS foram incorporados ao ligante base CAP 50-70 a partir do emprego de um misturador de alto cisalhamento de laboratório, modelo L5M-A da Silverson. A modificação para se produzir o ligante $3 \%$ NA foi realizada na temperatura de $150^{\circ} \mathrm{C}$, sob velocidade de cisalhamento de $5.000 \mathrm{rpm}$ e período de compatibilização igual a 100 minutos. Para o ligante $3 \%$ NA + 2\% SBS, adotou-se a temperatura de modificação de $180^{\circ} \mathrm{C}$ e o período de mistura de 180 minutos, mantendo-se a velocidade de $5.000 \mathrm{rpm}$. Estes procedimentos foram definidos com base no estudo da literatura (Yu et al., 2009; Goh et al., 2011; Zare-Shahabadi et. al, 2010; Pamplona et al., 2012; Farias et al., 2016; Merusi et al., 2014; Galooyak et al., 2010; Golestani et al., 2012; Golestani et al., 2015).

Posteriormente, os ligantes modificados foram caracterizados segundo as propriedades de penetração (ABNT NBR 6576), ponto de amolecimento (ABNT NBR 6560), recuperação elástica (ABNT NBR 15086), separação de fase (ABNT NBR 15166) e viscosidade aparente (ABNT NBR 15184).

\subsubsection{ETAPA 2: DEFINIÇÃO DOS TEORES DE LIGANTE DE PROJETO DAS MISTURAS ASFÁLTICAS}

Na Etapa 2, foram definidos os teores de ligante de projeto das misturas asfálticas, empregando-se a metodologia de dosagem Superpave, de acordo com as normas AASHTO M 323 e AASHTO R 35. Para o 
tamanho nominal máximo de agregado de $19 \mathrm{~mm}$ e para rodovia de alto volume de tráfego (onde estão inseridos os segmentos monitorados), os teores de ligante de projeto corresponderam àqueles em que foram atendidos, simultaneamente, os critérios de dosagem relacionados a seguir: (1) porcentagem de volume de vazios no $\mathrm{N}_{\text {inicial }}\left(9\right.$ giros, $\mathrm{V}_{\mathrm{v}} @ \mathrm{~N}_{\text {inicial }}$ ) > 11,0\%; (2) porcentagem de volume de vazios no $\mathrm{N}_{\text {projeto }}$ (125 giros, $\mathrm{V}_{\mathrm{v}} @ \mathrm{~N}_{\text {projeto }}$ = 4,0\%; (3) vazios do agregado mineral (VAM) 213,0\%; (4) relação betume-vazios (RBV) entre 65\% e 75\%; e (5) relação pó-betume entre 0,8 e 1,6.

\subsubsection{ETAPA 3: AVALIAÇÃO DO DANO POR UMIDADE INDUZIDA}

Após a definição do teor de ligante de projeto, foi avaliado o efeito da ação deletéria da água nas misturas, através da realização do ensaio de Lottman modificado (ABNT NBR 15617).

Para tanto, foram previamente moldados seis corpos de prova para cada mistura, cada qual com diâmetro de $100 \mathrm{~mm}$, volume de vazios entre 6,0\% e 8,0\%, e teor de ligante igual àquele definido no estudo de dosagem. Dos seis corpos de prova de cada mistura, três permaneceram em repouso em laboratório, enquanto os outros três foram submetidos ao condicionamento conforme especificado pela citada norma. Posteriormente, os corpos de prova foram rompidos à tração indireta, na temperatura de $25^{\circ} \mathrm{C}$ (DNIT 136$\mathrm{ME}$ ).

Deste modo, foram determinadas a resistência do grupo condicionado ( $\mathrm{RT}_{1}$ ) e a resistência do grupo não condicionado $\left(\mathrm{RT}_{2}\right)$, bem como a relação entre elas. Cabe destacar que, para a aceitação da mistura, recomenda-se a obtenção de uma relação (RRT = $\mathrm{RT}_{1} / \mathrm{RT}_{2}$ ) maior do que 70\% (DNIT 180-ME).

\section{APRESENTAÇÃO E DISCUSSÃO DOS RESULTADOS}

\subsection{CARACTERIZAÇÃO DOS LIGANTES MODIFICADOS}

A Tabela 5 apresenta a caracterização dos ligantes asfálticos modificados em laboratório.

Tabela 5: Caracterização dos ligantes asfálticos 3\% NA e 3\% NA + 2\% SBS

\begin{tabular}{|c|c|c|c|c|}
\hline \multirow[b]{2}{*}{ Propriedade } & \multirow[b]{2}{*}{ Unidade } & \multirow[b]{2}{*}{ Norma } & \multicolumn{2}{|c|}{ Ligante asfáltico } \\
\hline & & & $3 \%$ NA & $\begin{array}{c}3 \% \text { NA + } \\
2 \% \text { SBS }\end{array}$ \\
\hline Penetração & $0,1 \mathrm{~mm}$ & ABNT NBR 6576 & 55 & 36 \\
\hline Ponto de amolecimento & ${ }^{\circ} \mathrm{C}$ & ABNT NBR 6560 & 50,2 & 56,9 \\
\hline Recuperação elástica & $\%$ & ABNT NBR 15086 & 6 & 49 \\
\hline Separação de fase (24h/48h) & ${ }^{\circ} \mathrm{C}$ & ABNT NBR 15166 & $1,0 /-$ & $0,5 / 0,8$ \\
\hline Viscosidade aparente & \multirow{4}{*}{ cP } & \multirow{4}{*}{ ABNT NBR 15184} & & \\
\hline a $135^{\circ} \mathrm{C}$ (spindle $\left.21,20 \mathrm{rpm}\right)$ & & & 410 & 760 \\
\hline a $150{ }^{\circ} \mathrm{C}$ (spindle $\left.21,50 \mathrm{rpm}\right)$ & & & 210 & 370 \\
\hline a $175^{\circ} \mathrm{C}$ (spindle $\left.21,100 \mathrm{rpm}\right)$ & & & 90 & 160 \\
\hline
\end{tabular}

Comparando-se os resultados da Tabela 5 com a caracterização empírica do CAP 50-70 (Tabela 3) e do ligante SBS 60/85E (Tabela 4), observa-se que, conforme esperado, a modificação dos ligantes resultou na diminuição da penetração e no aumento do ponto de amolecimento. Entre os resultados, pode-se destacar a penetração relativamente baixa obtida para o ligante 3\% NA + 2\% SBS e o ponto de amolecimento relativamente alto do ligante SBS 60/85E, demonstrando os ganhos de rigidez do primeiro em contraste com os ganhos relacionados à sensibilidade a elevadas temperaturas do segundo. Estas características indicam a formulação de misturas asfálticas bastante resistentes à deformação permanente, cuja previsão de comportamento, sobretudo a partir da penetração, pode ser considerada adequada se levados em consideração os resultados apresentados anteriormente por Carlesso et al. (2019). Nesta direção, os autores realizaram ensaios empregando-se o simulador de tráfego LCPC (Laboratoire Central des Ponts et Chaussées) 
com as respectivas misturas, e demonstraram a resistência à deformação permanente muito superior, aos 30.000 ciclos, para a mistura 3\% NA + 2\% SBS (58\% em relação à convencional). No entanto, é importante ressaltar que a previsão de desempenho das misturas asfálticas a partir da caracterização empírica dos ligantes modificados apresenta grandes limitações.

Quanto à propriedade de recuperação elástica, pode-se observar a obtenção de um valor mais elevado para o ligante SBS 60/85E. Tal resultado deve-se ao teor de polímero elastomérico relativamente alto incorporado ao material (em torno de 4\%). Em contrapartida, a baixa recuperação elástica do ligante 3\% NA relaciona-se ao fato de que a nanoargila não funciona como um produto elastomérico na modificação.

Em relação à estabilidade à estocagem, os ensaios realizados com os ligantes 3\% NA e 3\% NA + 2\% SBS demonstraram que estes materiais não apresentam separação de fases considerável, estando os resultados abaixo do limite máximo (de $5{ }^{\circ} \mathrm{C}$ ) estabelecido pela Especificação Brasileira de Asfalto-Polímero (ANP, 2010).

Além disso, cabe comentar que os resultados obtidos para a viscosidade dos ligantes modificados também se enquadram nos limites estabelecidos pela Especificação Brasileira de Asfalto-Polímero (ANP, 2010), ainda que tenham sido identificados aumentos consideráveis em comparação ao CAP 50-70 (convencional).

\subsection{DEFINIÇÃO DOS TEORES DE LIGANTE DE PROJETO DAS MISTURAS ASFÁLTICAS}

A Tabela 6 relaciona os teores de ligante de projeto obtidos a partir do estudo de dosagem volumétrica.

Tabela 6: Teores de ligante de projeto das diferentes misturas asfálticas

\begin{tabular}{|l|c|}
\hline \multicolumn{1}{|c|}{ Ligante asfáltico } & $\begin{array}{c}\text { Teor de ligante } \\
\text { de projeto }(\%)\end{array}$ \\
\hline CAP 50-70 & 4,4 \\
\hline $3 \%$ NA & 4,1 \\
\hline SBS 60/85E & 4,5 \\
\hline 3\% NA + 2\% SBS & 4,3 \\
\hline
\end{tabular}

Como é possível observar na Tabela 6, a adição de nanoargila ao ligante convencional propicia uma redução no teor de ligante de projeto da mistura asfáltica. Em contrapartida, a incorporação do polímero SBS faz com que seja requerido um teor de ligante superior. Deste modo, o resultado intermediário obtido para a mistura 3\% NA + 2\% SBS no estudo de dosagem demonstra a combinação do efeito positivo da nanoargila, em termos de trabalhabilidade da mistura, ao efeito negativo oriundo da presença do polímero. Contudo, é possível admitir que as variações nos teores de ligante de projeto estão no interior do intervalo de $\pm 0,3 \%$ permitido, em campo, pelas especificações construtivas vigentes no Brasil.

\subsection{AVALIAÇÃO DO DANO POR UMIDADE INDUZIDA}

As Figuras 2 e 3 apresentam, respectivamente, a resistência à tração dos corpos de prova condicionados e não condicionados e a relação entre elas (RRT). 
Figura 2: Resistência à tração dos corpos de prova condicionados e não condicionados

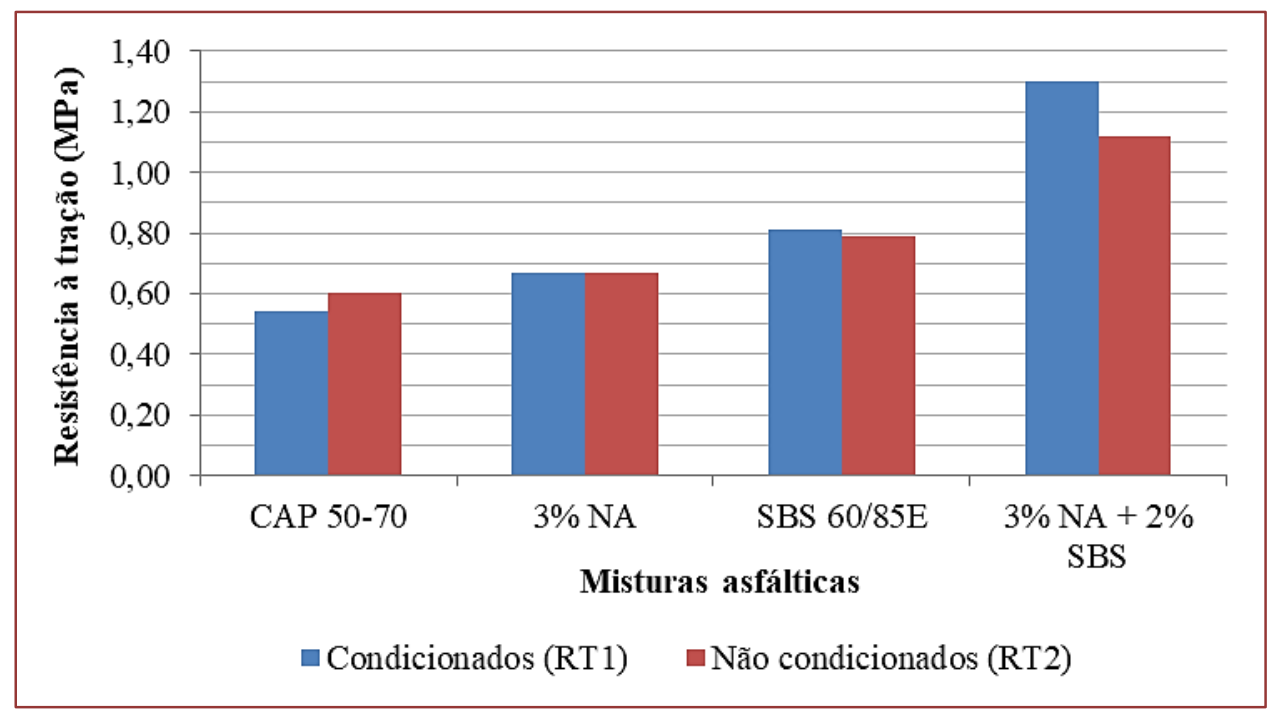

Figura 3: Relação de resistência à tração dos corpos de prova condicionados e não condicionados (RRT $\left.=\mathrm{RT}_{1} / \mathrm{RT}_{2}\right)$

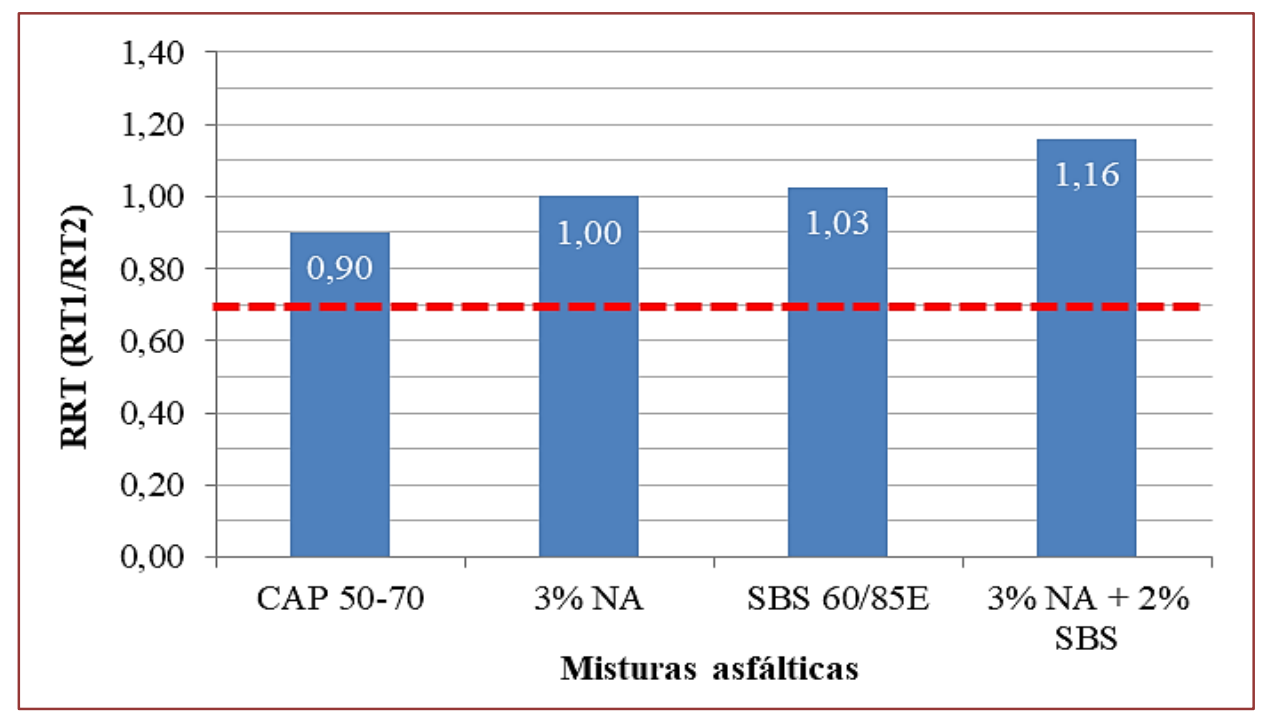

Inicialmente, da observação da Figura 2, destacam-se os valores mais elevados de resistência à tração obtidos para a mistura $3 \% \mathrm{NA}+2 \% \mathrm{SBS}$, tanto para os corpos de prova condicionados quanto para aqueles não condicionados. Estes resultados podem ser atribuídos à forte ligação/adesividade estabelecida entre o ligante e os agregados e, adicionalmente, à alta rigidez do referido ligante em comparação aos demais, conforme observado na caracterização empírica dos ligantes modificados.

Tratando-se da relação entre as resistências dos corpos de prova submetidos a diferentes tratamentos (RRT), conforme é possível observar na Figura 3, todas apresentaram desempenhos considerados satisfatórios em comparação com o limite estabelecido para a aceitação das misturas (RRT mínima = 70\%), inclusive a mistura convencional (de referência). Neste sentido, é interessante mencionar que ambas foram produzidas com agregados de origem basáltica e possuem cal hidratada em sua composição, influenciando positivamente na ligação entre ligantes e agregados.

No contexto das diferentes misturas avaliadas, cabe ressaltar a ausência de dano por umidade induzida nas misturas modificadas por nanoargila e por SBS, indicando que estes modificadores também podem auxiliar na inibição da ação deletéria da água, atuando, inclusive, como melhoradores de comportamento na presença de umidade. 
Entre os resultados de RRT obtidos para as diferentes misturas, destaca-se o desempenho superior da mistura produzida com o ligante 3\% NA + 2\% SBS. Neste contexto, acredita-se que a ação benéfica isolada da nanoargila e do polímero nas misturas asfálticas é combinada quando da aplicação simultânea de ambos, o que pode representar melhorias mais significativas no desempenho destas misturas, em campo, diante da alta pluviosidade de muitas regiões brasileiras.

Desta maneira, em termos de resistência à ação da água, tem-se como principal resultado o melhor comportamento da mistura 3\% NA + 2\% SBS, que é seguido pelo comportamento da mistura SBS 60/85E, da mistura 3\% NA e da mistura convencional. Na pesquisa de Golestani et al. (2015), a mesma hierarquia foi estabelecida para os valores de RRT de misturas análogas.

\section{CONCLUSÕES E CONSIDERAÇÕES FINAIS}

De acordo com o objetivo definido para esta pesquisa, seu desenvolvimento possibilitou a avaliação e posterior estudo comparativo da resistência à ação deletéria da água de quatro misturas asfálticas distintas: uma produzida com ligante convencional (CAP 50-70); uma com ligante modificado somente por nanoargila (3\% NA); outra com ligante modificado somente por polímero SBS (SBS 60/85E); e outra com ligante modificado simultaneamente por nanoargila e por SBS (3\% NA + 2\% SBS).

Como resultado, a partir dos ensaios de Lottman modificado, observou-se que tanto a nanoargila quanto o polímero SBS, de modo isolado, podem ser capazes de atuar na melhoria da resistência à ação deletéria da água, inclusive inibindo os efeitos negativos da umidade identificados no caso da mistura convencional. Contudo, entre as misturas avaliadas, o melhor resultado foi observado para aquela duplamente modificada (3\% NA + 2\% SBS), cujos corpos de prova submetidos ao ciclo de saturação, congelamento e descongelamento, se comparados àqueles que permaneceram em repouso, chegaram a apresentar um aumento de resistência que pode ser considerado significativo. Deste modo, o emprego da mistura 3\% NA $+2 \%$ SBS poderia representar grandes ganhos de desempenho em regiões de alta pluviosidade, por exemplo.

No mesmo sentido, com ênfase para o emprego da nanotecnologia na modificação de misturas asfálticas, cabe mencionar que, em estudo publicado anteriormente (Carlesso et al., 2019), os autores também demonstraram, sob outros aspectos, o comportamento satisfatório das misturas modificadas por nanoargila. Entre elas, também merece destaque a mistura modificada simultaneamente por nanoargila e SBS, sobretudo em termos de resistência à deformação permanente. Desta maneira, os resultados desta pesquisa, em conjunto com aqueles anteriormente apresentados por Carlesso et al. (2019), corroboram para a ideia de que a associação entre a ciência dos polímeros e a nanotecnologia, apesar de relativamente recente, possui elevado potencial para promover grandes avanços no desempenho de misturas asfálticas modificadas.

\section{AGRADECIMENTOS}

O primeiro e o quarto autores agradecem ao CNPq e a CAPES pelas bolsas de Mestrado. Os autores agradecem a Rede Temática de Tecnologia do Asfalto/Petrobras, pelos investimentos realizados no Laboratório de Pavimentação da Universidade Federal de Santa Catarina (UFSC).

\section{REFERÊNCIAS}

[1] AASHTO (2013) AASHTO M 323: Standard Specification for Superpave Volumetric Mix Design. American Association of State Highway and Transportation, Washington, DC.

[2] AASHTO (2012) AASHTO R 35: Standard Practice for Superpave Volumetric Design for Hot-Mix Asphalt (HMA). American Association of State Highway and Transportation, Washington, DC.

[3] AASHTO (2012) AASHTO T 112: Standard method of test for clay lumps and friable particles in aggregates. American Association of State Highway and Transportation, Washington, DC.

[4] AASHTO (2008) AASHTO T 176: Standard method of test for plastic fines in graded aggregates and soils by use of the sand equivalent test. American Association of State Highway and Transportation, Washington, DC.

[5] ABNT (2016) ABNT NBR 6560: Ligantes asfálticos - Determinação do ponto de amolecimento - Método do anel e bola. Associação Brasileira de Normas Técnicas, Rio de Janeiro. 
[6] ABNT (2007) ABNT NBR 6576: Materiais asfálticos - Determinação da penetração. Associação Brasileira de Normas Técnicas, Rio de Janeiro.

[7] ABNT (1989) ABNT NBR 6954: Lastro-padrão - Determinação da forma do material. Associação Brasileira de Normas Técnicas, Rio de Janeiro.

[8] ABNT (2006) ABNT NBR 15086: Materiais betuminosos - Determinação da recuperação elástica pelo ductilômetro. Associação Brasileira de Normas Técnicas, Rio de Janeiro.

[9] ABNT (2004) ABNT NBR 15166: Asfalto modificado - Ensaio de separação de fase. Associação Brasileira de Normas Técnicas, Rio de Janeiro.

[10] ABNT (2004) ABNT NBR 15184: Materiais betuminosos - Determinação da viscosidade em temperaturas elevadas usando um viscosímetro rotacional. Associação Brasileira de Normas Técnicas, Rio de Janeiro.

[11] ABNT (2015) ABNT NBR 15617 - Misturas asfálticas - Determinação do dano por umidade induzida. Associação Brasileira de Normas Técnicas, Rio de Janeiro.

[12] ANITELLI, A. (2013) Estudo do dano por umidade de misturas densas com ligantes asfálticos convencional e modificado com polímero SBS. Dissertação de Mestrado. Programa de Pós-Graduação em Engenharia de Transportes Escola de Engenharia de São Carlos da Universidade de São Paulo, São Carlos.

[13] ANP (2010) Resolução ANP n 32, DE 21.9.2010 DOU 22.9.2010. Agência Nacional De Petróleo, Gás e Biocombustível, Brasília.

[14] ASTM (2013) ASTM C 88: Standard Test Method for Soundness of Aggregates by Use of Sodium Sulfate or Magnesium Sulfate. American Society for Testing Materials, West Conshohocken, PA.

[15] ASTM (2012) ASTM C 127: Standard test method for density, relative density (specific gravity), and absorption of coarse aggregate. American Society for Testing Materials, West Conshohocken, PA.

[16] ASTM (2014) ASTM C 131: Standard Test Method for Resistance to Degradation of Small-Size Coarse Aggregate by Abrasion and Impact in the Los Angeles Machine. American Society for Testing Materials, West Conshohocken, PA.

[17] ASTM (2006) ASTM C 1252: Standard Test Methods for Uncompacted Void Content of Fine Aggregate (as Influenced by Particle Shape, Surface Texture, and Grading). American Society for Testing Materials, West Conshohocken, PA.

[18] ASTM (2013) ASTM D 5: Standard Test Method for Penetration of Bituminous Materials. American Society for Testing Materials, West Conshohocken, PA.

[19] ASTM (2014) ASTM D 36 - Standard Test Method for Softening Point of Bitumen (Ring-and-Ball Apparatus). American Society for Testing Materials, West Conshohocken, PA.

[20] ASTM (2013) ASTM D 4402 - Standard Test Method for Viscosity Determination of Asphalt at Elevated Temperatures Using a Rotational Viscometer. American Society for Testing Materials, West Conshohocken, PA.

[21] ASTM (2013) ASTM D 5821: Standard Test Method for Determining the Percentage of Fractured Particles in Coarse Aggregate. American Society for Testing Materials, West Conshohocken, PA.

[22] Bernucci, L. B.; J. A. P. Ceratti; J. M. Chaves; E. Moura e A. D. Carvalho (1999) Estudo de Adesividade no Comportamento de Misturas Asfálticas. Anais do 10 Congresso Ibero-Latino-americano del Asfalto. Espanha.

[23] Carlesso, G. C. (2017) Estudo do comportamento de mistura asfáltica modificada por nanoargila e polímero SBS. Dissertação de Mestrado. Programa de Pós-Graduação em Engenharia Civil - Universidade Federal de Santa Catarina, Florianópolis.

[24] Carlesso, G. C.; G. Trichês; J. V. S. Melo; M. F. Marcon; L. P. Thives e L. C. Luz (2019) Evaluation of Rheological Behavior, Resistance to Permanent Deformation, and Resistance to Fatigue of Asphalt Mixtures Modified with Nanoclay and SBS Polymer. Applied Sciences, v. 9, n. 13, p. 2697 (1-16).

[25] Cavalcanti, L. S. (2010) Efeito de alguns modificadores de ligante na vida de fadiga e deformação permanente de misturas asfálticas. Dissertação de Mestrado. Programa de Pós-Graduação em Engenharia Civil, COPPE. Universidade Federal do Rio de Janeiro, Rio de Janeiro.

[26] Ceratti, J. A. P. e R. M. M. Reis (2011) Manual de dosagem de concreto asfáltico. Oficina de Textos, São Paulo.

[27] DNER (1995) DNER-ME 084: Agregado miúdo - determinação da densidade real. Método de ensaio. Departamento Nacional de Estradas de Rodagem, Rio de Janeiro.

[28] DNER (1994) DNER-ME 085: Material finamente pulverizado - determinação da massa específica real. Método de ensaio. Departamento Nacional de Estradas de Rodagem, Rio de Janeiro.

[29] DNIT (2018) DNIT-ME 136: Pavimentação asfáltica - Misturas asfálticas - Determinação do dano por umidade induzida - Método de ensaio. Instituto de Pesquisas Rodoviárias - IPR. Departamento Nacional de Infraestrutura de Transportes, Rio de Janeiro. 
[30] DNIT (2018) DNIT-ME 180: Pavimentação- Misturas asfálticas - Determinação da resistência à tração por compressão diametral - Método de ensaio. Instituto de Pesquisas Rodoviárias - IPR. Departamento Nacional de Infraestrutura de Transportes, Rio de Janeiro.

[31] Farias, L. G. A. T.; J. L. Leitinho; B. C. Amoni; J. B. S. Bastos; J. B. Soares; S. A. Soares e H. B. Sant'Ana (2016) Effects of nanoclay and nanocomposites on bitumen rheological properties. Construction and building materials, v. 125, p. 873883.

[32] Galooyak, S. S.; B. Dabir; A. E. Nazarbeygi e A. Moeini (2010) Rheological properties and storage stability of bitumen/SBS/montmorillonite composites. Construction and building materials, v. 24, n. 3, p. 300-307.

[33] Goh, S. W.; M. Akin; Z. You e X. Shi (2011) Effect of deicing solutions on the tensile strength of micro or nanomodified asphalt mixture. Construction and Building Materials, v. 25, n. 1, p. 195-200.

[34] Golestani, B.; F. M. Nejad e S. S. Galooyak (2012) Performance evaluation of linear and nonlinear nanocomposite modified asphalts. Construction and building materials, v. 35, p. 197-203.

[35] Golestani, B.; B. H. Nam; F. M. Nejad e S. Fallah (2015) Nanoclay application to asphalt concrete: characterization of polymer and linear nanocomposite-modified asphalt binder and mixture. Construction and building materials, v. 91, p. 32-38.

[36] Jahromi, S. G. e A. Khodaii (2009) Effects of nanoclay on rheological properties of bitumen binder. Construction and Building Materials, v. 23, n. 8, p. 2894-2904.

[37] Jahromi, S. G.; B. Andalibizade e S. Vossough (2010) Engineering properties of nanoclay modified asphalt concrete mixtures. The Arabian Journal for Science and Engineering, v. 35, n. 1B, p. 89-103.

[38] Leite, L. F. M.; G. Guerra; A. Martins e M. Cravo (2012) Efeito de nanomodificadores no envelhecimento e susceptibilidade térmica de cimentos asfálticos. Anais da 42aㅡ Reunião Anual de Pavimentação. Fortaleza.

[39] Marcon, M. F. (2016) Estudo e comparação do desempenho mecânico e reológico entre concretos asfálticos modificados por polímero SBS, borracha moída de pneu e nanomateriais. Dissertação de Mestrado. Programa de PósGraduação em Engenharia Civil - Universidade Federal de Santa Catarina, Florianópolis.

[40] Melo, J. V. S. (2014) Desenvolvimento e estudo do comportamento reológico e desempenho mecânico de concretos asfálticos modificados com nanocompósitos. Tese de Doutorado. Programa de Pós-Graduação em Engenharia Civil - Universidade Federal de Santa Catarina, Florianópolis.

[41] Merusi, F.; F. Giuliani; S. Filippi e G. Polacco (2014) A model combining structure and properties of 160/220 bituminous binder modified with polymer/clay nanocomposites. A rheological and morphological study. Materials and structures, v. 47, n. 5, p. 819-838.

[42] Pamplona, T. F.; B. C. Amoni; A. E. V. Alencar; A. P. D. Lima; N. M. P. S. Ricardo; J. B. Soares e S. A. Soares (2012) Asphalt binders modified by SBS and SBS/nanoclays: effect on rheological properties. Journal of the Brazilian Chemical Society, v. 23, n. 4, p. 639-647.

[43] Sebaaly, P. E.; D. Little; E. Y. Hajj e A. Bhasin (2007) Impact of Lime and Liquid Antistrip Agents on Properties of Idaho Hot-Mix Asphalt Mixture. Transportation Research Record: Journal of the Transportation Research Board, v. 1998, n. 1, 65-74.

[44] Silva, C. A. R. (2009) Estudo do agregado reciclado de construção civil em misturas betuminosas para vias urbanas. Dissertação de Mestrado. Programa de Pós-Graduação em Engenharia Civil - Universidade Federal de Ouro Preto, Ouro Preto.

[45] You, Z.; J. Mills-Beale; J. M. Foley; S. Roy; G. M. Odegard; Q. Dai e S. W. Goh (2011) Nanoclay-modified asphalt materials preparation and characterization. Construction and Building Materials, v. 25, n. 2, p. 1072-1078.

[46] Yu, J.; P. Feng; H. Zhang e S. Wu (2009) Effect of organo-montmorillonite on aging properties of asphalt. Construction and Building Materials, v. 23, n. 7, p. 2636-2640.

[47] Zare-Shahabadi, A.; A. Shokuhfar e S. Ebrahimi-Nejad (2010) Preparation and rheological characterization of asphalt binders reinforced with layered silicate nanoparticles. Construction and Building Materials, v. 24, n. 7, p. 12391244. 


\section{Capítulo 3}

\section{Análise da aplicação de dados planialtimétricos obtidos com Aeronave Remotamente Pilotada (ARP) para execução de projetos de terraplenagem}

Maelckson Bruno Barros Gomes

André Luís Silva dos Santos

Paulo Afonso Lopes da Silva

Maria da Anunciação Rodrigues Araújo

Resumo: Considerando a disseminação da tecnologia empregada nas aeronaves remotamente pilotadas (ARPs) e sua notável aplicação em diversos segmentos, esta pesquisa aplica os produtos oriundos do aerolevantamento, como a nuvem de pontos e o modelo digital do terreno (MDT) para confeccionar projetos de terraplenagem e comparar com os resultados obtidos na confecção de um mesmo projeto, no entanto, executados com base planialtimétrica obtida a partir de um par de receptores Global Navigation Satellite System (GNSS) pelo método Real Time Kinematic (RTK) pós processado. É realizada uma análise estatística das altimetrias obtidas nos dois levantamentos, adotando como altimetria de referência as obtidas no levantamento pelo método RTK pós processado. Esta análise identificou que as discrepâncias não têm um padrão de comportamento e permitiu demonstrar que o aerolevantamento com ARP, dotada de sensor imageador RGB, não é recomendado caso haja elevada densidade arbórea, tendo em vista as discrepâncias altimétricas e volumétricas observadas.

Palavras-chave: GNSS, ARP, levantamento planialtimétrico, terraplenagem, MDT. 


\section{INTRODUÇÃO}

Terraplenagem é a arte de modificar a configuração do terreno. Sendo substancial saber a maneira mais fácil e econômica de escavá-lo, transportá-lo e compactá-lo (Abram e Rocha, 2000). Para execução de um projeto de terraplenagem é necessário obter dados planialtimétricos da área a ser terraplenada. Nesse contexto, surgem diversas técnicas para obter-se tais informações, dentre outras, destaca-se a fotogrametria. Segundo Tuler e Saraiva (2014), o levantamento fotogramétrico consiste na medição das distâncias e dimensões reais de objetos pelo uso da fotografia.

Esta técnica era até pouco tempo tida como um serviço demasiadamente oneroso, pela logística envolvida no aerolevantamento, que abrange desde a captura de fotos em campo até o alto valor dos softwares de processamento. Com o advento de aeronaves remotamente pilotadas (ARP) com sensores embarcados disseminou-se o uso de aerolevantamentos em várias áreas: agricultura de precisão, planejamento urbano, monitoramento pecuário, inspeção de linhas de transmissão, obtenção de dados planialtimétricos, entre outros. Mccormac, et. al (2016) complementam ainda que a fotogrametria tem como características principais, a rapidez com que pode ser aplicada, a economia, a possibilidade de obter informações de difícil acesso e a grande quantidade de dados obtidos.

Contudo, vale destacar que as normas técnicas não acompanharam com a mesma rapidez os avanços tecnológicos das técnicas de levantamento. Como por exemplo, a Norma Brasileira (NBR) que discorre sobre Execução de levantamento topográfico, a NBR 13133. Esta norma, que é direcionada para levantamentos realizados com medidores eletrônicos de distância (MED), foi publicada em 1994 e até os dias atuais não teve atualizações. Outros exemplos são o padrão de exatidão cartográfica (PEC) concebido no decreto № $89.817 / 1984$ e os decretos-lei № 243/1967 e 1.777/1971 que apesar de regulamentarem aerolevantamentos e sugerirem uma classificação para as cartas obtidas, foram implementados em uma época que não era tão difundida a fotogrametria digital. 0 Departamento Nacional de Infraestrutura e Transportes (DNIT), publicou em 2006 a Instrução de Serviço IS-227, que trata de Levantamento Aerofotogramétrico para Projetos de Rodovias e em 2015, a Instrução de Serviço Ferroviário 202 (ISF-202), que trata de Levantamento aerofotogramétrico e perfilamento a laser para projetos executivos de ferrovias. Estas normas contém uma série de recomendações a serem seguidas na execução de aerolevantamento e, apesar de serem metodológicas, são voltadas para fotogrametria analógica.

Sendo assim, o presente artigo busca avaliar através de análise estatística das discrepâncias altimétricas, a viabilidade da utilização de ARP com câmera digital não métrica e receptor GNSS (Global Navigation Satellite System) embarcados, na obtenção de modelo digital do terreno (MDT) para execução de projetos de terraplenagem. Para isso foram feitos dois levantamentos utilizando duas geotecnologias distintas: GPS (Global Position System) geodésico e ARP. Foi realizado também a execução de dois projetos de terraplenagem através das informações planialtimétricas oriundas dos dois levantamentos, com a finalidade de avaliar as diferenças volumétricas entre os dois projetos. 0 artigo ainda apresenta as seguintes seções: a seção 2, que discorre sobre os dois levantamentos realizados em um terreno com área de aproximadamente $49.700 \mathrm{~m}^{2}$, a seção 3, que aborda a análise estatística dos dados altimétricos obtidos, a seção 4, que avalia os volumes gerados a partir dos projetos de terraplenagem e a seção 5 que conclui o artigo.

\section{LEVANTAMENTOS GEODÉSICOS REALIZADOS}

A área escolhida para realização dos levantamentos está localizada no bairro Vila Embratel, na cidade de São Luís, Maranhão. Tem aproximadamente $49.700,0 \mathrm{~m}^{2}$ e faz parte do patrimônio imóvel do Instituto Federal de Educação, Ciência e Tecnologia do Maranhão (IFMA). Nesta área foram executados os seguintes levantamentos: Levantamento geodésico com par de receptores GNSS pelo método Real Time Kinematic pós processado (RTK PP) e Aerolevantamento com ARP.

\subsection{LEVANTAMENTO FEITO COM GPS PELO MÉTODO RTK}

No levantamento RTK PP, foram utilizados receptores GNSS e Controlador de campo da fabricante Topcon, modelos Hyper V e FC-5000, respectivamente. Para processamento dos dados foi utilizado o software Magnet Tools. 


\subsubsection{PROCEDIMENTOS}

Em campo, primeiramente foi implantado o piquete referente ao ponto base. 0 critério de escolha foi o de um local seguro no qual não houvesse interferência de antenas, edificações e árvores adjacentes, fluxo de pedestres e veículos. 0 receptor GNSS (base) foi instalado e permaneceu recebendo dados de satélites referente ao posicionamento por aproximadamente 5,0 horas. 0 tempo de observação adotado para o recebimento de dados de satélite visou obter precisão milimétrica, conforme recomendações da norma do Instituto Brasileiro de Geografia e Estatística (IBGE), "Especificações e Normas para Levantamentos Geodésicos associados ao Sistema Geodésico Brasileiro" que estipula um tempo mínimo de observação do ponto de 4,0 horas para este fim.

Durante esse tempo coletou-se as coordenadas tridimensionais de pontos com o segundo receptor GNSS, aqui denominado rover, com o auxílio do controlador de campo (coletora). A coletora armazena a posição de cada ponto após a estabilização da comunicação entre o receptor base e o receptor rover. Os pontos coletados abrangeram toda a área de estudo, priorizando locais com acentuados desníveis e com presença de árvores, de tal forma que fosse possível verificar o comportamento do terreno nestes locais em escritório e comparar com o aerolevantamento.

Ao fim do levantamento obteve-se um total de 203 pontos, conforme a Figura 1.

Figura 1: Localização dos pontos coletados pelo método RTK.

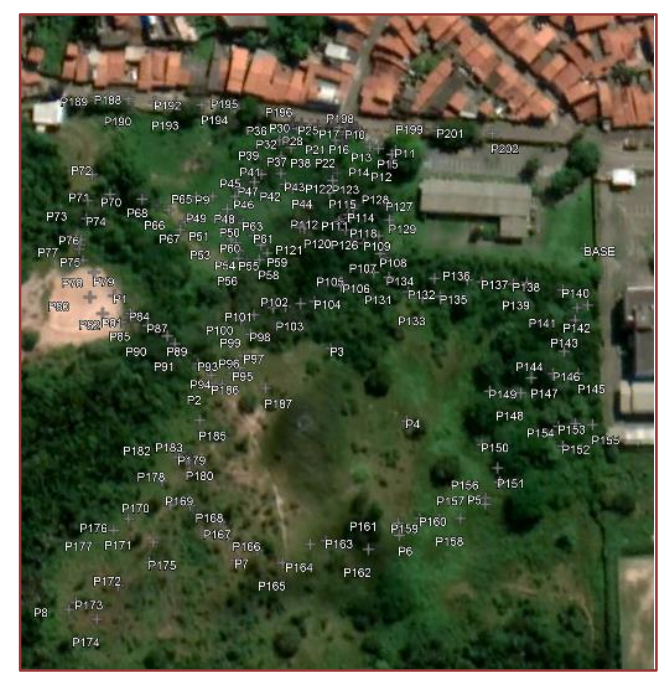

\subsection{AEROLEVANTAMENTO COM ARP}

0 aerolevantamento foi realizado com a aeronave da fabricante DJI modelo MAVIC PRO (Figura 2), multirotor, peso de $743 \mathrm{~g}$, câmera digital não métrica com sensor de imageamento CMOS (Complementary Metal Oxide Semiconductor) - 1/2.3", distância focal de 4,73 mm e resolução de 4000x3000 pixel (12 MP). Além disso, a aeronave é devidamente cadastrada no Sistema de Aeronaves não Tripuladas (SISANT) e se enquadrada na Classe 3, conforme o Regulamento Brasileiro de Aviação Civil Especial - RBAC-E no 94, da Agência Nacional de Aviação Civil (ANAC). Os receptores GNSS e o Magnet Tools, foram os mesmos utilizados no levantamento pelo método RTK da seção 2.1 deste artigo. 
Figura 2: Aeronave utilizada no levantamento fotogramétrico.

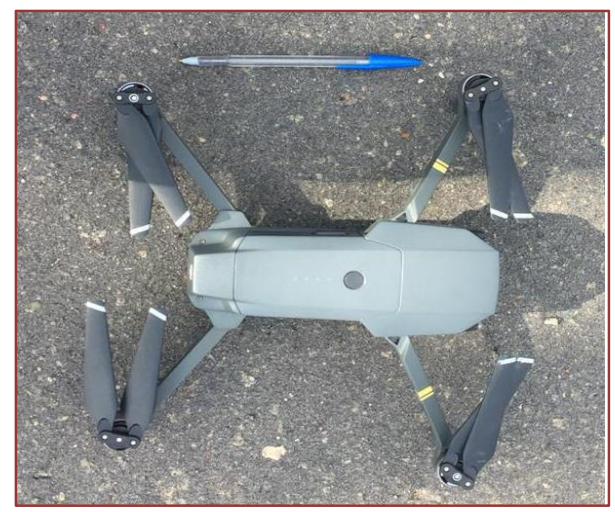

Para planejamento do voo utilizou-se o software Drone Deploy e para análise previa da área a ser levantada, o software Google Earth. Como pontos de apoio foram utilizadas placas de madeira compensada de 50x50 cm com o objetivo de prover acurácia ao aerolevantamento, conforme recomenda Alves Junior (2016). Para processamento das imagens capturadas no aerolevantamento fotogramétrico utilizou-se o software Agisoft Metashape.

\subsubsection{PROCEDIMENTOS}

A obtenção das coordenadas com o aerolevantamento realizado pode ser resumida de acordo com o que consta na Figura 3.

Figura 3: Fluxograma de etapas realizadas no decorrer do aerolevantamento.

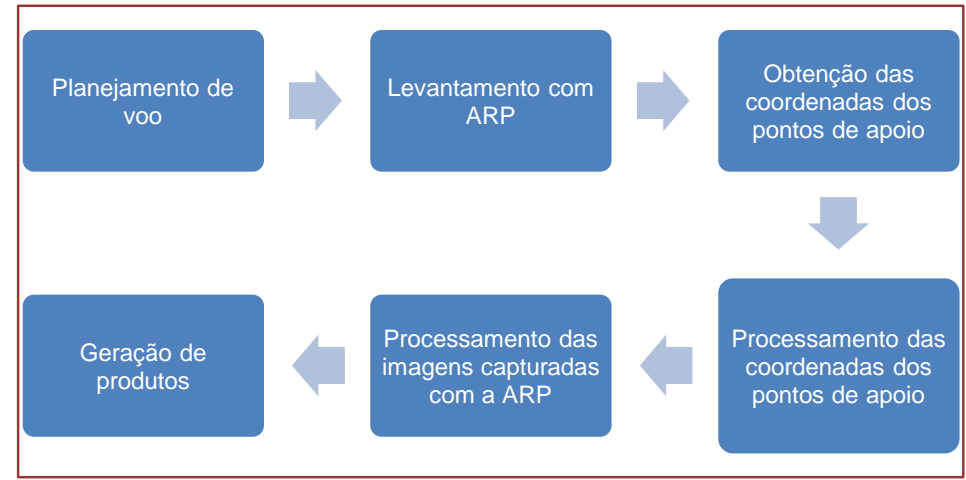

Inicialmente, ainda em escritório, procedeu-se uma análise expedita da área levantada através do software Google Earth. Esta análise consistiu em visualizar os limites do terreno e planejar a distribuição dos pontos de apoio. Após análise, foram sinalizados os locais onde as placas (alvos) foram implantadas. A implantação dos alvos nas linhas de voo e nas bordas da área sobrevoada foi impossibilitada devido a presença de obstáculos. Assim sendo, os critérios para definição dos locais foram: a quantidade de placas disponíveis para esta pesquisa, dez, a distribuição homogênea das placas no terreno levantado e a ausência de qualquer outro obstáculo que impedisse a visualização das placas no momento de captura das cenas.

Na figura a seguir temos a localização final dos pontos de apoio, onde os marcadores M1, M2, M3 e M4 são os limites do terreno pertencente ao IFMA e os marcadores P1 a P10 são os locais onde determinou-se que devem ser implantadas as placas (alvos). 
Figura 4: Localização dos pontos de apoio.

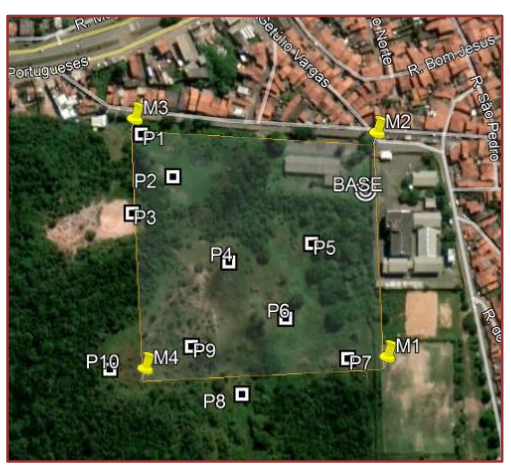

Os parâmetros definidos no planejamento de voo foram:

- Altura de voo: $100 \mathrm{~m}$;

- GSD: $3,0 \mathrm{~cm} /$ pixel;

- Velocidade de voo: $10 \mathrm{~m} / \mathrm{s}$;

- Sobreposição frontal: 75\%;

- Sobreposição lateral: 65\%;

- Área sobrevoada: $\pm 120.000,0 \mathrm{~m}^{2}$;

- Quantidades de fotos capturadas: 183;

- Tempo de voo: \pm 13 minutos.

Por motivos relacionados à logística de acesso ao terreno, iniciou-se o aerolevantamento com a ARP, às 8 horas e 18 minutos de 19 de outubro de 2019. A princípio estava previsto um único voo de aproximadamente 13 minutos para sobrevoar toda a área pretendida, porém devido a perdas de estabilidade da aeronave e variações na velocidade do vento que fizeram com que a ARP saísse da rota planejada, houve a necessidade de abortar o voo por duas vezes e reiniciar a partir da última cena capturada ainda na rota planejada. Assim, foi necessário pouco mais de 1 hora para finalizar o aerolevantamento, encerrando-se às 9 horas e 20 minutos.

Finalizado o aerolevantamento, iniciou-se o levantamento geodésico para a obtenção de coordenadas do centro de cada placa distribuída no terreno (pontos de apoio). Este foi feito com o receptor GNSS (rover) através do método estático rápido (Figura 5), permanecendo sobre cada alvo aproximadamente 5 minutos. Por fim, realizou-se o processamento das informações no Magnet Tools e Agisoft Metashape, bem como a geração da ortofoto e MDT. Ressalta-se que a obtenção do MDT através do aerolevantamento só foi possível graças a proposta de "filtragem dos pontos" presente no software Agisoft Metashape, que identifica pontos referentes a vegetação e ao terreno, usando para triangulação e obtenção do MDT somente os pontos referentes ao terreno. 
Figura 5: Obtenção de coordenadas dos pontos de apoio com receptor GNSS.

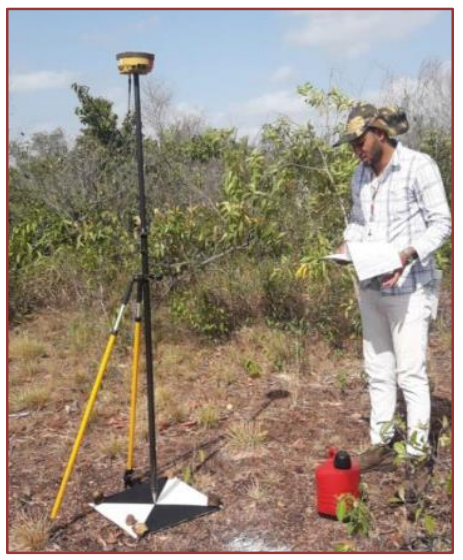

\section{AVALIAÇÃO DAS DISCREPÂNCIAS ALTIMÉTRICAS}

Para avaliar as discrepâncias realizou-se uma análise estatística utilizando os pontos comuns aos dois levantamentos, uma amostra de 203 pontos. Comparou-se a altimetria obtida em cada um desses pontos com as duas geotecnologias (Equação 1). As altitudes obtidas pelo método RTK ( $\mathrm{z}^{\text {rtk}}$ ) foram adotadas neste trabalho como as altitudes de referência, em relação as altitudes obtidas pela aeronave ( $\mathrm{z}^{\text {arp}}$ ). Toda a análise foi feita com o auxílio do software Microsoft Excel e utilizando as Equações 1, 2, 3 e 4 a seguir.

$$
\Delta \mathrm{z}_{\mathrm{i}}=\mathrm{z}_{\mathrm{i}}^{\mathrm{rtk}}-\mathrm{z}_{\mathrm{i}}^{\mathrm{arp}}
$$

Onde:

$\Delta \mathrm{z}_{\mathrm{i}}$ : Discrepância altimétrica nos $i$ pontos da amostra, onde $i=1,2, \ldots, \mathrm{n}$.

$\mathrm{z}_{\mathrm{i}}^{\mathrm{rtk}}$ : Altitude obtida com o GPS pelo método RTK no ponto $i$.

$\mathrm{z}_{\mathrm{i}}^{\text {arp }}$ : Altitude obtida com a aeronave no ponto $i$.

$$
\overline{\Delta \mathrm{z}}=\frac{1}{\mathrm{n}} \sum_{\mathrm{i}=1}^{\mathrm{n}} \Delta \mathrm{z}_{\mathrm{i}}
$$

Onde:

$\overline{\Delta z}$ : Média das discrepâncias altimétricas.

$$
S=\sqrt{\frac{1}{n-1} \sum_{i=1}^{n}\left(\Delta z_{i}-\overline{\Delta z}\right)^{2}}
$$

Onde:

s: Desvio padrão das discrepâncias altimétricas.

$$
\mathrm{t}=\frac{\overline{\Delta \mathrm{z}}}{\mathrm{s}} * \sqrt{\mathrm{n}}
$$

Onde:

t: Distribuição de student. 
No Gráfico 1 temos o histograma das 203 discrepâncias $(\Delta \mathrm{z})$ obtidas a partir da Equação 1, organizadas em 14 classes com amplitude de $24 \mathrm{~cm}$.

Gráfico 1: Histograma das discrepâncias

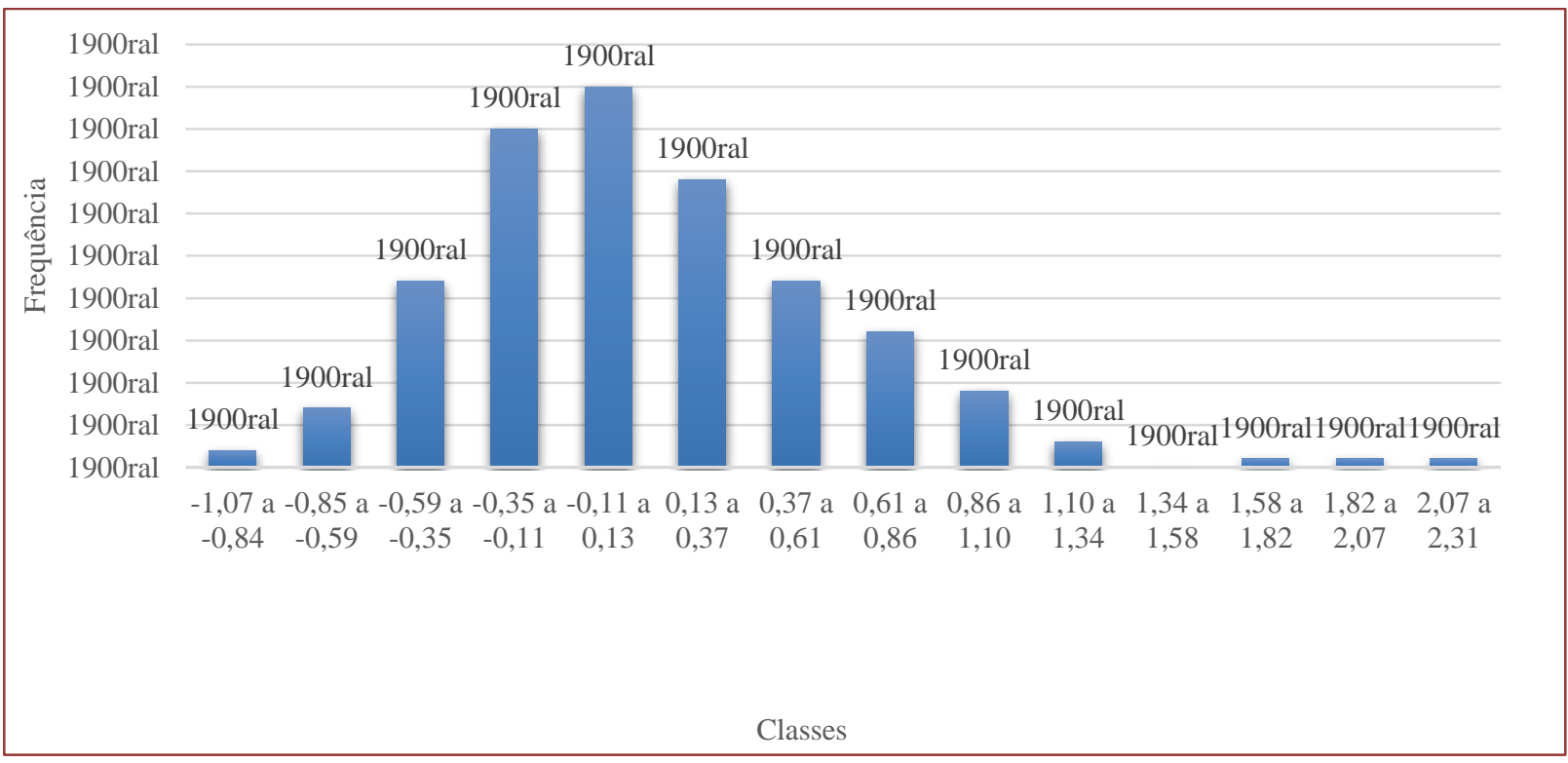

Observa-se que dos 203 levantados, 119 estão com diferença altimétrica de no máximo $35 \mathrm{~cm}$, o que corresponde a aproximadamente $59 \%$ dos pontos. É possível observar também que 45 pontos tiveram erro altimétrico máximo de $13 \mathrm{~cm}$, o que representa aproximadamente $23 \%$. Sendo assim, procedeu-se a análise estatística, onde foram formuladas as seguintes hipóteses:

$$
\begin{aligned}
& \mathrm{H}_{0}: \overline{\Delta \mathrm{z}}=\mathbf{0} . \\
& \mathrm{H}_{1}: \overline{\Delta \mathrm{z}} \neq \mathbf{0} .
\end{aligned}
$$

Ressalta-se que para esta análise foi adotado o nível de confiança de $90 \%$ por ser o mesmo nível de confiança utilizado na PEC № 89.817/1984, quanto a classificação da precisão de produtos cartográficos.

Acerca das hipóteses, a hipótese $\mathrm{H}_{0}$ presume que os modelos são iguais, ou seja, a média das discrepâncias é igual a 0,0 cm, com o nível de confiança de $90 \%$. Caso a média das discrepâncias seja diferente de 0,0 cm, com o nível de confiança de $90 \%$, rejeita-se $\mathrm{H}_{0}$ e não se rejeta $\mathrm{H}_{1}$, que presume que os modelos altimetricos não são iguais, ou seja, a média das discrepâncias é diferente de zero.

É valido destacar que optou-se pela não exclusão dos valores outliers, haja vista que no momento da utilização dos produtos gerados, esses valores servirão para gerar o MDT. 
Tabela 1: Resumo do teste de hipóteses.

\begin{tabular}{|l|c|}
\hline Estatística & $\Delta \mathrm{Z}=\mathrm{Z}^{\mathrm{RTK}}-\mathrm{Z}^{\mathrm{ARP}}$ \\
\hline $\mathrm{N}$ & 203 \\
\hline Média $(\overline{\mathbf{\Delta Z}}), \mathrm{CM}$ & 0,1173 \\
\hline Desvio Padrão (S), CM & 0,5091 \\
\hline Nível de Significância, \% & $10 \%$ \\
\hline Discrepância Mínima & $-1,0786$ \\
\hline Discrepância Máxima & 2,3083 \\
\hline Graus de Liberdade & 202 \\
\hline Ho & 0,0 \\
\hline T Crítico, Bilateral & 1,6524 \\
\hline T Para Ho & 3,2824 \\
\hline
\end{tabular}

A partir da Tabela 1, é possível observar que o fator associado ao grau de liberdade de 202 e com o nível de confiança de $90 \%$, aqui denominado tcrítico foi menor que o fator associado a hipótese de nulidade $\left(\mathrm{t}, \mathrm{H}_{0}>\right.$ $\mathrm{t}$,crítico), portanto deve-se rejeitar $\mathrm{H}_{0}$ e não se rejeitar a hipótese alternativa, $\mathrm{H}_{1}$, que afirma que os modelos altimétricos não são iguais.

Apesar da hipótese de nulidade formulada ter sido rejeitada, através do gráfico de dispersão entre os modelos altimétricos, é possível observar forte correlação linear entra as altimetrias (Gráfico 2).

Gráfico 2: Gráfico de dispersão entre as altitudes RTK e ARP.

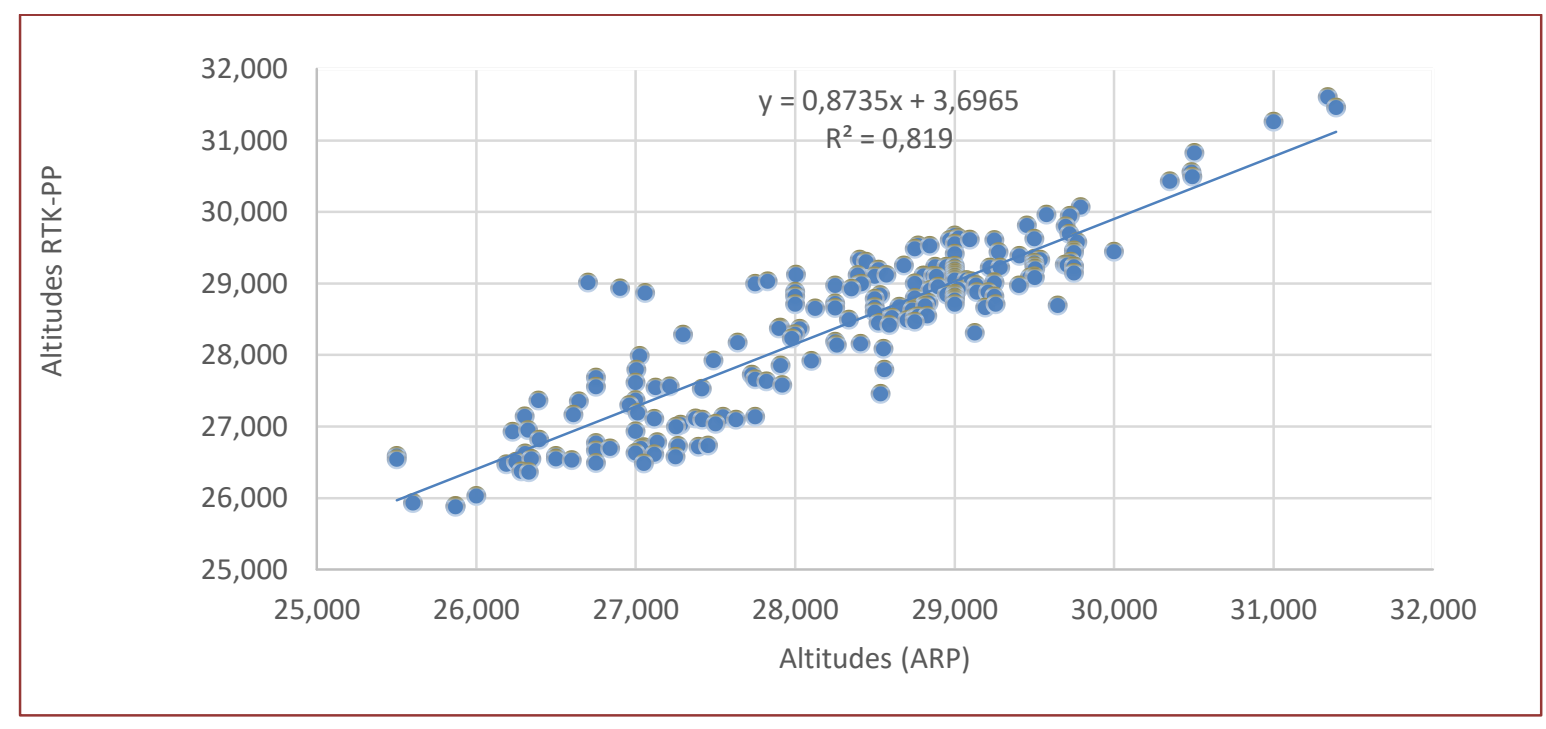

É importante entender a distribuição dos erros, ou seja, quais os motivos e como eles estão distribuídos no levantamento. Esse entendimento pode contribuir para a adoção de práticas que levem a atenuá-los quando forem realizados novos levantamentos ou, até mesmo, quanto a critérios de utilização dos produtos provenientes dos levantamentos. Portanto, buscou-se investigar se a variação altimétrica do terreno impactou nas discrepâncias obtidas. 
Gráfico 3: Gráfico de dispersão entre as altimetrias e as discrepâncias relativas.
Gráfico 4: Gráfico de dispersão entre as altimetrias e as discrepâncias absolutas.

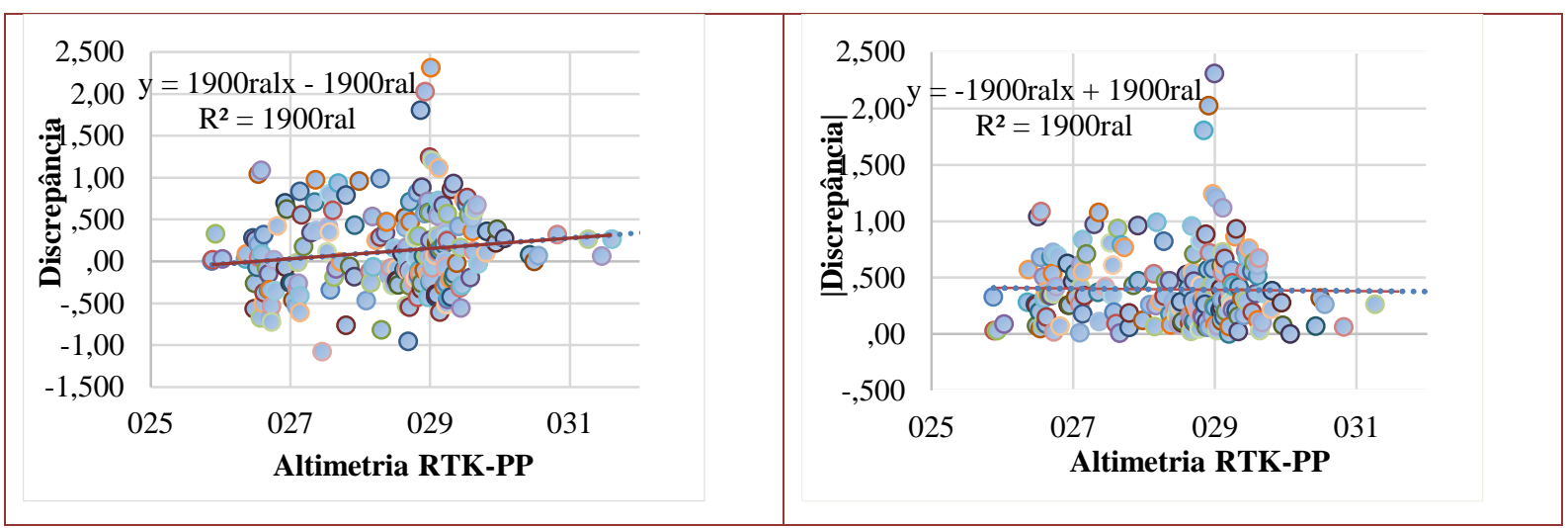

A partir dos gráficos 3 e 4, é possível observar que, tanto as discrepâncias em valores relativos $\left(\Delta \mathrm{h}=\mathrm{z}^{\mathrm{rtk}}\right.$ $\left.\mathrm{z}^{\text {arp }}\right)$ quanto em valores absolutos $\left(\Delta \mathrm{h}=\left|\mathrm{z}^{\text {rtk }}-\mathrm{z}^{\text {arp }}\right|\right)$, apresentaram coeficiente de determinação, $\mathrm{R}^{2}$, próximo a zero, indicando baixíssima relação linear entre as discrepâncias e a localização no terreno em termos altimétricos.

Diante disso, procurou-se observar a localização dessas discrepâncias na área levantada. Lançou-se no software Civil 3D, o ortomosaico obtido através do aerolevantamento bem como os 40 pontos que apresentaram as maiores discrepâncias (Figura 6) e os 40 pontos com as menores discrepâncias (Figura 7).

A partir da Figura 6 observa-se que os pontos com as maiores discrepâncias ficaram concentrados na parte superior do ortomosaico, tal acontecimento pode estar relacionado a, por exemplo, um número menor de pontos de apoio, três, em relação a metade inferior do ortomosaico, que contém 7 pontos de apoio distribuídos. Outra observação é que ocorrem em locais em que há densa vegetação.

Figura 6: Localização das 40 maiores discrepâncias.

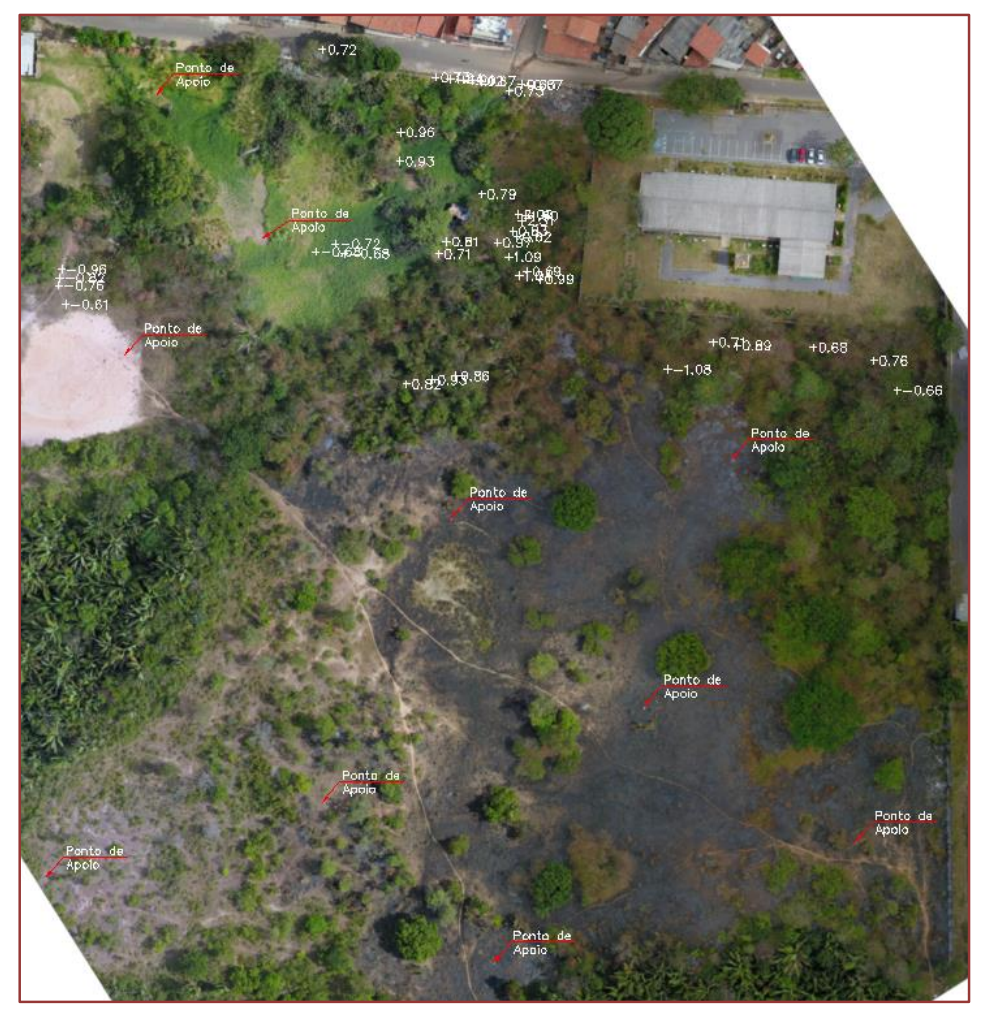


Figura 7: Localização das 40 menores discrepâncias.

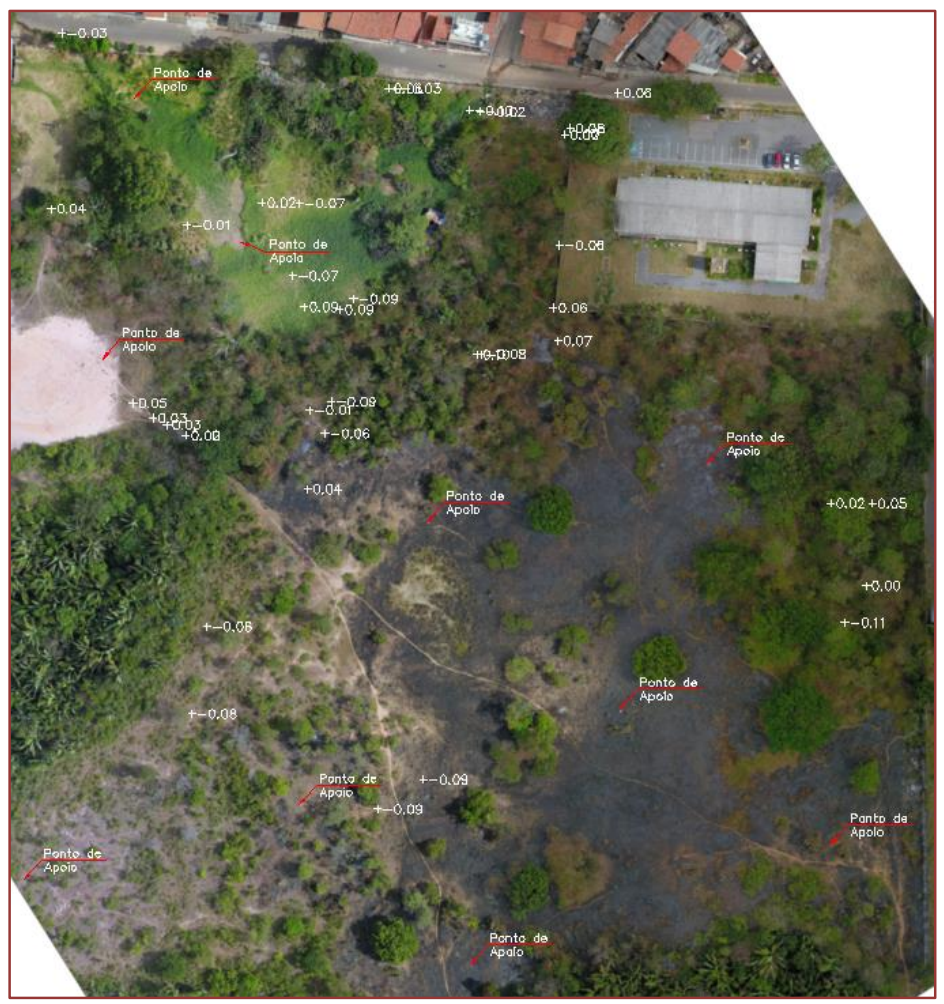

Por outro lado, ao lançar-se as menores discrepâncias (Figura 7), é possível verificar que muitas ocorreram, também, na metade superior do ortomosaico. Isso sugere que ter apenas três pontos de apoio não necessariamente tenha impactado na concentração de elevadas discrepâncias na metade superior do ortomosaico. Ainda em relação as menores discrepâncias, observa-se que, como esperado, ocorreram em locais livres de obstáculos. Contudo, também ocorreram baixas discrepâncias em locais próximos às árvores, evento que sugere eficiência da filtragem automática realizada pelo software no processamento das fotos nestes lugares.

\section{APLICABILIDADE DO MDT EM PROJETOS DE TERRAPLENAGEM}

Diante da não observação de padrões de comportamento das discrepâncias, estatisticamente, procedeu-se uma análise da aplicabilidade dos produtos para projetos de engenharia. Esta análise se deu especificamente na execução de projetos de terraplenagem no software Bentley Topograph observando os volumes gerados. Nas figuras a seguir temos os MDTs obtidos por cada método, bem como os platôs (cota = 29,0 m) implantados em cada MDT. 0 platô implantado foi arbitrário, apenas para observar o impacto das discrepâncias altimetricas nos volumes de corte e aterro gerados. 
Figura 8: MDT obtido com o RTK e MDT obtido com a ARP, respectivamente.

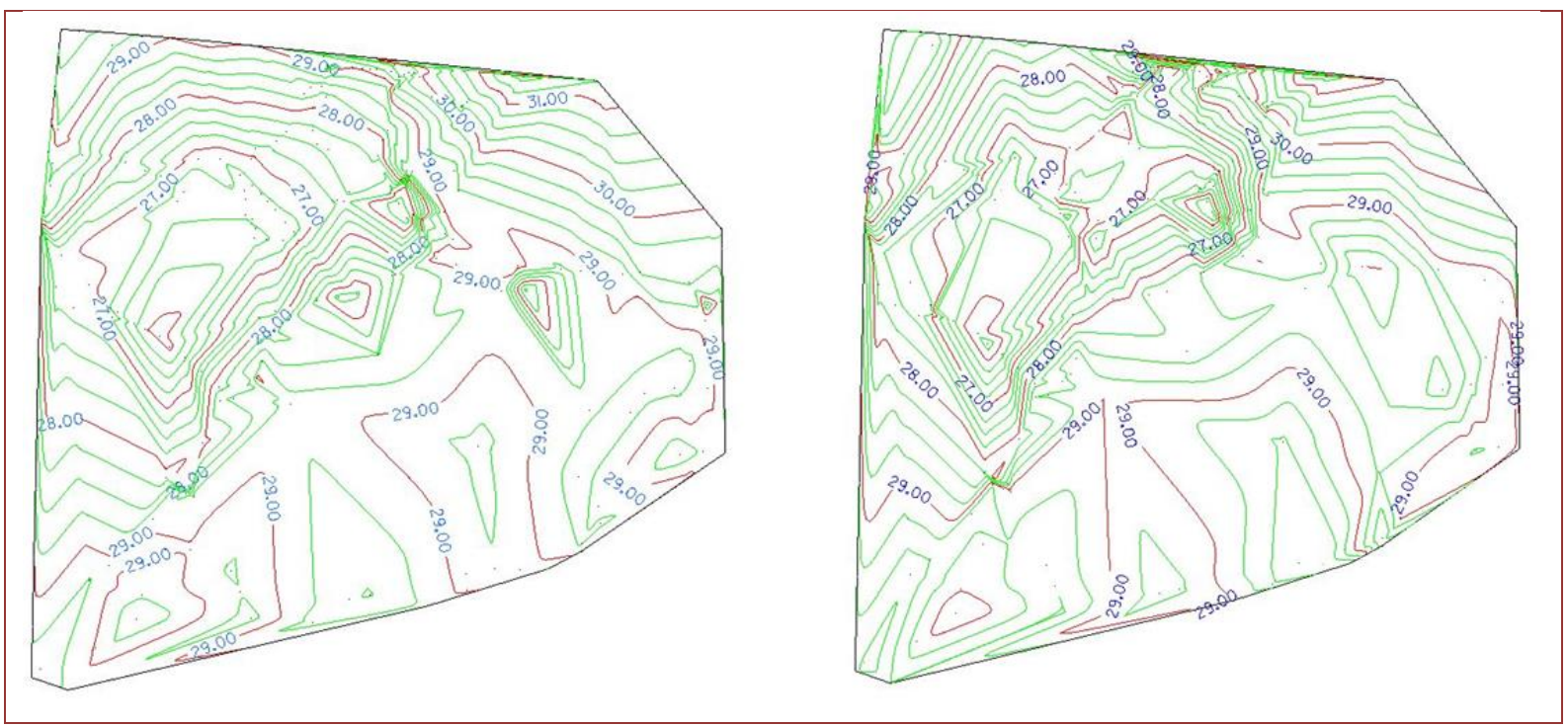

Figura 9: Projeto de terraplenagem no MDT RTK e no MDT ARP, respectivamente.

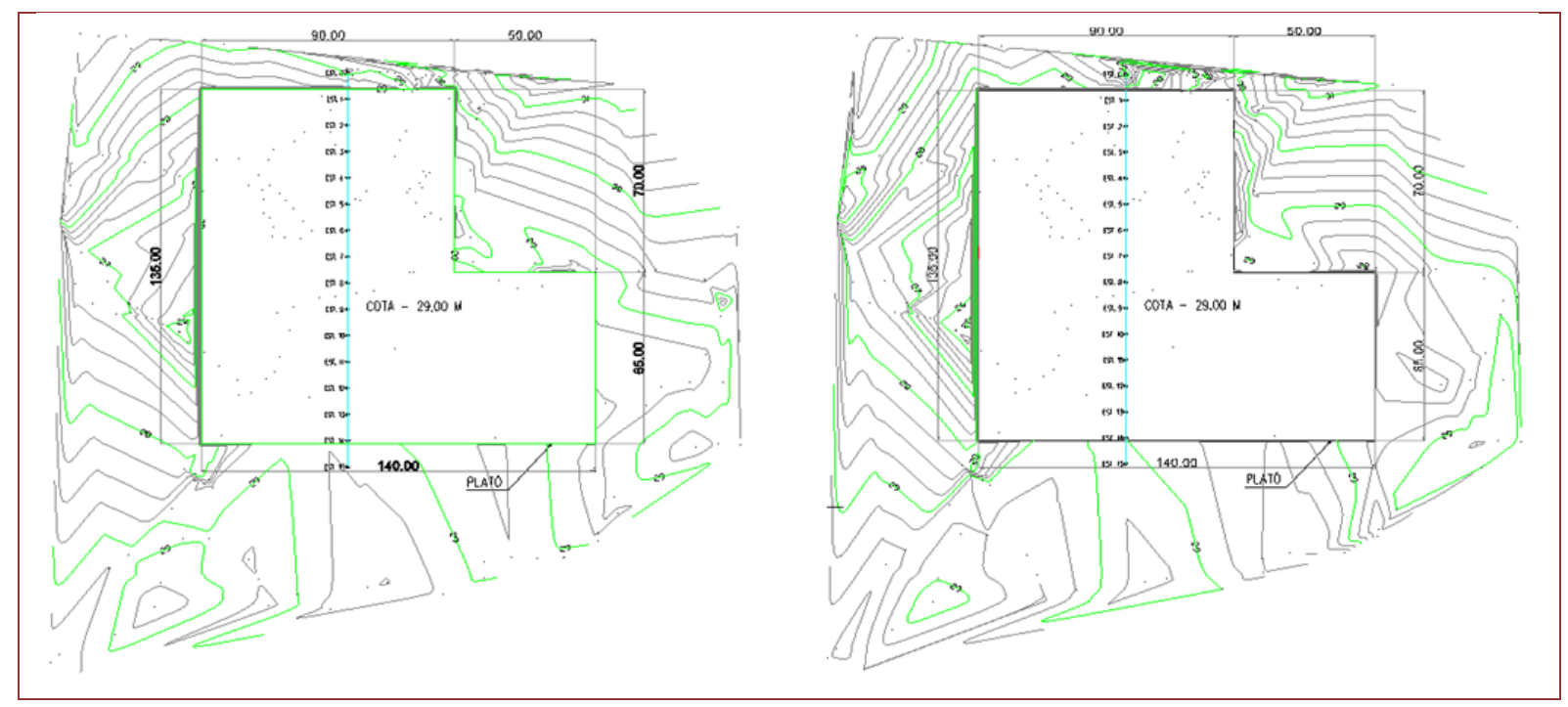

Os volumes obtidos estão nas Tabelas 2 e 3. Em termos quantitativos (Tabela 2), observa-se que, nos dois projetos, o platô implantado fez com que o serviço predominante fosse o de execução de aterro. Em termos percentuais, nota-se uma disparidade para o serviço de corte $(38,9 \%)$, em relação ao serviço de aterro $(19,6 \%)$.

Tabela 2: Tabela resumo de volumes dos projetos

\begin{tabular}{|l|c|c|c|c|}
\multicolumn{1}{c}{ Serviço } & \multicolumn{2}{c}{ ARP } & RTK & \multicolumn{2}{c|}{ Diferenças } \\
\hline Corte & $508,49 \mathrm{~m}^{3}$ & $366,1 \mathrm{~m}^{3}$ & $142,39 \mathrm{~m}^{3}$ & $38,89 \%$ \\
\hline Aterro & $17.043,97 \mathrm{~m}^{3}$ & $14.252,34 \mathrm{~m}^{3}$ & $2.791,62 \mathrm{~m}^{3}$ & $19,58 \%$ \\
\hline
\end{tabular}


Tabela 3: Tabela de volumes por estaca em cada projeto

\begin{tabular}{|c|c|c|c|c|c|c|}
\hline \multirow{2}{*}{ Estaca } & \multicolumn{5}{|c|}{ Volume de corte } & \multicolumn{3}{c|}{ Volume de aterro } \\
& RTK $\left(\mathrm{m}^{3}\right)$ & ARP $\left(\mathrm{m}^{3}\right)$ & $\begin{array}{c}\text { Diferenças } \\
\left(\mathrm{m}^{3}\right)\end{array}$ & RTK $\left(\mathrm{m}^{3}\right)$ & ARP $\left(\mathrm{m}^{3}\right)$ & $\begin{array}{c}\text { Diferenças } \\
\left(\mathrm{m}^{3}\right)\end{array}$ \\
\hline 0 & 0,000 & 0,000 & 0,000 & 0,000 & 0,000 & 0,000 \\
\hline 1 & 40,782 & 28,085 & 12,697 & 221,476 & 450,610 & $-229,134$ \\
\hline 2 & 42,712 & 22,000 & 20,712 & 751,360 & 1089,350 & $-337,990$ \\
\hline 3 & 12,203 & 0,153 & 12,050 & 1093,300 & 1484,803 & $-391,503$ \\
\hline 4 & 4,251 & 0,037 & 4,214 & 1366,607 & 1735,637 & $-369,030$ \\
\hline 5 & 0,895 & 0,138 & 0,757 & 1680,900 & 1971,963 & $-291,063$ \\
\hline 6 & 6,953 & 3,701 & 3,252 & 1812,848 & 2073,226 & $-260,378$ \\
\hline 7 & 17,691 & 15,791 & 1,900 & 1555,128 & 1798,391 & $-243,263$ \\
\hline 8 & 14,000 & 16,664 & $-2,664$ & 1344,191 & 1563,164 & $-218,973$ \\
\hline 9 & 5,010 & 4,539 & 0,471 & 1204,848 & 1437,626 & $-232,778$ \\
\hline 10 & 9,765 & 1,725 & 8,040 & 1050,049 & 1253,875 & $-203,826$ \\
\hline 11 & 20,023 & 8,831 & 11,192 & 829,630 & 954,394 & $-124,764$ \\
\hline 12 & 27,330 & 18,649 & 8,681 & 552,476 & 575,699 & $-23,223$ \\
\hline 13 & 51,201 & 89,452 & $-38,251$ & 381,914 & 343,115 & 38,799 \\
\hline 14 & 78,675 & 185,016 & $-106,341$ & 290,475 & 219,004 & 71,471 \\
\hline 15 & 34,611 & 113,715 & $-79,104$ & 117,146 & 93,115 & 24,031 \\
\hline
\end{tabular}

Para avaliar se os volumes são estatisticamente equivalentes utilizou-se o teste-t, também com nível de confiança de $90 \%$, com os volumes obtidos em cada estaca (Tabela 3). Os resultados do teste estão nas Tabelas 4 e 5.

Tabela 4: Teste-t para o volume de corte

\begin{tabular}{|l|c|c|}
\hline \multicolumn{2}{|c|}{ RTK $\left(\mathrm{m}^{3}\right)$} & ARP $\left(\mathrm{m}^{3}\right)$ \\
\hline Média & 24,4 & 33,9 \\
\hline Variância & 468,2 & 2870,6 \\
\hline Observações & 15 & 15 \\
\hline Correlação de Pearson & \multicolumn{2}{|c|}{0,86} \\
\hline Hipótese da diferença de média & \multicolumn{2}{|c|}{0,00} \\
\hline gl & \multicolumn{2}{|c|}{14} \\
\hline Stat t & \multicolumn{2}{|c|}{$-1,0055$} \\
\hline t crítico uni-caudal & \multicolumn{2}{|c|}{1,34503} \\
\hline
\end{tabular}


Tabela 5: Teste-t para o volume de aterro

\begin{tabular}{|l|c|c|}
\hline & RTK $\left(\mathrm{m}^{3}\right)$ & ARP $\left(\mathrm{m}^{3}\right)$ \\
\hline Média & 950,2 & 1136,3 \\
\hline Variância & 304528,7 & 440040,6 \\
\hline Observações & 15 & 15 \\
\hline Correlação de Pearson & \multicolumn{2}{|c|}{0,98} \\
\hline Hipótese da diferença de média & \multicolumn{2}{|c|}{0,00} \\
\hline gl & \multicolumn{2}{|c|}{14} \\
\hline Stat t & \multicolumn{2}{|c|}{$-4,80285$} \\
\hline t crítico uni-caudal & \multicolumn{2}{|c|}{1,34503} \\
\hline
\end{tabular}

A partir da tabela 4 verificamos que o valor da estatística de teste "Stat t" (Equação 4), é menor que o valor de $t$ crítico unicaudal, com isso, pode-se afirmar, com $90 \%$ de confiança, que os volumes de corte obtidos pelo método RTK são equivalentes aos volumes de corte obtidos pela ARP. Todavia, a partir da tabela 5 o valor da estatística de teste "Stat t", em módulo, é maior que o valor de t crítico unicaudal, sendo assim, pode-se afirmar, com $90 \%$ de confiança, que os volumes de aterro obtidos pelo ARP não são equivalentes aos volumes de aterro obtidos pelo RTK.

\section{CONCLUSÃO}

A área em que foi realizado os levantamentos para o estudo comparativo é bastante heterogênea em termos de densidade vegetativa e com acentuadas variações altimétricas, qualquer inferência a partir de uma única análise pode levar a equívocos. Contudo, com a evolução das aeronaves e seu emprego na construção civil, torna-se necessário estudos que orientem a tomada de decisão dos profissionais, das empresas e dos órgãos púbicos sobre a conveniência de usá-las ou não. Com isso, a partir deste artigo, mostrou-se que não é indicado realizar projetos executivos de terraplenagem a partir de dados planialtimétricos obtidos com aeronaves dotadas de sensores imageadores RGB (red, green and blue), pois a filtragem dos pontos proposta pelos softwares pode não ser eficiente e conduzir a quantidades errôneas de volumes de corte e aterro, como podemos observar na seção 4 .

Em termos de procedimentos, o aerolevantamento se mostrou bastante dinâmico tendo em vista que o voo pôde ser completamente automatizado. Outro ponto relevante é que através do ortomosaico é possível ter uma visão geral da área levantada com alta resolução espacial e identificar detalhes do terreno como, caminhos d'água, edículas e porções no terreno com vegetação rasteira ou com alta concentração de árvores.

A partir de ferramentas estatísticas, observou-se forte correlação linear entre os modelos altimétricos, analisando os pontos comuns aos dois levantamentos. Na seção 3 constatou-se que as discrepâncias encontradas entre o levantamento RTK e o levantamento com ARP não têm relação com a altitude do terreno e podem estar relacionadas a outros motivos. Por exemplo, obstáculos presentes na área levantada, como árvores, limitações do sensor imageador utilizado, limitações do software de processamento, erros de procedimentos no aerolevantamento ou no levantamento pelo método RTK, etc.

Como descrito na seção 2.2.1, a realização do voo foi interferida pelas condições meteorológicas, principalmente a ocorrência de ventos fortes (Figura 10). Não foi possível avaliar se essa interferência tem relação com as discrepâncias observadas, para isso é necessário pesquisas adicionais. Ainda assim, recomenda-se que sejam analisadas as condições básicas como velocidade do vento e ocorrência de chuvas da área a ser levantada previamente ao levantamento, ou seja, na fase de planejamento do voo. Recomendase também que sejam observados, concomitantemente as condições meteorológicas da região, os limites aerodinâmicos da ARP a ser utilizada. Além disso, é necessário estudos adicionais analisando volumes de terraplenagem oriundos de projetos feitos a partir de levantamentos realizados com ARP em áreas sem vegetação, arbustos ou outros obstáculos e com aeronaves dotadas de sensor capaz de operar em níveis de onda maiores, como por exemplo, os sensores infravermelhos.

Figura 10: Distribuição das fotos capturadas no aerolevantamento. 


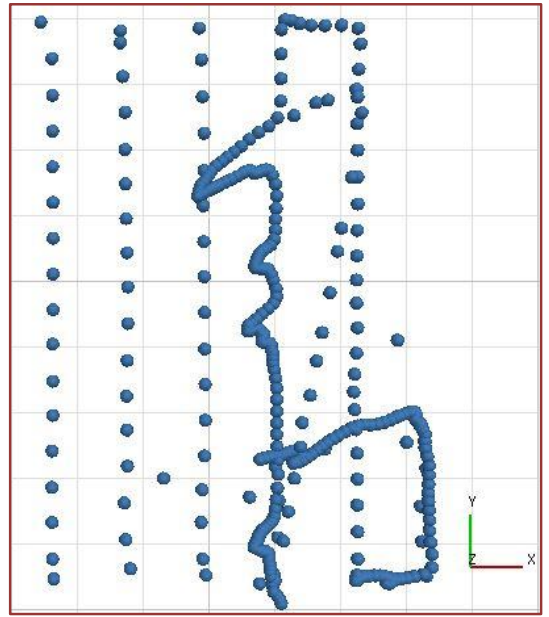

\section{AGRADECIMENTOS}

Ao campus Santa Inês do IFMA pelo empréstimo do par de receptores GNSS. Ao Josué Viegas por ter disponibilizado o Drone e realizado o voo. À empresa Fronteiras Consultorias e Geotecnologias pelo auxílio no levantamento RTK e ajustamento das coordenadas.

\section{REFERÊNCIAS}

[1] ABRAM, I. e ROCHA, A. V. (2000) Manual Prático de Terraplenagem. 1. ed. Salvador, BA.

[2] ALVES JÚNIOR, L. R (2015) Análise de produtos cartográficos obtidos com câmera digital não métrica acoplada a um veículo aéreo não tripulado em áreas urbanas e rurais no estado de Goiás. UFG: Programa de pós-graduação em Geografia. Dissertação de Mestrado, Goiânia.

[3] ABNT (1994) NBR 13133: Execução de levantamento topográfico. Associação Brasileira de Normas Técnicas, Rio de Janeiro.

[4] ANAC (2017) Requisitos Gerais para Aeronaves Não Tripuladas de Uso Civil. RBAC-E no 94. Agência Nacional de Aviação Civil, Brasília.

[5] BRASIL. (1967) Decreto-Lei no 243, de 28 de fevereiro de 1967. Fixa as Diretrizes e Bases da Cartografia Brasileira e dá outras providências. Diário Oficial da República Federativa do Brasil, Brasília.

[6] BRASIL. (1984) Decreto n. 89. 817, de 20 de junho de 1984. Estabelece as Instruções Reguladoras das Normas Técnicas da Cartografia Nacional. Diário Oficial da República Federativa do Brasil, Brasília.

[7] DNIT. (2006) IS-226 Levantamento Aerofotogramétrico para Projetos Básicos de Rodovias. In: Diretrizes Básicas para Elaboração de Estudos e Projetos Rodoviários Escopos Básicos/Instruções de Serviço - 3 a edição. Departamento Nacional de Infraestruturas de Transportes, Brasil.

[8] DNIT. (2006) IS-227: Levantamento Aerofotogramétrico para Projetos Executivo de Rodovias. In: Diretrizes Básicas para Elaboração de Estudos e Projetos Rodoviários Escopos Básicos/Instruções de Serviço - 3 a edição. Departamento Nacional de Infraestruturas de Transportes, Brasil.

[9] IBGE. (2017) Especificações e Normas Gerais para Levantamentos Geodésicos. Instituto brasileiro de geografia e estatística, Rio de Janeiro.

[10] MCCORMAC, J.; SARASUA, W.; DAVIS, W. (2016) Topografia. 6. ed., Editora LTC, Rio de Janeiro, RJ.

[11] TULER, M.; SARAIVA, S. (2014) Fundamentos de Topografia. Editora Bookman, Porto Alegre, RS. 


\section{Capítulo 4}

\section{Logística de última milha de bens e serviços essenciais durante a pandemia COVID-19: O caso das favelas brasileiras}

Joaquim José Guilherme de Aragão

Yaeko Yamashita

Lucas Cezar Santana Ferreira

Resumo: A pandemia e o isolamento social da COVID 19, está produzindo mudanças comportamentais e de mercado em direção a bens e serviços essenciais, florescendo uma indústria de entrega inovadora. Entretanto, a evolução da pandemia e a mudança de mercado colocam questões de igualdade social. Na regra, as famílias nas favelas e outros assentamentos informais são excluídas do mercado, e a falta de renda estável impõe uma luta diária para assegurar bens essenciais para a higiene e alimentos. A morfologia das redes de rua e a falta de endereço formal dos habitantes excluem a população dos serviços de entrega, implicando em desconsiderar as recomendações de distanciamento social. Enquanto a falta de renda está sendo tratada parcialmente pelo governo dentro de suas políticas de emergência de renda, as questões de acesso e entrega ainda não foram resolvidas. Além disso, as favelas no Brasil são empreendedoras e cada vez mais geram oportunidades para que seus moradores desenvolvam habilidades e explorem criatividade. Este documento visa analisar as diversas soluções para o acesso às necessidades básicas das populações das diferentes favelas e assentamentos do Brasil, em específico a favela do Complexo da Maré. Os resultados mostram a relevância e a estrutura da organização comunitária para a logística de última milha para abastecimento de bens de primeira necessidade.

Palavras-chave: Logística; Covid-19; favelas; assentamentos informais; desenvolvimento urbano. 


\section{INTRODUÇÃO}

A pandemia de COVID-19 para o novo coronavírus (SARS-CoV-2) apresentou-se como um dos maiores desafios globais de saúde deste século. Segundo as Nações Unidas (2021), até agosto de 2021 já tinham sido registrados mais de 200 milhões de casos no mundo, com cerca de 4,2 milhões de morte. Com relação à situação no Brasil, as mortes somavam 562 mil, sendo o segundo país com mais óbitos.

As ordens de distanciamento social foram, no início da pandemia em março de 2020, e continuam sendo ordenadas pelos governos estaduais, por meio das quais a aplicação e liberação dessas ordens seguem a evolução da situação pandêmica, mas também as pressões políticas (Freitas, Silva e Cidade, 2020).

A pandemia do COVID-19 e o isolamento social, seja voluntária ou ordenada pelo governo, está produzindo mudanças comportamentais e de mercado em direção a bens e serviços essenciais. O desenvolvimento da entrega e plataformas digitais permitem que a família mantenha a disciplina da quarentena; em outros lugares, os membros da família são encorajados ou forçados a retomar as atividades de compras e trabalho fora da casa.

Entretanto, as desigualdades sociais crônicas no país colocam dificuldades adicionais no cumprimento das regras sanitárias recomendadas pela OMS e pela administração pública. Especialmente nas favelas urbanas, onde sua população não tem acesso a serviços de saneamento e entrega e é espremida em pequenas moradias. Além disso, com a baixa renda torna-se difícil adquirir bens de higiene suficientes como sabonetes e álcool (ibid.).

A impossibilidade de manter medidas sanitárias e a necessidade premente de renda aumenta um conflito para políticas durante as pandemias da COVID, já que o Estado e a administração local foram forçados a abandonar prematuramente o distanciamento social, arriscando-se a enfrentar novas ondas de contágio (Pires et al., 2020; Cambricoli, 2020). A falta de liderança do Presidente e a subsequente crise institucional na gestão da pandemia agravou a situação no Brasil (Henriques e Vasconcelos, 2020).

Um fator que agravou a renda das classes mais baixas é o tipo de negócio do qual sua maior parte está vivendo. A pandemia afetou desproporcionalmente o setor de serviços e os serviços informais (Komatsu e Menezes Filho, 2020). A pandemia também provocou uma mudança do mercado de consumo opcional (por exemplo, roupas, veículos; ver Franco, 2020) em direção ao consumo de bens e serviços essenciais. Uma outra mudança importante é o aumento da logística de entrega, que tem sido um porto de segurança para os trabalhadores informais, mas a recompensa insuficiente e as condições de trabalho têm sido contestadas nos movimentos de parada (Rogenski, 2020).

Por outro lado, em várias comunidades de favelas, a população está se organizando em ações de autoajuda, que distribuem doações, oferecem empresa a pessoas isoladas e transmitem regras de segurança (Wikifavela, 2020).

O objetivo do presente documento é identificar as dificuldades de logística na entrega dos produtos de necessidades essenciais para as famílias em quarentena nas favelas e analisar a estrutura organizacional das diversas iniciativas realizadas pelas comunidades. Um estudo de caso sobre o Complexo da Favela da Maré, é apresentado para analisar a situação de saúde e abastecimento durante a pandemia covid-19. Os resultados mostrarão a relevância e a estrutura da organização da comunidade para a logística de última milha de fornecimento de bens de primeira necessidade.

O documento é estruturado da seguinte forma: A seção 2 oferece uma visão geral da evolução da COVID no Brasil, assim como das medidas sanitárias e políticas de apoio do governo. A seguir, a Seção 3 descreve a situação atual da população nas favelas com relação à renda, emprego, acesso à infraestrutura e os impactos da epidemia da COVID. A Seção 4 apresenta um estudo de caso do Complexo da Favela da Maré, começando com uma breve descrição dos impactos nesta comunidade em particular. A seção detalha posteriormente a organização da autoajuda na favela para atender a distribuição dos produtos de primeira necessidade com base em documentação e entrevistas. A seção 5 encerra com uma breve conclusão.

\section{A EVOLUÇÃO DAS PANDEMIAS COVID NO BRASIL: UM QUADRO GERAL}

A evolução diária das pandemias no Brasil está sendo registrada no site "COVID-19 NO BRASIL" (https://covid.saude.gov.br/), patrocinado pelo Ministério da Saúde. Os fatos mais relevantes são:

- O primeiro caso foi relatado em 26 de fevereiro de 2020, e a primeira morte, em 12 de março do mesmo ano. A doença foi introduzida inicialmente por passageiros vindos de avião da Europa; 
- A partir de São Paulo e Rio de Janeiro, a pandemia se espalhou pelo território, atingindo em meados de julho de 2020 mais de 2 milhões de pessoas infectadas e 80 mil mortes;

- Um ano depois desse registro, mesmo com vacinação, o país registrou 19 milhões de infectados e mais de 500 mil mortes;

- Ainda com esses números registrados, no país considera-se um alto nível de subnotificação de casos (França et al., 2020).

A partir de 13 de março de 2020, o Ministério da Saúde emitiu recomendações com relação à higiene e distanciamento social. Desde então, alguns governos estaduais ordenaram a paralisação de atividades "não essenciais" (shopping centers, teatros, academias, restaurantes e similares). 0 sistema escolar ficou bloqueado e apenas algumas das escolas particulares foram capazes de oferecer esquemas de ensino à distância (Noronha et al., 2020).

No entanto, as pressões para minimizar a situação resultaram que, atualmente, apenas $39 \%$ da população poderiam seguir as recomendações de distanciamento social (Cambricoli, 2020). Mesmo o uso de máscaras, embora obrigatório, não foi cumprido (G1, 2020).

As terríveis consequências para o setor de saúde são relatadas pelo Conselho Nacional de Assistência de Enfermagem, onde a insuficiência de funcionários nos hospitais e os riscos à saúde nos hospitais são críticos (Conselho Nacional de Enfermagem, 2020a, b).

Um estudo de Noronha et al. (2020) relata a falta de capacidade do sistema de saúde no Brasil, especialmente nas regiões Norte e Nordeste. Mas a abertura prematura do comércio foi produzindo um retorno do esgotamento das capacidades nas regiões Sudeste e Sul. Nesse sentido, outras insuficiências das regiões periféricas foram se apresentando, dentre elas: a falta de sistemas de ventilação nas residências e as longas distâncias até as unidades de saúde próximas.

Estudos de impacto que analisam como a Pandemia está afetando diferentes classes sociais e etnias são raros. Uma pesquisa contínua da Prefeitura de São Paulo (Secretaria Municipal da Saúde, 2020) revelou que as áreas administrativas que concentram as classes de menor renda têm sofrido taxas de contágio e mortalidade mais severas.

Os impactos econômicos da pandemia são severos. O Instituto Brasileiro de Estatística (IBGE, 2020) afirmou que $15 \%$ das empresas fecharam temporariamente. $17,6 \%$ fecharam definitivamente, sendo que $67 \%$ permanecem ativas, mesmo que parcialmente. Posteriormente, $12,4 \%$ das empresas demitiram pessoal; $17,8 \%$ reduziram as horas de trabalho com redução de salários; $28,6 \%$ suspenderam os contratos de trabalho; e 23,1\% implementaram férias obrigatórias (Sebrae, 2020). 0 relatório de Lameiras e Cavalcanti (2020) resumiu para junho de 2020 que:

- a taxa de desemprego se estabilizou em $13 \%$ na época;

- $14,2 \%$ da força de trabalho ocupada deixou o local de trabalho subsequentemente às regulamentações de distanciamento social, enquanto 12,7 estavam trabalhando em casa;

- $66,2 \%$ da força de trabalho não ocupada não procuravam locais de trabalho;

- $34,5 \%$ da força de trabalho trabalhava em atividades informais.

\section{A VIDA NAS FAVELAS DURANTE A PANDEMIA}

Nos últimos anos, uma descrição completa da vida nas favelas foi oferecida por diferentes ONGs, que reuniram as informações em um conjunto de dados chamado Datafavela. Três publicações deste conjunto de dados são discutidas nesta seção. A primeira foi publicada em 2015 (com 2000 entrevistas em 63 favelas brasileiras), e as outras duas foram publicadas em 2020, com dados atualizados após o impacto da pandemia da COVID-19 (a primeira em março daquele ano, com 1142 entrevistas em 262 favelas, e a segunda em junho, com 3321 entrevistas em 239 favelas). 


\subsection{DADOS GERAIS DA POPULAÇÃO DAS FAVELAS}

\subsubsection{DEMOGRAFIA}

Em 2020, 13,6 milhões de habitantes vivem em favelas, portanto 6,5\% do total da população do país (209 milhões). Na região mais industrializada do Sudeste, $7 \%$ de sua população são "favelados" (Figura 1). Na região Norte e Nordeste, eles representam $6 \%$ do total da população. Na região Sul e Centro-Oeste, a participação é de $2 \%$ e 1\%, respectivamente (Datafavela, 2020a).

Figura 1 - Porcentagem de população que vive em favelas no Brasil

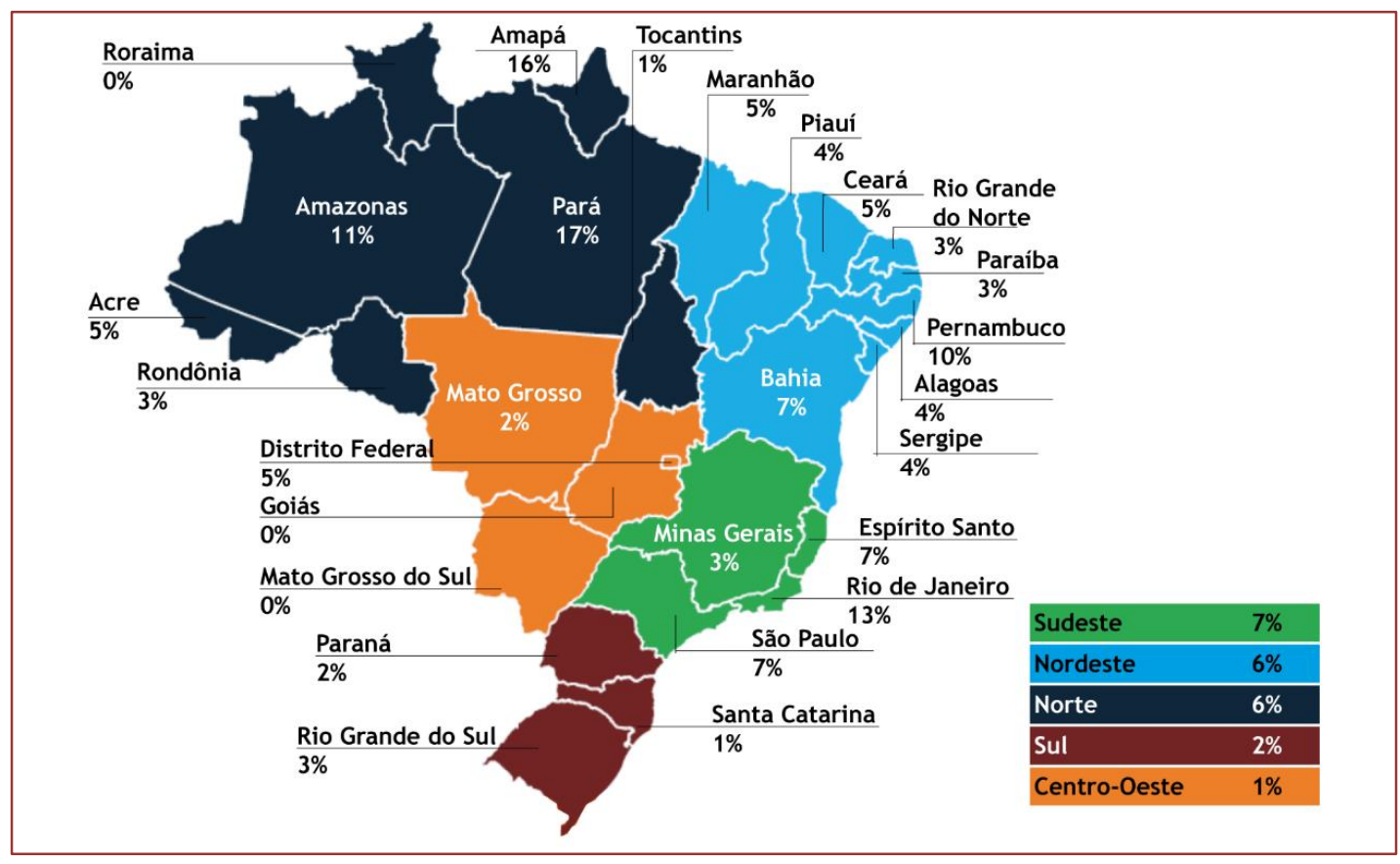

(Fonte: Datafavela, 2020a, adaptado pelos autores)

Uma descrição mais detalhada do padrão geral de vida nas favelas é oferecida pela pesquisa de 2015. Esta pesquisa revelou que $89 \%$ da população das favelas vive em áreas metropolitanas. Esta população é mais jovem do que a população do país, pois sua idade média era de 29,1 anos, em comparação com os 33,1 anos do Brasil. 67\% dos moradores eram negros (55\% no Brasil).

$53 \%$ da população da favela tem filhos. Para as mulheres, este percentual sobe para $70 \%$, sendo que a maioria delas deu o primeiro nascimento antes dos 20 anos de idade. $44 \%$ dos lares são comandados por mulheres, $22 \%$ são solteiros.

\subsubsection{RENDA}

0 nível médio de renda mensal em 2015 era de $R \$ 1.113$ reais ( $R$ \$ 1,002 reais no Brasil). Este valor representa um progresso significativo nos 10 anos anteriores, quando a massa de renda anual das favelas havia sido de 43,9 bilhões de reais em 2005; e de 68,5 bilhões de reais em 2015. Assim, a massa de renda total da população das favelas era maior que a massa de renda total em 15 Estados do Brasil (Datafavela, 2015).

Com relação à fonte de renda, 47\% da população é autônoma, e apenas 19\% estão formalmente empregados. $44 \%$ das mulheres trabalhavam como empregadas domésticas em residências de classes altas. A renda do trabalho é a principal fonte de renda, que pode ser complementada por pensão, renda de outros membros da família e por subsídios sociais.

O nível de baixa renda complica o pagamento de contas. 35\% das famílias estavam endividadas. $27 \%$ da população adulta (35-49 anos) estavam em situação de inadimplência. Apenas 15\% da população tem poupança. 4 milhões de favelados têm conta bancária, mas o acesso aos serviços financeiros é menor do que nas classes altas. Portanto, a solidariedade entre as famílias é comum: 48\% declararam ter emprestado cartões de crédito ou recebido apoio financeiro de membros da família, vizinhos ou amigos. 


\subsubsection{EMPREENDEDORISMO}

Na pesquisa de 2015, 55\% da população desejava ou precisava empreender a fim de assegurar uma fonte de renda, uma taxa mais alta do que a da população nacional. Destes $55 \%, 63 \%$ pretendiam empreender dentro de sua favela. A principal razão para empreender é não ter um chefe. A maioria dos empreendimentos desejados deveria estar na indústria alimentícia. $73 \%$ da população da empresa é negra.

\subsubsection{MORADIA}

Datafavela (2020b) informou que metade das casas nas favelas tem 4 ou mais pessoas, e $60 \%$ têm no máximo 2 quartos, o que significa que a média é superior a 4 pessoas por quarto. Um estudo sobre a situação das favelas em São Paulo (Observatório das Metrópoles, 2018) revelou que em 2010 a densidade das favelas era de 297,4 habitantes por hectare. No município, a densidade era de 80 habitantes por hectare.

Esta densidade dificulta a mobilidade e a coleta de lixo na favela, assim como a expansão das moradias, forçando a população a verticalizar as construções. Em 2010, apenas 30,48\% das unidades tinham apenas um andar, outras $61 \%$ tinham 2 ou mais andares, que foram adicionados sem cálculos estruturais. Esta expansão reduziu em $25 \%$ a densidade de moradias por dormitório. Mas as condições de isolamento e ventilação das residências continuam pobres. As moradias sem quarto de dormir desapareceram.

\subsubsection{INSTALAÇÕES}

A morfologia das favelas torna-se difícil para abastecer os bairros com asfalto, iluminação pública e serviço de transporte público. Entretanto, 88\% das unidades são abastecidas com água, 56\% com esgoto; $76 \%$ por coleta de lixo (Pasternak e D'Ottaviano, 2016). Em 2015, 50\% dos habitantes possuíam computador e 86\% tinham telefones celulares (Datafavela, 2015).

0 descontentamento com a qualidade da infraestrutura é alto. Em uma escala de classificação de 0 a 10, a média geral foi de 5,26 . As instalações mais bem colocadas eram coleta de lixo $(6,85)$; iluminação pública $(5,89)$; escolas públicas $(5,87)$; creche pública $(5,65)$; agentes de saúde $(5,46)$. Abaixo da classificação média estavam os transportes públicos $(5,17)$; manutenção de ruas e calçadas $(5,1)$; centros de saúde $(4,85)$; esgoto $(4,71)$; hospitais públicos $(3,59)$; segurança pública $(3,31)$ e delegacias de polícia $(3,24)$.

\subsubsection{FORNECIMENTO DE ALIMENTOS}

Os habitantes preferem fornecer nas lojas e mercados locais (90\%), onde as mulheres mais velhas são predominantemente responsáveis por esta atividade; elas também se encarregam da cozinha. A maioria das famílias tem mais de 3 refeições por dia (Datafavela, 2015).

\subsubsection{EDUCAÇÃo}

0 acesso à educação é generalizado. Os jovens estão interessados em investir em cursos superiores: 40\% dos jovens entre 19 e 24 anos desejam avançar para as faculdades e universidades. $62 \%$ dos jovens entre 14 e 18 anos desejam fazer um curso de formação profissional (Datafavela, 2015).

\subsubsection{CONDIÇÕES DE SAÚDE}

Nas favelas, a alta incidência de tuberculose, hipertensão, doenças cardíacas, diabetes tem sido relatada pelo Comitê Fiocruz Covid-19 nas Favelas (2020). Datafavela (2020b) mostra que 96\% dos moradores das favelas não possuem seguro saúde, enquanto que no Brasil o percentual é de 76\%. 


\subsubsection{CONSUMO}

Um quarto da população possui um carro; um quarto tem bicicletas. 3 de 4 moradias têm uma máquina de lavar roupa. Mais de um milhão de habitantes desejam adquirir televisores, cadernos e pastilhas.

\subsubsection{VIDA CULTURAL}

A vida cultural na favela consiste principalmente em espetáculos locais e festas de dança dentro das cidades, que são frequentados por um terço da população (Datafavela, 2015). Por outro lado, o acesso ao cinema e aos teatros e espetáculos maiores é baixo, também os jovens têm atestado seu desejo de frequentá-los.

$26 \%$ dos habitantes praticam esporte; $21 \%$ vão a academias. Metade da população masculina está preocupada com a aptidão física. $49 \%$ da população feminina frequentou salões de beleza (ibid.).

\subsubsection{VIOLÊNCIA}

$62 \%$ dos habitantes da favela já ouviram falar do assassinato de trabalhadores em seu bairro. $74 \%$ são informados sobre o tráfico de drogas na comunidade, mas $81 \%$ não veem nenhum benefício dessa presença. A conscientização sobre a violência é alta, mas a falta de serviços de saúde e educação de qualidade é listada como um grande problema. As operações de "pacificação" realizadas pela polícia não merecem uma visão favorável, uma vez que as forças policiais são consideradas altamente violentas.

\subsubsection{AUTOESTIMA}

$52 \%$ dos habitantes declararam ter sofrido discriminação. A imagem divulgada na mídia é considerada por $64 \%$ para reforçar o estigma contra as favelas. A população das favelas reconhece que têm menos oportunidades para melhorar as condições de vida. Não obstante, uma grande parte não está disposta a abandonar a comunidade se quiser dobrar seus ganhos.

\subsection{AS FAVELAS DURANTE O SURTO DA COVID-19}

Como mencionado anteriormente, os dados específicos sobre o impacto da pandemia nas comunidades faveladas foram publicados em 2020 por empresas privadas e organizações de autoajuda que vinham trabalhando há muitos anos nessas áreas. Por outro lado, não há pesquisas específicas das autoridades sobre o impacto da pandemia nas comunidades de favela. Reportagens da mídia (Agência Brasil, 2020a) notam que no Rio de Janeiro 75\% dos habitantes das favelas não procuraram atendimento médico, e 10\% das mortes ocorreram nas casas. As longas distâncias até os hospitais têm sido referidas como um empecilho ao tratamento.

A luta política em torno da gestão da pandemia (ver seção 2) e a produção de notícias falsas causa desorientação e diminui o cumprimento das recomendações das autoridades sanitárias com respeito ao distanciamento social (Jornal da USP, 2020).

A pesquisa da Datafavela (2020a) trouxe mais detalhes sobre os impactos da pandemia na subsistência das favelas:

- Em todo caso, $97 \%$ dos habitantes das favelas declararam ter modificado suas rotinas diárias durante a pandemia, e 67\% estão preocupados com os riscos.

- $86 \%$ das crianças em idade escolar ficaram longe da escola, e para $84 \%$ das famílias afetadas declararam que as despesas aumentaram. $75 \%$ declararam que a presença das crianças em suas casas é um obstáculo para o trabalho e para a obtenção de renda.

- Para $86 \%$ da população ativa, a pandemia reduziu as vendas das empresas em que trabalham.

- $54 \%$ da população preocupou-se com o risco de perder empregos, e $78 \%$ ficaram sabendo de amigos que têm sua renda reduzida.

- $80 \%$ das famílias cortaram custos. 
Ainda com relação à renda, o governo adotou um subsídio emergencial de renda de 600 reais por mês, posteriormente reduzido para 300 reais no primeiro semestre de 2021 e 230 reais para o segundo (UOL Notícias, 2021). Mas há reclamações sobre a burocracia nos procedimentos de inscrição, especialmente por meio de pedidos. A falta de documentos pessoais e de acesso à internet também são considerados um obstáculo relevante. 0 pagamento é realizado pela Caixa Econômica Federal, forçando os beneficiários a ficarem em longas filas (Rede de Pesquisa Solidária, 2020a).

Dentro das famílias beneficiárias, os destinos dos subsídios são alimentação (em 96\% das famílias), higiene (88\%), material de limpeza (87\%), pagamento de contas (68\%), medicamentos (64\%) e assistência a parentes (62\%; Agência Brasil, 2020b).

Para a população que tem a sorte de ter mantido o emprego, o deslocamento pendular representa um risco adicional, pois os operadores de transporte público decidiram reduzir a frequência em $60 \%$ a fim de manter o ponto de equilíbrio das empresas. As regras de distanciamento social dentro dos veículos têm sido desconsideradas (Folha de São Paulo, 2020).

A pandemia também está deteriorando a situação psicológica dos moradores da favela (Rede de Pesquisa Solidária, 2020b): Apesar das ações de solidariedade entre as famílias, a fome se alastrou. A redução da renda tornou difícil a aquisição de sabonetes e máscaras. As oportunidades de renda foram reduzidas, também por causa da falta de espaço nas habitações. A exaustão nervosa, o desespero, o medo da morte e a ausência de perspectiva estão chegando ao auge. A pandemia também tem agravado a violência, especialmente a violência doméstica.

\subsection{A EVOLUÇÃO MAIS RECENTE DA PANDEMIA DA COVID-19 NAS FAVELAS DO RIO DE JANEIRO}

Uma pesquisa de junho de 2020 sobre o impacto na condição de vida nas favelas do Rio de Janeiro foi publicada (SOS Favela, 2020). A pesquisa foi organizada por meio de um questionário estruturado e contou com 35.957 famílias, 406 comunidades faveladas e 32 municípios. Resultou em 889 respostas válidas, a maioria delas obtidas por esposas. 0 valor médio de habitantes por moradia foi de 3,7.

Quanto à propagação da pandemia, entre 29 e 17 de junho, a taxa de contágio aumentou em 89\%. Uma informação complementar foi trazida pelo site Voz das Comunidades (2020) para o dia 26 de julho de 2020: 4043 casos foram registrados nas favelas do Rio de Janeiro, resultando em 620 vítimas fatais, sendo que 3.316 foram curados.

Segundo a pesquisa da SOS Favela, a principal faixa etária são os habitantes entre 25 e 59 anos, a maioria das pessoas que não podem ficar em casa e devem trabalhar fora (apenas 18\% podem trabalhar em casa). As habitações com 2 habitantes foram responsáveis por 58\% das infecções; as habitações com 3 habitantes, por 49\% das infecções; e com 6 habitantes, por $27 \%$ das infecções.

Em maio de 2020, a situação da renda piorou em $20 \%$ por causa da pandemia, concentrada principalmente nas faixas de renda mais baixas. Em maio, apenas 29\% conseguiram ganhar dinheiro. 65\% dos habitantes em idade para trabalhar encontraram falta de oportunidades. $26 \%$ já estavam desempregados, $31 \%$ eram trabalhadores autônomos.

$78 \%$ das pessoas entrevistadas declararam ajudar outra família. $43 \%$ recebem cestas básicas, e 22\%, apoio de parentes; $46 \%$ recebem subsídios do governo. Somente $12 \%$ não receberam nenhuma ajuda ou subsídio. $55 \%$ são pessimistas quanto ao futuro, mas $25 \%$ estão confiantes quanto à melhoria.

Após uma pesquisa recente em julho daquele ano (Roma News, 2020), a disciplina de distanciamento social nas favelas é mais alta do que a média: 68\% dos habitantes das favelas seguem as recomendações das autoridades sanitárias, enquanto que para toda a população do Rio esta proporção é de 60\%, sendo o medo de doenças a principal razão para esta atitude. $84 \%$ das pessoas que não permanecem em casa declararam que têm que trabalhar fora.

As Empresas de Saneamento foram acusadas de racionar água nas favelas antes e durante o surto. Foi relatado que funcionários dentro da empresa ou pessoas de fora desviam o abastecimento de água de uma favela para outras (Rodrigues, 2020). 


\subsection{SOLIDARIEDADE NAS FAVELAS}

Como as comunidades de favela se sentem abandonadas pela administração pública, as iniciativas de autoajuda e movimento social têm crescido, com a ajuda de universidades e ONGs. Algumas organizações supracomunitárias, como a Central Única das Favelas, Instituto Locomotiva, Mães da Favela, Oficina das Favelas, SOS Favela, Rede de Pesquisa Solidária organizam ou ajudam as comunidades a organizar iniciativas de autoajuda, pesquisas e atividades de advocacia. Sua capacidade de levar aos governos locais informações estratégicas, mas também reivindicações tem ajudado a administração pública a melhorar políticas direcionadas ou, pelo menos, a estar ciente da situação das favelas (BBC News Brasil,2020; Confederação Nacional dos Municípios, 2020).

A maioria das iniciativas de autoajuda como resposta à pandemia abrange (Central Única das Favelas, 2020):

- a distribuição gratuita de água potável, álcool gel, sabão e alimentos;

- $\quad$ aluguel de quartos de hotel para cidadãos idosos ou grupos em risco;

- parcerias com locadoras de veículos ou operadoras de transporte público para o transporte de habitantes infectados a hospitais;

- $\quad$ assessoria para inscrição em subsídios de emergência;

- negociações com empresas de saneamento, energia e telecomunicações visando a isenção de tarifas para famílias de baixa renda durante a pandemia;

- campanhas em favor dos lojistas locais;

- negociações com empresas de telecomunicação para a instalação de postos de trabalho gratuitos nas favelas;

- financiamento para a instalação de mídia comunitária nas favelas (estações de rádio, sites, jornais, sites, canais de tv);

- ajuda financeira para as famílias que necessitam de serviços de creche;

- $\quad$ ajuda financeira para famílias com pessoas com deficiência;

- cooperação com os assistentes de saúde.

\section{CASO DE ESTUDO: O COMPLEXO DA FAVELA DA MARÉ}

\subsection{DESCRIÇÃO GERAL DO COMPLEXO DA FAVELA DA MARÉ}

Este complexo tem 140 mil habitantes vivendo em uma área de 330 ha. Ele está situado ao longo da estrada de saída Norte (Avenida Brasil) e é composto por 15 favelas (Figura 2).

Figura 2 - Localização do Complexo da Favela da Maré

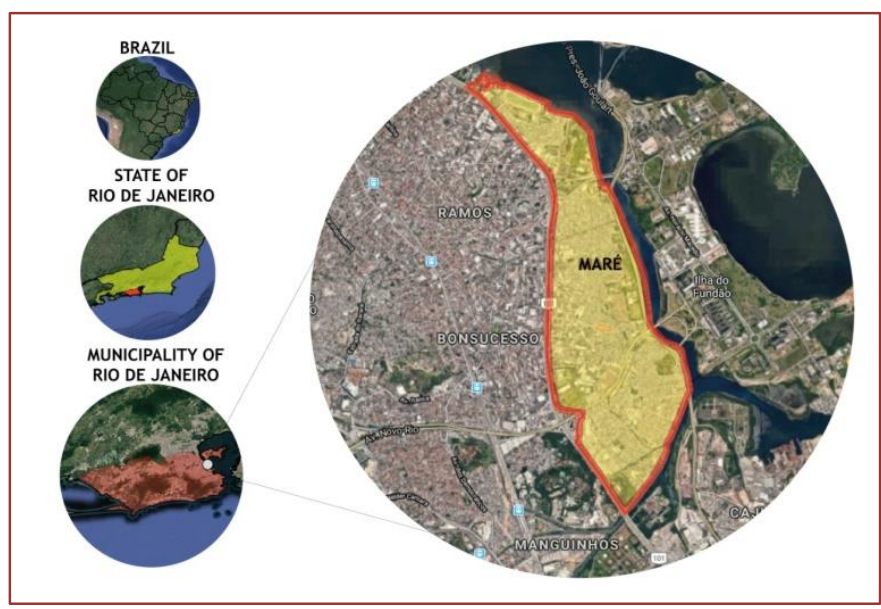

(Fonte: Google Earth, 2020, adaptado pelos autores) 
Um estudo organizado pela Prefeitura Municipal do Rio de Janeiro em 2017 oferece mais detalhes sobre a situação social (Instituto Municipal Pereira Passos, 2017):

- A construção da favela começou nos anos quarenta do século XX, mas nos anos oitenta, sofreu uma expansão explosiva por causa da crise econômica durante aquela década.

- Desde então, beneficiou-se de vários programas de urbanização e melhoramento, que, no entanto, não transformaram a comunidade em um bairro totalmente integrado.

- A população do Complexo Favela da Maré é relativamente jovem, em comparação com a população total do Rio de Janeiro: $70 \%$ da população tem idade inferior a 30 anos. A densidade resultante é de cerca de 110 habitantes por hectare.

- Em média, o número de habitantes por unidade habitacional é de 3,11, enquanto esta taxa é de 2,94 habitantes no Rio de Janeiro.

- Com relação ao nível de educação, 90\% da população entre 8 e 10 anos é alfabetizada. Para a faixa entre 10 e 14 anos, esta proporção sobe para 97\%.

- $70 \%$ da população tem uma renda per capita abaixo de 2 salários mínimos legais (200 dólares americanos).

- Em contraste, o complexo tem uma vida econômica interna, contando mais de 3000 empresas de propriedade dos habitantes, consistindo de bares $(22,4 \%)$, salões de beleza $(10,4 \%)$, lanches e pastelaria $(8,7 \%)$, vestuário $(7,3 \%)$, mercados de alimentos $(4,7 \%)$, veículos $(4,4 \%)$, restaurantes $(3,2 \%)$ e bares na Internet $(2,3 \%)$.

- Com relação à infraestrutura, como as 15 favelas foram construídas independentemente, a malha viária é fragmentada e composta de ruas estreitas. Entretanto, os sucessivos projetos de urbanização limitada do governo municipal forneceram o complexo com praças e parques. Estes programas têm assegurado que o complexo está totalmente equipado com energia elétrica, água, esgoto e coleta de lixo. No corredor de saída Norte adjacente, uma diversidade significativa de linhas de transporte público está em funcionamento.

\subsection{CONSUMO E LOGÍSTICA DA ÚLTIMA MILHA NO COMPLEXO DA FAVELA DA MARÉ}

Uma pesquisa sobre o consumo e a logística da última milha durante as pandemias provocou uma mudança de mercado em direção a bens e serviços essenciais, ou seja, alimentos (frescos e processados), produtos de limpeza e higiene, instalações urbanas (energia, água, esgoto, coleta de lixo), medicamentos, ferramentas de trabalho, manutenção doméstica, assistência médica e logística. Outra mudança pode ser observada na logística de última milha, onde os serviços de entrega e pagamento por cartão são preferidos (Aragão, 2020; Aragão e Ferreira, 2020).

Não obstante, a redução de renda por causa da pandemia já provocou em março uma forte queda no consumo das famílias nas favelas. As famílias correm o risco de não poder adquirir alimentos e bens de higiene. Além disso, a estrutura urbana particular das favelas dificulta o acesso aos bens e serviços: a rede de ruas, composta de redes descontínuas de becos estreitos e sinuosos e a ausência de endereços formais dificultam o uso dos serviços de entrega, mesmo que sejam organizados por mercearias locais. Portanto, as famílias têm que abandonar suas casas para adquirir os bens (Mundo do Marketing, 2020; Agência Brasil, $2020 b, c)$.

Assim, um papel relevante para a mobilidade dos habitantes das favelas dentro e fora das comunidades são os mototáxis (mototáxi), que na regra não são licenciados. Este serviço de transporte é também uma fonte de renda relevante para as famílias de baixa renda e fornece o único serviço que pode circular dentro da comunidade. Os motoristas organizam áreas de estacionamento, onde podem ser contatados, e perto das áreas, são instalados stands de alimentos e bebidas ou mesmo salões de beleza.

Eles desempenham um papel importante não apenas no que diz respeito ao deslocamento, mas também para levar as crianças à escola. Estes sistemas de transporte gozam de uma alta confiança por parte da comunidade, pois estão permanentemente conscientes dos lugares com riscos violentos que evitam.

A pandemia da COVID 19 atingiu severamente a renda dos motoristas de mototáxi, embora eles estejam mobilizados para entregar bens essenciais aos habitantes da comunidade (Observatório das Favelas, 2020). 


\subsection{COMPLEXO DA FAVELA DA MARÉ, A EPIDEMIA DA COVID E A REAÇÃO DAS ORGANIZAÇÕES COMUNITÁRIAS}

Ainda em maio de 2020, 261 foram infectados e 38 foram relatados que poderiam estar vinculados à COVID. Entretanto, entre 10 pessoas com sintomas apenas 4 tiveram acesso aos testes (Rede da Maré, 2020). Em junho do mesmo ano, a comunidade do complexo teve o maior número de mortes em comparação com outras comunidades (Nós Mulheres da Periferia, 2020).

A organização de autoajuda mais importante do complexo é a Rede da Maré. Em tempos normais, esta organização tem o seguinte foco de atividade:

a. Vida cultural: a organização se diverte através de parcerias com a administração pública, universidades e empresas bibliotecas locais, centros de arte, museus locais, eventos, oficinas (dança, música, culinária, etc.);

b. Desenvolvimento urbano: as atividades compreendem a participação e organização de pesquisas, planejamento urbano, gestão de espaços públicos e educação ambiental;

c. Segurança pública: as principais atividades são negociações com a força policial, levantamento de dados sobre violência;

d. Educação, compreendendo cursos de alfabetização, apoio à aprendizagem, treinamento profissional (trabalho de construção), cursos de preparação e educação de adultos.

Durante as pandemias, as Redes da Maré desenvolveram as seguintes ações:

a. distribuição de cestas contendo alimentos e bens para higiene pessoal e material de limpeza. ações especiais são dedicadas à população desabrigada;

b. coleta de recursos financeiros e doações;

c. doações de equipamentos de proteção pessoal e gel alcoólico;

d. desinfecção de ruas e vielas;

e. geração de renda para cozinheiros, costureiros, motoristas e artistas;

f. produção de vídeos, podcasts e boletins on-line com acompanhamento sobre a pandemia;

g. serviço online com respeito a questões de saúde;

Redes da Maré contratou 300 voluntários para a distribuição de alimentos e produtos de higiene e limpeza. Estes voluntários foram indicados por organizações locais. Alguns foram identificados por meio de ligações telefônicas e assistentes sociais.

Um ano e meio depois do começo da pandemia, no final de julho de 2021, o Complexo da Maré recebeu uma vacinação em massa, que engloba varias faixas etárias para um estudo sobre a efetividade da vacina contra a COVID-19. 0 estudo inédito no país só será possível graças a articulação da Redes da Maré dentro do território envolveu seus colaboradores, voluntários e moradores para auxilio no pré-cadastro e na comunicação de porta a porta (Redes da Maré, 2021).

\section{CONCLUSÕES}

O Brasil ocupa o segundo lugar em termos de vítimas da pandemia da COVID-19 e, juntamente com os Estados Unidos, uma "vitrine" de sua má administração. No final de julho de 2020, o país se aproximava do limiar cinzento de cem mil vítimas, atualmente, ultrapassou as 500mil. 0 Presidente já foi acusado de uma abordagem deliberadamente omissa em relação ao desastre.

A população das favelas é severamente atingida por uma pandemia. Por outro lado, o documento mostra a vontade da população das favelas de tomar a iniciativa de resolver seus problemas, juntamente com o governo local ou, se as autoridades negligenciarem as favelas, apesar delas. As redes de solidariedade têm abraçado não apenas a população, mas também as universidades e as ONG's.

A favela emerge das observações uma comunidade organizada, que produz 120 bilhões de reais por ano (Portal IG Economia, 2020), graças ao seu empreendedorismo vívido, liderado majoritariamente por mulheres. A vontade de elevar os padrões de vida através da educação profissional e superior é forte entre 
os jovens. As atividades educacionais e culturais têm uma forte presença nas comunidades. As organizações de autoajuda ajudam a melhorar o ambiente social e construído, e a solidarizar-se com a parte mais pobre da população. Até 2015, o humor dos habitantes estava confiante, como demonstraram as pesquisas.

Entretanto, as pandemias atingiram severamente as condições de vida e o estado de espírito das comunidades. 0 número de mortes tem sido proporcionalmente maior do que a média, e a perda de renda e o medo tem sido demonstrado como dominante pelas pesquisas em 2020.

Uma grande parte da população vive de serviços e atividades de venda, que foram substancialmente reduzidos. A pobreza e a fome estão se espalhando. 0 governo introduziu um subsídio mensal de 600 reais para a população sem renda, e o reduziu em $50 \%$ em meses seguintes. Este subsídio é distribuído entre as famílias e não reverte o estado de miséria. A população sofre de dificuldades para comprar alimentos essenciais, produtos de higiene e de limpeza. 0 abastecimento de água e esgoto é deficiente e complica a manutenção de uma boa higiene.

Os habitantes das favelas têm uma dificuldade particular em conseguir a entrega dos bens devido à falta de endereço oficial e à morfologia obstrutiva das redes de ruas. Portanto, eles têm que desconsiderar as recomendações de distanciamento social para fazer compras ou para trabalhar (no caso de manterem seu emprego, muitas vezes com pagamentos reduzidos). Os mototáxis informais ajudam a superar desvantagens logísticas e de mobilidade, mas a COVID reduziu consideravelmente sua renda.

Durante a pandemia, a rede de solidariedade não perturbou e foi capaz de evitar o pior. Informações sobre o contágio e medidas de segurança são disseminadas, cestas com alimentos e outros bens essenciais são coletadas e distribuídas, ruas são desinfetadas e oportunidades de renda são criadas. Em algumas favelas, as campanhas de conscientização foram capazes de reduzir as taxas de contágio e morte abaixo do valor médio nas cidades (UOL Notícias, 2020).

No entanto, as comunidades reclamam do relativo abandono por parte das autoridades, pelo qual nem mesmo estatísticas específicas sobre as favelas estão disponíveis. Sua negligência durante a COVID impulsionou o contágio geral e o número de mortes, colocando em risco a saúde e a vida de todas as classes de renda.

A principal lição trazida pela pesquisa é que as comunidades faveladas, apesar de sua má imagem em termos de violência, são capazes de tomar seu destino nas próprias mãos e produzir progresso para seu povo e para a comunidade. E que qualquer melhoria nas favelas e até mesmo nas cidades deve contar com sua participação para que as políticas estruturantes sejam mais assertivas. Desconsiderar continuamente sua situação ou impor medidas de cima para baixo prejudica não só as comunidades, mas também toda a cidade.

\section{AGRADECIMENTOS}

Agradecemos o Conselho Nacional de Desenvolvimento Científico e Tecnológico - CNPq pelo suporte para desenvolvimento desta pesquisa.

\section{REFERÊNCIAS}

[1] Aragão, J. J. G. (2020) ‘Domicílios em Quarentena: Logística de Suprimento'. LinkedIn. 28 de março de 2020, retirado em 26 de julho de 2020 de https://www.linkedin.com/posts/joaquim-aragao-bab33218_a-log\%C3\%ADsticade-suprimento-de-domic\%C3\%ADlios-confinados-activity-6649332006964477952-LOfh

[2] Aragão, Joaquim José Guilherme; Ferreira, Lucas Cézar. (2020) ‘A Logística de Suprimento de Famílias em Quarentena'. 21 de março de 2020 , retirado em 26 de julho de 2020 de https://www.linkedin.com/posts/joaquimaragao-bab33218_espa\%C3\%A7os-de-oportunidades-na-provis\%C3\%A3o-de-lares-activity-6651524765150400512$4 \mathrm{~d} 3 \mathrm{X}$.

[3] Comitê Fiocruz Covid-19 nas Favelas. (2020) ‘COVID-19 e Vulnerabilidades - Considerações sobre Proteção Social nas Favelas', Nota Técnica, Instituto Fiocruz, retirado de https://www.arca.fiocruz.br/bitstream/icict/41456/2/Covid-19Vulnerabilidades.pdf

[4] Datafavela. (2015) 'Fórum Nova Favela Brasileira', 2nd ed. Retirado de https://www.sebrae.com.br/Sebrae/Portal\%20Sebrae/UFs/AM/Anexos/Apresenta\%C3\%A7\%C3\%A3o_2\%C2\%BA \%20Forum\%20Favela_Consolidado.pdf

[5] Datafavela. (2020a) 'Coronavírus na Favela. Março 2020'. Retirado de http://www.cidadessaudaveis.org.br/cepedoc/wp-content/uploads/2020/04/Coronav\%C3\%ADrus-nasfavelas_divulg_rev2.pdf 
[6] Datafavela. (2020b) 'Pandemia na Favela - a realidade de 14 milhões de favelados no combate ao corona vírus'. Junho de 2020. Retirado de https://www.slideshare.net/ILocomotiva/pandemia-na-favela?from_action=save

[7] França, E. B.; Ishitani, L. H.; Teixeira, R. A.; Abreu, D. M. X.; Corrêa, P. R. L.; Marinho, F.; Vasconcelos, A. M. N. (2020) 'Óbitos por COVID-19 no Brasil: quantos e quais estamos identificando?', Revista Brasileira de Epidemiologia, 23, 22 Jun. 2020, retirado em 10 de julho de 2020 de https://doi.org/10.1590/1980-549720200053

[8] Franco, R. de M. (2020) 'Impactos da pandemia de COVID-19 sobre o Nível de Utilização da Capacidade Instalada da Indústria de Transformação’. Fundação Getúlio Vargas. Artigos, retirado em 5 de julho de 2020 de https://portal.fgv.br/artigos/impactos-pandemia-covid-19-sobre-nivel-utilizacao-capacidade-instalada-industria

[9] Freitas, C. M; Silva, I. V. de; Cidade, N. da C. (2020) 'Covid-19 as a Global Disaster: Challenges to risk governance and social vulnerability in Brazil'. Ambiente e Sociedade. vol.23. São Paulo, retirado em 03 de julho de 2020 https://doi.org/10.1590/1809-4422asoc20200115vu2020l3id

[10] Henriques, C. M. P.; Vasconcelos, W. (2020). 'Crises dentro da crise: respostas, incertezas e desencontros no combate à pandemia da Covid-19 no Brasil'. Estudos Avançados, 34(99), 25-44, retirado em 10 de julho de 2020 de https://doi.org/10.1590/s0103-4014.2020.3499.003

[11] IBGE. (2016) 'Pesquisa nacional por amostra de domicílios : síntese de indicadores 2015', Coordenação de Trabalho e Rendimento, Rio de Janeiro: IBGE, retirado dehttps://biblioteca.ibge.gov.br/visualizacao/livros/liv98887.pdf

[12] IBGE. (2020) 'PNAD-COVID19 Estatísticas Experimentais'. IBGE. Retirado de https://covid19.ibge.gov.br/

[13] Instituto Municipal Pereira Passos. (2017) 'Caderno da Maré', Cadernos Rio + Social, Rio de Janeiro: Prefeitura Municipal do Rio de Janeiro, retirado em 25 de julho de 2020 de http://www.data.rio/datasets/programariosocial-06-caderno-mar\%C3\%A9-mar\%C3\%A7o-2017

[14] Komatsu, B. K.; Menezes-Filho, N. (2020) 'Simulações de Impactos da COVID-19 e da Renda Básica Emergencial sobre o Desemprego, Renda, Pobreza e Desigualdade'. Policy Paper, 43, Abril, 2020. Insper - Instituto de Ensino e Pesquisa, retirado em 3 de julho de 2020 de https://www.insper.edu.br/wpcontent/uploads/2020/04/Policy-Paper-v14.pdf

[15] Lameiras, M. A. P.; Cavalcanti, M. A. F. de H. (2020) 'PNAD COVID-19: principais destaques', Carta de Conjuntura, 48, 17 de Julho, 2020, $3^{\circ}$ Trimestre de 2020, IPEA, retirado de https://www.ipea.gov.br/portal/images/stories/PDFs/conjuntura/200717_cc_48_pnad_covid_1707.pdf

[16] Noronha, K. V. M. de S.; Guedes, G. R.; Turra, C. M.; Andrade, M. V.; Botega, L.; Nogueira, D.; Almeida Calazans, J.; Carvalho, L.; Servo, L.; Ferreira, M. F. (2020) 'Pandemia por COVID-19 no Brasil: análise da demanda e da oferta de leitos hospitalares e equipamentos de ventilação assistida segundo diferentes cenários', Cadernos de Saúde Pública 2020, 36(6), retirado em 10 de julho de 2020 de https://scielosp.org/pdf/csp/2020.v36n6/e00115320/pt

[17] Pasternak, S.; D'Ottaviano, C. (2016) 'Favelas no Brasil e em São Paulo: avanços nas análises a partir da Leitura Territorial do Censo de 2010', Caderno Metrópoles, vol.18, 35, São Paulo Jan./Abr. 2016, retirado em 27 de julho de 2020 de https://doi.org/10.1590/2236-9996.2016-3504

[18] Pires, M. A.; Crokidakis, N.; Cajueiro, D. O.; Menezes, M. A. F.; Duarte Queirós, S. M. (2020). 'What is the potential for a second peak in the evolution of SARS-CoV-2 in Brazil? Insights from a SIRASD model considering the informal economy'. Portal do CBPF, retirado em 3 de julho de 2020 de https://arxiv.org/pdf/2005.09019.pdf

[19] Rede de Pesquisa Solidária. (2020a) 'Dificuldades com aplicativo e não uso da rede de proteção atual limitam acesso ao auxílio de emergência', Nota Técnica No. 5, 8 de maio de 2020, retirado de https://redepesquisasolidaria.org/wp-content/uploads/2020/05/boletim5.pdf

[20] Rede de Pesquisa Solidária. (2020b) 'Fome, desemprego, desinformação e sofrimento psicológico estimulam a violência e a desesperança em comunidades vulneráveis de seis regiões metropolitanas brasileiras', Nota Técnica No. 7, 22 de maio de 2020, retirado de https://redepesquisasolidaria.org/wp-content/uploads/2020/05/boletim-7pps.pdf

[21] Redes da Maré. (2020) 'Boletim De Olho no Corona', Rio de Janeiro: Redes da Maré, retirado em 27 de julho de 2020 de https://www.redesdamare.org.br/media/downloads/arquivos/05E03-BoletimDeOlho.pdf

[22] Redes da Maré. (2021) 'Vacina Maré: Experiência Coletiva Para Construção De Políticas Estruturantes', retirado em 13 de agosto de 2021 de https://www.redesdamare.org.br/media/downloads/arquivos/08E40deolhonocorona.pdf

[23] Rodrigues, R. I. (2020) 'A Covid-19, a Falta de Água nas Favelas e o Direito À Moradia no Brasil', Nota Técnica n 39, julho 2020, Diest. Brasília: IPEA. Retirado de https://www.ipea.gov.br/portal/images/stories/PDFs/nota_tecnica/200709_nt_diest\%20n\%C2\%BA_39_web.pdf

[24] Rogenski, R. (2020) 'Marcas se posicionam sobre greve dos apps de delivery'. Meio e Mensagem. 1 de julho de 2020, retirado em 10 de julho de 2020 de 
https://www.meioemensagem.com.br/home/marketing/2020/07/01/marcas-se-posicionam-sobre-greve-dosapps.html

[25] SEBRAE. (2020) 'O Impacto da pandemia de corona vírus nos Pequenos Negócios', 3a ed, Resultados Regionais. Pesquisa Online - de 30/04 a 05/05/2020, retirado de https://datasebrae.com.br/wpcontent/uploads/2020/05/Impacto-do-coronav\%C3\%ADrus-nas-MPE-3\%C2\%AAedicao_Regi\%C3\%A3o-v2.pdf

[26] Secretaria Municipal de Saúde. (2020) 'Como o MSP consolidou uma Rede de Atenção à Saúde - RAS fortalecida para controle da COVID-19', 22 de junho de 2020, retirado em 27 de julho de 2020 de https://www.prefeitura.sp.gov.br/cidade/secretarias/upload/saude/22062020\%20Vers\%C3\%A3oFinalCOMPLETAR ASInqueritoObitos22062020\%20PDF.pdf

[27] SOS Favela. (2020) 'Impacto Econômico da Pandemia nas Favelas e Periferias do Rio De Janeiro'. Pesquisa SOS Favela, Viva Rio e Academia Pérolas Negras, retirado de http://vivario.org.br/wordpress/wpcontent/uploads/2020/07/Power-Point-Pesquisa-Covid-Favelas-2-0-MN27jun20.pdf

[28] World Health Organization. (2020) 'Coronavirus disease (COVID-19) Situation Report - 181', retirado em 27 de julho de 2020 de https://www.who.int/docs/default-source/coronaviruse/situation-reports/20200719-covid-19sitrep-181.pdf?sfvrsn=82352496_2Notícias

[29] Agência Brasil. (2020) 'Covid-19: 75\% dos moradores de favelas não procuram atendimento médico', 26 de maio de 2020, retirado de https://agenciabrasil.ebc.com.br/saude/noticia/2020-05/covid-19-75-dos-moradores-defavelas-nao-procuram-atendimento-medico

[30] Agência Brasil. (2020) 'Pesquisa mostra que solidariedade é maior entre moradores de favelas', 26 de junho de 2020, retirado de https://agenciabrasil.ebc.com.br/direitos-humanos/noticia/2020-06/pesquisa-mostra-quesolidariedade-e-maior-entre-moradores-de

[31] Agência Brasil. (2020) 'Moradores de favelas relatam desabastecimento e medo de Covid-19', 8 de abril de 2020, retirado em 27 de julho de 2020 de https://agenciabrasil.ebc.com.br/saude/noticia/2020-04/moradores-defavelas-relatam-desabastecimento-e-medo-de-covid-19

[32] BBC News Brasil. (2020) 'Coronavírus: Sem plano do governo para favelas, moradores e organizações se juntam para controlar contágio', 29 de março de 2020, retirado de https://www.bbc.com/portuguese/brasil52032709

[33] Cambricoli, F. (2020) 'O que esperar da reabertura em meio ao aumento de novos casos de COVID'. Estado de São Paulo, retirado em 5 de julho de 2020 de https://www.estadao.com.br/infograficos/saude,o-que-esperar-dareabertura-em-meio-ao-aumento-de-novos-casos-de-covid,1104574

[34] Central Única das Favelas. (2020) 'Propostas de Medidas para Reduzir os Impactos da Pandemia de Covid19 nos Territórios das Favelas Brasileiras', 18 de março de 2020, retirado de https://www.cufa.org.br/noticia.php?n=MjYx

[35] Confederação Nacional dos Municípios. (2020) 'Governo prepara MP que trata de novas diretrizes para os programas habitacionais', retirado de https://www.cnm.org.br/comunicacao/noticias/governo-prepara-mp-quetrata-de-novas-diretrizes-para-os-programas-habitacionais

[36] Conselho Federal de Enfermagem (2020b) 'Covid-19: Enfermeiros e técnicos se contaminam 3 vezes mais do que médicos', 20 de julho de 2020, retirado em 27 de julho de 2020 de http://www.cofen.gov.br/covid-19enfermeiros-e-tecnicos-se-contaminam-tres-vezes-mais-do-que-os-medicos_81271.html

[37] Conselho Federal de Enfermagem. (2020a) 'Fiscalização aponta subdimensionamento na resposta à covid19'. 17 de julho de 2020, retirado em 27 de julho de 2020 de http://www.cofen.gov.br/fiscalizacao-apontasubdimensionamento-na-resposta-a-covid-19_81197.html

[38] Folha de São Paulo. (2020) 'Reduzindo a frota de ônibus, prefeitura agravou o risco de contaminação durante a semana crítica da pandemia', 6 de abril de 2020, retirado de https://www1.folha.uol.com.br/colunas/nabilbonduki/2020/04/reduzindo-a-frota-de-onibusprefeitura-agravou-o-risco-de-contaminacao-durante-a-semanacritica-da-pandemia.shtml

[39] G1. (2020) 'Flagrantes da falta de uso de máscaras se espalham por todo o Brasil'. 0 Globo, 7 de maio de 2020, retirado em 10 de julho de 2020 https://g1.globo.com/fantastico/noticia/2020/07/05/flagrantes-da-falta-deuso-de-mascaras-se-espalham-por-todo-o-brasil.ghtml

[40] Jornal da USP. (2020) 'Pandemia e suas consequências estimulam violência e desesperança em comunidades carentes', 26 de maio de 2020, retirado de https://jornal.usp.br/ciencias/pandemia-e-suas-consequencias-estimulamviolencia-e-desesperanca-em-comunidades-carentes/

[41] Mundo do Marketing. (2020) 'Consumo de moradores das favelas cai por causa do Coronavírus', 27 de março de 2020, retirado em 27 de julho de 2020 https://www.mundodomarketing.com.br/ultimasnoticias/38595/consumo-de-moradores-das-favelas-cai-por-causa-do-coronavirus.html 
[42] Nações Unidas. (2021). 'Mundo registra mais de 200 milhões de casos de Covid-19', 10 de agosto de 2021, retirado em 13 de agosto de https://news.un.org/pt/story/2021/08/1759492

[43] Nós Mulheres da Periferia. (2020) ‘Complexo da Maré (RJ): O dia a dia de ativistas contra a Covid-19'. Rio de Janeiro: Nós Mulheres da Periferia, retirado em 27 de julho de 2020 em http://nosmulheresdaperiferia.com.br/noticias/complexo-da-mare-o-dia-a-dia-de-ativistas-contra-a-covid-19-e-ogenocidio/

[44] Observatório das Favelas. (2020) 'A cidade também é um conjunto de fluxos', 23 de junho de 2020, retirado em 27 de julho de 2020 de http://of.org.br/noticias-analises/a-cidade-tambem-e-um-conjunto-de-fluxos/

[45] Observatório das Metrópoles. (2018) 'Políticas Habitacionais em Favelas: o caso de São Paulo'. 27 de Setembro de 2018, retirado em 27 de julho de 2020 de https://www.observatoriodasmetropoles.net.br/politicashabitacionais-em-favelas-o-caso-de-sao-paulo/

[46] Portal IG Economia. (2020) 'Favelas movimentam quase R\$120 bilhões por ano'. 28 de janeiro de 2020, retirado de https://economia.ig.com.br/2020-01-28/favelas-movimentam-quase-r120-bilhoes-por-ano.html

[47] Roma News. (2020) 'Pesquisa revela o impacto do Covid-19 na vida dos moradores das maiores favelas do país', 23 de julho de 2020, retirado de https://www.romanews.com.br/noticias/pesquisa-revela-o-impacto-do-covid19-na-vida-dos-moradores-das/86965/

[48] Voz das Comunidades. (2020) 'COVID-19 nas Favelas', 26 de julho de 2020, retirado de https://painel.vozdascomunidades.com.br/

[49] UOL Notícias. (2020) 'Paraisópolis controla coronavírus melhor do que a média municipal de SP'. 25 de junho de 2020, retirado de https://noticias.uol.com.br/ultimas-noticias/agencia-brasil/2020/06/25/territorio-precariocontrola-covid-19-melhor-que-a-media-de-sao-paulo.htm?cmpid=copiaecola

[50] UOL Notícias. (2021) 'Bolsonaro confirma fim do auxílio emergencial após lançar Auxílio Brasil', 12 de agosto de 2021. Retirado em 13 de agosto de 2021 de

https://economia.uol.com.br/noticias/reuters/2021/08/12/bolsonaro-confirma-fim-do-auxilio-emergencial-aposlancar-auxilio-brasil.htm

[51] Wikifavela (2020) 'Relatos e vídeos sobre a realidade da pandemia nas favelas', retirado em 10 de julho de 2020 de

https://wikifavelas.com.br/index.php?title=Materiais_e_audiovisuais_sobre_coronav\%C3\%ADrus_produzidos_pela_e_ para_favelas 


\section{Capítulo 5}

Identificando segmentos latentes de usuários em função dos atributos do Serviço de Transporte Público de Goiânia

\section{Ronny Marcelo Aliaga Medrano \\ Willer Luciano Carvalho}

Resumo: Os usuários cativos sempre foram um segmento da demanda do serviço de transporte público coletivo tratado de forma homogênea desde um ponto de vista sociodemográfico. Existirão diferenças entre usuários do serviço com similar renda ou similar tempo de viagem? 0 presente trabalho procura encontrar diferenças entre a demanda de usuários do serviço de transporte coletivo considerando uma abordagem baseada na percepção da qualidade do serviço e aplicando um método de cluster não supervisionado denominado de Lanent Class Cluster Analysis (LCCA). As análises realizadas para o sistema de transporte público da Região Metropolitana de Goiânia (RMG) apresentaram 4 cluster de usuários com similaridades nas características socio demográficas, mas com diferenças nos atributos operacionais e da percepção da qualidade.

Palavras-chave: Transporte público, Classes latentes, segmentos de clientes 


\section{INTRODUÇÃO}

O transporte coletivo urbano funciona como o meio de integração entre as atividades e os serviços de uma determinada comunidade, cidade ou região e os usuários desta mesma localidade. Dada a necessidade de locomoção das pessoas, principalmente nas regiões periféricas de um centro urbano, este sistema se tornou essencial. Sendo por base desta necessidade que o serviço é dimensionado e planejado para atender a demanda por deslocamentos.

Estudos recentes apontam que a satisfação do usuário com a qualidade do serviço o faz permanecer no serviço, sendo que em alguns casos atraem novos clientes para o sistema (Van Lierop, D. e El-geneidy, a, 2016; Fu et al., 2018; Li et al., 2018). Em situações onde existem fugas dos usuários deve-se investigar se a qualidade é um fator preponderante para esse fenômeno. 0 comportamento do usuário do serviço de transportes é alvo de interesse deste estudo. Assim, compreender quais fatores influenciam para que este usuário deixe o sistema é identificar os pontos fracos do sistema. Quando se identifica esses pontos se sabe onde melhorá-lo e assim manter os usuários fiéis a ele, além de propor melhorias que atraiam novos clientes.

O sistema de transporte público da Região Metropolitana de Goiânia (RMG) sofreu uma queda de 11\% no número de passageiros no primeiro semestre de 2016, enquanto era comum decréscimos anteriores entre $2 \%$ e 3\%. A região metropolitana se destaca no cenário nacional já que o percentual de saída de passageiros do sistema tem sido maior que a média brasileira (NTU, 2017). Segundo a NTU (2017) as principais razões para este fenômeno estão associadas à crise econômica, aos congestionamentos, a falta de priorização do transporte público na agenda do país e a redução de investimentos que priorizem essa área.

Um estudo em 2016 foi realizado pelo ministério público de Goiás em parceria com a Universidade Federal de Goiás e o Instituto Federal de Goiás para avaliar a qualidade do serviço de transporte público da RMG em função da percepção dos usuários do serviço. A pesquisa foi realizada considerando diversos fatores para a avaliação da qualidade, dentre eles, os ônibus, a infraestrutura, a operação, a segurança, a acessibilidade e o pessoal. Dentro dos resultados encontrados, alguns dos atributos do serviço apontados com baixa qualidade do serviço são o conforto, a segurança, o tempo e o custo de deslocamento que podem inicialmente ser consideradas como causas da saída de usuários do serviço (MPGO/FCT-UFG, 2017; Coelho Filho e Guimarães, 2018; Carvalho e Pereira, 2011).

Considerando o problema da queda da demanda de usuários, a análise da segmentação do mercado pode ser muita ajuda para uma melhor compreensão dos perfis dos usuários em função dos atributos do serviço. A segmentação de mercado facilita um marketing mais personalizado, adaptado às necessidades ou desejos específicos de diferentes grupos de passageiros. A noção é familiar nas empresas de hoje: personalizar o serviço aumenta a satisfação e a fidelidade do cliente (Cheung et al. 2003; Vesanen 2007). Informações sobre transporte público e campanhas de marketing visam expressamente encorajar o uso de transporte público (Sanjust et al. 2014).

Portanto, o objetivo principal deste estudo é aplicar uma técnica de análise de cluster para segmentar a amostra de usuários do serviço de transporte público da RMG para analisar a algumas percepções sobre a qualidade do serviço tendo em vista o perfil detalhado dos usuários clientes do serviço. Dessa forma o presente artigo está estruturado da seguinte forma: apresenta-se na fundamentação teórica os conceitos sobre a segmentação de mercado e suas aplicações na área de transporte; na parte de metodologia apresenta-se os dados utilizados e a técnica de análise cluster de classes latentes; posteriormente, é realizada a análise dos resultados da clusterização; e na última seção, são apresentadas as conclusões sobre a pesquisa.

\section{FUNDAMENTAÇÃO TEÓRICA}

A segmentação de mercado pode ajudar os operadores de transporte público a identificar grupos de passageiros que compartilham características particulares, necessidades e requisitos específicos sobre o serviço. Tradicionalmente, variáveis socioeconômicas têm sido utilizadas para realizar uma segmentação simples, embora exista heterogeneidade enquanto a satisfação sobre os atributos e percepção da qualidade do serviço entre os indivíduos pertencentes a um grupo (de Oña et al., 2016; Diez-Mesa et al., 2016).

$\mathrm{Na}$ literatura em transporte diferentes estudos estratificaram amostras de pesquisa para reduzir a heterogeneidade e propor modelos específicos (por exemplo, de Oña et al., 2016; Diez-Mesa et al., 2016; Haustein e Hunecke, 2013; Krizek e El-Geneidy, 2007; Lee et al., 2019). Além disso, a maioria dos estudos com amostragem estratificada tendem a se basear nas características sociodemográficas dos passageiros 
(ou seja, modelos para mulheres, idosos, de acordo com a renda) ou em seus hábitos de viagem (tipo de dia da viagem, hora do dia), frequência de uso. Onde, observa-se que a segmentação é baseada em decisões metodológicas ou no desejo de estudar um problema específico (Davis et al., 2018; Diez-Mesa et al., 2016; Haustein e Hunecke, 2013).

\subsection{SEGMENTAÇÃO DE MERCADO NO SETOR DE TRANSPORTES}

Segundo Haustein e Hunecke (2013) na pesquisa de marketing, existem duas abordagens de segmentação: a priori e post hoc. No caso de uma segmentação a priori, são definidas as variáveis constituintes dos segmentos, bem como os perfis dos segmentos, de modo que cada respondente possa ser claramente designado a um dos segmentos postulados. Exemplo, a segmentação a priori para classificar a população em grupos que já usam modos de transporte ambientalmente amigáveis regularmente ou não, e podem ou não estar interessados em mais informações. Na segmentação post hoc, os grupos são especificados com base em resultados empíricos. Os indivíduos são agrupados de acordo com sua similaridade em um conjunto de variáveis e, na maioria dos casos, o agrupamento é o resultado de uma análise de cluster (de Oña et al., 2016; Diez-Mesa et al., 2016; Haustein e Hunecke, 2013; Krizek e El-Geneidy, 2007; Lee et al., 2019).

Na medida em que a pesquisa no transporte foi desenvolvendo-se, novas abordagens foram surgindo para desenvolver segmentações mais complexas. Dentro das quatro abordagens principais identifica-se: abordagem comportamental, abordagem geográfica, abordagem socioeconômica e a abordagem baseada nas atitudes (sendo a última a mais nova entre as quatro) (Beckman e Goulias, 2008; Davis et al., 2018; de Oña et al., 2016; Haustein e Hunecke, 2013).

A abordagem baseada em comportamento define os segmentos da população pelo seu comportamento real de viagem, por exemplo, frequência de viagem, escolha de modo ou finalidade de viagem (Beckman e Goulias, 2008; de Oña et al., 2016; Haustein e Hunecke, 2013). Nas abordagens comportamentais, os grupos geralmente são formados a priori, de acordo com regras bem definidas, e o objetivo é basicamente descrever o desenvolvimento de diferentes grupos de usuários ao longo do tempo. Por outro lado, Prillwitz e Barr (2011) apresentaram grupos gerados com base em uma análise de cluster do comportamento diário das viagens. Eles distinguiram entre 'usuários persistentes de carros', 'usuários frequentes de carros', 'usuários restritos de transporte público', e 'viajantes ecológicos consistentes' e mostrou que os grupos estavam particularmente relacionados à idade, renda e pontos de vista políticos. No contexto das viagens a lazer, Boëhler et al. (2006) identificaram quatro grupos com base no número de viagens e quilômetros percorridos. Os segmentos variaram de acordo com a sociodemográfica, valores pessoais, escolha do modo de viagem e impacto ambiental, com os 'viajantes de longo curso' sendo responsáveis por $80 \%$ das emissões de toda a amostra.

Por outro lado, as abordagens geográficas agrupam as pessoas por aspectos de sua localização residencial, diferenciando, por exemplo, entre pessoas que vivem em áreas urbanas, suburbanas e rurais. Tais abordagens são, por exemplo, usadas em pesquisas nacionais de viagens para descrever a escolha de modos de pessoas em diferentes contextos espaciais. Outros estudos escolhem áreas de estudo específicas que representam diferentes estruturas de assentamento para examinar a influência das características da vizinhança no comportamento da viagem (Diez-Mesa et al., 2016; Haustein e Hunecke, 2013). Além de diferentes categorias geográficas, representações contínuas de localização são frequentemente aplicadas, por exemplo, 'acessibilidade' ou 'capacidade de locomoção'. As quais podem ser integradas em outras abordagens de segmentação no setor de transportes, exemplo, em abordagens predominantemente comportamentais ou predominantemente atitudinais (Haustein, 2012).

Na segmentação em função as categorizações sociodemográficas as mais comuns são baseadas em faixas etárias ou sexo. Diferentes ciclos de vida ou estágios de vida podem ser diferenciados pela consideração combinada de variáveis domésticas, idade e status do trabalho, a priori ou posteriormente (Beckman e Goulias, 2008; de Oña et al., 2016; Goulias e Kim, 2001; Haustein e Hunecke, 2013). O estudo de Ryley (2006) identificou 10 segmentos com base no estágio da vida (exemplo, "Alunos", "Renda alta com crianças", "Casal de Aposentados") por análise de cluster e mostrou que eles diferiam em seus padrões de viagem individuais. Salomon e Ben-Akiva (1983) realizaram uma das primeiras integrações de estilos de vida na pesquisa de viagens.

Atitudes e valores foram integrados à pesquisa de mobilidade sistematicamente na abordagem do estilo de vida. Os estilos de mobilidade podem ser considerados um desenvolvimento adicional da abordagem do estilo de vida. Nessa abordagem, atitudes e preferências relacionadas à mobilidade foram integradas, além das atitudes e valores mais gerais considerados nos estilos de vida (Haustein et al., 2018; Haustein e 
Hunecke, 2013; Lee et al., 2017). A identificação de diferentes estilos de mobilidade começou com base em análises sociológicas de entrevistas qualitativas sobre atitudes e comportamentos de transporte. Com o aumento do conhecimento sobre os diferentes motivos e preferências, os estilos de mobilidade são agora identificados na maioria dos casos com base em questionários padronizados (Davis et al., 2018; Goulias e Kim, 2001).

Embora o estilo de vida e as abordagens orientadas à mobilidade também incluam outras variáveis relacionadas à pessoa (por exemplo, variáveis socioeconômicas e comportamento), os tipos de mobilidade são geralmente baseados apenas em variáveis atitudinais. Nos últimos anos, o uso da segmentação de mercado "pura" baseada em atitudes para promover o transporte ambientalmente sustentável aumentou significativamente (Prillwitz e Barr, 2011; Haustein e Hunecke, 2013). Alguns autores recomendam basear os tipos de mobilidade em uma base teórica e naquelas variáveis que foram consideradas preditores relevantes para explicar o comportamento da mobilidade em pesquisas sociais e comportamentais. Entre as dimensões mais importantes da teoria do comportamento estão os construtos da Teoria do Comportamento Planejado (TPB) (Azjen, 1991), o construto de norma pessoal derivado da Teoria da Ativação da Norma (NAT) de Schwartz (1977). E atitudes que abrangem a avaliação afetivo-simbólica de diferentes modos de transporte, como status, autonomia, emoção e privacidade, geralmente relacionadas ao uso do carro. No contexto brasileiro, o estudo de Silva et al. (2012), realizou a aplicação da segmentação em função de estilos de vida dos habitantes brasileiros considerando atitudes sobre os diferentes modais de transporte.

\subsection{QUALIDADE DO SERVIÇO E SEGMENTACÃO DE CLIENTES DE TRANSPORTE PÚBLICO}

Dentro dos trabalhos levantados sobre a segmentação de clientes do transporte público têm sido aplicadas diferentes abordagens. Algumas abordagens mais direcionadas na segmentação com base nas características sócio demográficas, e outras focadas nos aspectos atitudinais sobre a qualidade do serviço do transporte público. 0 estudo de Krizek e El-Geneidy (2007) realizou uma segmentação dentro dos usuários do transporte público aplicando o método de cluster K-means. A segmentação foi realizada a priori procurando diferenciar entre dois grupos de usuários que escolhem utilizar o transporte público e aqueles que são cativos do transporte público. Em função das segmentações foram analisadas as atitudes e hábitos desses dois grupos.

Outra abordagem com método de clusterização não supervisionado foram os trabalhos de de Oña et al. (2020, 2016); Diez-Mesa et al. (2016) onde foram realizadas segmentações a posteriori em função de variáveis de níveis de serviço e percepções sobre a qualidade do serviço de transporte público. No estudo de Oña et al. (2016) para os usuários da cidade de Granada, Espanha foram encontradas 4 segmentações de usuários aplicando a análise cluster de classes latentes (LCCA). A diferença de outros estudos foram utilizadas variáveis normalmente utilizados para a estratificação dos passageiros (frequência de uso, sexo, idade e / ou renda mínima) para estimação dos cluster aplicando LCCA. Esse estudo implica uma segmentação mais avançada, ao considerar simultaneamente várias características socioeconómicas dos usuários e dos seus hábitos de viagem. Foram identificados perfis detalhados de usuários com opiniões mais homogêneas sobre o serviço.

O estudo conduzido por Diez-Mesa et al. (2016) com dados do metrô da cidade de Sevilla (Espanha) foram levantados 6 segmentos de usuários aplicando também o LCCA só com dados sócio demográficos e 4 segmentos de usuários aplicando o LCCA com dados sócio demográficos e atributos da qualidade do serviço do metrô. Os resultados apresentaram que aplicando os atributos de qualidade de serviço dentro da clusterização foi possível encontrar grupos mais homogêneos em função das percepções sobre a qualidade do serviço entre os usuários. 0 interessante dos resultados é que as segmentações com aplicação de classes latentes permitem trabalhar dentro da heterogeneidade dos dados. 0 que pode apresentar resultados mais importantes para estratégias de marketing, já que existem intra-clusters entre grupos hipoteticamente homogêneos. Considera-se que a aplicação de LCCA pode trazer resultados interessantes para o caso dos clientes de transporte público de Goiânia. 


\section{METODOLOGIA}

\subsection{DADOS}

Os dados utilizados são da pesquisa "Percepção do usuário com relação à qualidade do transporte coletivo da rede metropolitana de Goiânia" realizada pelo Ministério público do estado do Goiás em parceria com a Universidade Federal de Goiás e o Instituto Federal de Goiás. O período de coleta foi entre o 15 de novembro e 13 de dezembro do ano 2016. A amostra coletada foi de 2401 usuários do transporte público para um 95\% de nível de confiança e $2 \%$ de erro amostral. As entrevistas foram realizadas dentro dos terminais do transporte público. As características da amostra dos entrevistados apresentam-se na Tabela 1.

Tabela 1: Características da amostra de entrevistados

\begin{tabular}{|c|c|}
\hline Características & Estatísticas \\
\hline 1) Gênero & Homem (43\%); Mulher (57\%) \\
\hline 2) Idade & Até 30 anos (51\%); de 30 à 60 anos $(42,3 \%) ;$ mais de 60 anos $(6,7 \%)$ \\
\hline 3) Escolaridade & $\begin{array}{l}\text { Ensino fundamental }(26,4 \%) \text {; ensino médio }(51,8 \%) \text {; ensino superior incompleto } \\
(13,7 \%) \text {; ensino superior completo }(8,1 \%)\end{array}$ \\
\hline 4) Renda & $\begin{array}{l}\text { Até } \mathrm{R} \$ 880(40,7 \%) ; \text { de } \mathrm{R} \$ 880 \text { até } \mathrm{R} \$ 2.640(51,3 \%) ; \mathrm{R} \$ 2.640 \text { a } \mathrm{R} \$ 4.440(7,0 \%) ; \\
\mathrm{R} \$ 4.440 \text { a } \mathrm{R} \$ 7.040(0,8 \%) ; \text { Mais de } \mathrm{R} \$ 7.040(0,3 \%)\end{array}$ \\
\hline 5) Frequência de uso & $\begin{array}{l}\text { Mais de } 2 \text { dias na semana (frequentes) }(83,5 \%) ; 2 \text { ou menos dias } \\
\text { (esporádicos) }(16,5 \%)\end{array}$ \\
\hline 6) Motivo & Trabalho $(67,8 \%) ;$ estudo $(13,8 \%) ;$ Outras atividades $(18,4 \%)$ \\
\hline
\end{tabular}

*A renda foi classificada conforme os valores de salário mínimo em 2016.

\subsection{ANÁLISE DE CLUSTER DE CLASSES LATENTES (LATENT CLASS CLUSTER ANALYSIS)}

Para se atingir o objetivo deste trabalho, o método Latent Class Cluster Analysis (LCCA) foi utilizado mediante a seguinte sequência de passos para sua aplicação: I) formulação do LCCA; II) Definição dos indicadores e variáveis covariantes; III) aplicação da modelagem para LCCA; e, IV) análise dos resultados.

\subsubsection{FORMULAÇÃO DO LATENT CLASS CLUSTER ANALYSIS (LCCA)}

A análise cluster de classes latentes (também conhecida como finite mixture modeling) envolve a identificação de relações entre variáveis usando tanto indicadores observados, como é usado em modelos de regressão tradicionais, quanto não observados ou variáveis latentes, comumente utilizados em análise de equações estruturais (Magidson e Vermunt, 2002). A ideia por trás de uma análise de classes latentes é analisar os padrões de variância na variável dependente, e identificar grupos de indivíduos com comportamento relativamente homogêneo.

Latent class clustering (LCC) é um método particular que oferece algumas vantagens importantes sobre outros tipos de análise de cluster, como K-means, método de Ward ou o método de ligação única (Hair et al. 1998; Magidson e Vermunt 2002; Vermunt e Magidson 2014). Duas dessas vantagens são a possibilidade de utilizar diferentes tipos de variáveis (frequências, variáveis categóricas, métricas) sem necessidade de padronização prévia que pudesse alterar os resultados; e a disponibilidade de vários critérios estatísticos que ajudam a decidir o número mais adequado de clusters.

A formulação do LCCA (Magidson e Vermunt 2002; Vermunt e Magidson 2014) é a seguinte: temos uma amostra de dados de $\mathrm{N}$ casos, medidos com um conjunto de variáveis observadas, $\mathrm{Y} 1, . . ., \mathrm{Yj}$, que são consideradas indicadores de uma variável latente $\mathrm{X}$; essas variáveis formam um modelo de classe latente (LCM) com T classes. Se cada valor observado contém um número específico de categorias (Yi contém categorias $\mathrm{Ii}$, com i = 1 ... j), então as variáveis de manifesto fazem uma tabela de contingência múltipla com $\prod_{i=1}^{j} I_{i}$ 
Padrões de resposta. Se $\pi$ denota probabilidade, $\pi(\mathrm{Xt})$ representa a probabilidade de que um caso selecionado aleatoriamente pertença à classe t latente, com $t=1,2, \ldots$, T. A expressão regular de LCMs é dada pela Eq. (1):

$$
\pi_{Y_{i}}=\sum_{t=1}^{T} \pi_{X_{t}} \pi_{Y_{i} \mid X_{t}^{\prime}}
$$

Com Yi como o vetor de padrão de resposta do caso i; $\pi(\mathrm{Xt})$ a probabilidade anterior de associação t; e $\pi_{Y_{i} \mid X_{t}^{\prime}}$ a probabilidade condicional de que um caso selecionado aleatoriamente tenha um padrão de resposta Yi = $(\mathrm{y} 1, \ldots, \mathrm{yj})$, dada sua pertença à classe $\mathrm{t}$ da variável latente $\mathrm{X}$.

A suposição de independência local precisa ser verificada; portanto, a Eq. (1) é reescrito da seguinte forma:

$$
\pi_{Y_{i}}=\sum_{t=1}^{T} \pi_{X_{t}} \prod_{i=1}^{j} \pi_{Y_{i j} \mid X(t)}, \operatorname{com} \sum_{i=1}^{j} \pi_{Y_{i j} \mid X(t)}=1, e \sum_{t=1}^{T} \pi_{X_{t}}=1
$$

A estimativa do modelo é baseada na natureza das variáveis manifestas porque se assume que as probabilidades condicionais podem seguir diferentes funções formais (Vermunt e Magidson 2014). 0 método de máxima verossimilhança é usado para estimar os parâmetros do modelo. Uma vez que o modelo foi estimado, os casos são classificados em diferentes classes usando a regra de Bayes para calcular a probabilidade a posteriori de que cada n sujeito venha da classe t (são os valores estimados do modelo):

$$
\pi_{X_{t} \mid Y_{i}}=\frac{\hat{\pi}_{X_{t}} \hat{\pi}_{Y_{i} \mid X_{t}}}{\hat{\pi}_{\wedge_{y_{i}}}}
$$

Na prática, o conjunto de probabilidades é calculado para cada padrão de resposta e o caso é atribuído ao caso latente em que a probabilidade é mais alta. Assim, um determinado passageiro pode pertencer a diferentes casos latentes com uma determinada percentagem de adesão (sendo 100\% a soma total das probabilidades de adesão).

A priori, o número de clusters é desconhecido, o que significa que o objetivo é encontrar o modelo que pode explicar ou se adaptar melhor aos dados utilizados. O LCC aborda a seleção de modelos (incluindo a determinação do número de clusters) tentando vários modelos e computando vários critérios de informação, como os critérios de informação Bayesianos (BIC) (Raftery, 1986), o critério de informação Akaike (AIC) (Akaike, 1987) e o critério consistente de informações Akaike (CAIC) (Fraley e Raftery, 1998). 0 número adequado de clusters é aquele que minimiza a pontuação desses critérios porque tal modelo é mais parcimonioso e se adapta melhor aos dados do estudo (de Oña et al., 2016).

\subsubsection{DEFINIÇÃO DOS INDICADORES E VARIÁVEIS COVARIANTES}

Os indicadores e as variáveis covariantes definidos para a análise de cluster são apresentados na Tabela 2 . Os indicadores são considerados como as variáveis com maior impacto na conformação dos clusters, nesse sentido foram escolhidas as variáveis relacionadas com o nível de serviço do serviço de transporte coletivo, e o motivo da viagem e a frequência do uso. As variáveis covariantes são variáveis que tem um impacto de menor grau na conformação dos clusters ou podem ser covariantes inativas que não apresentam nenhum impacto na conformação dos cluster mais que contém informações importantes na análise. Para essa análise, a renda, sexo foram considerados como covariantes inativas em função de pré-testes realizados aonde essas variáveis não apresentaram significância no teste de Wald. 
Tabela 2: Categorização dos indicadores e as variáveis covariantes

\begin{tabular}{|c|c|}
\hline Variável & Categorização \\
\hline \multicolumn{2}{|l|}{ Indicadores } \\
\hline Frequência de uso & 1)Mais de 2 dias; 2) 2 ou menos dias \\
\hline Motivo & 1)Trabalho; 2)Estudo; 3)Outras atividades \\
\hline Tempo de viagem a pé ate o ponto de parada & Tempo em minutos \\
\hline Tempo de espera no ponto de parada ou terminal & Tempo em minutos \\
\hline Tempo de viagem no ônibus & Tempo em minutos \\
\hline \multicolumn{2}{|l|}{ Covariantes } \\
\hline Acesso à informação da operação por aplicativo & 1)Sim; 0) Não \\
\hline Idade & $\begin{array}{l}\text { 1)(Até } 30 \text { anos) jovens; 2)(de } 30 \text { a } 60 \text { anos) Adultos; } 3 . \\
\text { (mais de } 60 \text { anos) Idosos }\end{array}$ \\
\hline Escolaridade & $\begin{array}{l}\text { 1)Ensino fundamental; 2)Ensino médio; 3)Ensino } \\
\text { superior incompleto; 4) Ensino superior completo }\end{array}$ \\
\hline $\begin{array}{l}\text { Qualidade do Tempo de espera do ônibus nos } \\
\text { pontos de parada ou terminal }\end{array}$ & Escala likert de 1 à 5 ; sendo $1=$ péssimo e $5=$ ótimo \\
\hline Qualidade do Tempo de viagem dentro do ônibus & Escala likert de 1 à 5 ; sendo $1=$ péssimo e $5=$ ótimo \\
\hline $\begin{array}{l}\text { Qualidade do Tempo de espera do ônibus nos } \\
\text { pontos de parada ou terminal }\end{array}$ & Escala likert de 1 à 5 ; sendo $1=$ péssimo e $5=$ ótimo \\
\hline Qualidade da lotação do ônibus & Escala likert de 1 à 5 ; sendo $1=$ péssimo e $5=$ ótimo \\
\hline $\begin{array}{l}\text { Qualidade da segurança na viagem - assaltos } \\
\text { Qualidade da limpeza/higiene dos ônibus }\end{array}$ & Escala likert de 1 à 5 ; sendo 1 =péssimo e $5=$ ótimo \\
\hline Qualidade do conforto do veículo & Escala likert de 1 à 5 ; sendo 1 =péssimo e $5=$ ótimo \\
\hline \multicolumn{2}{|l|}{ Covariantes inativas } \\
\hline Renda & $\begin{array}{l}\text { 1)Até } \mathrm{R} \$ 880 ; 2 \text {.)de } \mathrm{R} \$ 880 \text { até } \mathrm{R} \$ 2.640 ; 3 \text { ) } \mathrm{R} \$ 2.640 \text { a } \\
\mathrm{R} \$ 4.440 ; 4) \mathrm{R} \$ 4.440 \text { a } \mathrm{R} \$ 7.040 ; 5) \text { Mais de } \mathrm{R} \$ 7.040\end{array}$ \\
\hline Sexo & 1)Homem; 2)Mulher \\
\hline
\end{tabular}

\subsubsection{APLICAÇÃO DA MODELAGEM}

O LCCA foi realizado utilizando o software Latent GOLD (5.1). A estratégia na modelagem com o LCCA é a realização de diferentes modelagens de cluster. Começando desde a modelagem com um único cluster até a modelagem com 10 clusters (Beckman e Goulias, 2008; Lee et al., 2017). Depois de aplicadas as modelagens os critérios de BIC, AIC, CAIC, número de parâmetros e erro das classes são analisados para escolher o modelo que apresente melhores valores nos critérios. Na Tabela 3 são apresentados os resultados dos modelos elaborados.

Tabela 3: Ajustes dos modelos construídos com o LCCA

\begin{tabular}{|c|c|c|c|c|c|c|}
\hline Modelo & LL & BIC(LL) & AIC(LL) & CAIC(LL) & Npar & Class.Err. \\
\hline 1-Cluster & $-27664,5$ & 55397,28 & 55347,05 & 55406,28 & 9 & 0 \\
\hline 2-Cluster & -26358 & 53140,58 & 52828,03 & 53196,58 & 56 & 0,0666 \\
\hline 3-Cluster & $-25940,1$ & 52661,16 & 52086,29 & 52764,16 & 103 & 0,1365 \\
\hline 4-Cluster & $-25645,5$ & 52428,24 & 51591,06 & 52578,24 & 150 & 0,1516 \\
\hline 5-Cluster & $-25628,2$ & 52749,95 & 51650,45 & 52946,95 & 197 & 0,151 \\
\hline 6-Cluster & $-25367,1$ & 52584,11 & 51222,29 & 52828,11 & 244 & 0,1846 \\
\hline 7-Cluster & $-25110,6$ & 52427,39 & 50803,26 & 52718,39 & 291 & 0,1767 \\
\hline 8-Cluster & -24585 & 51732,49 & 49846,04 & 52070,49 & 338 & 0,1478 \\
\hline 9-Cluster & $-24891,3$ & 52701,4 & 50552,63 & 53086,4 & 385 & 0,1611 \\
\hline 10-Cluster & $-24853,4$ & 52981,87 & 50570,79 & 53413,87 & 432 & 0,1827 \\
\hline
\end{tabular}

Segundo os resultados da Tabela 3, o modelo com 4 clusters foi selecionado porque apresentou os melhores valores para o BIC AIC e CAIC como no erro da classificação. Valores baixos para esses critérios estão associados a um melhor ajuste do modelo. No entanto, como os valores desses critérios continuaram diminuindo à medida que o número de classes latentes aumentava, consideramos as compensações entre o 
ajuste do modelo e a facilidade de interpretação dos resultados do modelo para determinar o número de classes latentes no modelo final. Consideração adicional foi dada ao descarte de soluções de modelo que incluíam classes muito pequenas como foi o caso do modelo de 8 clusters (contendo apenas alguns casos na amostra).

\section{ANÁLISE DOS RESULTADOS}

Conforme apresentado na seção anterior foi selecionado o resultado de 4 clusters de usuários de transporte público da RMG. A Tabela 4 apresenta os perfis resultados do modelo de 4 clusters com as variáveis indicadoras e as variáveis covariantes. Todas as variáveis indicadoras e covariantes tiveram significância no teste Wald com exceção das covariantes inativas. Os cluster 1 e 3 apresentaram melhores percepções sobre a qualidade do serviço comparados com os cluster 2 e 4 . 0 cluster 1 e o cluster 4 apresentaram a média de tempo de viagem no ônibus ligeiramente próximas. Como também, os cluster 2 e 3 apresentaram a média de tempo de viagem no ônibus próximas. Grandes diferenças entre os mesmos pares de cluster foi encontrado com o tempo de espera no ponto de parada ou terminal. Onde, o Cluster 1 tem menor tempo médio de espera no ponto de parada comparado com o Cluster 4. E o mesmo acontece com o Cluster 3 tem menor tempo médio de espera comparado com o Cluster 2.

Tabela 4: Características para os indicadores e covariantes para cada cluster.

\begin{tabular}{|c|c|c|c|c|}
\hline & Cluster1 & Cluster2 & Cluster3 & Cluster 4 \\
\hline Tamanho do cluster & $34,11 \%$ & $27,51 \%$ & $26,14 \%$ & $12,25 \%$ \\
\hline \multicolumn{5}{|l|}{ Indicadores } \\
\hline \multicolumn{5}{|l|}{ Frequência } \\
\hline Mais de 2 dias & $92,63 \%$ & $74,86 \%$ & $80,91 \%$ & $83,25 \%$ \\
\hline 2 dias ou menos & $7,37 \%$ & $25,14 \%$ & $19,09 \%$ & $16,75 \%$ \\
\hline \multicolumn{5}{|l|}{ Motivo } \\
\hline Trabalho & $72,06 \%$ & $60,80 \%$ & $67,99 \%$ & $71,46 \%$ \\
\hline Estudo & $18,73 \%$ & $9,84 \%$ & $15,55 \%$ & $4,99 \%$ \\
\hline Outras atividades & $9,22 \%$ & $29,36 \%$ & $16,46 \%$ & $23,56 \%$ \\
\hline $\begin{array}{l}\text { Tempo médio de viagem a pé até o ponto de parada } \\
\text { (min) }\end{array}$ & 9,59 & 9,11 & 5,35 & 22,79 \\
\hline $\begin{array}{l}\text { Tempo médio de espera no ponto de parada ou } \\
\text { terminal (min) }\end{array}$ & 15,00 & 33,24 & 12,89 & 42,19 \\
\hline Tempo médio de viagem no ônibus (min) & 62,62 & 34,95 & 27,33 & 85,23 \\
\hline \multicolumn{5}{|l|}{ Covariantes } \\
\hline \multicolumn{5}{|l|}{ Acesso a informação da operação do serviço } \\
\hline Não & $49,28 \%$ & $74,37 \%$ & $59,16 \%$ & $87,45 \%$ \\
\hline Sim & $50,72 \%$ & $25,63 \%$ & $40,84 \%$ & $12,55 \%$ \\
\hline \multicolumn{5}{|l|}{ Renda (Inativo) } \\
\hline Até $\mathrm{R} \$ 880$ & $37,68 \%$ & $41,05 \%$ & $38,07 \%$ & $46,80 \%$ \\
\hline De $R \$ 880$ até $R \$ 2.640$ & $51,38 \%$ & $50,69 \%$ & $50,31 \%$ & $45,40 \%$ \\
\hline De $R \$ 2.640$ a $R \$ 4.440$ & $7,60 \%$ & $5,91 \%$ & $7,74 \%$ & $4,83 \%$ \\
\hline De $\mathrm{R} \$ 4.440$ a $\mathrm{R} \$ 7.040$ & $1,00 \%$ & $0,62 \%$ & $0,61 \%$ & $0,77 \%$ \\
\hline De Mais de $\mathrm{R} \$ 7.040$ & $0,32 \%$ & $0,28 \%$ & $0,28 \%$ & $0,39 \%$ \\
\hline \multicolumn{5}{|l|}{ Idade } \\
\hline (Até 30 anos) jovens & $61,20 \%$ & $41,92 \%$ & $56,14 \%$ & $31,97 \%$ \\
\hline (de 30 à 60 anos) Adultos & $36,28 \%$ & $46,55 \%$ & $38,15 \%$ & $58,62 \%$ \\
\hline (mais de 60 anos) Idosos & $2,52 \%$ & $11,54 \%$ & $5,72 \%$ & $9,41 \%$ \\
\hline
\end{tabular}


Tabela 4: Características para os indicadores e covariantes para cada cluster.(Continuação)

\begin{tabular}{|c|c|c|c|c|}
\hline & Cluster1 & Cluster2 & Cluster3 & Cluster4 \\
\hline \multicolumn{5}{|l|}{ Sexo (Inativo) } \\
\hline Homem & $42,69 \%$ & $40,71 \%$ & $46,99 \%$ & $40,38 \%$ \\
\hline Mulher & $57,31 \%$ & $59,29 \%$ & $53,01 \%$ & $59,62 \%$ \\
\hline \multicolumn{5}{|l|}{ Escolaridade } \\
\hline Ensino fundamental & $20,05 \%$ & $35,30 \%$ & $19,24 \%$ & $39,12 \%$ \\
\hline Ensino médio & $50,75 \%$ & $51,37 \%$ & $56,00 \%$ & $47,24 \%$ \\
\hline Ensino superior incompleto & $19,96 \%$ & $7,92 \%$ & $15,69 \%$ & $4,72 \%$ \\
\hline Ensino superior completo & $9,24 \%$ & $5,42 \%$ & $9,07 \%$ & $8,93 \%$ \\
\hline \multicolumn{5}{|c|}{$\begin{array}{l}\text { Qualidade do tempo de espera do ônibus nos } \\
\text { pontos de parada ou terminal }\end{array}$} \\
\hline Péssimo + ruim & $36,78 \%$ & $71,99 \%$ & $19,09 \%$ & $82,37 \%$ \\
\hline Regular & $30,45 \%$ & $9,84 \%$ & $35,38 \%$ & $8,69 \%$ \\
\hline Ótimo + bom & $32,77 \%$ & $18,17 \%$ & $45,52 \%$ & $8,94 \%$ \\
\hline \multicolumn{5}{|c|}{ Qualidade Tempo de viagem dentro do ônibus } \\
\hline Péssimo + ruim & $47,66 \%$ & $38,54 \%$ & $19,51 \%$ & $65,53 \%$ \\
\hline Regular & $27,69 \%$ & $30,85 \%$ & $41,57 \%$ & $20,53 \%$ \\
\hline Ótimo + bom & $24,66 \%$ & $30,62 \%$ & $38,92 \%$ & $13,94 \%$ \\
\hline \multicolumn{5}{|c|}{ Qualidade pontualidade dos ônibus } \\
\hline Péssimo + ruim & $38,57 \%$ & $45,51 \%$ & $25,31 \%$ & $56,10 \%$ \\
\hline Regular & $30,43 \%$ & $26,64 \%$ & $33,69 \%$ & $24,60 \%$ \\
\hline Ótimo + bom & $30,99 \%$ & $27,85 \%$ & $41,00 \%$ & $19,29 \%$ \\
\hline \multicolumn{5}{|l|}{ Qualidade lotação do ônibus } \\
\hline Péssimo + ruim & $55,58 \%$ & $69,91 \%$ & $58,14 \%$ & $74,59 \%$ \\
\hline Regular & $12,85 \%$ & $13,50 \%$ & $17,13 \%$ & $13,07 \%$ \\
\hline Ótimo + bom & $31,56 \%$ & $16,59 \%$ & $24,72 \%$ & $12,34 \%$ \\
\hline \multicolumn{5}{|c|}{ Qualidade segurança na viagem - assaltos } \\
\hline Péssimo + ruim & $60,00 \%$ & $65,30 \%$ & $50,11 \%$ & $71,48 \%$ \\
\hline Regular & $16,87 \%$ & $13,16 \%$ & $19,10 \%$ & $8,84 \%$ \\
\hline Ótimo + bom & $23,14 \%$ & $21,54 \%$ & $30,79 \%$ & $19,67 \%$ \\
\hline \multicolumn{5}{|c|}{ Qualidade conforto do veículo } \\
\hline Péssimo + ruim & $48,10 \%$ & $56,67 \%$ & $44,33 \%$ & $61,76 \%$ \\
\hline Regular & $30,41 \%$ & $26,38 \%$ & $30,39 \%$ & $23,96 \%$ \\
\hline Ótimo + bom & $21,50 \%$ & $16,94 \%$ & $25,28 \%$ & $14,28 \%$ \\
\hline
\end{tabular}

O Cluster 1 é o maior com 34,11\% da amostra. Inclui ligeiramente mais mulheres do que homes. A maior parte são jovens com uma probabilidade de 61,20\%. Um 50,72\% dos usuários neste grupo tem acesso a informação do serviço pelo aplicativo de celular. Tem um tempo médio de viagem no ônibus de 62 minutos e um tempo médio de espera de 15 minutos. Com base essas características esse grupo foi denominado de "clientes que viajam na RMG com mais acesso a informação".

O Cluster 2 é o segundo em tamanho com 27,51\% da amostra. Inclui também ligeiramente mais mulheres do que homes. Enquanto idade temos uma proximidade entre jovens e adultos com probabilidades de $41,92 \%$ e $46,55 \%$ respectivamente e maior quantidade de idosos com $11,54 \%$. A viagem a trabalho é dominante em todos os cluster mais neste cluster temos mais viagens a outras atividades com uma probabilidade de $29,36 \%$ e mais usuários esporádicos com uma probabilidade de 25,14\%. 74,37\% não tem 
acesso a informação do serviço. Tem um tempo médio de viagem no ônibus de 34 minutos e um tempo médio de espera de 33 minutos. Com base essas características esse grupo foi denominado de "clientes que viajam dentro de Goiânia com pouco acesso à informação".

o Cluster 3 tem um tamanho de 26,14\% da amostra. Inclui também ligeiramente mais mulheres do que homes. A maior parte são jovens com uma probabilidade de 56,14\%. 40,84\% dos usuários neste grupo tem acesso à informação do serviço pelo aplicativo de celular. Os usuários esporádicos apresentam uma probabilidade de 19,09\%. Tem um tempo médio de viagem no ônibus de 27 minutos e um tempo médio de espera de 13 minutos. Com base essas características esse grupo foi denominado de "clientes que viajam dentro de Goiânia com mais acesso à informação".

O Cluster 4 é o menor com 12,25\% da amostra. Inclui ligeiramente mais mulheres do que homes. Os adultos formam um 58,62\% e os idosos 9,41\%. 87,45\% dos usuários neste grupo não tem acesso à informação do serviço pelo aplicativo de celular. As viagens a outras atividades apresentam uma probabilidade de $23,56 \%$. Tem um tempo médio de viagem no ônibus de 85 minutos e um tempo de espera de 42 minutos. Com base essas características esse grupo foi denominado de "clientes que viajam na RMG com pouco acesso à informação".

Observa-se que a renda e escolaridade tiveram variações entre os clusters selecionados, onde a maior parte da amostra encontra-se abaixo de $\mathrm{R} \$ 2.640$. Sobre as percepções da qualidade do serviço, interessantemente os cluster 1 e 3 que apresentam usuários com maior acesso à informação avaliaram com melhores notas indo de regular para bom todos os aspectos de qualidade sobre tempo de espera, tempo de viagem, conforto, pontualidade. No caso de segurança, lotação as avaliações foram ligeiramente melhores do que as avaliações realizadas pelos cluster 2 e 4 .

Pelos perfis dos cluster observa-se que o cluster 1 e 4 mesmo sendo próximos nos atributos operacionais do serviço as percepções são diferentes porque o cluster tem mais acesso a informação do que o cluster 4 . Observa-se também que o cluster 1 tem mais usuários jovens do que o cluster 4. Essa situação também acontece na comparação do cluster 2 e 3 aonde a percepção da qualidade é melhor para o cluster 3 que tem mais usuários com acesso a informação do serviço.

\section{CONCLUSÃO}

Observando as características da amostra de entrevistados analisada neste trabalho, pode-se identificar que temos os usuários classicamente categorizados na literatura de transporte. 0 presente trabalho atingiu o objetivo de segmentar esse grupo de usuários com a aplicação de uma abordagem baseada nas atitudes e uma técnica de cluster não supervisionado denominada como LCCA. Além disso, uma vantagem do LCCA com outros métodos de cluster é que ela consegue trabalhar com a heterogeneidade da amostra permitindo encontrar classes ou agrupações que dificilmente poderiam ser identificados com uma técnica de cluster a priori.

Os resultados apresentam que os usuários do sistema de transporte coletivo da RMG são heterogêneos entre si, e não conformam um grupo homogêneo único como poderia ser extraído só considerando uma segmentação sociodemográfica. Além disso, foram encontrados indícios de que o acesso à informação para os clientes do sistema melhora a qualidade percebida e o comportamento das viagens, já que foi possível evidenciar nos resultados que os grupos com maior acesso a informação apresentaram melhores desempenhos em tempo de espera.

No momento que o serviço de transporte público precisa se reinventar a causa da queda da demanda e eventos como a pandemia covid-19, o marketing personalizado pode ser uma opção para propor novas formas de serviço ou melhorias que o serviço de transporte público pode realizar com o objetivo de aumentar a qualidade e a captação de demanda. A aplicação do LCCA pode trazer resultados interessantes para o marketing personalizado que atenda as empresas de transporte público.

\section{REFERÊNCIAS}

[1] Ajzen I (1991) The theory of planned behavior. Some unresolved issues. Org Behav Hum Decis Process, 50:179-211.

[2] Beckman, J.D., Goulias, K.G., (2008). Immigration, residential location, car ownership, and commuting behavior: A multivariate latent class analysis from California. Transportation (Amst). 35, 655-671.

https://doi.org/10.1007/s11116-008-9172-x 
[3] Coelho Filho L., Guimarães M. (2018). Qualidade do transporte público da Região Metropolitana de Goiânia: uma avaliação a partir da percepção dos usuários e não usuários do sistema. Trabalho de conclusão de Curso. Escola de Engenharia Civil e Ambiental. Goiânia.

[4] Davis, A.W., McBride, E.C., Goulias, K.G. (2018). A latent class pattern recognition and data quality assessment of non-commute long-distance travel in California. Transp. Res. Rec. 2672, 71-80. https://doi.org/10.1177/0361198118787362

[5] de Oña, J., de Oña, R., López, G., (2016). Transit service quality analysis using cluster analysis and decision trees: a step forward to personalized marketing in public transportation. Transportation (Amst). 43, 725-747. https://doi.org/10.1007/s11116-015-9615-0

[6] de Oña, J., Estévez, E., de Oña, R., (2020). Perception of Public Transport Quality of Service among Regular Private Vehicle Users in Madrid, Spain. Transp. Res. Rec. 2674, 213-224.

https://doi.org/10.1177/0361198120907095

[7] Diez-Mesa, F., De Oña, R., De Oña, J. (2016). The Effect of Service Attributes' Hierarchy on Passengers' Segmentation. A Light Rail Transit Service Case Study. Transp. Res. Procedia 18, 234-241. https://doi.org/10.1016/j.trpro.2016.12.032

[8] Goulias, K.G., Kim, T. (2001). Multilevel Analysis of Activity and Travel Patterns Accounting for Person- and Household-Specific Observed and Unobserved Effects Simultaneously. Transp. Res. Rec. 23-31.

[9] Haustein, S. (2012). Mobility behavior of the elderly: An attitude-based segmentation approach for a heterogeneous target group. Transportation (Amst). 39, 1079-1103. https://doi.org/10.1007/s11116-011-9380-7

[10] Haustein, S., Hunecke, M. (2013). Identifying target groups for environmentally sustainable transport: Assessment of different segmentation approaches. Curr. Opin. Environ. Sustain. 5, 197-204.

https://doi.org/10.1016/j.cosust.2013.04.009

[11] Haustein, S., Thorhauge, M., Cherchi, E. (2018). Commuters' attitudes and norms related to travel time and punctuality: A psychographic segmentation to reduce congestion. Travel Behav. Soc. 12, 41-50. https://doi.org/10.1016/j.tbs.2018.04.001

[12] Hair Jr, J.F., Anderson, R.E., Tatham, R.L., Black, W.C. (1998) Multivariate Data Analysis. Prentice Hall, Englewood Cliffs, NJ

[13] Magidson, J., Vermunt, J.K. (2002) Latent class models for clustering: a comparison with K-means. Can J Mark Res 20,37-44

[14] MPGO - Ministerio Público de Goiás (2017). Percepção do usuário com relação à qualidade do Transporte Coletivo da Região Metropolitana de Transporte Coletivo de Goiânia. MPGO. Goiânia.

[15] NTU - Associação Nacional das Empresas De Transporte Urbano (2017). Anuário 2016-2017. Brasília: NTU, 2017. Disponível em: <https://www.ntu.org.br/novo/upload/Publicacao/Pub636391736883773822.pdf>. Acessado em junho de 2018.

[16] Krizek, K., El-Geneidy, A. (2007). Segmenting Preferences and Habits of Transit Users and Non-Users. J. Public Transp. 10, 71-94. https://doi.org/10.5038/2375-0901.10.3.5

[17] Lee, J.H., Davis, A., Yoon, S.Y., Goulias, K.G. (2017). Exploring daily rhythms of interpersonal contacts: Timeof-day dynamics of human interactions with latent class cluster analysis. Transp. Res. Rec. 2666, 58-68. https://doi.org/10.3141/2666-07

[18] Lee, Y., Circella, G., Mokhtarian, P.L., Guhathakurta, S. (2019). Are millennials more multimodal? A latent-class cluster analysis with attitudes and preferences among millennial and Generation X commuters in California. Transportation (Amst). https://doi.org/10.1007/s11116-019-10026-6

[19] Prillwitz J, Barr S. (2011) Moving towards sustainability? Mobility styles, attitudes and individual travel behaviour. J Trans Geogr, 19:1590-1600.

[20] Ryley T. (2006) Use of non-motorised modes and life stage in Edinburgh. J Trans Geogr, 14:367-375.

[21] Salomon I, Ben-Akiva M (1983) The use of the life-style concept in travel demand models. Environ Plan A, 15:623-638.

[22] Schwartz S. H. (1977) Normative influence on altruism. In Advances in experimental social psychology. Academic;:221-279.

[23] Silva, A. H. ; Medrano, R. M. A. ; Taco, P. W. G. (2012) Estudo das relaçõ es entre o estilo de vida e a escolha modal: uma analise de classes latentes. In: XXVI ANPET Congresso de Ensino e Pesquisa em Transporte, 2012, Joinville. XXVI ANPET conference procedings.

[24] Van Lierop, D., El-Geneidy, A. (2016). Enjoying loyalty: The relationship between service quality, customer satisfaction, and behavioral intentions in public transit. Research in Transportation Economics, 59, 50-59.

[25] Vermunt, J.K., Magidson, J. (2014) Latent GOLD 5.1 user's guide. Statistical Innovations Inc., Belmont, MA 


\section{Capítulo 6}

Entre os planos e a realidade: Até que ponto os planos diretores de Fortaleza determinaram as alterações na malha viária da cidade?

Rebeca Froés de Assis

Camila Bandeira Cavalcante

André Soares Lopes

Luádyna Almeida Bezerra

Gabriel Sato Feitosa Arrais

Resumo: 0 presente trabalho tem como objetivo verificar a exequibilidade das propostas dos planos diretores de Fortaleza (1960-2010), no que diz respeito ao sistema viário da cidade. Nesse sentido, pretende-se contribuir com as discussões sobre os esforços de planejamento urbano, com ênfase na investigação da relação plano versus realidade, isto é, entre os discursos contidos nos planos e as práticas adotadas pelas gestões. Para tanto, foi necessário levantar as proposições contidas nos quatro planos elaborados para o período, bem como averiguar suas condições de execução (não-executada, parcial ou totalmente executada) a partir da comparação morfológica entre bases cartográficas distintas e da medição de caixas viárias utilizando aerofotogrametria (Google Earth Pro). Como resultado, fruto de um exercício de mapeamento, evidencia-se o abismo existente entre aquilo que foi proposto e o que, de fato, foi executado.

Palavras-chave: planejamento urbano; sistema viário; planejamento integrado; plano diretor; 


\section{INTRODUÇÃO}

A literatura usual sobre o planejamento urbano brasileiro costuma apontar para a existência de um abismo entre os discursos contidos nos planos e as práticas efetivamente adotadas pelas instâncias governamentais (Villaça, 2005; Singer, 1995). Tratando-se de um plano diretor, enquanto mecanismo que visa orientar o desenvolvimento dos municípios, esse desalinho entre o dito e o realizado culmina na concepção de duas cidades distintas: I- a real, construída por meio de processos de gestão, um termo que remete ao tempo presente; e II - a idealizada ou planejada, assumindo-se que planejar é um processo que se desenvolve com ênfase no futuro (Souza, 2002) e, nessa perspectiva, aproxima-se do conceito de utopia: "uma legítima, reprimida e existente forma de conhecimento de futuros possíveis" (Teixeira, 2016, p 262).

Importante salientar que, historicamente, o texto de um Plano Diretor traz tanto propostas de caráter compulsório (sobretudo no que se refere ao controle do uso e ocupação do solo), quanto proposições sem qualquer validade ou imposição legal, geralmente obras e serviços ou medidas administrativas (Villaça, 2005). Dessa forma, apesar de ser comum se encontrar um elenco de obras nos planos diretores, não existe nenhuma determinação jurídica que torne obrigatória a execução dessas intervenções pelo poder municipal. Contudo, assumindo que "planejar" consiste na aplicação sistemática do conhecimento humano para respaldar a tomada de decisões adequadas e racionais (Holanda, 1983) e que a principal pretensão do planejamento é a promoção do desenvolvimento urbano (Villaça, 1999; Souza, 2010; Brasil, 2004), as alternativas resultantes de tal processo deveriam ser valorizadas.

Nesse sentido, alguns pesquisadores têm se esforçado para avaliar a influência dos planos urbanos na atuação das administrações municipais. É o caso, por exemplo, de alguns textos mencionados por Costa (1994), mas, infelizmente, nenhum dos títulos retrata experiências brasileiras, sendo a maioria das obras americanas e francesas. Lima, Lopes e Façanha (2019) também realizaram feito semelhante, mas tiveram como escopo a análise das propostas ambientais, contidas nos planos urbanos, sobre as práticas adotadas pelas gestões de Teresina, além de avaliarem a evolução dos mecanismos contidos nesses planos. Dito isso, destaca-se que é justamente nessa linha de pesquisa que o presente trabalho pretende contribuir, com a avaliação dos esforços de planejamento, na forma de planos diretores, e o seus rebatimentos na malha viária de Fortaleza, entre os anos de 1960 e 2010.

Assim, registra-se a questão que motivou esta pesquisa da seguinte forma: Podemos considerar que os Planos Diretores de Fortaleza têm efetiva influência sobre o processo de construção da cidade, em termos de infraestrutura viária? Para responder a essa questão central, foram elaboradas questões menores, a saber: (a) Qual a necessidade e a importância do exercício de planejamento para as cidades atuais? (b) Qual é o papel dos planos diretores no processo de construção das cidades? (c) Podemos evidenciar o descompasso entre plano e prática na realidade? As três seções que dão continuidade a esta introdução são dedicadas à discussão dessas questões, sendo a seção 4 destinada à análise dos planos elaborados para a cidade de Fortaleza. Por fim, na seção 5, são elaborados tanto comentários finais, na tentativa de responder a questão-central, como algumas observações para pesquisas futuras.

\section{A IMPORTÂNCIA DO PLANEJAMENTO URBANO}

Historicamente, pode-se relacionar o surgimento das cidades ao fenômeno do sedentarismo e, mais precisamente, à consciência de comunidade, elemento crucial ao processo de diversificação das funções e atividades que tornaram a relação homem versus natureza amplamente favorável ao homem (Vargas; Castilho, 2015). Entretanto, à medida que os núcleos urbanos cresciam desacompanhados de infraestrutura adequada (Gouvêa, 2008), a ideia da cidade como solução para uma estrutura socioeconômica se tornava questionável, sobretudo, do ponto de vista da saúde coletiva. 0 ápice desse cenário se deu com o desdobramento da Revolução Industrial, quando passou a se observar uma drenagem populacional dos campos em benefício das cidades sem precedentes. Surgiu, então, a necessidade de uma ciência que atendesse à nova ordem instaurada pela sociedade, isto é, uma disciplina dedicada ao planejamento da cidade industrial (Choay, 2015).

Por inferência, pode-se compreender a consolidação do Urbanismo, enquanto ciência, a partir do aumento da complexidade das cidades, uma vez que o ritmo de produção, imprimido pela industrialização, provocou mudanças estruturais na condição urbana (Sposito, 2017), o que afetou não só o espaço intraurbano, mas também as relações interlocacionais, dada a formação das redes de cidades. Daí, até hoje, alguns autores justificarem a necessidade do planejamento com base na complexidade dos aglomerados urbanos, bem como pela condição da interconectividade (Levy, 2016) entre os elementos ou subsistemas que já são utilizados por modelos de representação espacial - uso do solo, transportes, atividades (Wan Wee, 2002; Lopes, 2015). 
Nesse sentido, assume-se a compreensão da cidade como sistema complexo, isto é, um conjunto de diferentes elementos que, juntos, produzem resultados não atingíveis pela simples soma dos elementos isolados (Sokolowsky e Banks, 2009).

Todavia, Lopes e Loureiro (2012) reconhecem que a prática do planejamento urbano ocorre tradicionalmente de forma fragmentada, dentro das diferentes disciplinas que consideram a dimensão espacial do sistema cidade. Como consequência, cada elemento que compõe a realidade urbana tende a ser tratado de forma isolada, tomando os demais elementos como dispositivos secundários na compreensão de seus próprios fenômenos. Isto posto, evidencia-se que neste trabalho o fenômeno urbano, apesar de multifacetado, é compreendido na sua singularidade, sendo necessário o emprego de abordagens integradoras durante o processo de planejamento. Sobre este último, destaca-se a definição de Ferrari (1979 apud Magalhães; Yamashita, 2009, p 7), que coloca tal processo como "um método contínuo destinado à solução racional de problemas que afetam uma sociedade, espacialmente e temporalmente localizada e determinada, antecipando suas consequências num momento futuro". Matus (1991), em uma perspectiva social, explica o planejamento através da analogia de um jogo. Em sua metáfora, o plano seria o resultado de um jogo semi-controlado, no qual os participantes disputam por seus próprios interesses, apesar de caber ao apostador (entenda-se o tomador de decisão) a escolha pelo melhor resultado.

Ciente das discussões acima, Soares (2014) reforça que o exercício do planejamento não depende apenas do domínio sobre a complexidade do fenômeno analisado, uma vez que também envolve a mediação dos diferentes atores envolvidos no processo. Dessa forma, é possível sintetizar o planejamento urbano como um processo sistemático que, tendo como objeto de análise um conjunto complexo e composto por várias camadas, apresenta caráter tanto multidisciplinar, como mediatório, culminando numa espécie de contrato, que se materializa em um produto final: o plano. Para tanto, Matus (1984) defende a consciência e a força do Homem Coletivo como elementos essenciais ao funcionamento dessa dinâmica, no sentido de levar o Homem Indivíduo a atuar na direção da "Vontade Humana". Importante notar que o Plano Diretor exemplifica tal compreensão, uma vez que pretende significar um espaço de debate entre os agentes envolvidos na construção da cidade (Brasil, 2004), além de considerar os diversos elementos que compõem o aspecto urbano.

Em uma breve perspectiva histórica, observa-se que "planejar", sobretudo no século XIX, assumiu um papel importante para a solução dos problemas urbanos existentes, sendo comum tanto a adoção imediata de intervenções físicas no espaço, como a elaboração dos códigos e posturas que serviram de base para a atual legislação urbana. No século seguinte, ganharam notoriedade as práticas de reorganização territorial de usos e atividades, seguindo os princípios do urbanismo modernista (Le Corbusier, 1993) e do conceito de “comprehensive planning" (Kelly, 2010) que, já na década de 1910, englobava três fatores, a saber: (I) a inclusão de toda a área sujeita à jurisdição do governo local, responsável pelo exercício de planejamento; (II) a inclusão de todos os aspectos relacionados ao desenvolvimento físico da comunidade, tangenciando questões de uso do solo, transportes, meio ambiente, dentro outros; e (III) um horizonte de longo-prazo. Consequentemente, ainda na primeira metade do século XX, surgiram experiências como: propostas de zoneamento em cidades norte-americanas (Nobre, 2006); projetos de melhoramento, embelezamento e extensão em cidades francesas (Azevedo e Costa, 2013); e o desenvolvimento de grandes planos urbanos para algumas cidades da América Latina - o Plano Agache no Rio de Janeiro de 1930 e o Plano Diretor de Buenos Aires em 1937 são alguns exemplos (Filgueiras Gomes, 2009). À nível nacional, é possível constatar que o planejamento e a legislação urbana atingiram suas expressões máximas através da consolidação dos Planos Diretores, objeto de discussão da próxima seção.

\section{O PAPEL DO PLANO DIRETOR ENQUANTO INSTRUMENTO URBANÍSTICO}

É sabido que o Plano Diretor consiste em um dispositivo legal mais abrangente que as propostas de zoneamento experimentadas por algumas cidades. Enquanto instrumento isolado, o zoneamento se refere exclusivamente ao controle do uso e da ocupação do solo por meio de parâmetros construtivos e da adequação dos usos à cada uma das zonas definidas para a cidade. Já o Plano Diretor, na qualidade de lei municipal, incorpora o zoneamento em seu texto e propõe-se a tratar de todas as questões fundamentais de uma cidade - incluindo aquelas relacionadas aos transportes, ao saneamento, meio-ambiente, à educação, economia, moradia etc. (Villaça, 2005). Por essa razão, a jurisdição nacional reconhece o Plano Diretor como “o instrumento básico da política de desenvolvimento e expansão urbana" (Brasil, 2001, p. 33) e, dada a sua importância, determina o seu conteúdo mínimo obrigatório: 
Art. 42. 0 plano diretor deverá conter no mínimo: I - a delimitação das áreas urbanas onde poderá ser aplicado o parcelamento, edificação ou utilização compulsórios, considerando a existência de infraestrutura e de demanda para utilização, na forma do art. 5o desta Lei; II - disposições requeridas pelos arts. 25, 28, 29, 32 e 35 desta Lei; III - sistema de acompanhamento e controle. (BRASIL, 2001, p. 34)

Importante esclarecer que os artigos citados na lei acima remetem a outros instrumentos urbanísticos que, assim como o Plano Diretor, também foram regulamentados pela Lei № 10.257 de 10 de junho de 2001 Estatuto da Cidade (EC). Isto posto, percebe-se que a atual legislação urbana brasileira atribui a esse dispositivo um caráter normativo, não sendo o seu papel essencial o elenco de obras e intervenções no tecido urbano. Contudo, deve-se reconhecer que, na prática, os planos diretores assumiram essa função, sendo bastante comum a presença de propostas de intervenção viária, principalmente, nos textos que precedem o EC e, por essa razão, foram elaborados a partir de uma concepção diferente do próprio plano. Vale ressaltar que as alternativas que foram sendo propostas e, oficialmente registradas pelos planos diretores, nunca tiveram a obrigação legal de serem executadas. Isso porque, dentre outras razões, impor um conjunto de obras a uma determinada gestão significaria ferir a prerrogativa de autonomia do Executivo (Villaça, 2005). Dessa forma, tais propostas podem ser compreendidas como meras sugestões.

Em perspectiva histórica, percebe-se que tais planos, até o período imediatamente posterior à revolução de 1930, sofreram os reflexos das mudanças socioeconômicas da época e passaram a pensar a cidade como um todo (Deák E Schiffer, 1999). Esta tendência já vinha sendo expressa nas práticas internacionais, na forma dos "comprehensive planning". Planos desta época eram fortemente propositivos, como será observado adiante no estudo de caso. Isto muda após a década de 1970, quando os planos diretores começam a perder complexidade e rebuscamento técnico, estabelecendo-se como planos singelos, voltados mais para a determinação de diretrizes e objetivos do que para a proposição de soluções (Villaça, 1999).

\section{ESTUDO DE CASO: OS PLANOS DIRETORES DE FORTALEZA}

No Brasil, a ideia do planejamento com abrangência municipal existe, pelo menos, desde 1930, em virtude da elaboração do Plano Agache para a cidade do Rio de Janeiro. Segundo consta em Villaça (2005), foi nesse documento que o termo "plano diretor" apareceu pela primeira vez em uma legislação brasileira. Desde então, a ideia de se considerar a escala territorial de um município para fins de planejamento se tornou uma estratégia amplamente utilizada no País, sobretudo, quando se trata de capitais ou metrópoles em geral. No caso de Fortaleza, o primeiro plano diretor data de 1963 e, até o presente momento, foram aprovados outros três documentos de mesma natureza. De maneira geral, cada um desses textos apresenta propostas para o sistema viário da cidade, embora seja notória a transformação do plano diretor em um instrumento cada vez mais normativo, como discutido anteriormente. Dito isso, com o intuito de verificar até que ponto os esforços de planejamento urbano (aqui representados unicamente pelos planos diretores) são considerados pelos dirigentes municipais, analisa-se os quatro documentos supracitados, tendo como critério apenas a exequibilidade das proposições viárias e não o alcance dos objetivos traçados.

\subsection{MÉTODO DE INVESTIGAÇÃO}

Para verificar a exequibilidade das propostas contidas nos planos, as seguintes etapas foram seguidas: I Levantamento de bases cartográficas (atual e anteriores); II - Levantamento das propostas de intervenção para o sistema viário, a partir da leitura dos planos; III - Busca e reconhecimento das propostas a partir da comparação entre bases cartográficas distintas e da medição das caixas viárias por intermédio de imagens aéreas obtidas pelo Google Earth Pro; IV - Mapeamento das propostas e das obras realizadas, utilizando o software QGIS Desktop 3.4.9. Importante mencionar que a leitura de outros documentos, como decretos e notícias, tornou-se fundamental para a espacialização das propostas, dada a mudança na nomenclatura de algumas vias. Além disso, como será observado adiante, as propostas realizadas foram classificadas como parcial ou totalmente executadas, independente do momento de sua execução. 


\subsection{ANÁLISE DOS PLANOS DIRETORES}

\subsubsection{PLANO DIRETOR DE FORTALEZA (1963)}

O Plano Diretor de Fortaleza de 1963, elaborado pelo urbanista Hélio Modesto, foi aprovado pela Lei № 2.128, de 20 de março de 1963. Representou o primeiro plano de diagnóstico e expansão da cidade, a partir de seu centro comercial, a apresentar uma abordagem integradora de aspectos econômicos, sociais e administrativos dentro de uma mesmo esforço de planejamento (Lima, 2013). Tendo como horizonte os vinte anos seguintes, o plano contemplou proposições de zoneamento, sistemas de transporte (viário, ferroviário, aéreo e marítimo), equipamentos básicos (como sistema de abastecimento de água e energia) e de caráter social (religioso, recreativo e de saúde), e etc. No que concerne ao sistema viário, destacam-se: prolongamento e alargamento de vias existentes, criação de vias que convergem em direção ao centro da cidade e a implantação das chamadas "praças de circulação" cujo principal objetivo, de acordo com o próprio plano, era distribuir o tráfego proveniente das vias de penetração. Abaixo, apresenta-se a espacialização de algumas dessas propostas.

Figura 1: Análise das propostas do Plano Diretor de 1963 para o sistema viário, (A) Vias propostas e (B) Vias construídas.

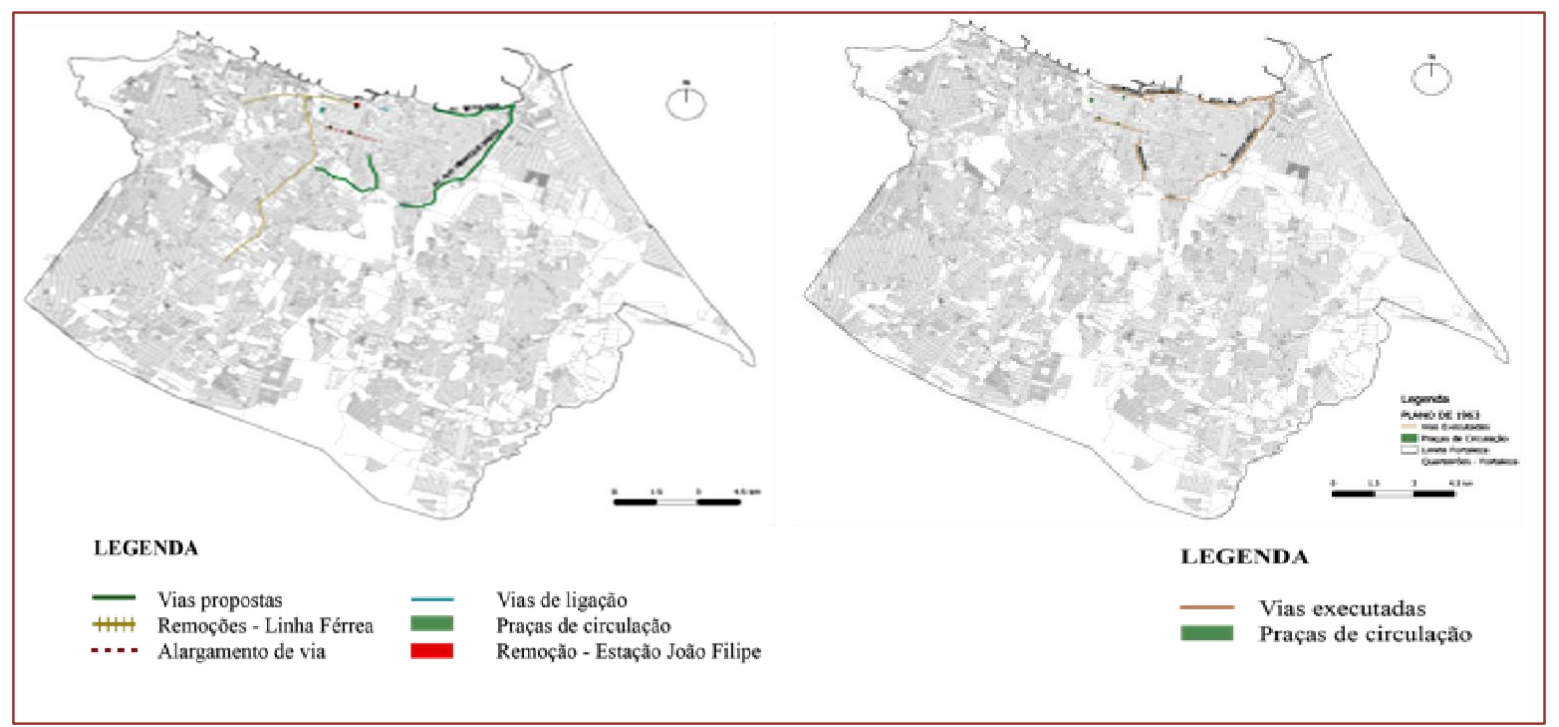

Fonte: Produção autoral.

Conforme observamos, em comparação às vias demarcadas no plano diretor (Figura 1-A), as vias que de fato foram executadas (Figura-B) somam um total de seis propostas, às quais ainda se acrescentam a construção das praças de circulação, que podem ser compreendidas como espécies de terminais de pequeno porte. Ao analisarmos a classificação atual das vias que foram executadas (Tabela 1), nota-se que as mesmas possuíram grande impacto na malha viária: o equilíbrio entre as proposições concluídas é um destaque, nas quais 34\% são vias expressas e outros 34\% são vias arteriais II, conforme classificação disponível na Lei de Parcelamento, Uso e Ocupação do Solo - LUOS.

Tabela 1: Percentuais das vias construídas por tipo, conforme a atual classificação viária para o Plano Diretor de 1963

\begin{tabular}{|l|c|}
\hline \multicolumn{1}{|c|}{ Tipo } & Percentual (\%) \\
\hline Via Expressa & $34 \%$ \\
\hline Via Arterial I & $34 \%$ \\
\hline Via Arterial II & $16 \%$ \\
\hline Via Local & $16 \%$ \\
\hline
\end{tabular}

Fonte: Produção autoral 


\subsubsection{PLANO DIRETOR DE FORTALEZA (1975)}

O Plano Diretor de 1975, aprovado pela Lei no 4.486 de 27 de fevereiro de 1975, foi um plano elaborado por meio de um consórcio entre: Serete S/A, S.D. Consultoria e Jorge Wilheim Arquitetos Associados. Enquanto planejamento estratégico, abrangeu além da cidade de Fortaleza, os outros municípios da região metropolitana e enfatizou propostas tanto de uso e ocupação do solo, como para o sistema viário. As propostas para esse último sistema são, em sua maioria, obras de alargamento de vias, expressando uma tentativa de adequar a rede viária existente à previsão de uma futura demanda. Vale salientar que essa adequação esteve atrelada à determinação da classificação viária, que trouxe as definições de vias expressas, arteriais e coletoras. Observando a espacialização dessas propostas (Figura 2), nota-se a intenção de facilitar os deslocamentos entre o centro da cidade de Fortaleza, que concentrava a maior parte das atividades urbanas, e os demais municípios da região metropolitana.

Figura 2: Análise das propostas do Plano Diretor de 1975 para o sistema viário, (A) Vias propostas e (B) Vias construídas.

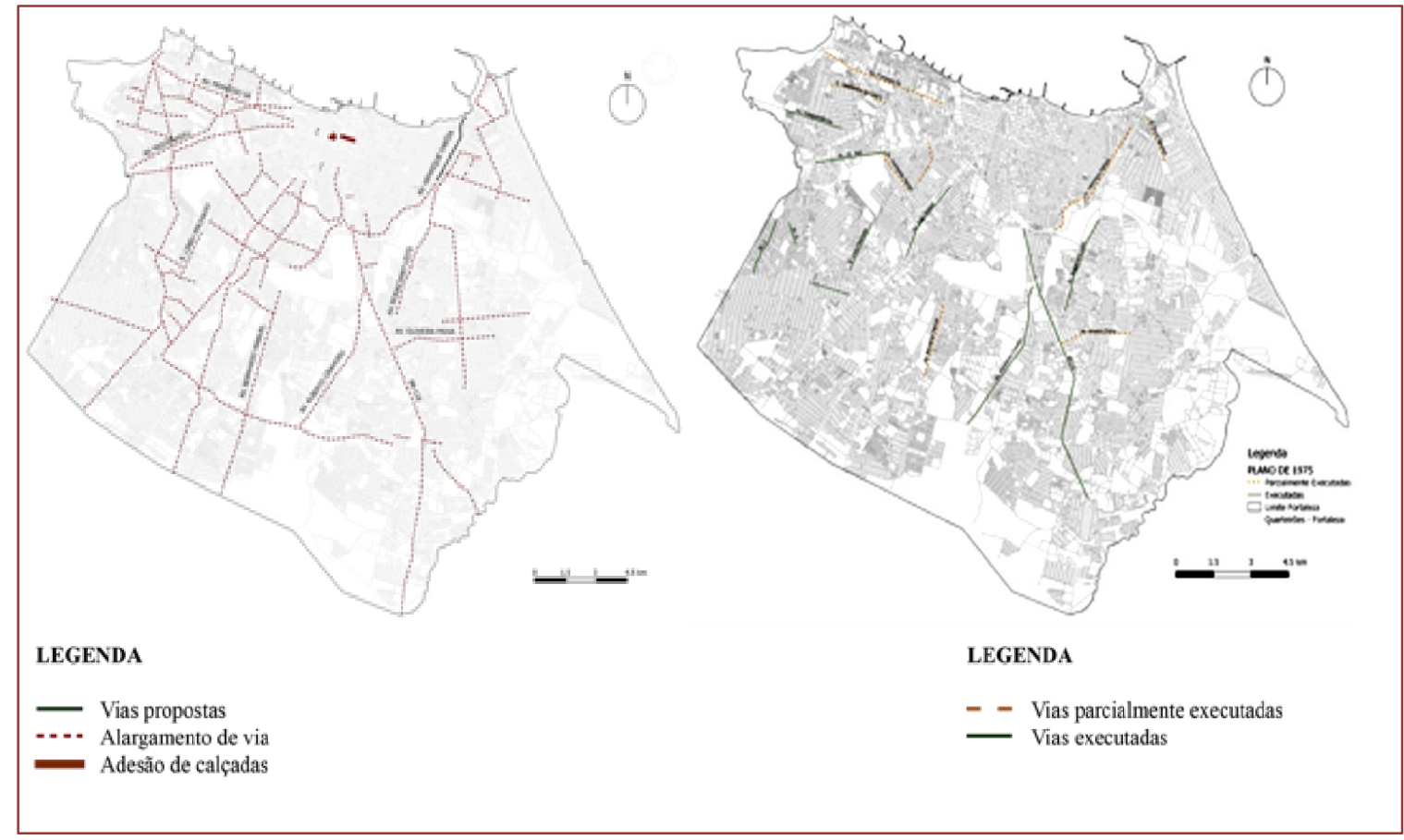

Fonte: Produção autoral.

Levando em consideração as propostas que não foram executadas tal como sugerido pelo plano, em termos de dimensionamento das vias, a Figura 2-b classifica as modificações em dois tipos: as parcialmente executadas e totalmente executadas. Em algumas regiões, é possível perceber conexões entre as vias alargadas, e em outras nota-se o alargamento de vias isoladas, como é o caso das avenidas João Pessoa, Lineu Machado e Alberto Craveiro. Importante mencionar ainda as chamadas "alterações especiais", que previam tanto o alargamento de vias quanto a adesão de calçadas, visando uma melhoria na acessibilidade universal. Em comparação com a situação anterior, percebe-se um maior número de vias construídas em termos absolutos. Com a classificação atual, baseadas na Lei de Parcelamento, Uso e Ocupação do Solo - LUOS, observamos que a maioria das proposições são de vias que hoje são consideradas coletoras, reiterando a preocupação com o tráfego proveniente das vias de maior capacidade, assim como fez o Plano de 1963. Em seguida, têm-se as vias arteriais I (34\%) e vias expressas (17\%), como as vias mais importantes e de números expressivos já implantadas. 
Tabela 2: Percentuais das vias construídas por tipo, conforme a atual classificação viária para o Plano Diretor de 1975

\begin{tabular}{|l|c|}
\hline \multicolumn{1}{|c|}{ Tipo } & Percentual (\%) \\
\hline Via Expressa & $17 \%$ \\
\hline Via Arterial I & $34 \%$ \\
\hline Via Arterial II & $6 \%$ \\
\hline Via Local & $4 \%$ \\
\hline Via Coletora & $39 \%$ \\
\hline \multicolumn{2}{|c|}{ Fonte: produção autoral } \\
\hline
\end{tabular}

\subsubsection{PLANO DIRETOR DE DESENVOLVIMENTO URBANO (1992)}

O Plano Diretor de Desenvolvimento Urbano (PDDU-FOR) foi aprovado pela Lei Municipal № 7.061, de 16 de janeiro de 1992, durante a gestão do então prefeito Juraci Vieira de Magalhães. Substancialmente, esse plano definiu tanto o ordenamento das funções urbanas, como as diretrizes gerais e setoriais de desenvolvimento, tendo como objetivo a viabilização da política urbana, estabelecida pela Constituição de 88, no horizonte do ano 2000. Seu conteúdo foi dividido em três títulos principais, os quais foram segmentados em capítulos e estes, em seções. No que concerne à temática central deste trabalho, destacase que as questões relacionadas ao sistema viário aparecem, inicialmente, no capítulo "Da estrutura urbana" para a definição de dois subsistemas:

Art. 33 - O Sistema Viário do Município será composto de dois subsistemas:

I - o estrutural constituído de eixo e anéis expressos, arteriais, vias ferroviárias convenientemente interconectadas e espaçadas, tendo como função o aumento e a uniformização da acessibilidade em toda a área, possibilitando a ordenação da estrutura urbana, a dinamização da economia, a melhoria da qualidade do meio ambiente, a conexão com vias metropolitanas e regionais, a ligação de área de geração de tráfego e de pólos de atividades e a racionalização de rotas de transporte coletivo e de carga, conforme consta indicado no anexo I desta Lei;

II - o de apoio, formado por vias comerciais, coletoras e locais convenientemente interconectadas com o subsistema estrutural, tendo como função dar suporte ao desenvolvimento das áreas onde estão inseridas. (FORTALEZA, 1992, p 50-51)

O tema volta a ser abordado apenas no nono capítulo do plano, momento em que são definidas as "Diretrizes para o Sistema de Circulação e Transporte". Vale salientar que, ao longo do texto, não se menciona nenhum tipo de intervenção ou obra viária, o que corrobora o entendimento de Villaça (1999) sobre a perda do caráter propositivo dos planos diretores, como foi mencionado anteriormente. As poucas propostas que constam no material podem ser identificadas em seu Anexo I, onde são apresentadas as vias do subsistema estrutural. Na Figura 3, essas ligações encontram-se espacializadas no território de Fortaleza, com exceção de uma, cujas referências não foram suficientes para a sua localização. 
Figura 3: Análise das propostas do PDDU-FOR para o sistema viário, (A) Vias propostas e (B) Vias construídas.

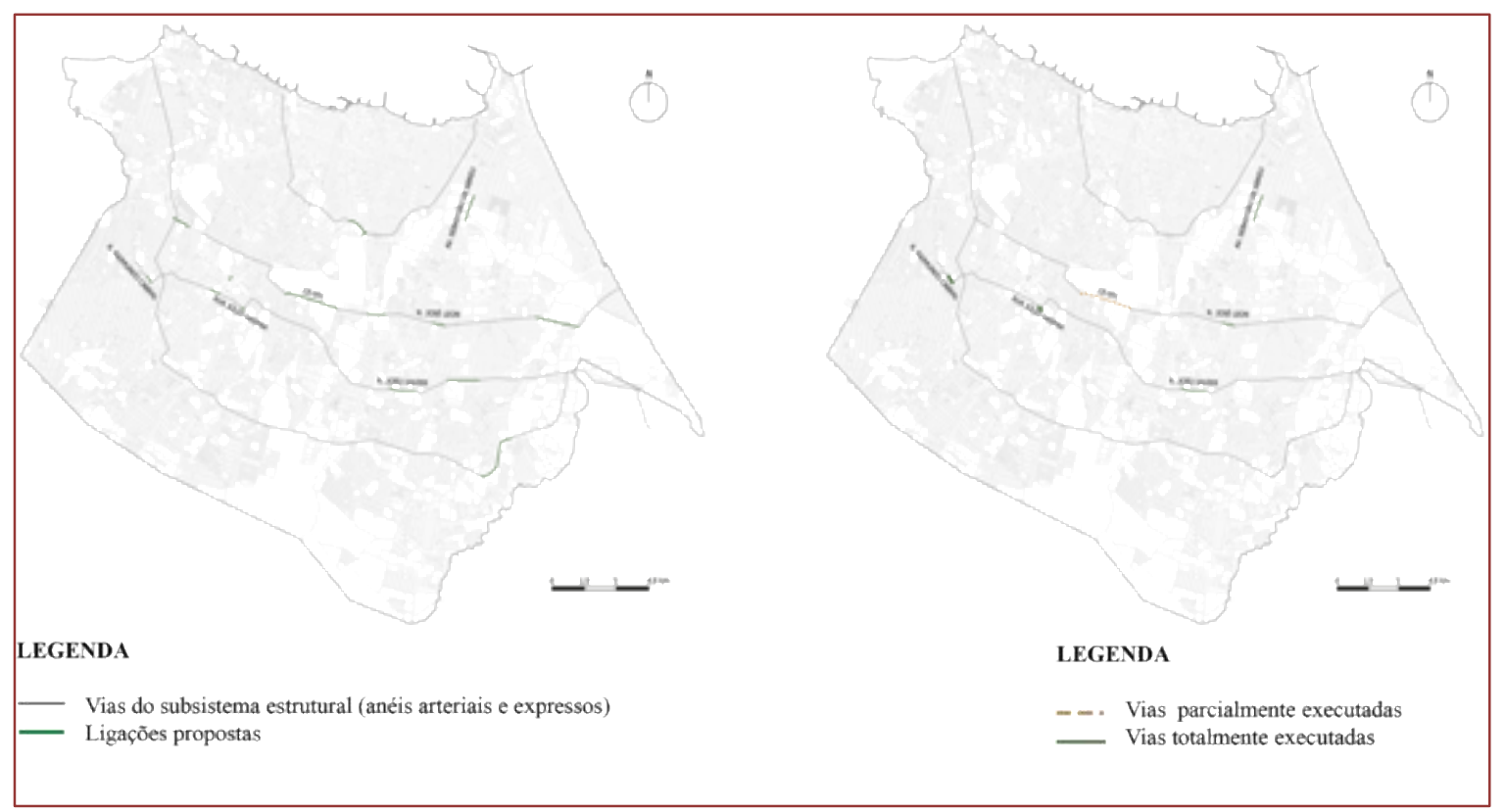

Fonte: Produção autoral.

Como pode ser observado, das 14 vias espacializadas acima (Figura 1-A), apenas 6 foram construídas (B) uma em caráter parcial, já que os dois extremos previstos para esse trecho acabaram não sendo conectados. Dada a incerteza proveniente da via não encontrada, pode-se dizer que foram executadas de 40 a $46 \%$ das intervenções propostas pelo plano (parcial ou totalmente). Importante mencionar que o documento não trouxe a classificação das vias pertencentes ao subsistema de apoio e tampouco apresentou propostas para o mesmo. Somente anos mais tarde, com a aprovação da Legislação de Parcelamento, Uso e Ocupação do Solo - LUOS (1996) é que essa categorização foi devidamente concluída. A Tabela 3 mostra o percentual de cada tipo das ligações construídas, de acordo com a lei supracitada que vigora até os dias atuais. A partir disso, é possível constatar que mais de 60\% das proposições identificadas se referem a vias que, hoje, são consideradas coletoras ou arteriais.

Tabela 3: Percentuais das vias construídas por tipo, conforme a atual classificação viária para o Plano Diretor de 1992

\begin{tabular}{|l|c|}
\multicolumn{1}{|c|}{ Tipo } & Percentual (\%) \\
\hline Local & 16,5 \\
\hline Coletora & 33,5 \\
\hline Arterial & 33,5 \\
\hline Paisagística & 16,5 \\
\hline Expressa & 0 \\
\hline \multicolumn{2}{|c|}{ Fonte: produção autoral } \\
\hline
\end{tabular}

\subsubsection{PLANO DIRETOR PARTICIPATIVO DE FORTALEZA (2009)}

O Plano Diretor Participativo de Fortaleza (PDP-FOR) foi aprovado pela Lei Complementar № 062, de 02 de fevereiro de 2009, durante a segunda gestão da então prefeita Luizianne Lins. À época, o desenvolvimento desse plano representou o atendimento não só às disposições da Constituição/88, mas também às do Estatuto da Cidade (EC), publicado em 2001. Vale mencionar que o PDP-FOR desempenhou um papel simbólico no que diz respeito à garantia da participação popular, já que foi elaborado após a tentativa de 
aprovação do Plano Diretor de Desenvolvimento Urbano e Ambiental (PDDUA-FOR), um documento contestado justamente pela ausência de metodologia participativa (MACHADO, 2010).

No que diz respeito à rede viária, o PDP-FOR a menciona em seus objetivos gerais, colocando-a como um instrumento de promoção da acessibilidade e da mobilidade universal (FORTALEZA, 2009). Ainda no segundo título do documento, no capítulo "Da Política de Mobilidade", são definidas algumas ações estratégicas que, em verdade, podem ser compreendidas como medidas administrativas ou simplesmente como pretensões, e não como propostas espacializadas no território. Determinou-se também a elaboração do "Plano Diretor de Mobilidade Urbana de Fortaleza" cujo processo deveria ser finalizado no prazo de dois anos. Adiante, no capítulo "Do Sistema de Mobilidade Urbana", declara-se que outra lei municipal seria responsável por redefinir a classificação do sistema viário, não sendo listadas possíveis alterações ou propostas de novas ligações viárias. Importante destacar que a referida lei não foi aprovada e, por essa razão, a classificação da LUOS de 1996 só foi substituída em 2017, com a publicação da Lei Complementar № 236, de 17 de agosto de 2017 - Parcelamento, Uso e Ocupação do Solo.

De forma geral, é possível classificar o PDP-FOR como um plano de caráter normativo, voltado mais para a definição de diretrizes, medidas administrativas, zonas e parâmetros de ocupação. No que tange à rede viária, nota-se não só a redução da natureza propositiva, como também a fragmentação do exercício de planejamento, com as sugestões de planos e leis complementares como as citadas acima. Por essa razão, diferente das análises anteriores, esta não apresenta o mapa das intervenções propostas e, tampouco, das obras que foram executadas. Porém, tendo em vista a qualidade ininterrupta do processo de produção de uma cidade, apresenta-se, na Tabela 4, outros planos e esforços que, de alguma forma, exerceram influência sobre o traçado urbano de Fortaleza.

Tabela 4: Outros planos e medidas com influência sobre o traçado de Fortaleza

\begin{tabular}{|c|l|}
\hline Data & \multicolumn{1}{c|}{ Plano/ Programa } \\
\hline 2008 & Programa de Transporte Urbano de Fortaleza (Transfor) \\
\hline 2012 & Pacote da Copa Mobilidade Urbana \\
\hline 2013 & Plano de Ações Imediatas em Transporte e Trânsito de Fortaleza (PAITT) \\
\hline 2015 & Plano de Mobilidade de Fortaleza - PlanMob \\
\hline 2016 & Plano Fortaleza 2040 \\
\hline 2018 & Projeto Novo Centro \\
\hline
\end{tabular}

\section{CONSIDERAÇÕES FINAIS}

Assumindo o planejamento urbano enquanto forma de intervenção sistêmica no espaço, é possível atribuir a sua importância a duas qualidades que são intrínsecas ao sistema cidade: a complexidade e a interconectividade entre seus componentes. Assim, o ato de se planejar pode ser compreendido como um esforço multidisciplinar que carece do emprego da racionalidade humana na forma de método sistêmico, já que trata de um fenômeno complexo como o urbano. Além disso, torna-se necessário evidenciar o aspecto mediatório existente nesse processo, tendo em vista os diversos atores que participam da produção do espaço. Nesse sentido, os Planos Diretores (aqui entendidos como produtos dos esforços de planejamento), exemplificam essa discussão na medida em que pretendem reconhecer os conflitos entre esses agentes, bem como tratar dos diversos subsistemas urbanos. Na qualidade de instrumento legal, atribui-se a ele a definição de medidas compulsórias (usos permitidos, parâmetros construtivos etc.), bem como o delineamento dos objetivos estratégicos gerais e específicos a cada subsistema. Vale salientar que esses objetivos devem ser considerados por qualquer tipo de esforço complementar de planejamento municipal, à exemplo dos planos de mobilidade.

Analisando os planos elaborados para o contexto de Fortaleza, percebe-se que historicamente esses textos apresentavam um elenco de obras relacionadas à rede viária. Contudo, de acordo com os resultados obtidos, é possível verificar um descompasso entre aquilo que foi proposto e o que, de fato, foi executado, existindo algumas repetições entre os planos, como no caso da proposta de construção da Av. Almirante Henrique Sabóia. 
Dessa forma, conclui-se que os planos diretores exerceram uma influência razoável sobre as práticas adotadas pelas gestões municipais no âmbito da infraestrutura viária. Além disso, como pôde ser observado nos planos, existiu uma tendência de priorização das obras e intervenções em vias coletoras, indicando uma tentativa de distribuição do tráfego existente nas vias estruturais.

\section{REFERÊNCIAS}

[1] Azevedo, M. N. S.; Costa, M. S. (2013) O Urbanismo do início do século XX: a escola francesa de urbanismo e suas repercussões no brasil: trajetórias de Alfred Agache e Attilio Correa lima. Revista Urbana, v. 5, n. 7, p. 64-97

[2] Brasil (2001). Lei 10.257/2001- Regulamenta os arts. 182 e 183 da Constituição Federal, estabelece diretrizes gerais da política urbana e dá outras providências. Brasília, DF.

[3] Brasil (2004) Política Nacional de Desenvolvimento Urbano - Cadernos MCidades no 1 - SeMob, Ministério das Cidades, Brasília, DF.

[4] Choay, F. (2015). O Urbanismo: Utopias e realidades, uma antologia (7o ed). Perspectiva, São Paulo, SP.

[5] Costa, L. C. (1994) Plano Diretor: Um Personagem à Procura de seus Autores. Tese de Doutorado apresentada à Faculdade de Arquitetura e Urbanismo da Universidade de São Paulo, São Paulo, SP.

[6] Déak, C.; Schiffer, S. R. (1999) O Processo de Urbanização no Brasil. Ed. Universidade de São Paulo, São Paulo.

[7] Filgueiras Gomes, M. A. A. (2009) Urbanismo na América Latina: circulação de ideias e constituição do campo, 1920-1960. (1º ed). EDUFBA, Salvador, BA. Disponível em: http://books.scielo.org. Acesso em: 16 abr. 2020.

[8] Fortaleza (1992). Lei no 7061, de 16 de janeiro de 1992. Aprova o Plano Diretor de Desenvolvimento Urbano de Fortaleza - PDDU-FOR e dá outras providências. Fortaleza, CE: Prefeitura Municipal de Fortaleza, 16 jan. 1992.

[9] Fortaleza (2009). Lei no 062, de 02 de fevereiro de 2009. Institui o Plano Diretor Participativo do município de Fortaleza e dá outras providências. Fortaleza, CE: Prefeitura Municipal de Fortaleza, 13 abr. 2009.

[10] Gouvêa, L. A. (2008). Cidade Vida: Curso de Desenho Ambiental Urbano. Nobel, São Paulo, SP

[11] Holanda, N. (1982) Planejamento e projetos. Universidade Federal do Ceará, Fortaleza, CE.

[12] Instituto Pólis (2001). Estatuto da cidade: guia para implementação pelos municípios e cidadãos: Lei n. 10,257, de 10 de julho de 2001, que estabelece diretrizes gerais da política urbana. Instituto Pólis, Brasília, DF.

[13] Kelly, E. D. (2010). Community Planning: an introduction to the comprehensive plan (2. ed). Island Press, Washington, DC, USA.

[14] Le Corbusier (1993). A Carta de Atenas. HUCITEC-EDUSP, São Paulo, SP.

[15] Lima, T. M. P. (2013). Planos de Bairro: Experiências Europeias e Potenciais Lições para o Contexto Português. Dissertação (Mestrado). Universidade de Lisboa, Lisboa, PT.

[16] Lima, S. M. S. A., Lopes, W. G. R., \& Façanha, A. C. (2019). Desafios do planejamento urbano na expansão das cidades: entre planos e realidade. urbe. Revista Brasileira de Gestão Urbana, 11, e20190037. https://doi.org/10.1590/2175-3369.011.e20180037

[17] Levy, J. M. (2016) Contemporany Urban Plan (11. ed). Routledge, New York, NY.

[18] Lopes, A. S. (2015) Transportes, uso do solo e atividades: modelagem conceitual para o planejamento da acessibilidade urbana. Tese (Doutorado em Engenharia de Transportes). Universidade Federal do Ceará, Fortaleza, CE.

[19] Lopes, A. S. e Loureiro, C. F. G. (2012) Dimensões do Planejamento Urbano Integrado: Revisão Histórica e Discussão Conceitual. In: PLURIS 5o Congresso Luso Brasileiro para o Planejamento Urbano Regional Integrado e Sustentável, 2012, Brasília, DF.

[20] Machado, E. G (2010) Planejamento Urbano, Democracia e Participação Popular: O caso da revisão do Plano Diretor de Fortaleza (2003 a 2008). Tese (Doutorado em Sociologia). Universidade Federal do Ceará, Fortaleza, CE.

[21] Magalhães, M. T. Q. e Yamashita, Y. (2009) Repensando o Planejamento. Centro de Formação de Recursos Humanos em Transportes - CEFTRU, Universidade de Brasília, DF.

[22] Matus, C. (1984) Política y Plan. IVEPLAN, Caracas, DC, VEN.

[23] Matus, C. (1991) O Plano como Aposta. In: São Paulo em perspectiva 5(4): 28-42, Out/Dez. São Paulo, SP.

[24] Nobre, E. A. C. (2006) 0 ideário urbanístico e a legislação na cidade de São Paulo: do código de posturas ao estatuto da cidade. Anais do Seminário de História da Cidade e do Urbanismo, ANPUR, São Paulo, v-9, p. 1-16.

[25] Singer, P. (1995) O Plano Diretor de São Paulo, 1989-1882: A política do Espaço Urbano. In: Magalhães, M. C. Na Sombra da Cidade. Editora Escuta Ltda., São Paulo, SP. 
[26] Soares, F. D. P (2014). Proposta Metodológica de Compreensão da Problemática das Relações entre Uso do Solo e Transportes no Planejamento Urbano Integrado. Dissertação (Mestrado em Engenharia de Transportes). Universidade Federal do Ceará, Fortaleza, CE.

[27] Sokolowsky, J. A.; Banks, C. M. (2009) Principles of modeling and simulation: A multidisciplinary approach. John Wiley \& Sons Inc., New Jersey, USA.

[28] Sposito, M. E. B. (2017) Capitalismo e Urbanização (16. ed). Contexto, São Paulo.

[29] Souza, M. L. (2002) Mudar a cidade: uma introdução crítica ao planejamento e gestão urbanos. Ed. Bertrand Brasil, Rio de Janeiro, RJ.

[30] Souza, M. L. de (2010) Mudar a cidade: uma introdução crítica ao planejamento e gestão urbanos. 6ª ed. Ed.: Bertrand Brasil, Rio de Janeiro, RJ.

[31] Teixeira, M. A. A. (2016) Utopia como método: a reconstituição imaginária da sociedade. Sociedade e Estado, v. 31, n. 1, p 261-265. FapUNIFESP (SciELO), São Paulo, SP. http://dx.doi.org/10.1590/s0102-69922016000100013.

[32] Vargas; H. C.; Castilho, A. L. H. (2015) Intervenções em centros urbanos: objetivos, estratégias e resultados (3. ed.). Ed. Manole, Barueri, SP.

[33] Villaça, F. (1999) Uma contribuição para a história do planejamento urbano no Brasil. In: Deák, C; Schiffer, S. R. (1999) 0 processo de urbanização no Brasil. EdUSP, São Paulo, SP.

[34] Villaça, F. (2005) As Ilusões do Plano Diretor (1. ed.). Edições do Autor, São Paulo, SP.

[35] Van Wee, B. (2002) Land use and transport: Research and policy challenges. Journal of Transport Geography, v. 10, n. 4 , p. $259-271$ 


\section{Capítulo 7}

Caracterização de pedestres obedientes e oportunistas em travessias semaforizadas de Fortaleza

\section{Kaio Gefferson de Almeida Mesquita}

Francisco Altanizio Batista de Castro Júnior

Moisés Gomes de Holanda Cunha

Resumo: 0 crescente aumento da taxa de motorização em países em desenvolvimento aumentou o risco de acidentes para usuários de modos de transporte vulneráveis, como os pedestres. Nesse sentido, este trabalho tem como objetivo caracterizar o comportamento dos pedestres obedientes e oportunistas em travessias semaforizadas de Fortaleza. Para realizar essa caracterização foram utilizados dados coletados através de vídeos gravados pelas câmeras de monitoramento da Prefeitura do município. Foram selecionadas travessias estratégicas, que possuem um maior fluxo de pedestres e de carros. Hipóteses foram testadas a fim de conhecer melhor o fenômeno a ser estudado. Para os testes dessas hipóteses foram utilizadas ferramentas como: tabela de contingência, teste chi-quadrado, análises descritivas e modelo logit. Os resultados revelam que não há correlação de dependência entre o sexo dos pedestres e o seu comportamento, mas há uma maior tendência de pedestres com faixa etária avançada serem mais obedientes. 


\section{INTRODUÇÃO}

De acordo com a Organização Mundial de Saúde, uma estratégia chave para alcançar um sistema seguro é minimizar os conflitos entre pedestres e veículos. Nesse contexto, a avaliação dos riscos de colisão entre pedestres e automóveis oferece uma ferramenta poderosa e informativa nos regimes de planejamento urbano e pode ser aproveitada para informar o posicionamento adequado de melhorias e projetos de tratamento para melhorar a segurança dos pedestres (MURPHY et al., 2017).

Segundo Zhang (2005), acidentes de trânsito envolvendo pedestres tornaram-se um grande problema de segurança em todo o mundo, principalmente nos países em desenvolvimento, como o Brasil, devido à alta densidade populacional, rápida urbanização e falta de aderência às regras de trânsito por motoristas e pedestres. As estatísticas indicam que um terço dos acidentes de trânsito em todo o mundo envolvem pedestres, os quais têm a gravidade definida predominantemente pela velocidade veicular conflitante no momento de sua ocorrência. Para um veículo trafegando a $40 \mathrm{~km} / \mathrm{h}$, a distância de parada é $23 \%$ menor do que um veículo trafegando a $48 \mathrm{~km} / \mathrm{h}$, ou seja, a redução de velocidade implica que muitos acidentes podem ser evitados (WRI BRASIL, 2015).

Os pedestres em interseções semaforizadas podem ser classificados em dois tipos: os obedientes à semaforização e os oportunistas. Os oportunistas decidem realizar a travessia durante o tempo de vermelho do sinal, desrespeitando o tempo semafórico reservado à passagem de veículos e não de pedestres. Tal comportamento é influenciado por vários fatores, os quais se configuram como requisitos para sua compreensão (Liu et al., 2000; Yang et al., 2006). Jacobsen (2011) descreve que esse comportamento violador tem forte relação na movimentação dos pedestres durante os seus deslocamentos. Fatores como a velocidade de deslocamento, a qual dita tempo de travessia, e a interação com outros pedestres, que caracterizam a travessia em grupo, têm relação mútua com esse tipo de comportamento.

A compreensão do comportamento dos pedestres oportunistas é essencial em um contexto em que diversas cidades, localizadas principalmente em países de Terceiro Mundo, têm experienciado consideráveis incrementos na taxa de motorização de suas populações. De acordo com Torres et al. (2019), os investimentos em eficiência econômica muitas vezes são realizados com o intuito de melhorar a segurança dos mais vulneráveis, no caso, os pedestres. Apesar disso, nos últimos anos, os deslocamentos a pé estão se tornando cada vez mais perigosos em muitas cidades ao redor do mundo.

Diante do exposto, o objetivo desse trabalho é caracterizar o comportamento dos pedestres em oportunistas e obedientes, dentro da região centro-comercial de Fortaleza. Para contemplar esse objetivo, o trabalho está dividido em sete tópicos. Passando pela introdução e desenvolvimento da problemática, e revisão da literatura a respeito dos fatores que influenciam nesse comportamento, no tópico 2 . Nos tópicos 3, 4, 5 e 6 serão apresentado o método de análise, separados em contextualização da região de estudo, análises exploratórias e modelagem, respectivamente. Por fim, serão apresentadas as considerações finais no tópico 7 e a proposição de pesquisas complementares.

\section{FATORES QUE INFLUENCIAM O COMPORTAMENTO DE PEDESTRES}

Múltiplos fatores podem influenciar o comportamento dos pedestres nas travessias. Para Jacobsen (2011) os atributos que podem influenciar a maneira como os pedestres se movimentam podem ser subdivididos em dois grupos: i) características dos pedestres, como idade, gênero e motivo do deslocamento e ii) características do ambiente, como declividade, número de faixas e a possibilidade de conflito com outros modos em caso de travessia.

Jay et al. (2020) estudou o comportamento de hesitação e aceleração na travessia de pedestres na França e no Japão em travessias durante tempo de vermelho. Foi descoberto que existe uma tendência dos pedestres a aumentar a velocidade de caminhada quando existem mais pessoas realizando a travessia. Além disso, o estudo também evidenciou que os pedestres japoneses têm um período mais longo de incerteza e hesitam mais em violar o sinal vermelho comparados com os pedestres franceses.

Zafri et al. (2020) realizaram um estudo em Bangladesh, na cidade de Dhaka, usando um modelo de regressão logístico para encontrar os fatores que mais influenciam no comportamento de risco na travessia. Os fatores apontados foram o tipo de controle da interseção, o tamanho da via, o fluxo veicular, a brecha disponível, a idade, o número de pessoas atravessando e se atravessavam na faixa de pedestres. Esse trabalho demonstrou que pessoas mais novas têm cinco vezes mais chances de realizar uma travessia perigosa. 
Alguns estudos se concentraram na investigação da influência das características dos pedestres na travessia em tempo de vermelho em interseções semaforizadas. Bernhoft et al (2008) descobriram em seu estudo que pedestres mais velhos tendem a ser mais cautelosos que pedestres mais novos. No estudo dos autores Rosenbloom et al. (2004), pedestres do sexo masculino são mais suscetíveis a violar a sinalização do que pedestres do sexo feminino.

Estudos demonstram a influência da atitude de violação da sinalização dos fatores do ambiente construído. Esses fatores são o uso do solo, a densidade de pedestres, as condições do pavimento, existência de faixas de pedestres e canteiros (Mukherjee e Mitra, 2020; Vignali et al., 2020; Zhang et al., 2019). Outro fator importante é o tempo disponível de travessia, onde diversos estudos demonstram a sua importância (Koh e Wong, 2014; Mukherjee e Mitra, 2019, 2020; Patra et al., 2019).

Com relação às características do ambiente, Bandeira (2019) lista alguns outros atributos, além dos fatores descritos anteriormente, são eles: programação semafórica, demanda de pedestres, fluxo veicular e presença de veículos estacionados. De acordo com Yang et al. (2006) e Zhuping et al. (2011), a obediência dos pedestres está relacionada à pressa dos indivíduos e fluxo veicular baixo. É importante ressaltar que a pressa dos usuários, fluxo veicular e a presença de veículos estacionados são características que estão relacionadas com as atividades realizadas nas vizinhanças. Portanto, acredita-se que ainda é importante acrescentar uma outra característica na categoria de características do ambiente, o uso do solo na vizinhança. Outros estudos analisaram o comportamento dos pedestres pela teoria do comportamento planejado (TPB), utilizando questionários, assim, obtendo uma resposta através da percepção dos próprios usuários da via (Demir et al., 2019; Zhou et al., 2016).

\section{METODOLOGIA}

A metodologia proposta para esse trabalho consistiu em 4 fases: Contextualização, Análise Exploratória, modelagem e, por fim, considerações finais. Na primeira etapa da contextualização, foram elaboradas as hipóteses que orientam esse estudo, baseando-se na análise de revisão da literatura empreendida anteriormente, na qual essas hipóteses são apresentadas. Em seguida, os dados referentes às travessias e aos pedestres foram coletados. No final, foi efetuada uma caracterização de cada interseção do estudo quanto ao uso do solo nas adjacências e suas medidas geométricas.

A segunda fase, a Análise Exploratória, compreendeu primeiramente uma análise estatística descritiva das variáveis coletadas para então efetuar o teste de correlação estatística categórico, a fim de investigar as hipóteses elaboradas. Em seguida, na modelagem, foi efetuada por meio do modelo logit do tipo categórico, para evidenciar questões não representadas na última análise. Por fim, com base nos resultados obtidos, foram elaboradas conclusões a respeito do comportamento de travessia dos usuários. Essa proposta está ilustrada na Figura 1.

Caso não fossem encontradas evidências que corroboram com uma dada hipótese, foi considerado que não haviam evidências estatísticas significativas o suficiente para atestar a validade desta hipótese. Na última fase do estudo, a modelagem, modelos categóricos do tipo logit foram desenvolvidos para avaliar as chances dos pedestres serem oportunistas. Considerando variáveis explicativas como sexo, idade, se estava realizando a travessia sozinho ou em grupo, a velocidade de travessia e a interseção.

Duas medidas de ajuste foram implementadas para se avaliar a qualidade dos modelos logit: (i) Pseudo $\mathrm{R}^{2}$, baseado no $\mathrm{R}^{2}$ de McFadden; e (ii) teste da razão de verossimilhança, que compara a verossimilhança do modelo proposto com a do modelo restrito (nulo). Nos modelos, se adotou nível de confiança de $90 \%$ para as variáveis. A variável dependente foi o comportamento de obediência de pedestres, enquanto que as variáveis independentes foram de acordo com cada hipótese proposta sobre o fenômeno, variando de atributos individuais como gênero e idade a aspectos geométricos e de uso do solo das redondezas dos cruzamentos. As variáveis que apresentaram todas as categorias não significativas foram retiradas e novos coeficientes foram estimados. No entanto, aquelas que apresentaram pelo menos uma categoria significativa foram mantidas. 
Figura 1: Método de caracterização da obediência de pedestres em travessias semaforizadas em Fortaleza.

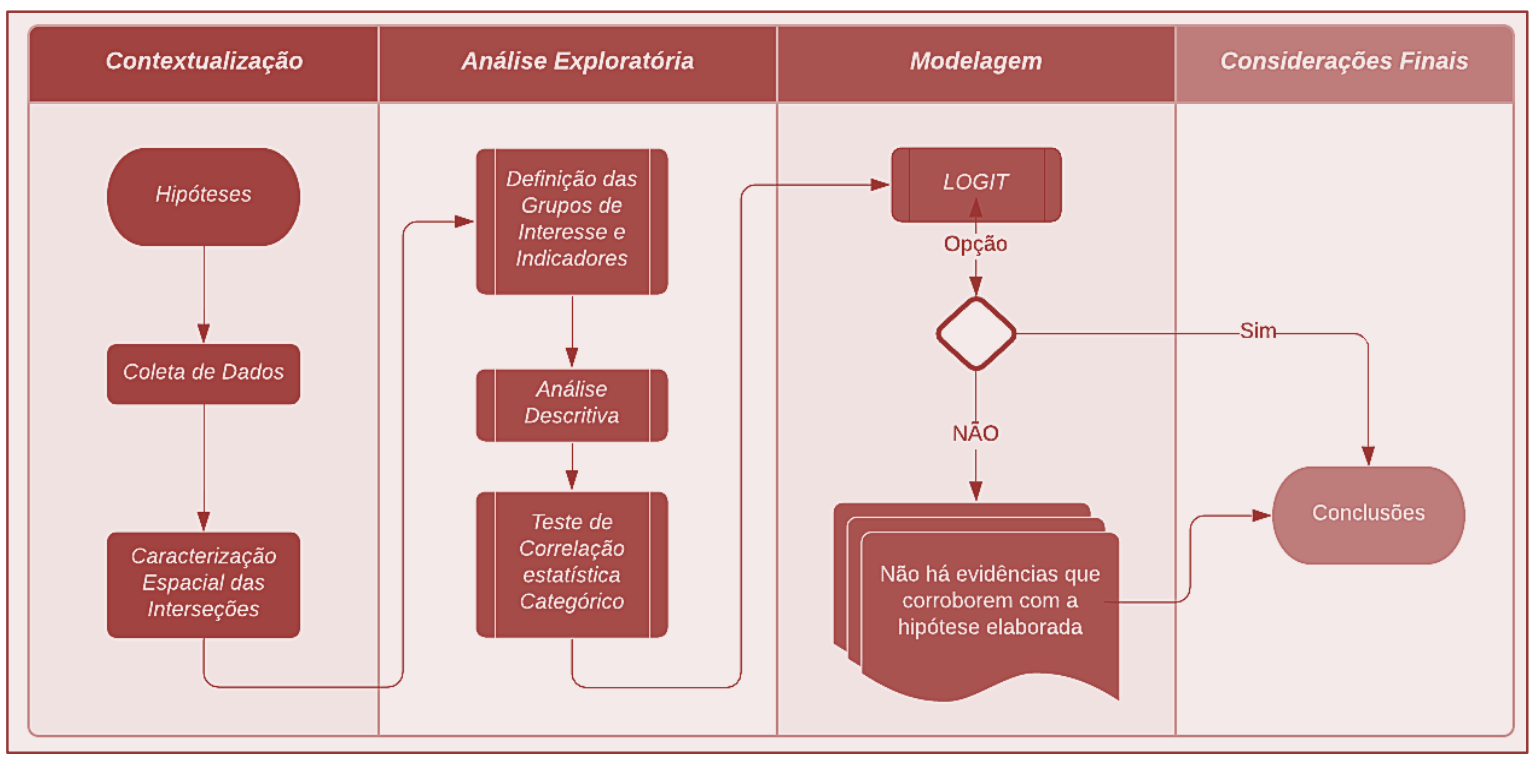

\section{CONTEXTUALIZAÇÃO}

Nessa primeira fase do estudo foram elaboradas as hipóteses que embasam as análises posteriores. Além disso, nessa etapa os dados para a investigação das hipóteses foram coletados, bem como a caracterização geométrica das interseções e das atividades que acontecem na vizinhança das interseções, analisando os usos dos lotes nas proximidades.

\subsection{HIPÓTESES SOBRE O COMPORTAMENTO DE PEDESTRES EM TRAVESSIA DE FORTALEZA}

A partir da análise de revisão da literatura deste trabalho, foram levantadas hipóteses sobre o comportamento dos pedestres obedientes e oportunistas a serem testadas a partir de ferramental estatístico. As hipóteses levantadas estão descritas a seguir:

1. Existe uma relação de dependência entre o sexo do pedestre e a obediência;

2. Quanto maior a faixa etária dos pedestres mais propenso a respeitar a sinalização;

3. Quanto maior a distância de travessia, menor é a porcentagem de pedestres oportunistas;

4. Os pedestres oportunistas tem uma velocidade de caminhada superior à dos pedestres obedientes.

As duas primeiras hipóteses dizem respeito a uma característica do pedestre, que já foram salientadas em outros estudos (Rosenbloom et al., 2004; Bernhoft et al.,2008), a fim de verificar sua validação para a região de estudo do município de Fortaleza. A terceira hipótese está relacionada a uma característica da interseção, assim como definido no estudo de Bandeira (2019). A quarta hipótese está relacionada a uma característica dos pedestres, que embora já tenha sido citado em outros estudos (Jacobsen, 2011; Zafri et al., 2020), não houve confirmação de sua influência no comportamento dos pedestres. É válido ressaltar que embora essas hipóteses tenham sido testadas em outros estudos, o fenômeno pode mudar de acordo com a região em análise. 


\subsection{COLETA DE DADOS}

Os primeiros dados a serem coletados foram os dados referentes ao comportamento dos pedestres. Estes foram coletados das câmeras de videomonitoramento do CTAFor (instituição municipal responsável por monitorar e gerenciar o tráfego e os semáforos em Fortaleza). As informações obtidas foram referentes a demanda (fluxo de pedestres por hora) durante os intervalos de coleta, padrão de chegada, atraso (segundos), formação de pelotão, tipo de travessia (durante verde, verde intermitente e vermelho) e características dos pedestres (gênero e idade). Em específico a variável de idade, foi possível identificar por meio da observação, já que as faixas etárias definidas estavam bastante espaçadas (<18; 19-59; $>59)$. Os dados foram coletados por um grupo de 8 pessoas, com contagens do período da hora pico da tarde (13:00 às 14:00), durante dias úteis de uma semana. Posteriormente foram levantados os dados de taxa de chegada, baseado no tempo de espera dos pedestres, em segundos, por contagem utilizando macros. Vale ressaltar que foram evidenciados apenas veículos individuais motorizados, ônibus e caminhões durantes o período de vermelho para os pedestres como fator de influência de travessia.

Os dados referentes ao uso do solo e à geometria das interseções foram obtidos através da base georreferenciada de uso do solo (em formato shape file) da SEFIN (Secretaria de Finanças do município de Fortaleza) e do Google Maps, onde foi possível coletar dados como largura das travessias, número de faixas e existência de canteiros, medida em metros, como largura total, por meio da ferramenta de régua do Google Earth. Por último, foi utilizada uma base de dados dos usos por lote proveniente da Secretaria de Finanças do Município, referente ao ano de 2015 para caracterizar o uso do solo nas proximidades. Vale ressaltar que após a coleta da largura de travessia e o respectivo tempo de travessia de cada pedestre, foi possível delimitar uma velocidade média por interseção.

\subsection{CARACTERIZAÇÃO ESPACIAL DAS INTERSEÇÕES}

A terceira subetapa da caracterização comportamental dos pedestres foi a contextualização preliminar dos cruzamentos, quando foi analisado aspectos geométricos dos cruzamentos e de uso do solo não-residencial nos lotes próximos às travessias, se baseando nas hipóteses de estudo relacionadas a esses atributos. A porcentagem de uso do solo não residencial, as representações dos logradouros de cada interseção, assim como o tamanho das pistas, e número de ciclofaixas estão dispostas respectivamente na Tabela 1, a seguir:

Tabela 1: Cruzamentos analisados

\begin{tabular}{|c|l|l|c|c|c|c|} 
Código & \multicolumn{1}{|c}{ Logradouro A } & \multicolumn{1}{c}{ Logradouro B } & Ciclofaixas & $\begin{array}{c}\text { Não } \\
\text { Residencial }\end{array}$ & Faixas & $\begin{array}{c}\text { Distância } \\
\text { Travessia } \\
(\mathrm{m})\end{array}$ \\
\hline C12 & Av. Dom Luís & Av. Des. Moreira & 1 & $86 \%$ & 4 & 15,75 \\
\hline C06 & Av. Dom Manuel & Av. Monsenhor Tabosa & 0 & $81 \%$ & 3 & 17,5 \\
\hline C21 & Av. da Universidade & Av. 13 de maio & 0 & $100 \%$ & 4 & 17,5 \\
\hline C31 & Av. Des. Moreira & Av. Antônio Sales & 1 & $100 \%$ & 3 & 12,5 \\
\hline C35 & Abolição & Av. Barão de Studart & 0 & $82 \%$ & 4 & 19 \\
\hline
\end{tabular}

Um aspecto interessante de ser apontado é que as interseções C06 e C31 detém uma ciclofaixa cada, alterando o espaço de travessia. Essa característica foi englobada no espaço geométrico da análise. Vale ressaltar que a região de estudo é compreendida pela zona central de Fortaleza, tendo alta monitorização e disponibilidade de dados, característica pelo forte comércio e alto fluxo de pedestres devido a concentração das atividades, estando as interseções C21 e C31 em lotes totalmente não-residenciais. A Figura 2, evidencia a divisão entre aspectos do uso do solo do centro de Fortaleza, tendo uma maior distribuição no tipo Comercial, Misto e Residencial. 
Figura 2: Distribuição do Uso do Solo na região de estudo

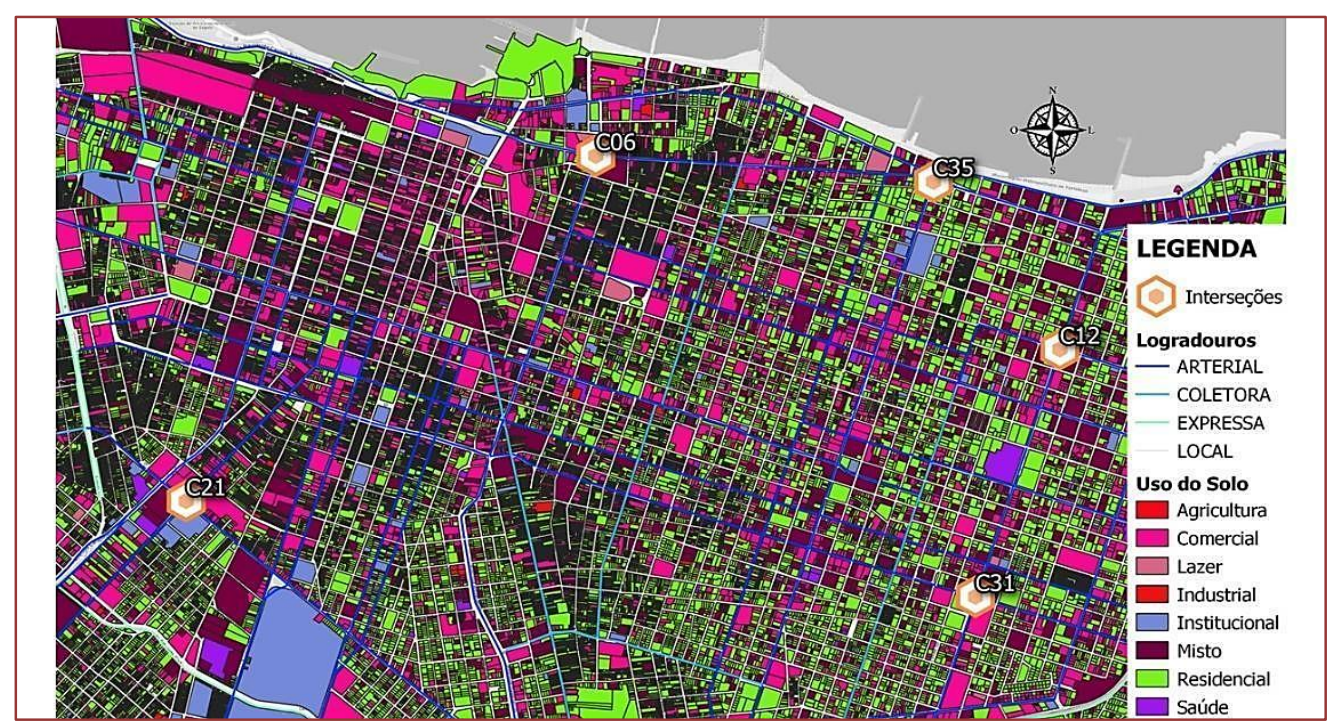

Diante dos dados acima, nota-se que o cruzamento C06, Av. Dom Manoel com Monsenhor Tabosa é o que possui maior uso residencial dentre os cruzamentos analisados. Já as interseções C21, Av. Da Universidade com Av. 13 de Maio e C31, Av. Des. Moreira com Av. Antônio Sales são os cruzamentos com a maior porcentagem de uso do solo não residencial. A proporção referente a Av. 13 de maio, provavelmente se deve ao fato desse cruzamento estar situado muito próximo ao campus do Benfica da UFC (Universidade Federal do Ceará) e ao Shopping Benfica. 0 maior comprimento de travessia encontra-se na avenida Abolição, C31, medindo aproximadamente $19 \mathrm{~m}$. A menor distância de travessia corresponde a interseção da avenida Antônio Sales com a Des. Moreira, com $9 \mathrm{~m}$ de comprimento.

Essas características, principalmente o comprimento de travessia, podem impactar em como os pedestres se comportam. Outro atributo que pode influenciar o comportamento de travessia de pedestres é o tempo semafórico, que varia conforme a interseção. Acredita-se ainda que características de distribuição espacial de atividades da vizinhança, possam, igualmente, influenciar esse comportamento, sendo essa análise prévia, portanto, essencial para a compreensão do comportamento dos pedestres.

\section{ANÁLISE EXPLORATÓRIA}

Nesta etapa de análise é preciso tornar evidente que os dados agrupados são valores amostrais, sendo delimitada como população os pedestres da região do comércio central de Fortaleza na hora pico da tarde. Nesta etapa, se fez uso de técnicas de análise estatísticas que fornecessem parâmetros para que fosse possível tomar uma decisão sobre a validade das hipóteses propostas, iniciando por uma análise descritiva, e finalizando com a criação de tabela de contingência e o teste Chi-quadrado. Essas técnicas foram selecionadas pelo fato de serem as mais adequadas para analisar variáveis do tipo categóricas. 0 teste Chiquadrado foi feito com o auxílio do software estatístico $R$ Studio.

\subsection{DEFINIÇÃO DOS GRUPOS DE INTERESSE E INDICADORES}

A primeira etapa da análise exploratória foi a definição das categorias de interesse. Isso é necessário, uma vez que as características as quais serão analisadas neste trabalho são de ordem qualitativa, e é necessário definir essas categorias primeiro, com base nas hipóteses levantadas, para que seja possível investigar cada grupo de interesse, e se comportam-se de maneira distinta ou não. Portanto, de posse das hipóteses levantadas anteriormente, definiu-se as seguintes categorias de interesse, que deram margem aos indicadores por categoria: faixa etária, agrupamento de travessia e gênero dos indivíduos. Adotou-se ainda o indicador de velocidades médias dos pedestres (relação entre a distância de travessia e o tempo de travessia) para testar a hipótese relativa à velocidade de caminhada dos pedestres, além da distância de travessia, englobando o aspecto do ambiente. 


\subsection{ANÁLISE DESCRITIVA}

Foi realizado uma descrição das variáveis, a nível de agregação decimal, divididas em grupos, por se tratarem de variáveis categóricas, além de uma análise de forma, valendo ressaltar que para esta última, apenas as velocidades dos pedestres foram consideradas. Na Figura 3, está um resumo do levantamento das variáveis divididos quanto a característica da travessia (modo semafórico, durante a travessia), características do pedestre (gênero, idade e grupo), além do próprio ciclo semafórico representados pelas cores marrom, azul e cinza, respectivamente.

Figura 3: Proporção das variáveis levantadas por interseção

\begin{tabular}{|c|c|c|c|c|c|c|}
\hline \multicolumn{2}{|c|}{ Variáveis } & C12 & C06 & C21 & C31 & C35 \\
\hline \multirow{2}{*}{$\begin{array}{c}\text { Número de } \\
\text { Pedestres em } \\
\text { Travessia }\end{array}$} & Verde & 0,97 & 0,83 & 0,96 & 0,32 & 0,65 \\
\cline { 2 - 7 } & Intermitente & 0,02 & 0,02 & 0,01 & 0,03 & 0,03 \\
\cline { 2 - 7 } & Vermelho & 0,02 & 0,15 & 0,03 & 0,09 & 0,30 \\
\cline { 2 - 7 } & Não Informado & 0,00 & 0,00 & 0,01 & 0,55 & 0,03 \\
\hline \multirow{2}{*}{ Gênero } & Masculino & 0,50 & 0,63 & 0,40 & 0,51 & 0,68 \\
\cline { 2 - 7 } & Feminino & 0,51 & 0,37 & 0,60 & 0,49 & 0,33 \\
\hline \multirow{4}{*}{ Idade } & $<18$ & 0,05 & 0,02 & 0,01 & 0,14 & 0,10 \\
\cline { 2 - 7 } & $19-59$ & 0,81 & 0,87 & 0,96 & 0,81 & 0,85 \\
\cline { 2 - 7 } & $>59$ & 0,15 & 0,11 & 0,03 & 0,05 & 0,05 \\
\hline \multirow{2}{*}{ Grupo } & Sozinho & 0,32 & 0,61 & 0,74 & 0,50 & 0,38 \\
\cline { 2 - 7 } & 2 ou mais & 0,68 & 0,39 & 0,26 & 0,50 & 0,63 \\
\hline \multirow{2}{*}{$\begin{array}{c}\text { Ciclo } \\
\text { Semafórico - } \\
\text { carros (s) }\end{array}$} & Vermelho & 65 & 73 & 109 & 62 & 73 \\
\cline { 2 - 7 } & Intermitente & 3 & 3 & 3 & 3 & 3 \\
\cline { 2 - 7 } & Verde & 80 & 55 & 46 & 66 & 54 \\
\hline
\end{tabular}

A Figura 3 pode ser analisada por grupo de interesse ou por linha demonstrando a relação de cada componente em todas as interseções. Fica evidente que as interseções C06 e a C35 tiveram valores maiores de pedestres atravessando no sinal vermelho, onde as duas citadas correspondem a uma região com uso do solo parcialmente residencial e a segunda com interseção de maior distância de travessia, tendo possivelmente um maior fluxo de veículos e maior tempo de atraso dos pedestres. A partir da tabela, também, é possível evidenciar que mais de $80 \%$ dos pedestres dessa hora pico estão na faixa etária entre 19 e 59 anos. Existe um maior fluxo de pessoas caminhando em grupos nas travessias de maior distância. As duas interseções com maiores número de pedestres oportunistas, detém ciclos semafóricos com tempos de vermelho altos e tempos de verde menores que 1 minuto, ou seja, embora a travessia C21 contrarie esse levantamento, há evidências que para outras interseções o ciclo semafórico pode ter influência sobre a travessia dos pedestres, referente ao curto espaço de tempo para atravessar, e longo período de espera.

Além disso, se investigou as diferenças entre as velocidades de caminhada de pedestres obedientes e de pedestres oportunistas. Para isso, se construiu gráficos do tipo Box Plot com as velocidades de caminhada de cada uma dessas categorias de pedestres. Esses gráficos podem ser melhor observados na Figura 4 , abaixo. 
Figura 4: Relação entre a velocidade (m/s) de pedestres obedientes e oportunistas

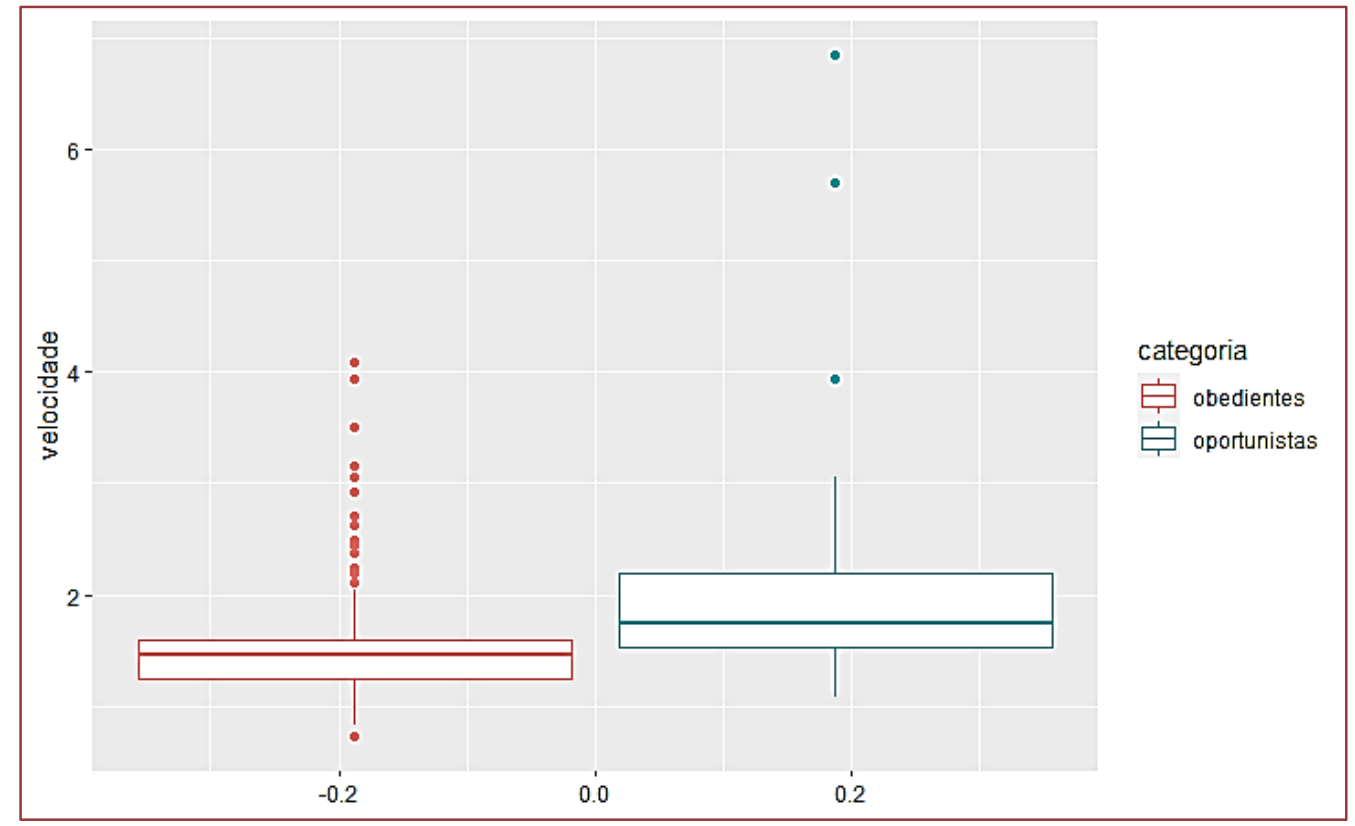

Ao comparar os Box Plot's da velocidade de caminhada dos pedestres obedientes com a dos pedestres oportunistas, se pode notar que a velocidade dos pedestres oportunistas é maior que a de pedestres obedientes, uma vez que o primeiro quartil do Box Plot da velocidade de caminhada dos pedestres oportunistas está próximo do terceiro quartil do Box Plot dos pedestres obedientes, indicando que os pedestres oportunistas podem caminhar mais rápido do que os pedestres obedientes nesses cruzamentos. Isso ocorre muito provavelmente devido a pressa para aproveitar a brecha deixada entre os veículos e atravessar a rua, enquanto que os pedestres obedientes não precisam se preocupar com isso, pois tem a sinalização a seu favor. Vale ressaltar também que a variabilidade das velocidades dos pedestres oportunistas é superior a dos pedestres obedientes.

\subsection{ANÁLISE DE CORRELAÇ̃̃o ESTATÍSTICO CATEGÓRICO}

Nesta subetapa foram realizados testes estatísticos para variáveis categóricas a fim de investigar a validade das hipóteses propostas. 0 teste adotado foi o teste chi-quadrado realizado a partir das tabelas de contingência. Foram realizados dois testes, um para a hipótese de que há uma influência do sexo sobre a tendência de serem violadores, e um outro em relação a quanto maior a distância de travessia que uma via tiver, menor será o número de pedestres violadores. A hipótese à respeito da idade dos pedestres influenciar na obediência, foi contemplada na modelagem logit. A seguir na Tabela 1 estão a relação dos valores para gênero e local.

Tabela 1: Tabela de Contingência para locais e gênero

\begin{tabular}{|c|c|c|c|}
\hline Variáveis & Obedientes & Oportunistas & Total \\
\hline C12 & 132 & 4 & 136 \\
\hline C06 & 39 & 7 & 46 \\
\hline $\mathrm{C} 21$ & 196 & 4 & 200 \\
\hline C31 & 248 & 26 & 274 \\
\hline C35 & 28 & 12 & 40 \\
\hline Masculino & 337 & 32 & 369 \\
\hline Feminino & 306 & 21 & 327 \\
\hline
\end{tabular}


Para testar a hipótese de que homens tendem a ser mais violadores que mulheres, foram retirados os dados coletados com a categorização de semáforo não informado, estando apenas nesta análise os pedestres que atravessam no sinal verde, intermitente e vermelho. Posterior a construção da tabela de contingência, foi realizado o teste de independência com chi-quadrado, a fim de verificar uma possível relação de dependência das variáveis categóricas com o comportamento dos pedestres. A Tabela 2 demonstra os resultados por categoria.

Tabela 2: Resultados do teste de chi-quadrado

\begin{tabular}{|c|c|c|c|}
\hline Relação & \multicolumn{1}{c}{ x-squared } & df & \multicolumn{1}{c|}{-value } \\
\hline Gênero & 0,9483 & 1 & 0,3302 \\
\hline Local & 46,824 & 4 & $1,659 \mathrm{e}-09$ \\
\hline
\end{tabular}

Considerando que o teste aceita a hipótese de dependência quando o índice de $p$-value é inferior a 5\%, ou seja, os dados estariam estatisticamente dentro do intervalo de nível de confiança. Primeiramente analisando o resultado por gênero, onde o p-value, foi de 0,3302 (33,02\%), muito acima do valor de 0,05(5\%) demonstrado que não há evidências suficientes para se alegar dependência do gênero dos pedestres com o fato deles serem oportunistas. Esse fato pode decorrer tanto por não existir uma relação de causa e efeito, quanto pelo contingente de dados levantados não ser o suficiente para demonstrar uma relação de dependência. Enquanto que o teste para a relação da distância de travessia com o comportamento retornou um p-value de 1,659e-09 dando evidências de que existe uma relação entre a distância das travessias com o comportamento do pedestre.

\section{MODELAGEM}

A seguir, são apresentados e discutidos os resultados dos modelos de regressão logística desenvolvidos, os quais a variável resposta de todos os modelos é zero para pedestres não oportunistas e um para pedestres oportunistas. 0 modelo da Tabela 3, com 541 observações, refere-se aos pedestres oportunistas de todas as interseções em conjunto, optando-se em usar todas as variáveis neste modelo. A análise dos resultados do modelo sugere que, mantendo-se todas as outras variáveis constantes, os pedestres com 19 a 59 anos têm menos chances de serem oportunistas em relação a pedestres com 0 a 18 anos $(\mathrm{OR}=0,29)$ e essa diferença é ainda maior comparando pedestres com mais de 60 anos $(O R=0,16)$. As variáveis de sexo, grupo e velocidade não foram significativas nesse modelo.

Com relação a variável interseções, a C12 foi usada como referência e os resultados do modelo sugerem que todas as outras interseções apresentam uma maior chance de terem pedestres oportunistas, com exceção da interseção C21 (p-valor > 0,05). A C06 apresenta 8,79 mais chances de ter pedestres oportunistas, enquanto a C35 tem 18,11 e a C31 tem 11,56. Ao comparar as características dessas interseções, percebese que estas possuem ciclos semafóricos com tempos de vermelho altos e tempos de verde menores que um minuto, com exceção da C31, ou seja, há evidências que para outras interseções o ciclo semafórico pode ter influência sobre a travessia dos pedestres, referindo ao curto espaço de tempo para atravessar e longo período de espera, uma vez que essas interseções têm as maiores distâncias de travessia. 
Tabela 3: Modelo logit para pedestres oportunistas por variável categórica

\begin{tabular}{|c|c|c|c|c|c|}
\hline Variável & Categoria & $\begin{array}{l}\text { Odds } \\
\text { Ratio }\end{array}$ & \multicolumn{2}{|c|}{ I.C. $(90 \%)$} & p-valor \\
\hline Sexo & (1) Masculino & \multicolumn{3}{|c|}{ ref } & - \\
\hline & (2) Feminino & 0,70 & 0,40 & 1,19 & 0,27 \\
\hline Idade & (1) $0-18$ & \multicolumn{3}{|c|}{ ref } & - \\
\hline & (2) 19-59 & 0,29 & 0,13 & 0,66 & 0,01 \\
\hline & (3) $60+$ & 0,16 & 0,03 & 0,61 & 0,04 \\
\hline Grupo & (1) Sozinho & \multicolumn{3}{|c|}{ ref } & - \\
\hline & (2) Grupo & 0,90 & 0,52 & 1,58 & 0,76 \\
\hline Interseção & Av. Dom Luís x Av. Desembargador Moreira (C12) & \multicolumn{3}{|c|}{ ref } & - \\
\hline & Av. Dom Manuel x Av. Monsenhor Tabosa (C06) & 8,79 & 3,02 & 28,02 & 0,00 \\
\hline & Av. Abolição x Av. Barão de Studart (C35) & 18,11 & 6,58 & 56,80 & 0,00 \\
\hline & Av. Da Universidade x Av. 13 de Maio (C21) & 1,49 & 0,43 & 5,18 & 0,59 \\
\hline & Av. Desembargador Moreira x Av. Antônio Sales (C31) & 11,56 & 4,97 & 32,18 & 0,00 \\
\hline Velocidade & Variável contínua $[\mathrm{m} / \mathrm{s}]$ & 1,18 & 0,71 & 1,91 & 0,58 \\
\hline McFadden & & 0,20 & & & \\
\hline \multicolumn{2}{|c|}{ Razão de Verossimilhança (valor p) } & 0,00 & & & \\
\hline \multicolumn{2}{|c|}{ Número de observações } & 541 & & & \\
\hline
\end{tabular}

Foi realizado, também, um modelo geral sem a variável da interseção e um modelo para cada interseção individualmente. As interseções C06 e C21 não tiveram nenhuma variável significativa, por isso, não estão na Tabela 4. Nestes modelos só foram usadas as variáveis que tinham pelo menos uma categoria significativa e as categorias não significativas estão representadas pelo elemento "-" na Tabela 4. 0 modelo T é o modelo com todas as interseções sem a variável do local. 0 modelo da interseção C35 tem 38 observações e sua única variável significativa é a velocidade dos pedestres, porém o modelo apresenta um baixo número de observações, devido ao fluxo baixo de pedestres nesta interseção, mesmo sendo realizado em hora-pico e o modelo C31 não apresentou métricas de ajuste adequadas, portanto, não será analisado.

Tabela 4: Modelo logit por interseção

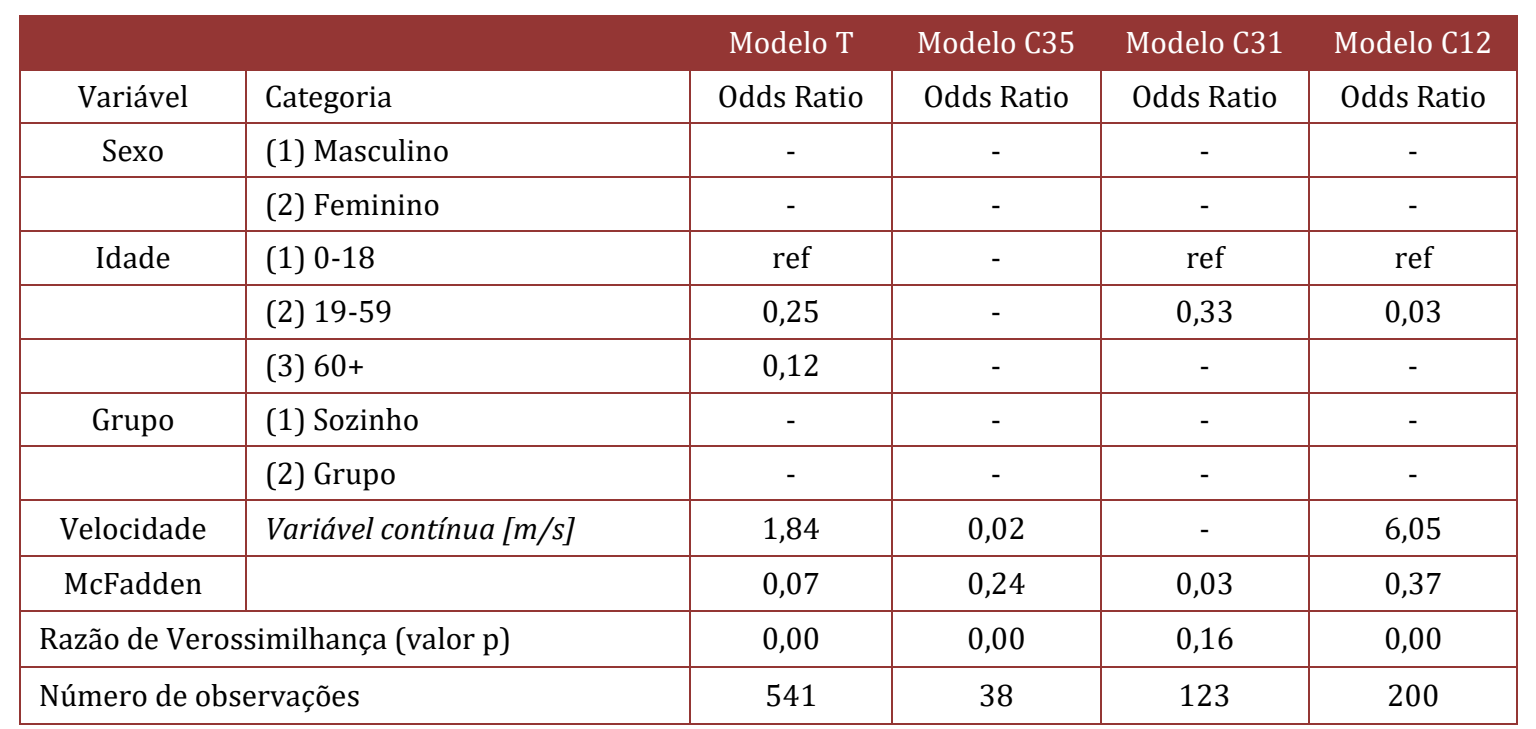

Em todos os modelos pessoas mais velhas são sujeitas a não serem oportunistas e as variáveis de sexo e agrupamento de travessia não são significativas. 0 modelo C12, com 200 observações, tem as variáveis de idade e velocidade significativas, demonstrando que nesta interseção pedestres mais jovens são propensos a serem mais oportunistas e pedestres oportunistas tendem a terem velocidade mais altas $(0 \mathrm{R}=6,05)$. A velocidade tem coeficiente maior que um no modelo T e C12, somente no modelo C35 apresentou abaix o de um, entretanto essa interseção possui poucas observações e a média de velocidade dos pedestres é 2,19 
m/s, sendo a média dos obedientes de 2,35 e 1,85 dos oportunistas. 0 valor da velocidade média na C35 é elevado, significando que nesta interseção os pedestres atravessam de forma mais rápida em relação às outras interseções, pelo boxplot das velocidades observa-se que estes pedestres obedientes seriam outliers. Quanto à significância estatística dos modelos, todos os testes de razão de verossimilhança resultaram em valores-p praticamente iguais a zero, com exceção do C31, confirmando que os modelos são estatisticamente significativos.

\section{CONSIDERAÇÕES FINAIS}

Diante dos resultados obtidos, houve-se uma maior compreensão do fenômeno do comportamento dos pedestres na região de estudo da cidade de Fortaleza. Os resultados podem auxiliar os tomadores de decisão na elaboração e implementação de políticas públicas eficazes para abordar problemas relacionados à segurança viária. Através das hipóteses testadas se conseguiu determinar as características de pedestres violadores, uma vez que se verificou, por exemplo, que o sexo não importa para definir oportunistas com base nos dados coletados. 0 teste de qui-quadrado gerado pela tabela de contingência dessa variável categórica, mostrou que essa tendência encontrada é não significativa estatisticamente, uma vez que não há correlação de dependência entre o sexo dos pedestres e o seu comportamento. Os modelos logit confirmaram essas hipóteses, os quais todos deram insignificante para o gênero.

O teste estatístico foi útil também, para identificar outros fatores que podem influenciar o comportamento dos pedestres na cidade. De acordo com os resultados do teste chi-quadrado e dos modelos logit, se pode afirmar que não há evidências suficientes para descartar a hipótese de que existe relação entre o tamanho da travessia com a obediência dos pedestres. Ainda em relação às características do ambiente, ficou evidente que os locais com maior distância de travessia, detém o menor tempo para travessia, e consequentemente as maiores velocidades de caminhada e maior número de oportunistas, sendo uma proposta aos tomadores de decisão reavaliar os ciclos semafóricos dessas interseções. Outros fatores encontrados foram que pedestres mais velhos tendem a ser menos oportunistas e os oportunistas apresentam velocidades mais elevadas. Essas observações fornecem aos tomadores de decisão informações importantes para prover mais segurança nas travessias, pois atestam que características físicas dos pedestres são menos importantes do que mesmo as atividades que são realizadas nas proximidades.

Uma das limitações deste trabalho é não incluir formas mais diversas de uso do solo no estudo, uma vez que a quase totalidade das interseções está em áreas centrais que concentram muito uso do solo não residencial. Além disso, as categorias de tipos de uso foram muito agregadas, separando apenas em residencial e não residencial. No entanto, haviam regiões como, por exemplo, a Avenida da Universidade que é do tipo educacional, o qual pode gerar alguma influência nos resultados, uma vez que os frequentadores desta região são em sua maioria estudantes. Portanto, é recomendável que haja uma análise mais desagregada quanto ao uso do solo, pois esse foi um dos atributos que se mostrou mais relevante para explicar o comportamento dos pedestres.

\section{REFERÊNCIAS}

[1] Bandeira, T.P. A Method for Microscopic Modeling of Pedestrian Delay at Signalized Crossings. Dissertação de Mestrado. Universidade Federal do Ceará. Fortaleza:2019.

[2] Bernhoft, I. M.; Carstensen, G. Preferences and behaviour of pedestrians and cyclists by age and gender. Transportation Research Part F: Traffic Psychology and Behaviour 11.2 (2008): 83-95. 16.

[3] Demir, B., Özkan, T., e Demir, S. (2019) Pedestrian violations: Reasoned or social reactive? Comparing theory of planned behavior and prototype willingness model. Transportation Research Part F: Traffic Psychology and Behaviour, 60, 560-572. doi:10.1016/j.trf.2018.11.012

[4] Jacobsen, A. C. Microssimulação da Travessia de Pedestres. Dissertação de Mestrado. Universidade Federal do Rio Grande do Sul: 2011.

[5] Jay, M., Régnier, A., Dasnon, A., Brunet, K., e Pelé, M. (2020) The light is red: Uncertainty behaviours displayed by pedestrians during illegal road crossing. Accident Analysis and Prevention, 135(November 2019), 105369. doi:10.1016/j.aap.2019.105369

[6] Koh, P. P., e Wong, Y. D. (2014) Gap acceptance of violators at signalised pedestrian crossings. Accident Analysis and Prevention, 62, 178-185. doi:10.1016/j.aap.2013.09.020

[7] Liu, R.; Silva, J.P.;Seco, A.J.A bi-modal micro-simulation tool for the assessment of pedestrian delas and traffic management.9th International Association of Travel Behavior Research Conference., Gold Coast, Australia: 2000. 
[8] Mukherjee, D., e Mitra, S. (2019) A comparative study of safe and unsafe signalized intersections from the view point of pedestrian behavior and perception. Accident Analysis and Prevention, 132(October 2018), 105218. doi:10.1016/j.aap.2019.06.010

[9] Mukherjee, D., e Mitra, S. (2020) A comprehensive study on factors influencing pedestrian signal violation behaviour: Experience from Kolkata City, India. Safety Science, 124(October 2019), 104610. doi:10.1016/j.ssci.2020.104610

[10] Patra, M., Perumal, V., e Rao, K. V. K. (2019) Modelling the effects of risk factor and time savings on pedestrians' choice of crossing facilities at signalised intersections. Case Studies on Transport Policy, (October), 0-1. doi:10.1016/j.cstp.2019.10.010

[11] Ronsenbloom, T.; Nemrodoy, D.; Barkan H. For heaven's sake follow the rules: pedestrians' behavior in an ultra-orthodox and a non-orthodox city. Transportation Research Part F: Traffic Psychology and Behaviour 7.6 (2004): 395-404.

[12] Torres et. al. Behavioral Evaluation of Different Types of Pedestrian Crossing Facilities: a Case Study in Fortaleza - Brazil. Transport Research Board: 2019.

[13] Vignali, V., Pazzini, M., Ghasemi, N., Lantieri, C., Simone, A., e Dondi, G. (2020) The safety and conspicuity of pedestrian crossing at roundabouts: The effect of median refuge island and zebra markings. Transportation Research Part F: Traffic Psychology and Behaviour, 68, 94-104. doi:10.1016/j.trf.2019.12.007

[14] WRI BRASIL. (2015) Impactos da redução dos limites de velocidade em áreas urbanas. Embarq Brasil.

[15] Yang, J. et al. Modeling pedestrians' road crossing behavior in traffic system micro-simulation in China. Transportation Research Part A, v. 40, p. 280-290. 2006

[16] Zafri, N. M., Sultana, R., Himal, M. R. H., e Tabassum, T. (2020) Factors influencing pedestrians' decision to cross the road by risky rolling gap crossing strategy at intersections in Dhaka, Bangladesh. Accident Analysis \& Prevention, 142(December 2019), 105564. doi:10.1016/j.aap.2020.105564

[17] Zhang, C., Chen, F., e Wei, Y. (2019) Evaluation of pedestrian crossing behavior and safety at uncontrolled midblock crosswalks with different numbers of lanes in China. Accident Analysis and Prevention, 123(January 2018), 263273. doi:10.1016/j.aap.2018.12.002

[18] Zhou, H., Romero, S. B., e Qin, X. (2016) An extension of the theory of planned behavior to predict pedestrians' violating crossing behavior using structural equation modeling. Accident Analysis and Prevention, 95, 417-424. doi:10.1016/j.aap.2015.09.009

[19] Zhuping, Z et al. Pedestrian crossing behaviors at signalized intersections: observational study and survey in China. In: TRANPORTATION RESEARCH BOARD 90th ANNUAL MEATING, 2011, Washington, DC. ANAIS...Washington, DC.:TRB, 2011. DVD-ROMAssociação Brasileira de Normas Técnicas, Rio de Janeiro.

[20] Zhang, D. Evaluation System of Road Traffic Safety Management. China Communication Press, Beijing, 2005.

[21] Murphy, Brendan; Levinson, David M.; Owen, Andrew. Evaluating the Safety In Numbers effect for pedestrians at urban intersections. Accident Analysis \& Prevention, v. 106, p. 181-190, 2017. 


\section{Capítulo 8}

Diagnóstico técnico-operacional para implementação de Postos de Pesagem Veicular (PPVs) com Agente Remoto

\section{Leonardo Perim Guerson \\ Vanessa Espíndola \\ Valter Zanela Tani \\ Amir Mattar Valente \\ Marcelo Bavier Marcos}

Resumo: Este artigo aborda a definição e a execução de um processo de diagnóstico técnico-operacional dos Postos de Pesagem Veicular (PPVs) no Brasil. 0 método de diagnóstico foi elaborado com o objetivo de prover diretrizes para a adaptação dos PPVs ao modelo de operação com agente remoto, no qual o agente de trânsito exerce suas funções em uma localidade remota às áreas de pesagem. Ainda, o diagnóstico visa analisar viabilidade da implantação de sistemas de pesagem em movimento em alta velocidade, do inglês High-Speed Weigh-in-Motion (HS-WIM), para pesagem seletiva de potenciais infratores nesses postos. Nesse contexto, o processo de diagnóstico culminou no levantamento in loco de 29 PPVs na malha rodoviária sob administração da Agência Nacional de Transportes Terrestres (ANTT), em que foram observados principais elementos que incidem sobre a operação de PPV com agente remoto e sobre a viabilidade técnica da implantação dos sistemas HS-WIM. 0 diagnóstico técnico-operacional constitui a primeira etapa do processo de adaptação dos PPVs para a operação com agente remoto e é utilizado como a principal referência para a elaboração de projetos executivos e funcionais que visem à implementação desse modelo de operação.

Palavras-chave: HS-WIM. Posto de Pesagem Veicular (PPV). Pesagem em Movimento. 


\section{INTRODUÇÃO}

A prática do excesso de peso em veículos prejudica a segurança dos usuários das rodovias, compromete a durabilidade da infraestrutura de pavimentos e de pontes e resulta em impactos negativos à concorrência leal entre operadores e modais de transportes (JACOB e FEYPELLDE LA BEAUMELLE, 2010). Nesse sentido, a fiscalização de peso em veículos constitui o principal método de controle do excesso de peso em rodovias no Brasil, na qual o principal meio de inspeção são postos de pesagem localizados às margens das rodovias. Recentemente, buscando aumentar eficiência e a efetividade no controle do excesso de peso, instituiu-se, no Brasil, um novo modo de fiscalização de peso, tendo em vista os avanços das tecnologias para inspeção de veículos. Para consolidar essa mudança, a Agência Nacional de Transportes Terrestres (ANTT) e o Laboratório de Transportes de Logística (LabTrans), da Universidade Federal de Santa Catarina (UFSC), realizaram um estudo para diagnóstico técnico-operacional dos atuais Postos de Pesagem Veicular (PPVs) localizados na malha rodoviária federal concedida, visando prover recomendações específicas para adaptação desses Postos ao novo modelo de fiscalização.

O novo modelo de fiscalização de peso desenvolvido no Brasil é denominado, pela ANTT, como Postos de Pesagem Veicular (PPVs) com Agente Remoto, tendo sido regulamentado pelo órgão através da Resolução no 5.379, de 5 de julho de 2017. A referida Resolução estabelece diretrizes técnicas e parâmetros de desempenho para os equipamentos, os sistemas e as instalações operacionais do modelo de fiscalização e de operação dos PPVs com Agente Remoto sob a responsabilidade da ANTT. As diretrizes e os parâmetros introduzidos por essa Resolução visam promover a padronização e o funcionamento contínuo dos PPVs da malha rodoviária federal concedida.

O PPV com Agente Remoto se difere dos métodos anteriores em dois aspectos principais. O primeiro diz respeito à introdução de dispositivos de Sistemas de Inteligentes de Transportes, do inglês Intelligent Transportation Systems (ITS), que permitem maiores níveis de automação nos processos de inspeção e de autuação, além de viabilizarem a atuação do agente de trânsito em uma localidade remota, durante todo o processo de fiscalização. 0 segundo aspecto que caracteriza o novo modelo diz respeito à possibilidade de utilização de sistemas de pesagem em movimento em alta velocidade, do inglês High-Speed Weigh-in-Motion (HSWIM), para pré-seleção de veículos potencialmente infratores à velocidade diretriz das rodovias.

A fiscalização remota em postos de pesagem, apesar de ser um aspecto inovador, já foi introduzida de forma limitada em províncias do Canadá, onde se utiliza esse tipo de solução em rodovias de baixo volume de tráfego (WAGAR; BUSHMAN; TAYLOR, 2007). Em relação à utilização de sistemas HS-WIM para pré-seleção de potenciais infratores à velocidade diretriz da via, essa solução é amplamente utilizada nos Estados Unidos desde a década de 1990, conforme documentado nos trabalhos de Leavitt (1995), Trischuk et al. (2002), Klashinsky et al. (2009), Hanson et al. (2010) e Chotickai (2012).

Considerando o contexto apresentado, os diagnósticos visam trazer respostas sobre as necessidades de adaptação dos atuais PPVs em termos de operação e de solução tecnológica, assim como viabilizam as avaliações técnica e econômica da implantação de pistas seletivas com sistemas HS-WIM nesses locais. Além do potencial técnico dos PPVs em suas condições atuais, o processo de diagnóstico técnico-operacional visa verificar a conformidade de cada PPV com os regulamentos vigentes para essa modalidade de fiscalização.

\section{POSTO DE PESAGEM VEICULAR (PPV)}

Na década de 1970, o governo federal, através do então Departamento Nacional de Estradas de Rodagem (DNER), estabeleceu um Plano Nacional de Pesagem, com o intuito de associar o controle de sobrepeso nas rodovias federais do Brasil com a mínima perturbação do fluxo de tráfego (DNIT E LABTRANS, 2007). Desde então, os PPVs, com utilização de sistemas de pesagem em movimento, consolidaram-se como o modo de fiscalização de peso predominante no país. A Figura 1 mostra uma imagem aérea do PPV de Tanguá/RJ, com destaque para as suas pistas de pesagem, localizadas às margens da rodovia. 
Figura 1: PPV de Tanguá/RJ

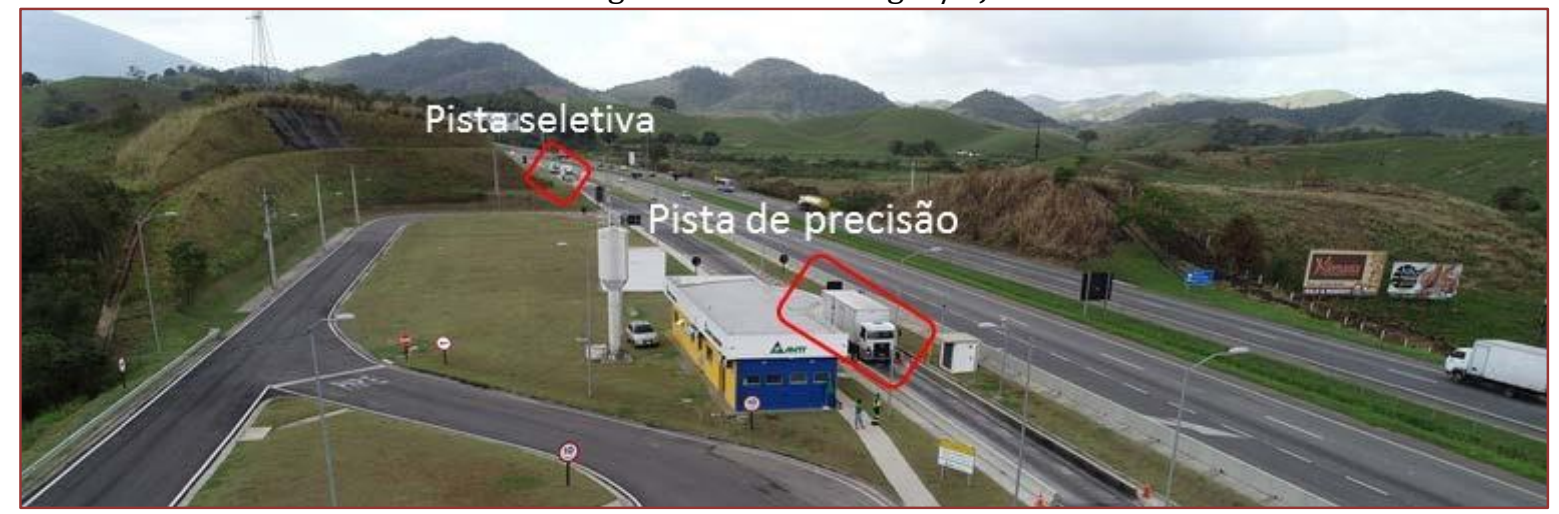

Nos atuais PPVs, são utilizados tanto um sistema de pesagem em movimento, Weigh-inMotion (WIM), para pré-seleção de veículos potencialmente infratores em velocidades de até $60 \mathrm{~km} / \mathrm{h}$ (Pista Seletiva), quanto sistema WIM, de alto desempenho, para fiscalização de veículos em velocidades de até $12 \mathrm{~km} / \mathrm{h}$ (Pista de Precisão). Nesses Postos, todos os condutores de veículos infratores são encaminhados para o pátio, onde estacionam o veículo e se encaminham para atendimento no prédio administrativo.

A operação dos PPVs depende da presença física do agente de trânsito, que realiza a lavratura de autos de infração, a aplicação de medidas administrativas e a coordenação das operações de pesagem in loco, no posto de pesagem.

\subsection{PPV COM AGENTE REMOTO E HS-WIM}

Recentemente, três inovações tornaram-se viáveis para os PPVs da ANTT, sendo essas: a fiscalização remota; a Pista Seletiva HS-WIM; e a operação automatizada. Assim, gradualmente, será implementado um modelo que constitui uma versão atualizada dos PPVs introduzidos nos anos 70, com uma infraestrutura física similar e a atualização dos recursos tecnológicos. A Figura 2 apresenta um leiaute simplificado dos PPVs com Agente Remoto e com HS-WIM para visualização e para descrição da sua operação (ANTT e LABTRANS, 2018).

Figura 2: Modelo de PPV com Agente Remoto e com HS-HIM

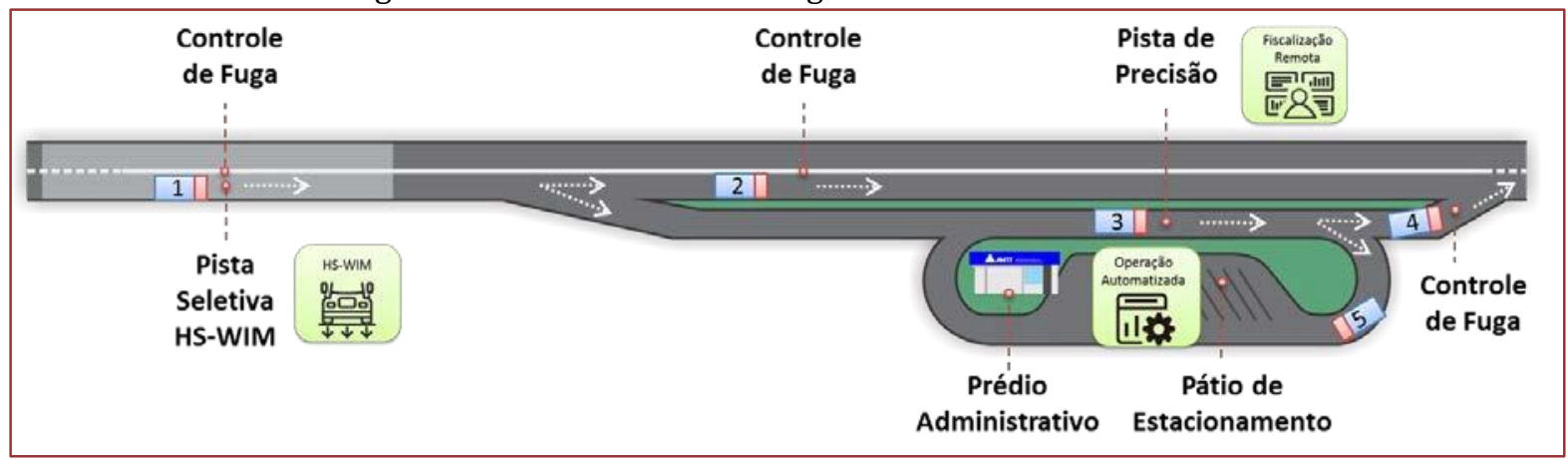


1. Quando um veículo pesado se aproxima de um PPV com Agente Remoto e com HSWIM, o condutor é orientado, através de sinalização vertical, a manter-se na faixa da direita, onde é realizada a pré-seleção de veículos potencialmente infratores na Pista Seletiva HS-WIM. Nesse local, os veículos são pesados na velocidade diretriz da própria rodovia, e os condutores são informados, através de dispositivo luminoso, sobre a necessidade de entrada na Pista de Precisão para uma segunda pesagem.

2. Caso não seja detectada uma potencial infração na passagem pela Pista Seletiva, o veículo é encaminhado a seguir viagem na rodovia. Por sua vez, o veículo pesado que é selecionado na Pista Seletiva HS-WIM, mas que não se dirige à Pista de Precisão, é registrado para penalização por deixar de adentrar as áreas destinadas à pesagem de veículos. O registro dessa infração ocorre em local imediatamente posterior à entrada da faixa de desaceleração para a Pista de Precisão.

3. Os veículos potencialmente infratores, pré-selecionados na Pista Seletiva, serão encaminhados automaticamente para a Pista de Precisão, onde é realizada a fiscalização dos limites de peso em velocidades de até $12 \mathrm{~km} / \mathrm{h}$. Com base nessa medição, determinam-se a necessidade de autuação e o encaminhamento do veículo.

4. Caso o resultado da pesagem de fiscalização não indique a necessidade de serem feitas medidas administrativas (transbordo e/ou remanejamento da carga), o veículo será encaminhado para a saída do Posto, retornando à rodovia. Em casos de retenção ou de necessidades de repesagem, o condutor que retornar à rodovia deverá ter a infração registrada pelo Controle de Fuga para posterior penalização por transpor o bloqueio viário localizado na saída do Posto.

5. Quando uma infração é registrada na Pista de Precisão e há necessidade de transbordo e/ou de remanejamento, o veículo é encaminhado para o Pátio de Estacionamento. Após estacionar, o condutor se dirige ao Prédio Administrativo, onde obtém informações sobre a sua infração para viabilizar a regularização da carga.

Nessa modalidade de fiscalização, o agente de trânsito exerce suas funções de uma localidade remota conectada às áreas de pesagem. A partir dessa localidade, com o apoio de tecnologias de informação, o agente realiza a lavratura de autos de infração, a aplicação de medidas administrativas e a coordenação das operações de pesagem.

\subsubsection{AMPARO LEGAL PARA INOVAÇÕES NOS PPVS}

O infográfico na Figura 3 apresenta uma linha do tempo com as Resoluções e as Portarias lançadas desde 2010 e um resumo dos respectivos impactos sobre a operação dos PPVs na malha rodoviária do Brasil.

Figura 3: Amparo legal dos PPVs com Agente Remoto e HS-WIM

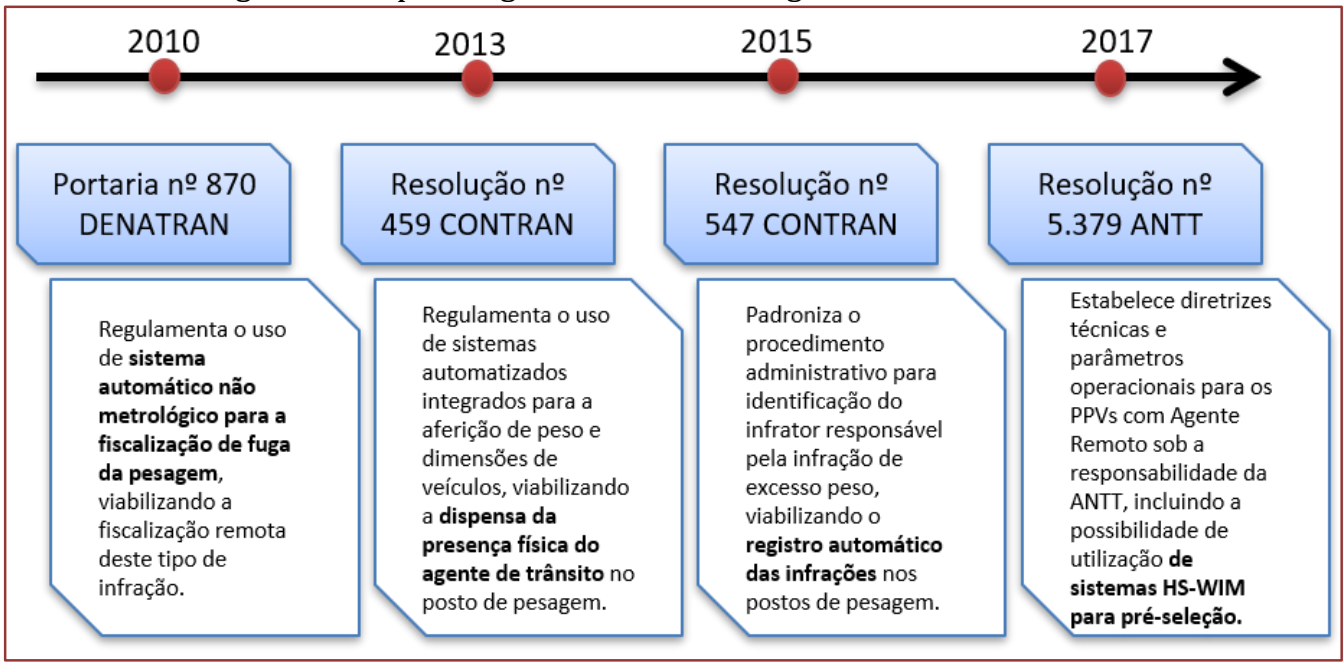




\section{MÉTODO PARA DIAGNÓSTICO TÉCNICO-OPERACIONAL}

Em relação à sua orientação teórica, o estudo apresentado neste artigo se trata de uma pesquisa qualitativa e quantitativa. Os aspectos qualitativos do trabalho tratam do aprofundamento da compreensão sobre a situação técnica-operacional dos postos de pesagem, enquanto os aspectos quantitativos se referem à aplicação de listas de verificação e de variáveis numéricas para quantificação do nível de adequação de cada PPV analisado. Além disso, verifica-se que a pesquisa possui natureza aplicada, pois busca a obtenção de conhecimentos para aplicação prática, direcionados à solução de problemas específicos e imediatos. Quanto aos procedimentos adotados, o estudo é amplamente baseado em pesquisas de campo, onde as atuais situações técnica e operacional dos PPVs são investigadas no local de operação desses Postos, de forma participante, junto aos indivíduos que atuam nessa operação.

0 método adotado para o processo de diagnóstico se baseia no modelo de revisão proposto por Levy e Ellis (2006), sendo baseado em três estágios: 1) Entrada; 2) Processamento; e 3) Saída. Nesse sentido, o diagnóstico técnico-operacional considera, como entrada, os dados e as informações coletados no levantamento de campo. Por sua vez, o parecer técnico com as propostas de adaptações são as saídas do processo, conforme mostra a Figura 4.

Figura 4: Método para diagnóstico técnico-operacional

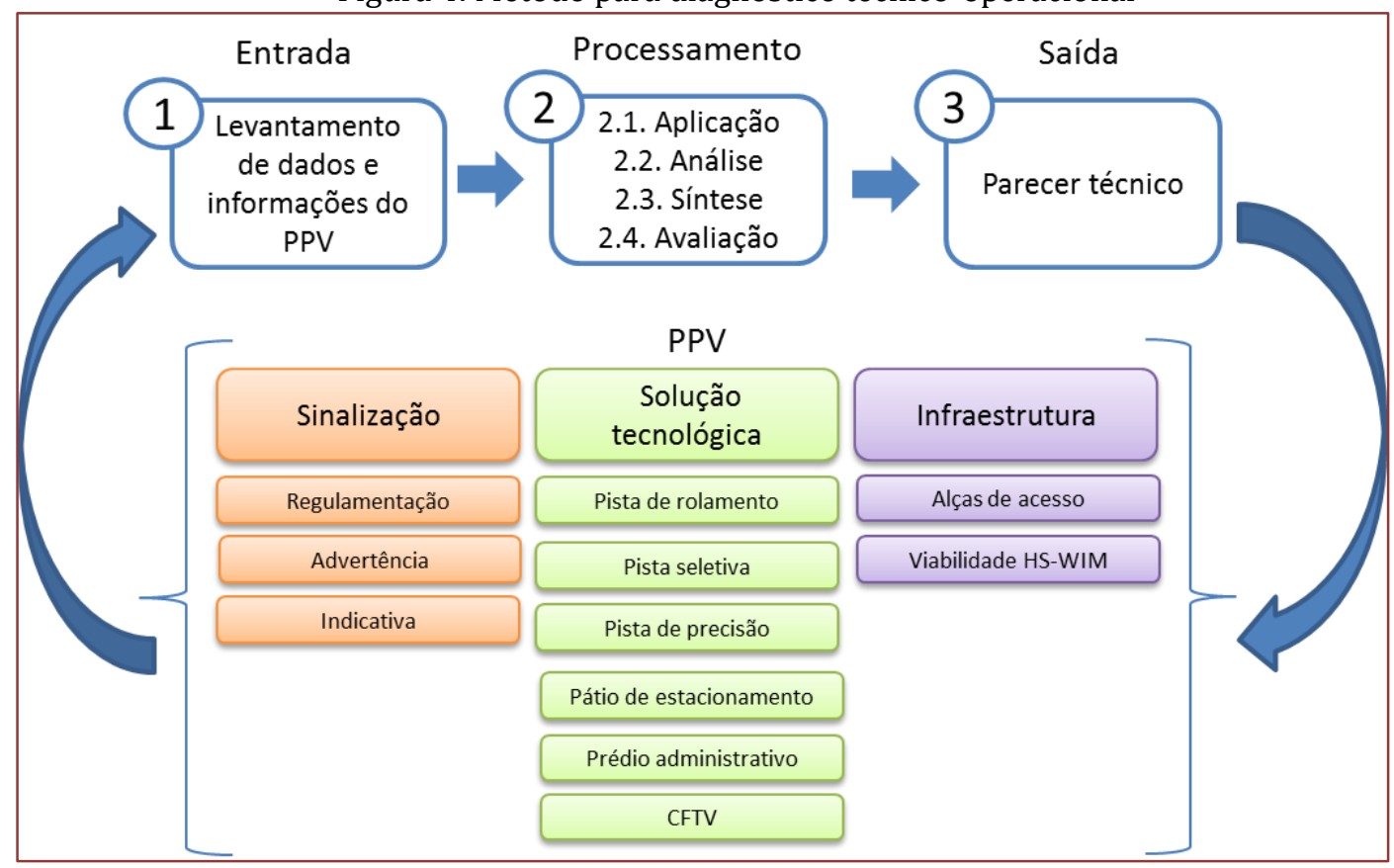

Conforme mostra a Figura 4, o diagnóstico técnico-operacional dos PPVs é processado com base em dados e em informações levantados in loco, referentes à sinalização, à solução tecnológica e à infraestrutura de cada PPV. Na sequência, os dados e as informações de entrada são processados de forma a gerar um parecer técnico com propostas de adaptação para os mesmos elementos que foram anteriormente levantados.

\subsection{SINALIZAÇÃo}

No presente processo de diagnóstico técnico-operacional, o levantamento da sinalização dos PPVs tem como objetivo viabilizar a avaliação da sua conformidade em relação aos padrões e às diretrizes estabelecidos pelo Conselho Nacional de Trânsito (CONTRAN) para a modalidade de fiscalização de peso com agente remoto. Nesse contexto, o infográfico da Figura 5 apresenta um exemplo de diagnóstico realizado sobre a sinalização do Posto de Fazenda Rio Grande/PR. 
Figura 5: Diagnóstico da sinalização do PPV de Fazenda Rio Grande/PR

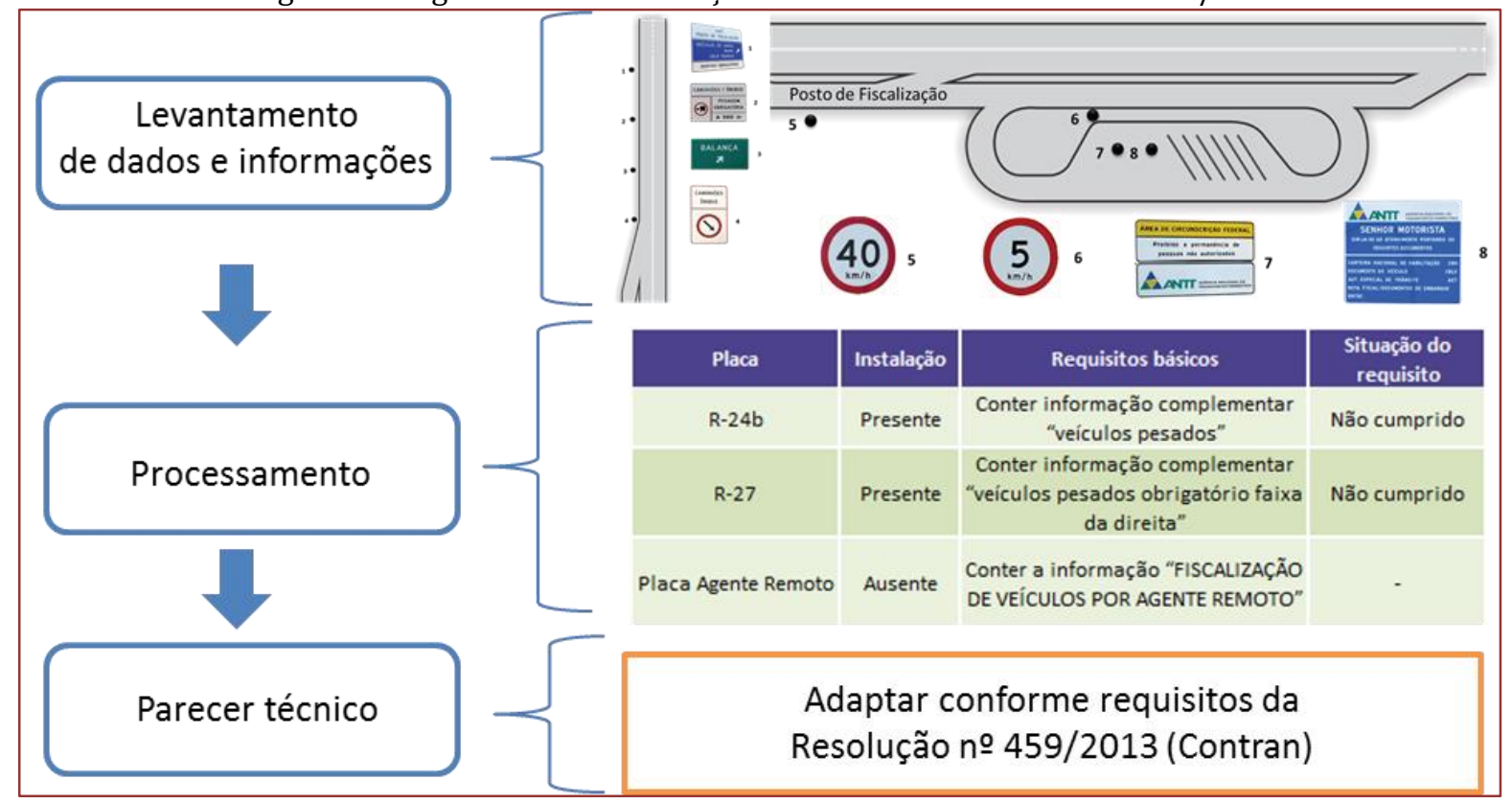

Conforme mostra a Figura 5, o levantamento fotográfico da sinalização é realizado de forma a registrar e a documentar os itens de sinalização vertical com influência sobre a operação do PPV, localizados na entrada do PPV e no próprio Posto de Fiscalização. Com base nesse levantamento, torna-se possível avaliar a adequabilidade das sinalizações indicativa, de advertência e de regulamentação para a operação do PPV com Agente Remoto.

A Resolução no 459/2013, do CONTRAN, é o regulamento base da fiscalização de peso com agente remoto e apresenta requisitos mínimos de sinalização para postos de pesagem que vierem a operar nessa modalidade. Portanto, as recomendações para adaptação da sinalização de determinado PPV são realizadas com base no cumprimento dos requisitos dessa Resolução.

\subsection{SOLUÇÃO TECNOLÓGICA}

O levantamento e o diagnóstico de aspectos relacionados à solução tecnológica dos PPVs têm o propósito de documentar as soluções utilizadas pelas Concessionárias para os principais processos executados na operação do Posto e de demonstrar quais elementos específicos devem ser abordados em seu processo de adaptação para a operação com agente remoto. Para isso, a avaliação é estruturada com um roteiro específico, composto pela abordagem dos seguintes processos:

- Orientação ao condutor na Pista de Rolamento.

- Controle de fuga por deixar de passar na Pista Seletiva.

- Pré-seleção de veículos na Pista Seletiva.

- $\quad$ Controle de fuga por deixar de passar na Pista de Precisão.

- Fiscalização de veículos na Pista de Precisão.

- Controle de fuga por deixar de adentrar o Pátio de Estacionamento.

- Monitoramento da fiscalização.

- $\quad$ Autuação e medidas administrativas. 
A Figura 6 apresenta um exemplo de diagnóstico realizado sobre o processo de "controle de fuga por deixar de passar na pista de precisão", no PPV de Uberaba/MG.

Figura 6: Diagnóstico da solução tecnológica do PPV de Uberaba/MG

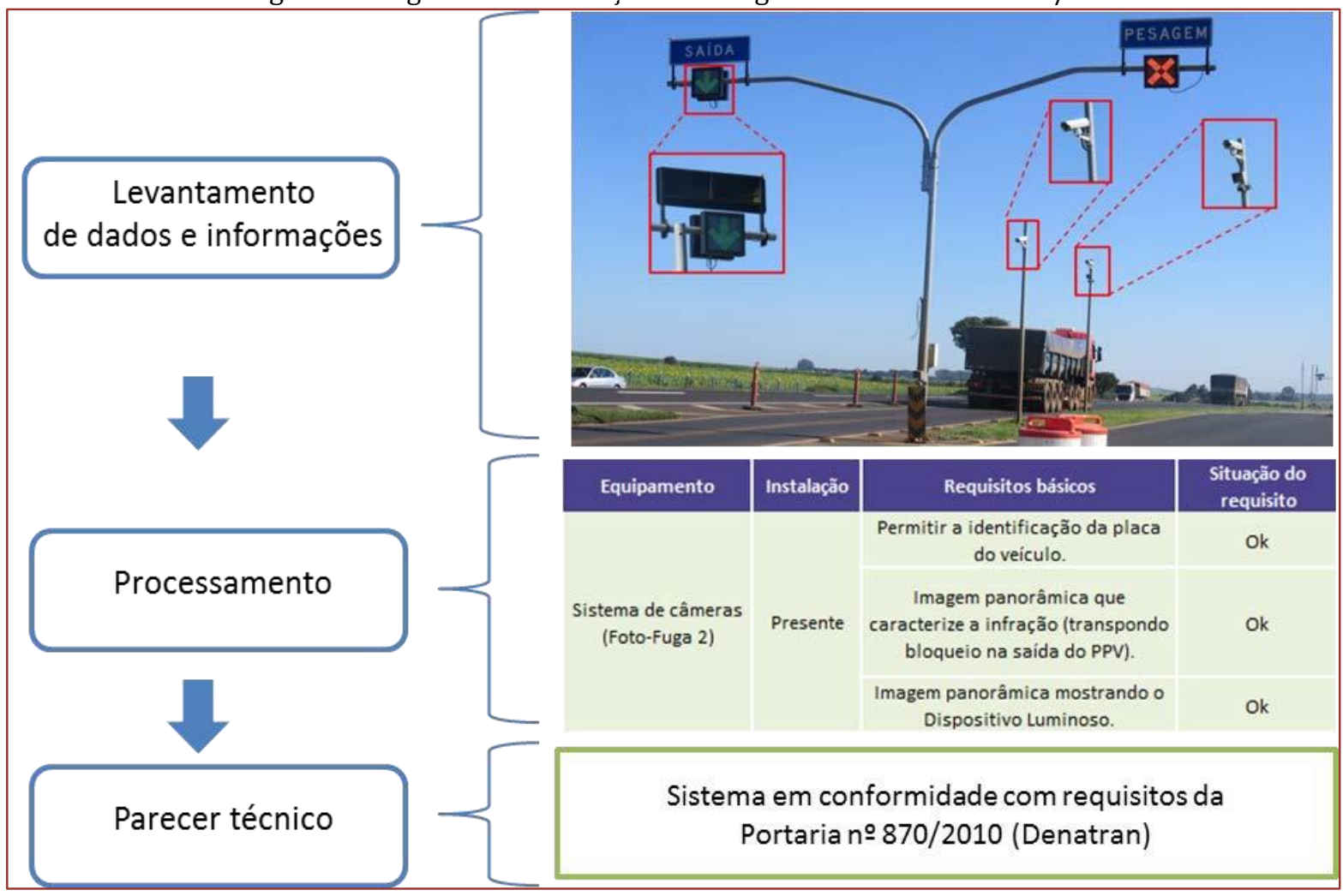

Como exibe a Figura 6, o levantamento da solução tecnológica permite que seja observada a composição de equipamentos e de sistemas que atuam na operação do PPV. Assim, com base na comparação dos atributos observados com os regulamentos vigentes, é desenvolvida a proposta de adaptações para cada PPV levantado.

A proposta de adaptações referente à solução tecnológica dos PPVs analisados é dividida em duas categorias: 1) ações imprescindíveis; e 2) ações necessárias, que devem ser executadas em sequência. As ações imprescindíveis são aquelas que levam em consideração, primeiramente, os requisitos da Resolução no 459, de 29 de outubro de 2013, do CONTRAN. Por sua vez, as ações necessárias são formuladas com base nas adequações das diretrizes presentes na Resolução nํ⒌379, de 5 de julho de 2017, da ANTT, e contém um número maior de requisitos.

\subsection{INFRAESTRUTURA}

O levantamento da infraestrutura busca obter respostas sobre a viabilidade da instalação de sistema HSWIM para pré-seleção na Pista de Rolamento, através da avaliação das características geométricas da rodovia. Nesse sentido, a Figura 7 apresenta um exemplo de alocação do potencial ponto de instalação de sistema HS-WIM nas imediações do PPV de Lavras/MG. 
Figura 7: Alocação de ponto HS-WIM no PPV de Lavras/MG

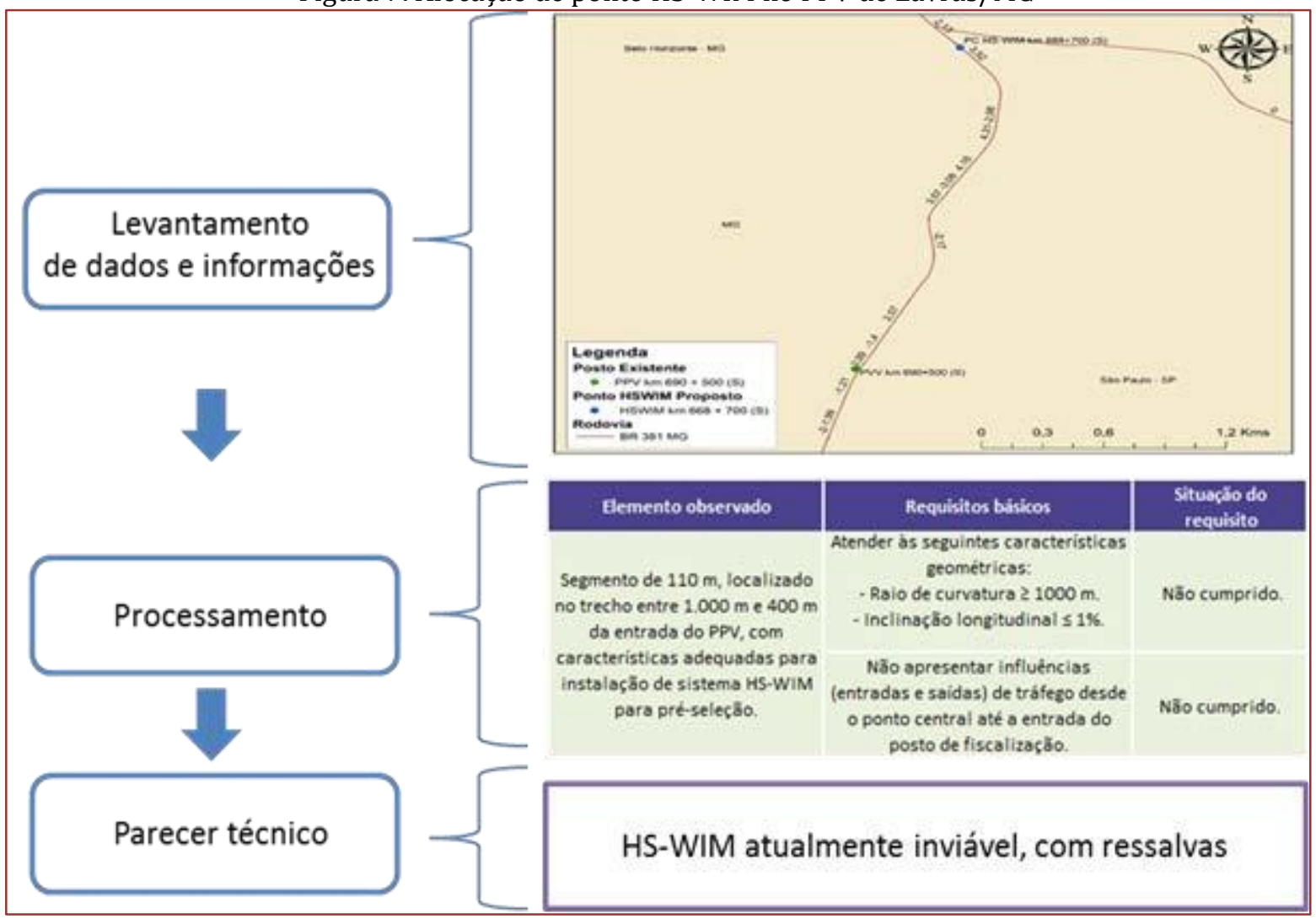

O levantamento demonstrado na Figura 7 foi realizado com apoio do restituidor as built, um software desenvolvido pelo LabTrans/UFSC, da, que analisa os dados geográficos em 3D sobre o traçado de vias, com o objetivo de segmentá-los conforme as suas características geométricas (como tangentes ou curvas) e de determinar parâmetros geométricos para os segmentos identificados (como raios e ângulos internos de curvas horizontais e gradientes na vertical).

Os resultados obtidos com o software representam a situação as built do eixo da via utilizado para analisar o trecho específico da localização do Posto e da Estação HS-WIM. A restituição da geometria do segmento analisado é apresentada na parte superior da Figura 7, na qual são identificados os valores da inclinação longitudinal, representado pela linha em destaque, na cor vermelha, e sua respectiva inclinação. A linha permanece sem destaque quando a inclinação for próxima a zero.

\section{RESULTADOS}

Os diagnósticos técnico-operacionais foram realizados em 29 PPVs localizados em rodovias federais concessionadas, em nove estados brasileiros. 0 processo de diagnóstico técnicooperacional descrito neste artigo culminou nos seguintes resultados específicos:

- Elaboração de um inventário sobre a situação de cada PPV em operação na malha rodoviária federal concedida, incluindo informações sobre operação e sobre a infraestrutura do Posto e do seu entorno.

- Composição de pré-projetos com recomendações específicas para cada PPV analisado, a serem utilizados como referência pelas Concessionárias para elaboração dos projetos para adaptação dos Postos ao modelo de operação com agente remoto.

Nesse contexto, a Figura 8 apresenta a distribuição, no mapa, dos PPVs para os quais processo de diagnóstico técnico-operacional foi desempenhado. 
Figura 8: Mapa com a localização dos PPVs

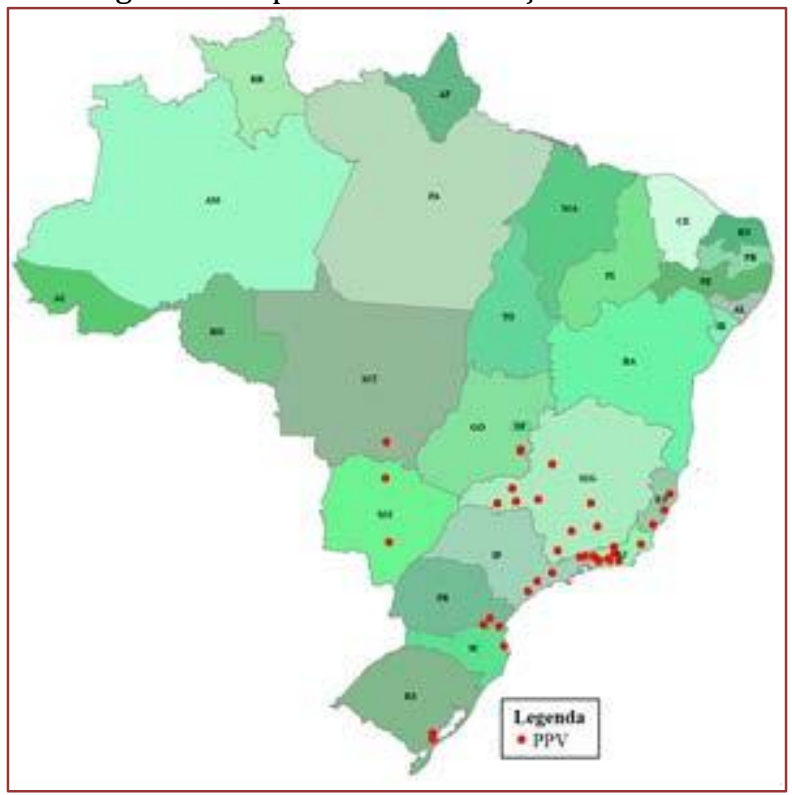

Assim como o método de levantamento, os resultados dos diagnósticos são divididos em três grupos, sendo eles: sinalização; solução tecnológica; e infraestrutura para implantação de HS-

WIM.

\subsection{SINALIZAÇÃO}

0 diagnóstico técnico-operacional referente à sinalização revela diretrizes para que os Postos analisados estejam em conformidade com os requisitos mínimos para operação com agente remoto, conforme estabelece a Resolução no 459/2013, do CONTRAN. Nesse contexto, verificou-se que, dentre os 29 Postos levantados, três PPVs (10\%) já apresentavam sinalização adequada para a operação com agente remoto, sem a necessidade de serem efetuadas adaptações. Quando considerados os PPVs com necessidades de adaptações em sua sinalização, a não conformidade mais comum verificada é a ausência da sinalização indicativa com a expressão "Fiscalização de Veículos por Agente Remoto".

Os requisitos de sinalização para operação dos PPVs com Pista Seletiva HS-WIM não foram abordados nesses diagnósticos técnico-operacionais. Dessa forma, caso determinado PPV comece a operar com Pista Seletiva HS-WIM, deverá ser implantada sinalização específica para esse fim.

\subsection{SOLUÇÃO TECNOLÓGICA}

Os requisitos presentes na Resolução no 5.379/2017, da ANTT, constituem a base para o diagnóstico técnico-operacional referente à solução tecnológica dos PPVs, pois contemplam não somente os regulamentos do CONTRAN e do DENATRAN para a operação com o agente remoto, mas também as diretrizes da própria Agência para esse tipo de fiscalização. Considerando essa conjuntura, a solução tecnológica a ser implementada nos PPVs com Agente Remoto da ANTT consiste em um total de oito sistemas, que, por sua vez, são compostos por 13 elementos distintos (equipamentos e software). Por fim, considerando-se todos os elementos, há um total de 44 requisitos específicos a serem considerados na solução tecnológica desses PPVs.

No processo de diagnóstico, verificou-se que nenhum dos Postos visitados atende integralmente às diretrizes e aos requisitos fixados para a operação com agente remoto. Assim, os diferentes PPVs foram classificados em função de três diferentes níveis de conformidade, conforme mostra a Figura 9. 
Figura 9: Nível de conformidade dos PPVs com os requisitos estabelecidos

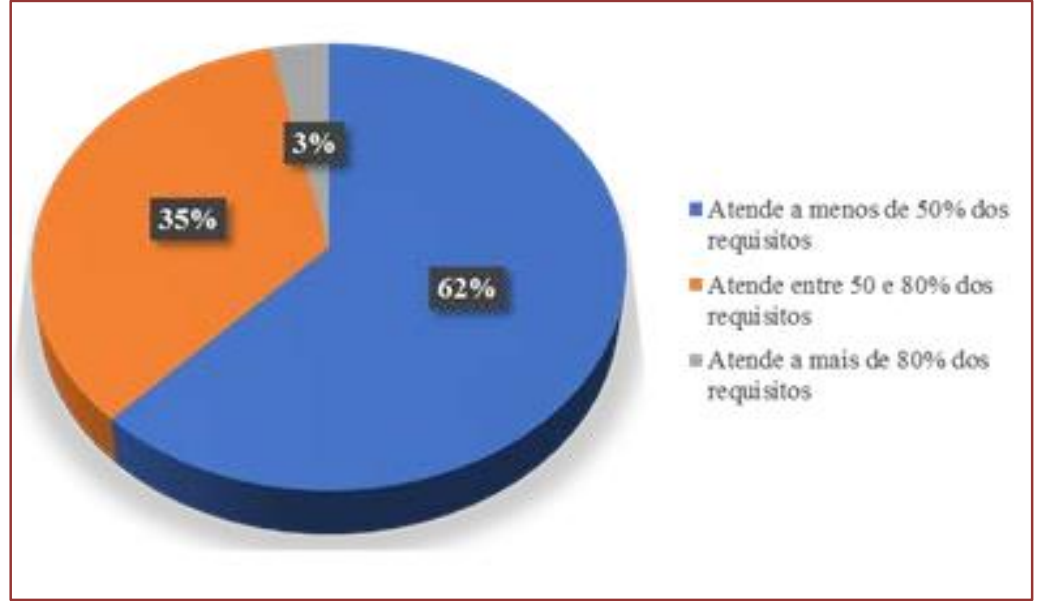

Dentre os 29 PPVs analisados, 18 Postos (62\%) apresentaram menos de 50\% dos requisitos atendidos. Nesse contexto, dos 44 requisitos específicos a serem considerados na solução tecnológica desses PPVs, o requisito menos cumprido se refere ao sistema de classificação veicular, que, segundo a Resolução no 5.379/2017, deve operar sem interrupções para determinação dos limites de peso de cada veículo. Essa funcionalidade se mostrou ausente em $96 \%$ dos PPVs.

A Figura 10 mostra os elementos da solução tecnológica dos PPVs, sejam eles equipamentos sejam eles softwares, com maiores níveis de não conformidade com os requisitos e as diretrizes estabelecidos para a operação com agente remoto.

Figura 10: Elementos da solução tecnológica com maiores índices de não conformidade

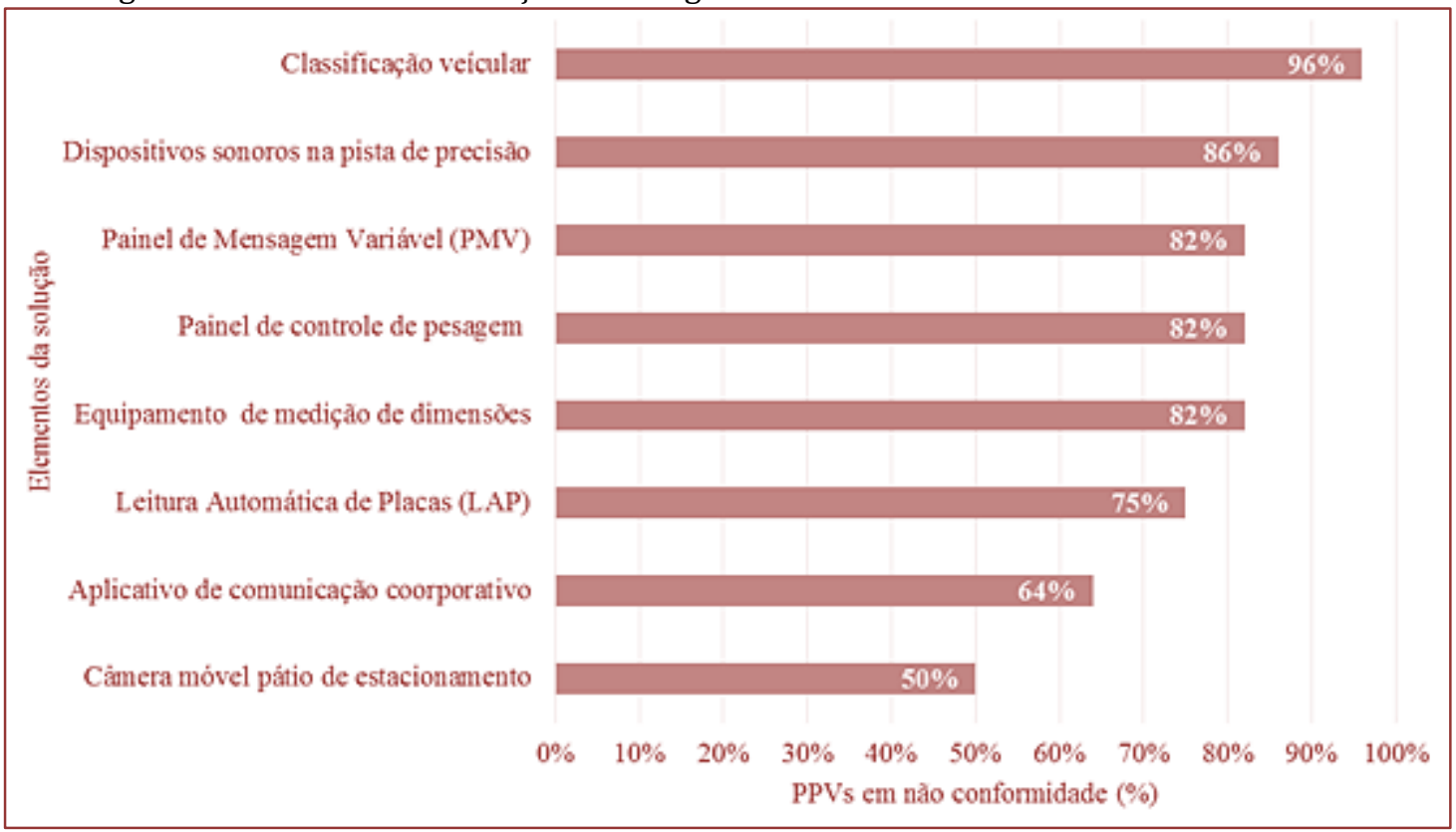




\subsection{INFRAESTRUTURA}

O diagnóstico da infraestrutura nas imediações dos PPVs determina a viabilidade técnica para a implantação de sistemas HS-WIM para fins de pré-seleção de veículos potencialmente infratores, a partir de medições realizadas na velocidade diretriz das rodovias. Assim, o resultado dos diagnósticos apontou que, dentre os 29 Postos levantados, quatro PPVs (14\%) atendem integralmente aos requisitos de infraestrutura e de geometria necessários para a implantação imediata desse tipo de solução, conforme explicitado no subcapítulo 3.2 deste artigo. No entanto, outros PPVs podem implantar os sistemas HS-WIM desde que sejam realizadas as adaptações sugeridas no diagnóstico técnico-operacional.

0 requisito menos atendido para a implantação de sistemas HS-WIM se refere à necessidade de alocação de um segmento na rodovia que não apresente influências (entradas e saídas) de tráfego desde o seu ponto central até a entrada do Posto de Fiscalização. Nesse contexto, dos 29 totais analisados, 19 (66\%) Postos possuem alguma influência de tráfego desde o ponto central do segmento viável para instalação de HS-WIM até a entrada do Posto. A ausência de entradas ou de saídas entre o ponto de instalação do sistema HS-WIM e o Posto de Fiscalização é importante para que todos os veículos passem pelo devido processo de inspeção.

\section{CONSIDERAÇÕES FINAIS}

0 diagnóstico técnico-operacional tratado neste artigo representa uma etapa anterior à elaboração dos projetos para adequação dos PPVs, da ANTT. Nesse sentido, os diagnósticos atuam como facilitadores na elaboração desses projetos, pois contém uma visão objetiva sobre os elementos específicos que precisam ser adaptados para a operação com agente remoto e sobre a viabilidade da implantação de sistemas HSWIM.

Tanto a operação com agente remoto quanto a utilização de sistemas HS-WIM são inovações regulamentadas nos âmbitos técnico e legal no Brasil. Portanto, o método de levantamento de campo elaborado para o processo de diagnóstico busca abordar não somente o potencial técnico dos PPVs em operação, mas também evidenciar diretrizes para que os Postos operem em conformidade com os regramentos vigentes para fiscalização.

O processo de adaptação dos PPVs ao modelo de operação com agente remoto iniciou em 2018, mesmo ano em que o primeiro Posto implantou essa modalidade de fiscalização em Tanguá/RJ, após a adaptação dos elementos de sinalização e de solução tecnológica apontados pelo diagnóstico. Em relação à implantação de sistemas HS-WIM para pré-seleção, esse tipo de operação será testado e validado por meio de um projetopiloto no PPV de Itapecerica da Serra/SP, localizado na altura do $\mathrm{km} \mathrm{296}$, da rodovia BR-116, sentido São Paulo/SP.

\section{REFERÊNCIAS}

[1] ANTT (2017) - Resolução no 5.379 de 05 de julho de 2017. Agência Nacional de Transportes Terrestres, Brasília.

[2] ANTT e LABTRANS (2018) - Termo de Execução Descentralizada 01/2017/ANTT - Caderno 4: Modelo de Projeto Funcional de Posto de Fiscalização com Utilização de Sistemas de Pesagem HS-WIM. Agência Nacional de Transportes Terrestres; Laboratório de Transportes e Logística da Universidade Federal de Santa Catarina, Florianópolis.

[3] ANTT e LABTRANS (2019) - Termo de Execução Descentralizada 01/2017/ANTT - Relatório Gerencial 05 (RG05). Agência Nacional de Transportes Terrestres; Laboratório de Transportes e Logística da Universidade Federal de Santa Catarina, Florianópolis.

[4] Chotickai, P. (2012) - Field Evaluation of Weigh-In-Motion Systems on Weight Enforcement Operation. Advances in Civil Engineering and Building Materials - Selected Peer Reviewed Papers from 2012 2nd International Conference on Civil Engineering and Building Materials, CEBM 2012. Anais...2012.

[5] CONTRAN (2013) - Resolução no 459 de 29 de outubro de 2013. Conselho Nacional de Trânsito, Brasília.

[6] CONTRAN (2015) - Resolução no 547 de 19 de agosto de 2015. Conselho Nacional de Trânsito, Brasília.

[7] DENATRAN (2010) - Portaria no 870 de 26 de outubro de 2010. Departamento Nacional de Trânsito, Brasília.

[8] DNIT e LABTRANS (2007) - Levantamento de Sistemas de Pesagem em Movimento Existentes no Mundo.

[9] Departamento Nacional de Infraestrutura de Transportes; Laboratório de Transportes e Logística da Universidade Federal de Santa Catarina, Florianópolis. 
[10] Hanson, R.; Klashinsky, R.; Mcgibney, S. (2010) - ITS Technologies for Commercial Vehicle Compliance in the Maritimes. TAC/ATC 2010 - 2010 Annual Conference and Exhibition of the Transportation Association of Canada: Adjusting to New Realities. Anais...

[11] Jacob, B.; Feypell-De La Beaumelle, V. (2010) - Improving truck safety: Potential of weigh-in-motion technology. IATSS research, v. 34, n. 1, p. 9-15.

[12] Klashinsky, R.; Hanson, R.; Mcgibney, S. (2009) - Real World Applications of Virtual Weigh Stations. TAC/ATC 2009 - 2009 Annual Conference and Exhibition of the Transportation Association of Canada: Transportation in a Climate of Change. Anais...

[13] Leavitt, W. (1995) - ITS on the way. Trucking Technology, v. 2, n. 4, p. 18-27.

[14] Levy, Y; Ellis, T.J. (2006) - A Systems Approach to Conduct an Effective Literature Review in Support of Information Systems Research. Informing Science Journal, Florida, USA, v. 9, p.181-212..

[15] Trischuk, D.; Berthelot, C.; Taylor, B. Weigh-in-motion applications for intelligent transportation systemscommercial vehicle operations: Evaluation using WESTA. Transportation Research Record, n. 1816, p. 87-95, 2002.

[16] Wagar, B.; Bushman, R.; Taylor, B. (2007) - Development and Deployment of a Remotely Controlled Weigh Station. TAC/ATC 2007 - 2007 Annual Conference and Exhibition of the Transportation Association of Canada: Transportation - An Economic Enabler. Anais... Saskatchewan Highways and Transportation, Saskatoon, SK, Canada. 


\section{Capítulo 9}

Análise do transporte de minério: Uma abordagem financeira utilizando o método de Black \& Scholes em opções reais ${ }^{2}$

\section{Rodrigo Rodrigues de Freitas \\ Diego Manoel Enedino Gonçalves \\ Thiago de Souza Cardoso Mayrink Paiva}

Resumo: 0 custo em transporte possui um peso grande na tomada de decisão dos agentes de negócios. A escolha correta poderá proporcionar retornos maiores em médio e longo prazo, uma vez que, a maior parte do aporte se concentra em bens físicos. Na pesquisa procura-se abordar o modelo de Black \& Scholes com procedimento twin security (comparação de dois modelos com métodos semelhantes). Esse método de precificação de ativos financeiros é mais utilizado no momento, pois absorve as oscilações de mercados em ex-nunc, ou seja, daqui para frente. Foram utilizadas três empresas: MRS Logística S.A. e Companhia Siderúrgica Nacional - CSN para ferrovia, em relação ao mineroduto a empresa foi Anglo Ferrous Brazil subsidiária da Anglo American. Sobre quaisquer hipóteses, o transporte por ferrovia foi o melhor no período analisado (2008 e 2016).

Palavra-Chave: Opções reais, Análise de investimento, Transporte de minério

${ }^{2}$ Artigo apresentando no 32 Congresso de Pesquisa e Ensino em Transporte da ANPET. 


\section{INTRODUÇÃO}

0 transporte de carga é um dos parâmetros que compõe o custo logístico, em um terminal de distribuição. Técnicas e ferramentas de gestão orientam o gestor na tomada de decisão, a fim de mitigar o risco inerente ao mercado de transporte. Um sistema de transporte eficiente proporciona uma sociedade mais consciente a preservação do meio ambiente, a integração das pessoas e uma distribuição de mercadorias com preços acessíveis aos cidadãos e as empresas. Segundo D`Agosto (2015) o sistema de transporte é a integração de recursos materiais, humanos, financeiros e intelectual necessários para o deslocamento, como de pessoas e de cargas.

Empresas presentes no mercado de transporte de carga têm suas receitas afetadas por diversas variáveis, os principais fatores capazes de influenciar o custo de transporte são o volume de carga, periodicidade de transporte e os custos de manutenção e operação. Os custos são muito sensíveis a choques externos e volatilidade de mercado, alguns exemplos são: variações no preço dos insumos, valor da mercadoria, demanda, inflação, impacto ambiental entre outros. Shafiee, Topal e Nehring (2009) descreve o método de avaliação de opções reais - ROV como forma de maximizar a produção de minas e enfatiza que a variável mais importante é o preço e tamanho da reserva. Fatores que exige do gestor habilidades constantes na tomada de decisões referentes a projetos que possam agregar valor, reduzir os riscos e lidar com a volatilidade e incerteza presentes tanto em projetos de investimento, quanto no mercado de atuação. Venables, Laird e Overman (2014) enfatiza que os impactos do sistema de transporte são amplos, se tratando de três dimensões: benefícios ao usuário, aumento de produtividade e efeitos em investimento e emprego.

Os dados da pesquisa foram copilados em dois períodos após o investimento inicial, entre os anos de 2014 até 2016, projetado a taxa livre de risco de 6,13\% ao ano. 0 investimento na estrada de ferro corresponde dois trechos distintos, o primeiro pertence a Companhia Siderúrgica Nacional - CSN, e o segundo a MRS Logística S/A. 0 trecho que compreende $428 \mathrm{~km}$ entre as cidades de Brumadinho e Itaguaí no estado do Rio de Janeiro, mais 98km que compreende a Casa da Pedra até Congonhas de responsabilidade de Companhia Siderúrgica Nacional - CSN, ambas no estado de minas Gerais, totalizando 526 km de distância. As obras do duto são referentes ao maior mineroduto do mundo da empresa Anglo Ferrous Brazil (pertencente à Anglo American) onde os investimentos estavam estimados em 3,6 bilhões de dólares com prazo de execução de três anos. As obras iniciaram em 2008 e foram finalizados em 6 anos, com investimento de 15 bilhões de dólares. A pesquisa compreende valores aproximados do real planejado, uma vez que, os dados não foram solicitados as empresas citadas, e sim pesquisadas em balanço social e agências reguladoras.

Visando tomar decisões financeiras em projetos, o investidor utiliza diversas ferramentas de análise de investimentos com objetivo de obter uma visão mais clara e ampla do projeto, além de fornecer ao mesmo tempo, um olhar mais crítico, permitindo tomar decisões mais assertivas. A importância da utilização de diversas ferramentas, mediante ao fato que, nenhuma ferramenta é capaz de fornecer todas as respostas, porém, uma combinação pode complementar, e em muitos casos é suficiente para decidir entre diferentes projetos, analisando suas características, mensurando seu potencial para agregar maior valor as empresas, ao retorno do investimento, período de execução do projeto, entre outros.

A pesquisa comparou o transporte de carga ferroviário e dutoviário estabelecidos e operacionais, a fim de, verificar em quais modelos são mais eficientes, quais variáveis afetam mais as decisões de aporte em projetos, à luz de ferramentas de análise de investimento sob incerteza. Ambos os modos de transporte possuem o mesmo produto e finalidade. 0 transporte de minério de ferro em minas, localizado no estado de Minas Gerais sendo transportado para o estado do Rio de Janeiro. Na impossibilidade de obter resultados de uma linha de mineroduto ao lado de uma linha férrea, utiliza-se na pesquisa o mesmo produto com quilometragem semelhante. A proposta da pesquisa é demonstrar a importância das ferramentas financeiras sob incerteza, a fim de obter maior resultado e poder de decisão. Segundo Minardi (2004) a flexibilidade em um projeto financeiro é apenas uma possibilidade, e não uma obrigação, porém aumenta as chances de acerto na tomada de decisão. Aplica-se a teoria das opções reais - TOR como processo de comparação twin security, mediante o incremento do movimento geométrico browniano. Lee (2011) diz a respeito que a opção está vinculada a incerteza do projeto, pois ao contrário do fluxo de caixa descontado, onde o valor do investimento se deprecia com o aumento da volatilidade, o método TOR valoriza a flexibilidade gerencial como uma opção incorporada. Como a proposta é analisar possíveis empresas estabelecidas ou em implantação, o processo faz-se uma análise probabilística em ex-nunc, ou seja, daqui para frente. 
A análise compreende dois projetos de transporte de minério, um através do investimento no mineroduto, e outro através do investimento em estrada de ferro, ambos entre os estados de Minas Gerais e Rio de Janeiro com aproximadamente $530 \mathrm{~km}$ de extensão. Após a introdução, a segunda sessão tem por objetivo justificar a motivação para a realização desta pesquisa, a terceira sessão apresenta os métodos e modelos utilizados, na quarta sessão deste artigo aplica-se os resultados obtidos através dos métodos e modelos matemáticos previamente introduzidos, e por fim, a quinta sessão contempla a conclusão e os resultados obtidos.

\section{FORMULAÇÃO DO PROBLEMA}

A pesquisa tem por finalidade apresentar a melhor proposta de acordo com o método de teoria das opções reais - TOR, utilizando-se da comparação entre os modelos de transporte ferroviário e dutoviário, uma vez que, ambos possuem o menor custo por produto transportado em longo prazo, porém com alto custo de implementação. 0 mineroduto possui uma extensão de aproximadamente $530 \mathrm{Km}$ entre as cidades de Alvorada de Minas no estado de Minas Gerais até a cidade de São João da Barra no norte do estado do Rio de Janeiro, passando por 32 cidades. Possui a capacidade de transportar em média $2.500 \mathrm{~m}^{3} / \mathrm{h} \mathrm{ou}$ 15.000.000 de toneladas ao ano com um investimento de 15 bilhões de dólares em seis anos. A estrada de ferro compreende dois trechos, o primeiro entre as cidades de Congonhas até Brumadinho com a extensão de $98 \mathrm{~km}$, e segundo trecho entre Brumadinho até Itaguaí com a extensão de 428 km, totalizando 526 km da extensão até o transbordo.

Os métodos tradicionais de análise de investimento como é o caso do Fluxo de Caixa Descontado - FCD, não satisfazem uma pesquisa de longo prazo, pois ao longo do tempo, a economia e os indicadores financeiros sofrem perturbações externas e oscilações temporais. Segundo Dixit e Pindyck (1994) o método do Valor Presente Líquido - VPL ou o Fluxo de Caixa Desconto - FCD não conseguem absorver o valor da flexibilidade, pois não consegue se antecipar ao risco previsto, ocorre principalmente porque utiliza de desconto uma taxa constante, logo esse método é utilizado para análise livre de risco, uma vez que, a taxa de desconto é constante e não mudará ao longo do tempo. Segundo Sharpe (1964), Lintner (1965), Black (1972), a taxa livre de risco é utilizada para reduzir risco do investimento em portfólio, por mais que foi muito criticada por Fama e French (1992) por não proporcionar correlação positiva entre o retorno e o beta de mercado. Para determinar a melhor estimação dos dados Copeland, Koller e Murrin (1995) propuseram que a melhor taxa livre de risco seria o retorno de um portfólio com beta igual a zero, já proposto por Black (1972).

O FCD é orientado para ambiente com baixa ou sem oscilação, partindo dessa premissa, optou-se pela aplicação da Teoria das Opções Reais - TOR, devido a sua capacidade de incorporar incertezas ao valor do projeto além de precificar o valor da opção, auxiliando no processo de tomada de decisão. Segundo Santos e Pamplona (2001) e Dixit e Pindyck (1994) o fluxo de caixa tradicional não absorve mudanças probabilísticas e são irreversíveis, contudo, a utilização da TOR mitiga o risco do projeto, pois esse método possui características reversíveis antecipando movimentos de forma probabilística. O FCD possui características irreversíveis, assumindo uma posição de agora ou nunca com a taxa de desconto estacionária ao longo do tempo.

No processo gerencial deve-se observar como as informações afetam a tomada de decisão, os impactos e sua relação com o ambiente interno e externo da empresa. A assimetria de informação distorce a interface e a percepção que o gestor tem em relação aos dados ambientais. Segundo Minardi (2000) e Trigeorges (1993), a assimetria resultante criada pela adaptabilidade requer uma regra para um VPL expandido que reflita os dois valores componentes: o VPL tradicional (estático ou passivo) e o valor da opção de operação e adaptabilidade estratégica. Dessa forma, têm-se:

$V P L=-$ Investimento $+\sum_{i=0}^{\infty} \frac{C F}{(1+i)^{n}},($ VPL estático)

e;

VPL expandido = VPL estático (passivo) + Valor da Opção (Flexibilidade administrativa) (2) 
A flexibilidade administrativa está relacionada ao valor da opção, neste caso se utiliza opções europeias de compra e de venda ao longo da pesquisa. Segundo Santos e Pamplona (2005) a opção de compra é o valor da flexibilidade administrativa pelo fato do investidor ter o direito, mas não a obrigação de exercê-la. Entre os tipos de precificação se aplica o modelo de Black \& Scholes (1973) para estabelecer uma aproximação da realidade de acordo com oscilação do mercado e de choques exógenos, pois o modelo possui variáveis que mensura os impactos do mercado no valor da empresa.

\section{METODOLOGIA APLICADA}

A utilização do procedimento metodológico proporciona uma visão mais esclarecedora do processo de pesquisa, uma vez que, utilização do processo twin security onde procura-se replicar um fluxo de caixa de um ativo similar. Para ambos os modelos de transporte, ferroviário ou dutoviário, faz-se uma comparação utilizando o modelo Black \& Scholes para determinar qual ativo em situação de compra ou de venda é mais rentável.

\section{Modelo de Black \& Scholes}

\section{Opção de compra}

$$
C=S_{0} \cdot N\left(d_{1}\right)-E_{C} e^{-r \cdot T} \cdot N\left(d_{2}\right)
$$

Em que:

$C=$ Preço da Opção de Compra.

$S_{0}=$ Preço do ativo real no momento atual.

$E c=$ Valor do investimento em produtividade.

$r=$ Taxa livre de risco.

$T$ = Tempo para o vencimento da opção, em anos.

$\sigma=$ Volatilidade do preço do ativo, expressa ao ano.

$N(.)=$. Função de distribuição normal acumulada.

\section{Opção de venda}

$$
P=+E_{v} \cdot e^{-r \cdot T} \cdot N\left(-d_{2}\right)-S_{0} \cdot N\left(-d_{1}\right)
$$

Em que:

$P=$ Preço da Opção de Venda.

$S_{0}=$ Preço do ativo real no momento atual.

$E_{v}=$ Preço de venda do projeto E (valor de mercado).

$r=$ Taxa livre de risco.

$T=$ Tempo para o vencimento da opção, em anos.

Onde:

$$
d_{1}=\frac{\ln \left(\frac{S_{0}}{E_{v}}\right)+\left(r+\frac{\sigma^{2}}{2}\right) T}{\sigma \sqrt{T}}
$$

e;

$$
d_{2}=d_{1}-\sigma \sqrt{T}
$$




\section{OBSERVAÇÃO DOS EFEITOS GERADOS EM LONGO PRAZO DO MODELO BROWNIANO EM RELAÇÃO À VOLATILIDADE}

O modelo de Black \& Scholes segue o movimento browniano geométrico (MGB) com drift e volatilidade constante de acordo com o Processo de Wiener, contudo, é orientado a utilização em ambientes com volatilidade até $30 \%$, pois acima desse valor o modelo não apresenta confiabilidade de projeção adequada, em países com grandes oscilações de risco de seus ativos financeiros, o modelo de Black \& Scholes não é recomendado. Testes realizados utilizando métodos de Monte Carlo demonstram que o aumento da volatilidade possui tendência a zero no longo prazo.

Alguns produtos, nesta pesquisa demonstrada em commodities, sofre interferência de variações exógenas, como o modelo possui variáveis estocásticas, quanto maior o prazo de utilização, maior será o choque externo em relação a tendência. De acordo com Evatt et al. (2010) e Haque, Topal e Lilford (2014), a utilização da abordagem estocástica possui limitações em relação ao tempo, esse problema está associado ao sistema de Hamilton-Jacobi-Bellman de equações diferencial parcial, por isso, é usual a utilização de métodos numéricos. O MGB segue uma distribuição de probabilidade log-normal, não admitindo valores negativos.

Em simulações computacionais, o aumento da volatilidade apresentou uma sensibilidade para valores em até $30 \%$, respeitando uma certa tendência em longo prazo com aumento de entropia. 0 aumento da volatilidade aumenta a entropia no modelo, pois a linha do gráfico passa a ter uma tendência a zero perdendo a sua eficácia. Como os investidores são esperançosos em obter maiores retornos para seus projetos, em ambientes de alta volatilidade, esses ficaram "sempre" na expectativa da taxa aumentar para obter um maior retorno.

Esse modelo é orientado para situações de médio prazo em ativos de commodities, pois a extensão de tempo de execução, assim como a oscilação da taxa de risco poderão induzir uma análise errada do projeto. Segundo Jovanovic (2014) os preços das commodities comumente são impactados pela oscilação e incerteza sobre o preço futuro, uma vez que, esses produtos são negociações de forma antecipada, podendo impactar no preço de venda no futuro. Por isso, Kulatilaka e Marcus (1992), Laughton e Jacoby (1993), Pickles e Smith (1993), Kulatilaka e Trigeorgis (1994), Mauer e Ott (1995), Palm e Pearson (1986), Cavender (1992) passaram a utilizar nos métodos de análise a opção de abandono especificamente no mercado de Petróleo e Gás como forma de verificar outras oportunidades de negócios ou esgotamento do projeto, pelas constantes oscilações dos preços das commodities.

Em testes de Monte Carlo, a utilização de valores aleatórios, mensurando a sensibilidade do modelo em relação ao risco do ativo, o modelo perde a eficácia com volatilidade acima de 30\%. A figura 1 apresenta uma simulação com variações acima de $50 \%$, a volatilidade tende a zero. Quando a volatilidade se aproxima de $30 \%$, o aumento do prazo de avaliação tende a aumentar a oscilação dos dados. 0 aumento da volatilidade provoca um estado de entropia de forma acentuada até $30 \%$, porém ainda aceitável, e transpondo a faixa de $50 \%$ a volatilidade tende a zero perdendo a sua eficácia.

Figura 1: Volatilidade histórica simulada do preço do minério de ferro (março/86 - março/2016

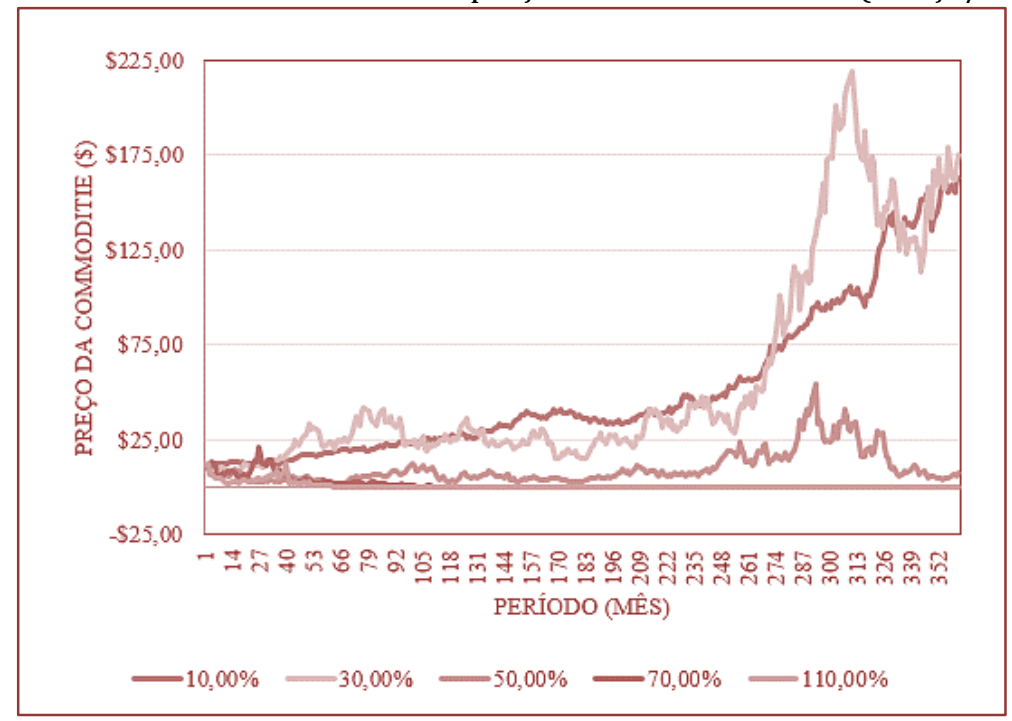




\section{APLICAÇÃO COMPARATIVA UTILIZANDO O MODELO DE BLACK \& SCHOLES EM TWIN SECURITY}

A escolha do modelo comparativo entre os fluxos de caixa, por si só, não corresponde qual investimento poderá oferecer o maior retorno ao longo de tempo, pois simplesmente a escolha do maior volume monetário não é critério, uma vez que, os investimentos iniciais são distintos um dos outros e o retorno no tempo é diferente na sua aplicação. 0 modelo ferroviário possui uma estrutura mais linear, contudo o modelo dutoviário possui uma necessidade de investimento maior no curto prazo, sendo amortizado ao longo dos anos. Utiliza-se como critério o espaço de dois períodos de análise, uma vez que, o modelo de Black \& Scholes precifica as opções em médio prazo partindo de uma observação ex-nunc ou "daqui para frente". Segundo Copeland e Antikarov (2003), "Uma opção é o direito, mas não a obrigação, de tomar uma ação (Ex. adiar, expandir, contratar ou abandonar) a um custo predeterminado chamado preço de exercício, durante um determinado período de tempo". A pesquisa recolheu dados de empresas envolvidas no transporte de minério da extração até o porto para exportação, onde ambos os modelos de transporte são utilizados para exportação via navio.

Tabela 1: Expectativas dos valores do modo ferroviário 2014-2016

\begin{tabular}{|l|c|}
\hline \multicolumn{1}{|c|}{ Modo ferroviário } & (a.a) \\
\hline Fluxo de caixa atual (2015) & $\$ 536.427 .939,88$ \\
\hline Valor Presente (VP) (2015) & $\$ 3.831 .628 .142,00$ \\
\hline Valor Presente (VP) (2017) & $\$ 4.314 .157 .373,45$ \\
\hline Valor de mercado em longo prazo & $\$ 21.551 .182 .979,23$ \\
\hline Valor de mercado atual (2017) & $\$ 3.017 .165 .617,09$ \\
\hline Investimento inicial (2014) & $\$ 2.592 .010 .543,39$ \\
\hline Investimento inicial (2017) & $\$ 2.918 .430 .751,47$ \\
\hline Taxa Básica de juros em 10/2016 & $14 \%$ \\
\hline Taxa livre de risco (a.a) & $6,11 \%$ \\
\hline Volatilidade do ativo & $30,00 \%$ \\
\hline Vencimento (anos) & 2 \\
\hline Fonte: Produção própria * valor de mercado atualizado a inflação de 7,89\% a.a.
\end{tabular}

Substituindo os dados da Tabela 1 nos itens [5] e [6];

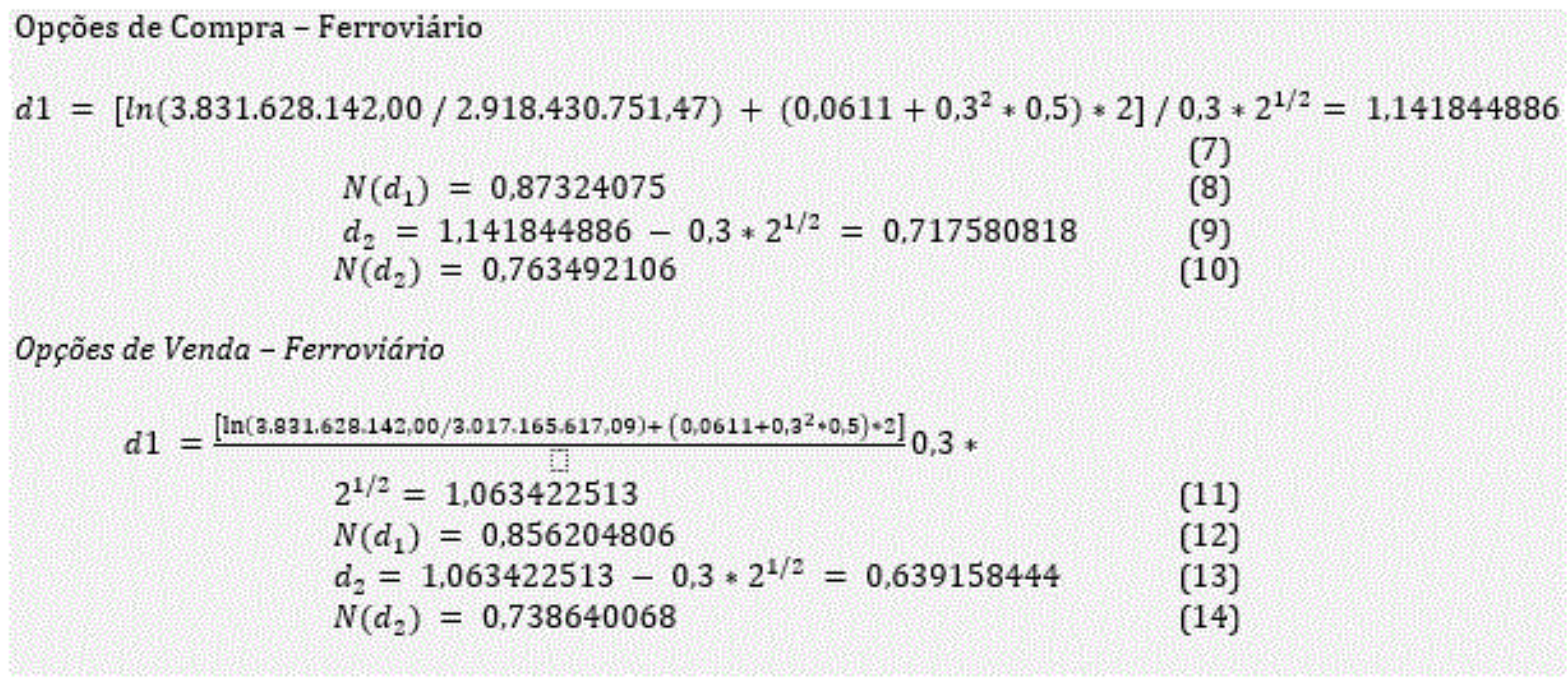


Tabela 2: Expectativas dos valores do modo dutoviário 2014-2016

\begin{tabular}{|c|c|}
\hline Modo dutoviário & (a.a) \\
\hline Fluxo de caixa atual (2015) & $\$ 346.568 .667,85$ \\
\hline Valor Presente (VP) (2015) & $\$ 2.475 .490 .484,64$ \\
\hline Fluxo Presente (VP) (2017) & $\$ 2.787 .236 .947,70$ \\
\hline Valor de mercado em longo prazo & $\$ 29.932 .076 .828,57$ \\
\hline Valor de mercado atual (2017) & $\$ 4.190 .490 .756,00$ \\
\hline Investimento inicial (2014) & $\$ 3.600 .000 .000,00$ \\
\hline Investimento inicial (2017) & $\$ 4.053 .359 .556,00$ \\
\hline Taxa Básica de juros em 10/2016 & $14 \%$ \\
\hline Taxa livre de risco (a.a) & $6,11 \%$ \\
\hline Volatilidade do ativo & $30,00 \%$ \\
\hline Vencimento (anos) & 2 \\
\hline
\end{tabular}

Fonte: Produção própria * valor de mercado atualizado a inflação de 7,89\% a.a.

Substituindo os dados da Tabela 2 nos itens [5] e [6];

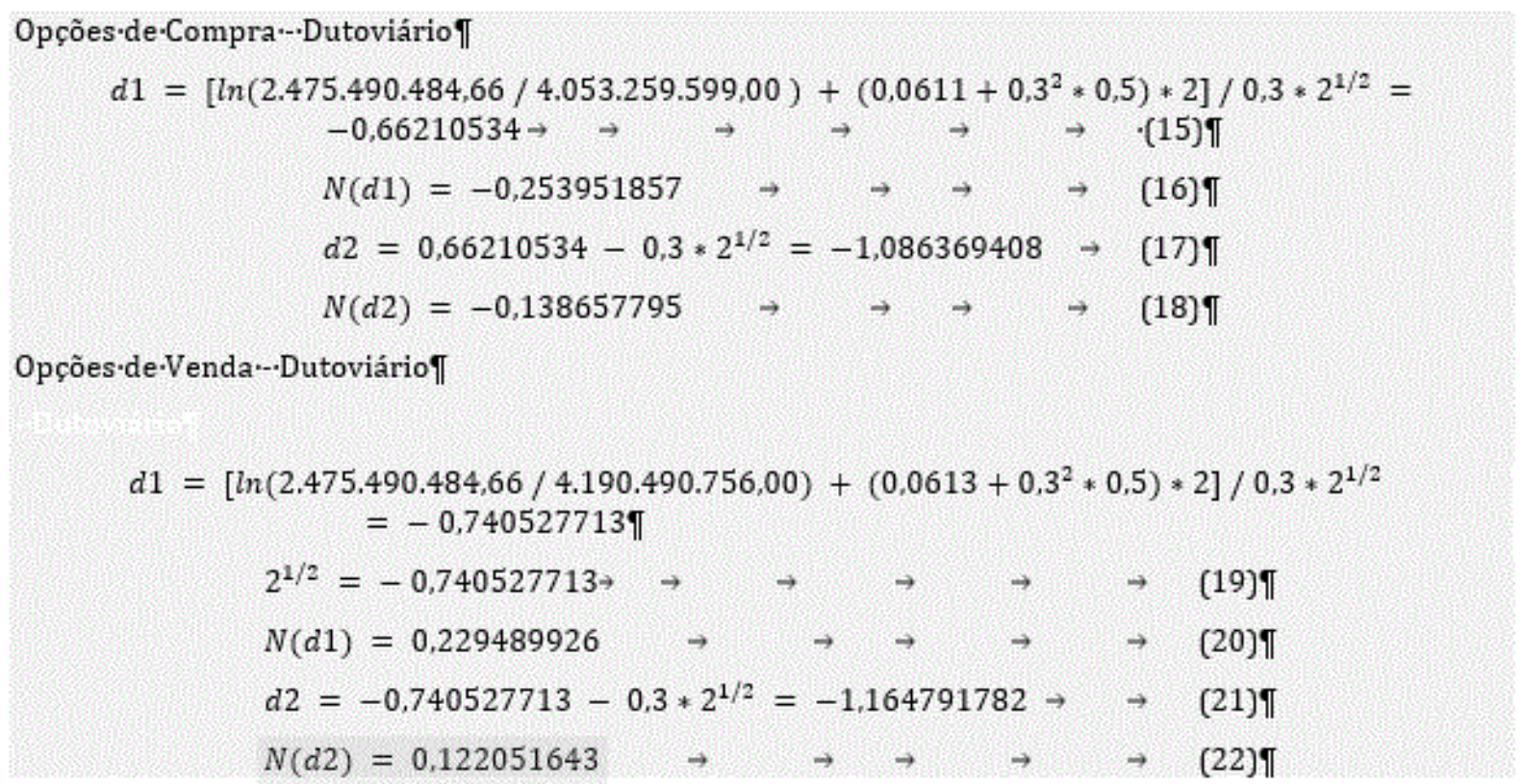

Desta forma, pode-se obter os dados das opções de compra e de venda para os modos ferroviário e dutoviário, substituindo nos itens [3] e [4]; 


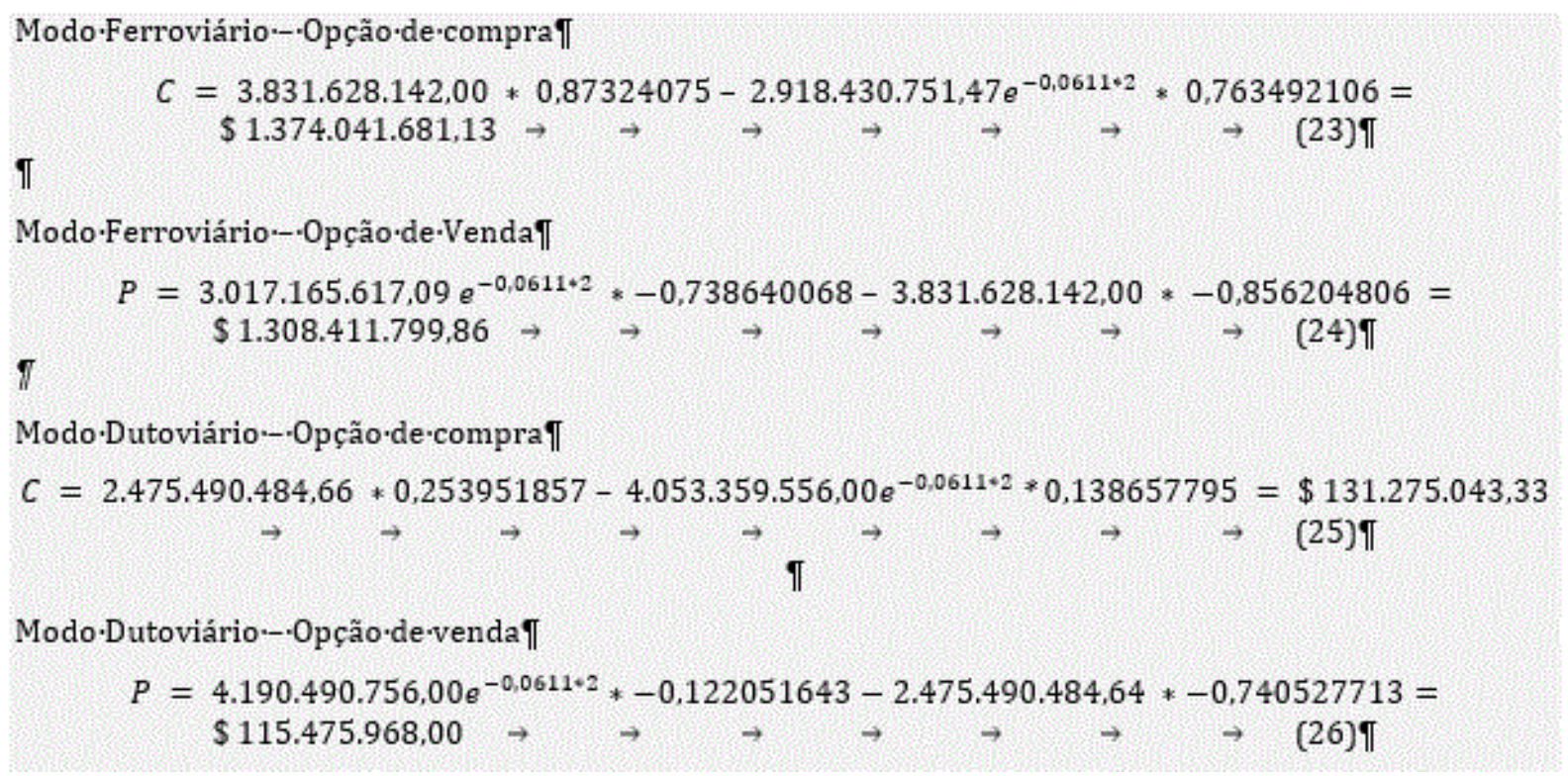

De acordo com Minardi (2000) e Trigeorges (1993) deve-se calcular o VPL expandido para ter o valor do projeto com a flexibilidade administrativa. Utilizando os dados dos itens [1] em perpetuidade, [2] e [3] para opção de compra e venda sucessivamente;

Substituindo os dados da Tabela 1 no item [2];

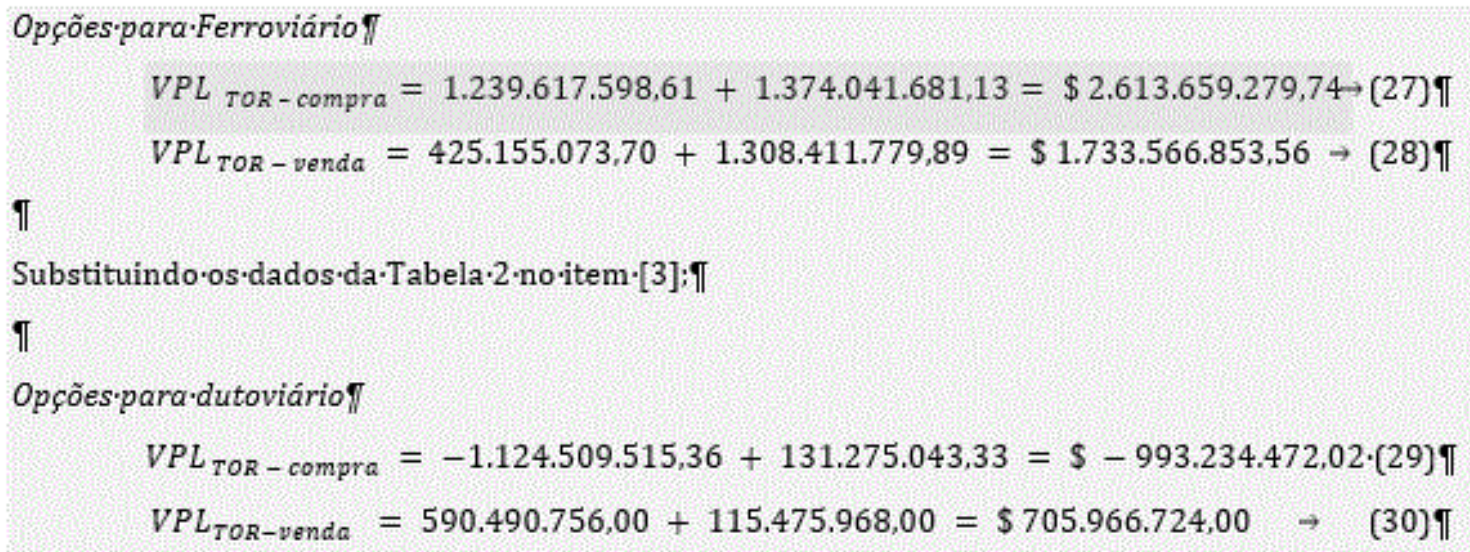

Os dados da pesquisa apontam que o cenário econômico de 2016, a melhor opção para investimento em transporte de minério foi Ferroviário, pois o investimento inicial de 3,6 bilhões de dólares no modo dutoviário não se mostrou favorável em relação ao fluxo de caixa anual de $\$ 346.568 .667,85$. 0 valor presente atual em perpetuidade de \$2.475.490.484,64, não cobre o investimento inicial em 2016. Logo, não deverá ocorrer nenhum investimento no modelo dutoviário neste cenário.

A tabela 3 simula os dados da pesquisa com a taxa livre de risco de 7,1\% ao ano e taxa básica de juros de 13\%, esse cenário ocorreu em agosto de 2008, quando a Anglo American compra os direitos para exploração e implantação do mineroduto. Observando o período proposto, ainda assim, não é vantajoso adquirir os direitos do mineroduto, pois a opção de compra está descoberta em relação ao investimento de 3,6 bilhões de dólares. O fluxo de caixa anual de $\$ 346.568 .667,85$, ou valor presente atual em perpetuidade de \$2.665.912.829,62 não cobre o investimento inicial. 
Tabela 3: Simulação taxa livre de risco de 7,1\% (a.a) e taxa básica de juros de $13 \%$

\begin{tabular}{|l|c|}
\multicolumn{1}{|c|}{ Método } & Resultado \\
\hline VPL $_{(\mathrm{TOR})}$ ferroviário compra & $\$ 3.173 .417 .253,03$ \\
\hline $\mathrm{VPL}_{(\mathrm{TOR})}$ ferroviário venda & $\$ 2.001 .166 .078,36$ \\
\hline $\mathrm{VPL}_{(\mathrm{TOR})}$ dutoviário compra & $\$-748.061 .269,12$ \\
\hline $\mathrm{VPL}_{(\mathrm{TOR})}$ dutoviário venda & $\$ 638.432 .194,84$ \\
\hline
\end{tabular}

Fonte: Produção Própria

A tabela 4 demonstra que no modelo dutoviário, mesmo com investimento de 15 bilhões de dólares, o modelo ferroviário ainda seria a melhor opção. Pois a opção de compra estaria em descoberto. O VPL (TOR) de ambas as opções não cobre o investimento inicial no período atual. Optou-se pelo tempo de dois anos na simulação, pois foi observado que neste período ocorrem as principais mudanças nos valores referentes ao risco do investimento.

Tabela 4: Simulação com investimento no mineroduto em \$ 15 bilhões em 2014

\begin{tabular}{|l|c|}
\hline \multicolumn{1}{|c|}{ Método } & $\begin{array}{c}\text { Resultado } \\
\text { VPL(TOR) ferroviário compra }\end{array}$ \\
\hline VPL(TOR) ferroviário venda & $\$ 579.224 .718,18$ \\
\hline VPL(TOR) dutoviário compra $_{(12.273,93}$ & $\$-12.524 .503 .386,71$ \\
\hline VPL $_{(\mathrm{TOR})}$ dutoviário venda & $\$ 2.460 .382 .464,30$ \\
\hline
\end{tabular}

Fonte: Produção Própria

\section{CONSIDERAÇÕES FINAIS}

0 resultado final confere o valor da opção ou da flexibilidade administrativa para tomada de decisão, pois a utilização do modelo de Black \& Scholes absorve as oscilações de mercado, reduzindo os impactos em relação as diferenças do retorno financeiro e auxilia na tomada de decisões gerenciais.

A comparação da opção de compra ou de venda devem ser feitas em relação ao investimento, a opção de

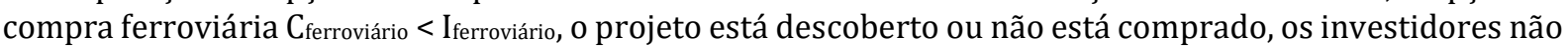
poderão optar pelo investimento em produtividade. A opção de venda ferroviária $\mathrm{P}_{\text {ferroviário }}<\mathrm{I}_{\text {ferroviário, }} \mathrm{a}$ operação está descoberta, ou não está vendido. 0 investidor poderá obter duas decisões. Exercer a opção de abandono, vendendo o projeto ao preço atual de mercado ou continuar com o projeto, pois a opção de compra é maior que a opção de venda, e a opção de compra está entre os dois investimentos no período, mudanças na taxa básica da economia e inflação poderão favorecer o investimento. Em relação ao investimento em duto, a opção de compra Cdutoviário < Idutoviário, a operação está descoberto ou não está comprada, os investidores não poderão optar por investir para produzir, no longo prazo o fluxo de caixa

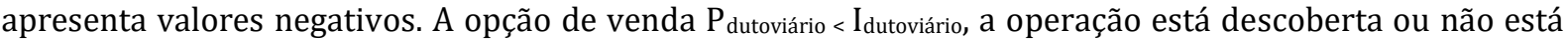
vendida, não existe melhor opção, exercer o direito de abandono é a única opção, contudo, a diferença entre a opção de venda e o valor atual de mercado será um desafio conseguir um comprador. 0 investimento em transporte por duto não deverá ser exercido de acordo com o cenário de 2016, a taxa livre de risco em 6,13\% a.a. e taxa básica de juros em 14\% a.a.

As principais contribuições da pesquisa foram a simulação da volatilidade do modelo geométrico browniano - MGB, onde admite a precificação de ativos com valores estocásticos de no máximo 30\%, acima desse valor, o modelo apresentou uma tendência de queda, o que é improvável no longo prazo. A importância do modelo de Black \& Scholes para ambientes de alta volatilidade e intensidade de variáveis externas torna-se uma opção interessante na apuração de um valor presente líquido - VPL, sendo mais apropriado ao ambiente de negócios incertos, justamente por apresentar um valor próximo da realidade. Uma vez que o modelo absorve as oscilações de mercado.

A taxa de juros e a inflação dos países possuem grande participação no desenvolvimento em infraestrutura, pois quanto maior as taxas, maior é o incentivo em financeirizar o capital, desincentivando o investimento em bens fixo de produção. Isso ocorre, porque o custo do dinheiro para o tomador de empréstimo fica maior, 
neste caso, a preferência dos investidores é aumentar os ganhos de capital com menor esforço, tornando-se emprestador.

O resultado do trabalho apresenta necessidades de simular o modelo em países com forte presença de choque cambial, assim como, os impactos da taxa básica de juros e da inflação no longo prazo e suas distorções entre nações desenvolvidas e em desenvolvimento.

\section{OBSERVAÇÃO}

0 modelo atual foi otimizado referente ao apresentado ao $32^{\circ}$ Congresso de Pesquisa e Ensino em Transporte da ANPET.

\section{REFERÊNCIAS}

[1] Black, F.; Jensen, M.; Scholes, M. (1972). The Capital Asset Pricing Model: Some Empirical Tests. Studies in the Theory of Capital Markets.

[2] Black, F.; Scholes, M. (1973). The pricing of options and corporate liabilities. Journal of Political Economy, v.81, n.3, p.637-654.

[3] Cavender, B. (1992). Determination of the optimum lifetime of a mining project using discounted cash flow and option pricing techniques, Mining Engineering, pp 1262-1268.

[4] Copeland, T; Koller, T.; Murrin, J. (1995). Valuation: Measuring and Managing the Value of Companies. McKinsey \& Company Inc.

[5] Copeland, T.; Antikarov. (2003). A. Real Options: A Practitioner's Guide; Texere, New York.

[6] D’agosto, M. A. (2015). Transporte, uso de energia e impactos ambientais - Uma abordagem introdutória - 1. ed. - Rio de Janeiro: Elsevier.

[7] Dixit, A. K.; Pindyck, R.S. (1994). Investment under uncertainty. Princeton, New Jersey: Princeton University Press.

[8] Evatt. G; Johnson. P, Duck. P.; Howell S. (2010). The measurement and inclusion of a stochastic ore-grade uncertainty in mine valuations using pdes. IAENG International Journal of Applied Mathematics, 40 (4):1-7.

[9] Fama, E. F.; French, K. R. (1992). The Cross-Section of Expected Stock Returns. The Journal of Finance. v.67, n. 2.

[10] Haque, M.; Topal, E.; Lilford. E. (2014). A numerical study for a mining project using real options valuation under commodity price uncertainty. Resources Policy, 39(1):115-123.

[11] Jovanovic, S.; (2014). Hedging Commodities: A practical guide to hedging strategies with futures and options. Harriman House, Belgrade.

[12] Kulatilaka, N.; Marcus, A J. (1992). Project valuation under uncertainty: When does DCF fail? Journal of Applied Corporate Finance, 5:92-100.

[13] Kulatilaka, N.; Trigeorgis, L. (1994). The general flexibility to switch: Real option revisited, The International Journal of Finance, 6:778-798.

[14] Laughton, D. G.; Jacoby, H. D. (1993). Reversion, timing options, and long-term decision-making, Financial Management, 22:225-240.

[15] Lee, H. (2011). A Real Option Approach to Valuating Infrastructure Investments. MSc Thesis, KDI School of Public Policy and Management. Retrieved.

[16] Lintner, John. (1965). The valuation of risk assets and the selection of risky investments in stock portfolios and capital budgets, Review of Economics and Statistics, 47 (1), 13-37.

[17] Mauer, D C.; Ott, S H. (1995). Investment under uncertainty the case of replacement investment decisions, The Journal of Financial and Quantitative Analysis, 30:581-605.

[18] Minardi, A.M.A.F. (2000) Teoria de opções reais aplicada a projetos de investimentos. Revista de Administração de Empresas (RAE-FGV), São Paulo, v.40, n.2, p.74-79.

[19] Minardi, A. M. A. F. (2004) Teoria das Opções aplicada a projetos de investimento. São Paulo: Atlas.

[20] Palm, S K.; Pearson, N D. (1986). Option pricing: A new approach to mine valuation, Canadian Institute of Mining, Metallurgy and Petroleum Bulletin, May, pp 61-79. 
[21] Pickles, E.; Smith, J L. (1993). Petroleum property valuation: A binomial lattice implementation of option pricing theory, The Energy Journal, 14:1-26.

[22] Sharpe, W. F. (1964). Capital Asset Market Prices: A Theory of Market Equilibrium Under Conditions of Risk. The Journal of Finance, v. 19, n. 3.

[23] Santos, E. M.; Pamplona, E. O. (2005). Teoria das Opções Reais: uma atraente opção no processo de análise de investimentos. Revista de Administração da USP - RAUSP, v.40, n.3.

[24] Shafiee, S.; Topal, E.; Nehring, M. (2009). Adjusted Real Option Valuation to Maximise Mining Project Value - A Case Study Using Century Mine. Project Evaluation Conference, Melbourne, Vic, 21.

[25] Trigeorgis, L. (1993). The nature of options interactions and the valuation of investments with multiple real options. Journal of Financial and Quantitative Analysis, v.28, n.1, p.1-21.

[26] Venables, A.; Laird, J.J.; Overman, HG (2014) Transport investment and economic performance: Implications for project appraisal. Research Report. Department for Transport. 


\section{Capítulo 10}

Seleção de sítios aeroportuários - Estudo de caso para o aeroporto de Balsas (MA)

\section{Teotonio Ko Freitag}

José dos Santos de Magalhães

Anderson Schmitt

Rafael Cardoso Cunha

Amir Mattar Valente

Resumo: 0 presente trabalho relata um processo de seleção de sítio para o aeroporto de Balsas (MA). Considerando-se que há necessidade de avaliar vários requisitos e opiniões conflitantes na seleção de um sitio aeroportuário, a metodologia da pesquisa está baseada na utilização do método Analytical Hierarchy Process (AHP). Foram indicados sete sítios potenciais e o processo foi conduzido por um time de especialistas e tomadores de decisão. Foram selecionados 14 critérios e definidos fatores para avaliação da importância relativa desses critérios, levando-se em consideração as normas e regulamentos referentes à implantação de um novo aeroporto e a experiência dos especialistas. As áreas potenciais para o novo sítio aeroportuário foram avaliadas em relação a cada um dos critérios elencados, utilizando-se uma escala Likert. Para apoiar essa avaliação, foram realizadas visitas técnicas e sobrevoo dos sítios. Ao final, recomendaram-se três áreas propícias para estudos mais aprofundados.

Palavras-chave: Seleção de sítio aeroportuário. Analytical Hierarchy Process (AHP). Aeroportos. 


\section{INTRODUÇÃO}

De acordo com a Secretaria Nacional de Aviação Civil (SAC), o desenvolvimento econômico observado na primeira década do século XXI, em conjunto com as medidas regulatórias e a liberdade tarifária aplicadas ao setor aéreo brasileiro causaram impactos positivos no crescimento do setor (Brasil, 2018). Dados da Agência Nacional de Aviação Civil mostram que a demanda por transporte aéreo no Brasil triplicou nos últimos dez anos. 0 futuro também se mostra positivo, pois a projeção de demanda da aviação civil no período entre 2017 e 2037 prevê um crescimento de 6,14\% ao ano, no cenário otimista, e 3,35\%, no cenário conservador (Brasil, 2017).

Diante desses cenários, é essencial que o Poder Público e os demais atores planejem ações conciliadas com o crescimento do setor e o desenvolvimento econômico e social do País. Entre as funções do planejamento do setor aéreo, está a localização de novas infraestruturas de transporte, dentre estas a de novos aeroportos (Merkisz-Guranowska et al., 2016). Nesse contexto, o Plano Aeroviário Nacional (PAN) 2018-2038 prevê a implantação de novos aeroportos regionais em seus cenários de desenvolvimento, os quais demandam estudos detalhados quanto à sua localização. (Brasil, 2018).

Novas infraestruturas de transportes impulsionam a economia local, gerando postos de trabalho e atraindo novos investimentos. É necessário, por um lado, localizar um novo aeroporto o mais próximo possível do polo gerador de demanda, visando minimizar os custos com relação à acessibilidade. Por outro lado, os aeroportos geram fenômenos indesejáveis, como a poluição sonora, exigindo que estejam situados a uma determinada distância de áreas residenciais e equipamentos públicos e privados com função social. Além disso, certas áreas podem apresentar restrições, como aquelas inseridas em áreas de proteção ambiental. Deste modo, os custos das compensações ambientais e desapropriações somam um montante que pode indicar inviabilidade perante os benefícios projetados para a infraestrutura. (Mim, 1994; MerkiszGuranowska et al., 2016; Brasil, 2018).

0 processo de planejamento de novos aeroportos requer a participação de diversos atores, como organizações públicas, ambientais e a população local. Os interesses e expectativas desses atores podem ser muitas vezes conflitantes, sinalizando a necessidade de um método flexível de tomada de decisão. Em cenários como este, o uso de uma abordagem multicriterial para a resolução do problema de localização mostra-se adequado (Merkisz-Guranowska et al., 2016).

Este trabalho apresenta uma aplicação real do Método de Análise Hierárquica (AHP - Analytic Hierarchy Process) na prospecção de um novo sítio aeroportuário no município de Balsas, no estado do Maranhão. A Seção 2 apresenta a área de estudo bem como as alternativas de áreas prováveis para a implantação do novo aeroporto. A Seção 3 detalha a metodologia aplicada, a Seção 4 apresenta a avaliação das áreas indicadas e os resultados obtidos e, por fim, a Seção 5 traz as conclusões do trabalho.

\section{2. ÁREA DE ESTUDO}

Situado no sul do estado do Maranhão e pertencente à Microrregião dos Gerais de Balsas, o município de Balsas conta com extensão territorial de $13.141,757 \mathrm{~km}^{2}$ e uma população de 93.829 habitantes, segundo estimativas do Instituto Brasileiro de Geografia e Estatística (IBGE, 2018). A cidade está localizada às margens do Rio das Balsas, à uma distância de 798 km da capital estadual, São Luís.

Para o estudo de seleção de uma área para o novo aeroporto, a Prefeitura de Balsas requisitou uma avaliação técnica para sete locais potenciais, sendo um de sua propriedade e os demais constituídos por áreas privadas oferecidas por seus proprietários para eventual negociação com a Prefeitura, em caso de sua seleção para o novo aeroporto. Na Figura 1, é possível visualizar o mapa da cidade e a localização dessas áreas.

A Área 1 está localizada dentro dos limites do município de Balsas, é de propriedade da Prefeitura Municipal, situa-se a $9 \mathrm{~km}$ do centro da cidade e é acessada pela BR-330. A Área 2, também dentro dos limites do município, é de propriedade particular e está situada a $13 \mathrm{~km}$ do centro da cidade. 0 acesso ao local se dá pela BR-230 e a área já dispõe de uma Pista de Pouso e Decolagem (PPD) utilizada por aeronaves da aviação agrícola. A Área 3 é de propriedade privada e situa-se no município, a aproximadamente $15 \mathrm{~km}$ do centro da cidade. 
Figura 1: Localização do munícipio de Balsas e das áreas potenciais

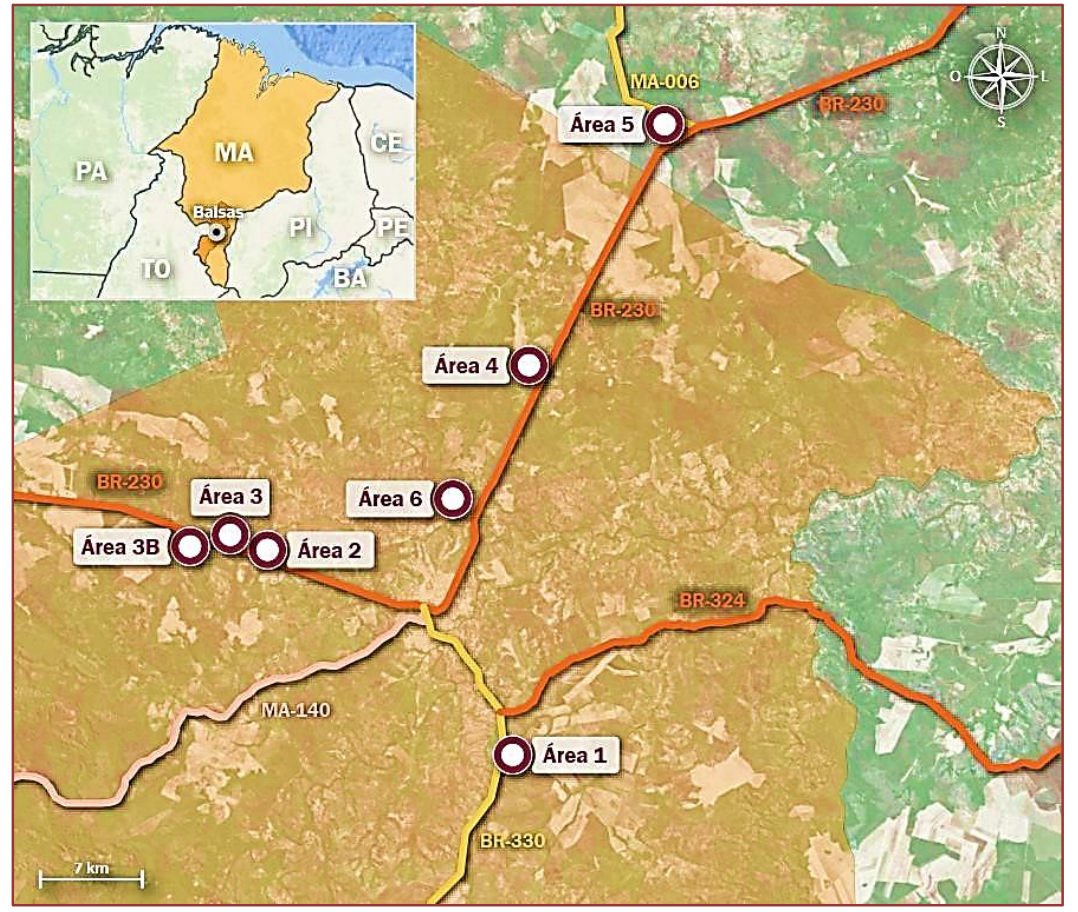

A Área 3B também é de propriedade particular, localiza-se no município de Balsas, a cerca de $17 \mathrm{~km}$ do centro da cidade, com acesso pela BR-230. A Área 4 é de propriedade particular, situa-se a aproximadamente $18 \mathrm{~km}$ do centro de Balsas e pode ser acessada a partir da BR230. A Área 5 é a área mais distante do centro de Balsas, de propriedade particular, porém, situada no município vizinho, Fortaleza dos Nogueiras. Essa área está a $37 \mathrm{~km}$ do centro de Balsas, a $52 \mathrm{~km}$ do centro de Fortaleza dos Nogueiras e o acesso ao local é feito por meio da rodovia BR-230. Por último, a Área 6, também é de propriedade particular e situa-se ao norte do município de Balsas. 0 acesso a o local é realizado por meio da rodovia BR-230 e a área está situada a $8 \mathrm{~km}$ do centro da cidade.

\section{MÉTODO}

0 processo de localização de um novo aeroporto é um problema complexo de tomada de decisão, complexidade esta que decorre dos diversos fatores quantitativos e qualitativos envolvidos, muitas vezes conflitantes entre si (Mim, 1994). Como a participação dos decisores na aplicação do método é fundamental para sua eficácia, é necessária a utilização de uma ferramenta de fácil compreensão teórica. Diante desse cenário, em que há necessidade de avaliar, também, vários requisitos e desenvolver avaliações complexas, pode-se recorrer ao método AHP proposto por Thomas L. Saaty (1980).

A Figura 2 apresenta o fluxograma com as etapas de utilização do método para a seleção de sítio para o Aeroporto de Balsas.

O método AHP facilita o processo de tomada de decisão em ambientes complexos por meio da simplificação do processo natural de tomada de decisão. Uma das vantagens do AHP é a possibilidade do estabelecimento de uma estrutura hierarquizada para análise do problema, a qual permite a percepção do modo como as mudanças de prioridades de variáveis de níveis mais altos impactam as prioridades de variáveis de níveis inferiores. Uma outra vantagem do método traduz-se na obtenção de uma visão estruturada do problema, dos cenários, dos atores, dos propósitos e das variáveis de decisão: os critérios. (Saaty e Vargas, 2013). 
Figura 2: Método AHP para escolha de sítio aeroportuário no município de Balsas (MA)

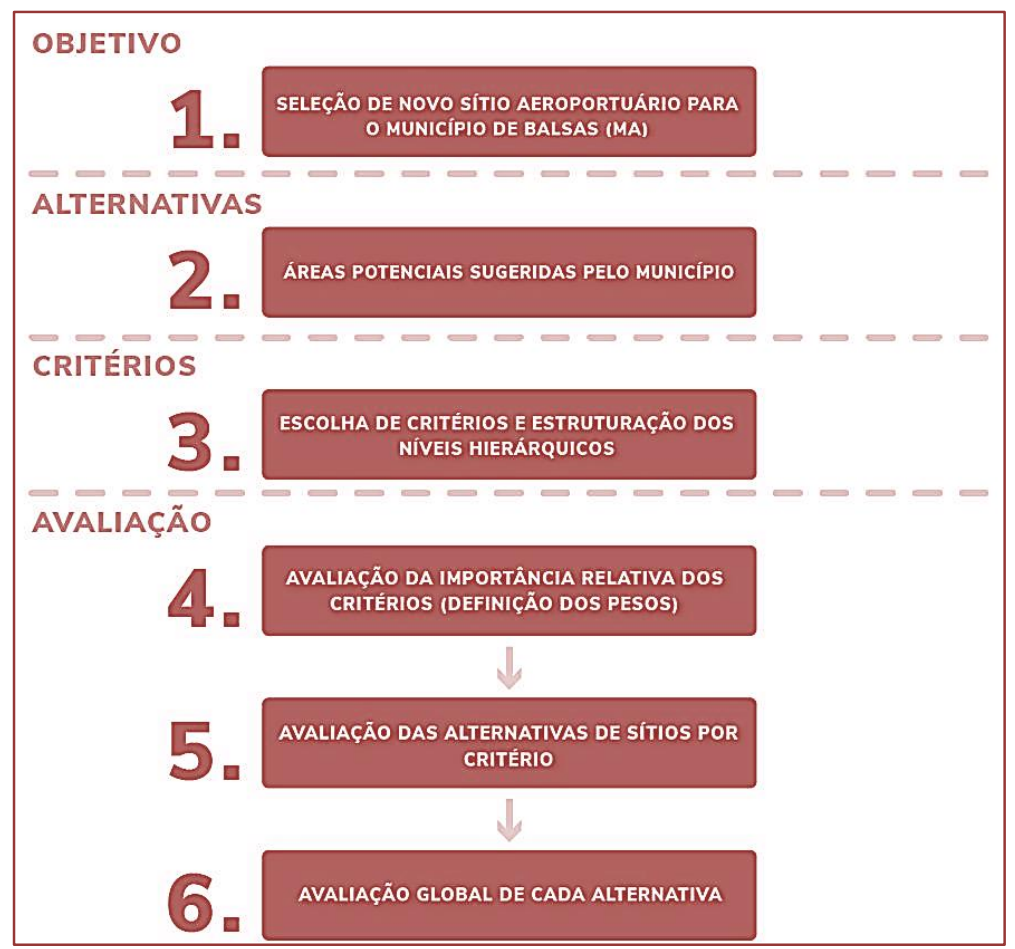

\subsection{ESCOLHA DOS CRITÉRIOS}

A escolha dos critérios foi feita levando-se em consideração as normas e regulamentos referentes à implantação de um novo aeroporto. Também foram feitas diversas reuniões entre técnicos e tomadores de decisão, que culminaram na seleção de 14 critérios, transcritos a seguir, tendo-se definido o que deveria ser observado em cada critério no momento das análises:

- Ventos predominantes: atendimento aos requisitos de orientação de pista com base na direção dos ventos predominantes. 0 movimento das aeronaves, tanto na decolagem quanto no pouso, acontece, sempre que possível, contra o vento. Assim, a orientação deve corresponder a um fator de utilização de pista de, pelo menos, 95\% das ocorrências indicadas no anemograma de distribuição dos dados de vento, observando-se, ainda, os componentes máximos permissíveis de vento de través (ANAC, 2018).

- Plano de Zoneamento de Ruído (PZR): atendimento aos limites das curvas de ruído que representam geograficamente a área de abrangência do ruído aeronáutico decorrente das operações no aeródromo e que apontam restrições quanto ao uso e à ocupação do solo. Para pontuação, deverá ser considerada a Tabela E-1 - Usos compatíveis e incompatíveis para áreas abrangidas pelo Plano Básico de Zoneamento de Ruído (PBZR), conforme o Regulamento Brasileiro de Aviação Civil (RBAC) no 161 (ANAC, 2013).

- Risco aviário: o perigo aviário é uma variável importante na avaliação do risco em que está imersa a atividade aérea. A proximidade a focos atrativos de pássaros pode aumentar a possibilidade de ocorrências de colisões de aeronaves com aves (ANAC, 2011). Deve-se considerar, também, a Resolução Conama no 4/95 (Brasil, 1995) e a Lei no 12.725/2012 (Brasil, 2012), que versam sobre o controle da fauna nas imediações de aeródromos.

- Desenvolvimento urbano: deve-se avaliar a compatibilidade do planejamento urbano ou o próprio desenvolvimento do município quanto à inserção de um aeroporto na área avaliada (Barcelos, 2001). Para tanto, o Plano Diretor Municipal e/ou a Lei de Uso do Solo devem ser considerados.

- Plano Básico de Zona de Proteção de Aeródromo (PBZPA): atendimento às restrições das superfícies limitadoras de obstáculo, as quais estabelecem os limites até onde os objetos podem se projetar no espaço aéreo sem afetar adversamente a segurança e a regularidade das operações aéreas (Brasil, 2015). 
Deve ser considerada a natureza do obstáculo, pois aqueles de fácil remoção e/ou baixo custo de remoção não devem pontuar negativamente.

- Impacto social: a existência de residências e atividades comerciais ou industriais muito próximas ao sítio pode demandar remanejamento de pessoas, empresas, áreas cultiváveis ou associações, devendo ser avaliada neste critério a quantidade de remoções a serem realizadas, seja por desocupações ou desapropriações (Migueis Pereira, 2017). Deve-se, nessa avaliação, diferenciar o tipo de ocupação (residencial, comercial etc.).

- Impacto ambiental: as normas brasileiras instituem a obrigatoriedade da elaboração de estudos de impacto ambiental para o licenciamento de atividades potencialmente danosas ao ambiente (Brasil, 1986). Portanto, a análise dos possíveis impactos do aeroporto no momento da escolha de um novo sítio mostrase importante. A presença de Áreas de Preservação Permanente (APP) e de espécies ameaçadas de extinção no entorno do sítio pode configurar limitação para a implantação ou ampliação do aeroporto. A necessidade de grandes modificações devido a cortes, aterros, remoções de vegetação e massas de água (rios, riachos e lagoas) pode gerar impacto ambiental. Também se deve atentar para a presença de vegetação nativa, fator que deve impactar negativamente. Ressalta-se, ainda, que existência de APP no sítio indicado inviabiliza a sua escolha.

- Impacto arqueológico: o meio socioeconômico deve ser investigado, destacando-se os sítios e monumentos arqueológicos, históricos e culturais da comunidade (Brasil, 1986). A existência de sítios arqueológicos e monumentos históricos pode ser um fator limitador à implantação e expansão do aeroporto, de forma que registros destes nas proximidades da área avaliada aumentam a probabilidade de impeditivos para implantação do novo aeroporto. Destaca-se que a existência de sítios arqueológicos na área potencial inviabiliza a sua escolha.

- Infraestrutura básica: este critério contempla a disponibilidade de fornecimento de água, distribuição de energia elétrica, serviços de telecomunicação, entre outros. Áreas com infraestrutura disponível são mais favoráveis à implantação do sítio, devendo-se avaliar, caso a caso, a possibilidade de se adotar soluções alternativas como poços artesianos, sistema filtro-fossa etc., de forma que não haja penalizações nas avaliações.

- Acessibilidade - qualidade: Segundo Braga e Guedes (2008), entende-se por acessibilidade a facilidade de se chegar ao destino desejado. Este critério corresponde à disponibilidade e qualidade do acesso viário do sítio aeroportuário ao(s) polo(s) gerador(es) de demanda.

- Acessibilidade - distância: Usando-se o mesmo conceito de acessibilidade, este critério corresponde à distância do aeroporto ao(s) polo(s) gerador(es) de demanda.

- Topografia e altimetria: a topografia e a altimetria estão relacionadas às atividades de movimentação de terra (terraplenagem), à possível existência de elevações naturais ou acidentes geográficos e à possibilidade ou não de expansão do aeroporto. Áreas com baixa variação de altimetria são mais favoráveis para a implantação do aeródromo e uma futura expansão.

- Hidrografia e drenagem: hidrografia e drenagem relacionam-se aos eventuais serviços necessários ao escoamento das águas do terreno ou mesmo à adequação da situação existente por meio de dutos, canais, valas, fossos e bueiros para adequação do sítio às obras de infraestrutura, devendo ser avaliada a destinação final do material. Deve-se considerar a presença de áreas inundáveis, as quais configuram risco de inviabilizar o sítio.

- Pedologia: a formação geológica da região e as características físicas do solo permitem calcular sua capacidade de suporte, que determina o tipo de estrutura de fundação, além de avaliar a necessidade de obras de estabilização de taludes e encostas. Permite, também, avaliar a capacidade de infiltração do solo.

\subsection{ESTRUTURAÇÃO DOS NÍVEIS HIERÁRQUICOS}

Após a definição dos critérios para análise, procedeu-se com a fase de construção da hierarquia, que envolve a estruturação do problema em níveis. Nessa fase, o AHP exige que os decisores dividam problemas complexos em uma estrutura hierárquica (Saaty e Vargas, 2013). Essa estruturação do problema faz com que o grupo de decisores participe direta e ativamente no processo decisório, o que pode ocasionar um 
maior comprometimento da implementação da decisão recomendada pelo modelo, visto que esta embute suas preferências e valores (Granemann e Gartner, 1998).

A estrutura hierárquica escolhida pelos decisores no problema de localização do sítio aeroportuário de Balsas possui três níveis, conforme a Figura 3.

Figura 3: Estrutura hierárquica para escolha de novos sítios

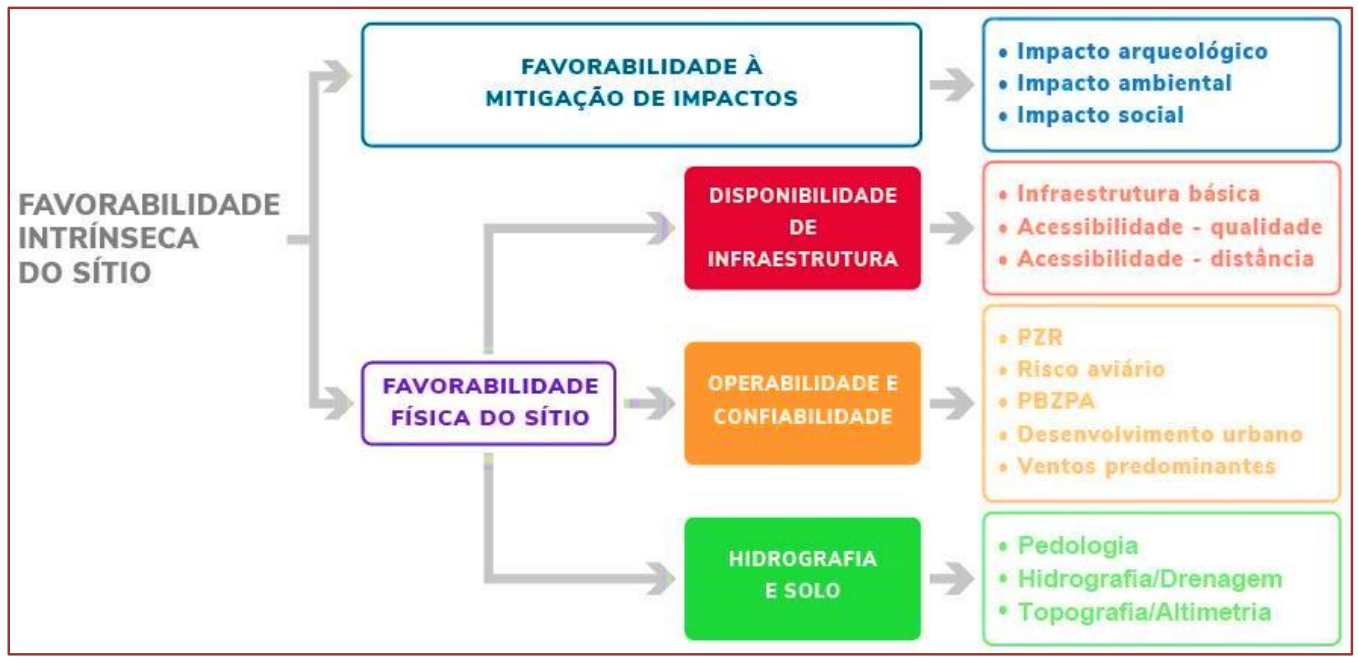

\subsubsection{AVALIAÇÃO DA IMPORTÂNCIA RELATIVA DOS CRITÉRIOS}

Após a hierarquização do problema, inicia-se a fase de avaliação, com a comparação paritária entre os critérios. Por meio dessa comparação, determinam-se as importâncias relativas de cada critério. A escala de pontuação utilizada, sugerida por Saaty e Vargas (2013), é apresentada na Tabela 1.

Tabela 1: Escala fundamental do método AHP

\begin{tabular}{|c|c|c|}
\hline $\begin{array}{l}\text { Intensidade de } \\
\text { Importância }\end{array}$ & Definição & Explicação \\
\hline 1 & Importância igual & $\begin{array}{l}\text { Os dois critérios contribuem igualmente para } \\
\text { o objetivo. }\end{array}$ \\
\hline 3 & $\begin{array}{l}\text { Importância fraca de um sobre o } \\
\text { outro }\end{array}$ & $\begin{array}{l}\text { A experiência e o julgamento favorecem } \\
\text { levemente um critério em relação ao outro. }\end{array}$ \\
\hline 5 & Importância forte & $\begin{array}{l}\text { A experiência e o julgamento favorecem } \\
\text { fortemente um critério em relação ao outro. }\end{array}$ \\
\hline 7 & Importância muito forte & $\begin{array}{l}\text { Um critério é fortemente favorecido em } \\
\text { relação ao outro e sua dominância é } \\
\text { demonstrada na prática. }\end{array}$ \\
\hline 9 & Importância absoluta & $\begin{array}{l}\text { A evidência favorecendo um critério em } \\
\text { relação ao outro é do mais alto grau de } \\
\text { certeza. }\end{array}$ \\
\hline
\end{tabular}

Fonte: Saaty e Vargas (2013).

Conforme definido por Saaty e Vargas (2013), os pesos ou prioridades relativas a serem atribuídos aos critérios são obtidos construindo-se uma matriz normalizada. Em seguida, procede-se à verificação da consistência nos julgamentos efetuados. Para isto, são calculados o autovalor máximo ( $\lambda$ máx) das matrizes de comparação entre variáveis, o Índice de Consistência $(C I)$ e verificada a Razão de Consitência $(C R)$ de 
cada matriz. A metodologia de verificação da consistência e as fórmulas de cálculo do $\lambda m a ́ x, C I$ e $C R$ são detalhadas em Saaty e Vargas (2013).

A etapa de avaliação dos critérios, em pares, de acordo com seu nível na estrutura hierárquica, retorna um vetor de pesos que define o grau de importância dos critérios na avaliação das áreas indicadas. A Figura 4 apresenta o peso final para cada critério. Após o cálculo, verificou-se que os critérios com maiores pesos na avaliação foram: PBZPA, Ventos predominantes e Topografia/Altimetria, que juntos representaram 53\% do peso na avaliação final.

Figura 4: Peso de cada critério avaliado

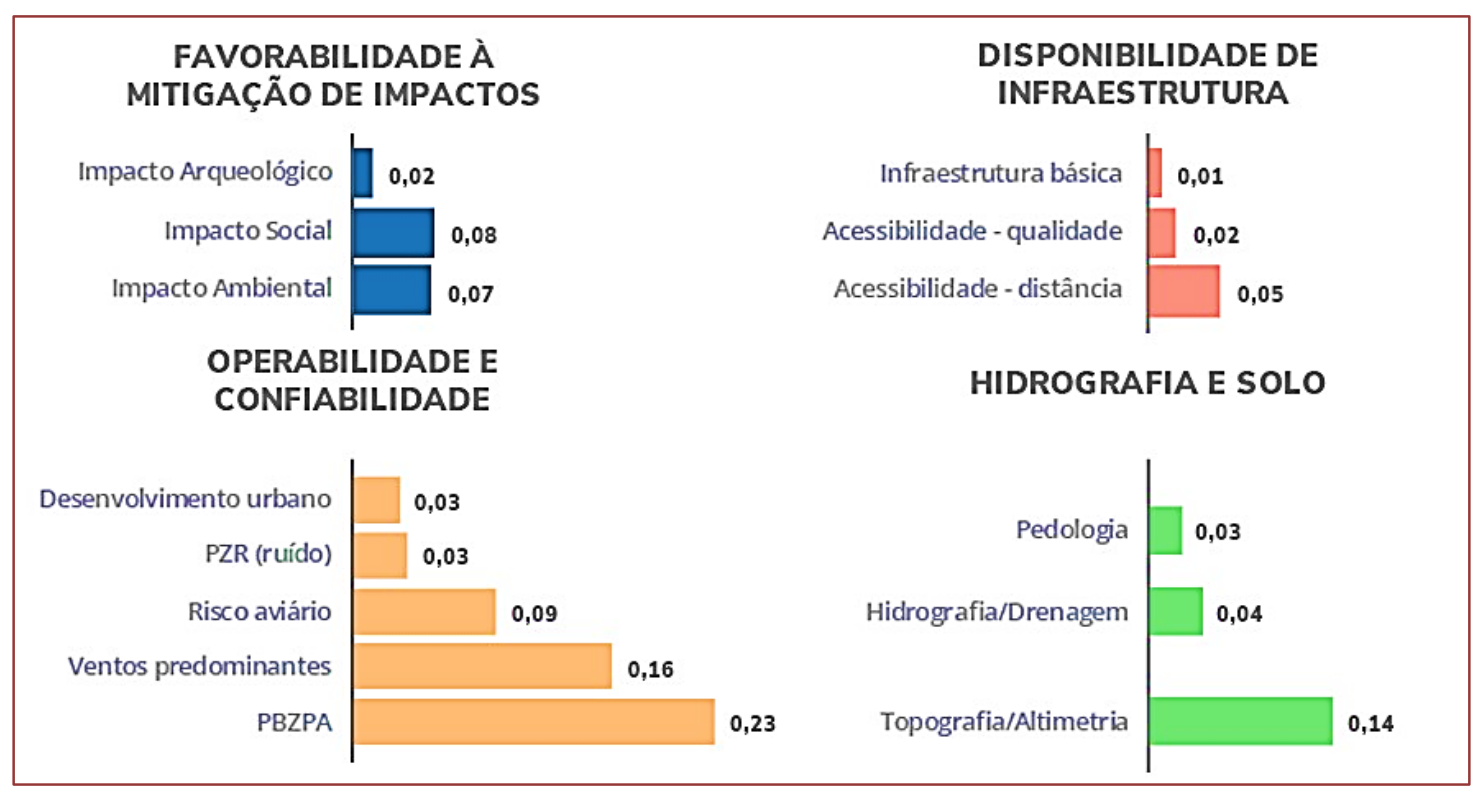

\subsection{AVALIAÇÃO DAS ÁREAS POTENCIAIS}

O próximo passo consistiu em avaliar as áreas potenciais para o novo sítio aeroportuário em relação a cada um dos critérios elencados. As áreas ou sítios potenciais foram pontuados em uma escala Likert (Likert, 1932) graduada de 1 a 5 quanto à sua condição diante dos critérios considerados. Para o quesito Favorabilidade à mitigação de impactos, o grau 5 correspondeu à condição de não haver impacto a considerar, o grau 3 correspondeu a uma condição avaliada como "Regular", e o grau 1 à condição de haver forte impacto. Os graus 2 e 4 foram utilizados para os julgamentos intermediários. Para os grupos Disponibilidade de infraestrutura, Operabilidade e Confiabilidade e Hidrografia e Solo, o grau 5 correspondeu a "Bom", o grau 3 a "Regular" e o grau 1 a "Ruim", sendo, igualmente, os graus 2 e 4 utilizados para condições julgadas como intermediárias.

A pontuação das áreas foi realizada concomitantemente por especialistas e tomadores de decisão, somando um total de dez profissionais. Julgamentos divergentes foram objeto de discussão, chegando-se, posteriormente, a um consenso geral para a pontuação final. A Tabela 2, a Tabela 3, a Tabela 4 e a Tabela 5 apresentam a descrição das condições estabelecidas para a graduação dos critérios pela escala Likert, para os quatro grupos de quesitos considerados. 
Tabela 2: Pontuação escala Likert - Favorabilidade à mitigação de impactos

\begin{tabular}{|c|c|c|c|}
\hline Critério & Impacta fortemente (1) & Regular (3) & Não há impacto (5) \\
\hline $\begin{array}{l}\text { Impacto } \\
\text { Arqueológico }\end{array}$ & $\begin{array}{l}\text { Há estudos que apontam sítios } \\
\text { arqueológicos e/ou monumento } \\
\text { histórico na área (ou distância menor } \\
\text { de } 1 \mathrm{~km} \text { do limite patrimonial). }\end{array}$ & $\begin{array}{l}\text { Há proximidade com } \\
\text { sítio arqueológico e/ou } \\
\text { monumento histórico já } \\
\text { mapeado (em uma média } \\
\text { de } 10 \mathrm{~km} \text { de raio do eixo } \\
\text { da pista planejada). }\end{array}$ & $\begin{array}{l}\text { Há estudos que confirmam } \\
\text { não haver sítio } \\
\text { arqueológico e/ou } \\
\text { monumento histórico na } \\
\text { área. }\end{array}$ \\
\hline \multirow{4}{*}{ Impacto Ambiental } & $\begin{array}{l}\text { Sítio com característica de impacto } \\
\text { ambiental, existência de APP em } \\
\text { grande parte da área avaliada, } \\
\text { podendo inviabilizar sua escolha. }\end{array}$ & $\begin{array}{l}\text { Sítio com área favorável, } \\
\text { devendo ser elencados } \\
\text { trabalhos de mitigação } \\
\text { de impacto. }\end{array}$ & $\begin{array}{l}\text { Sítio com área favorável } \\
\text { para construção de } \\
\text { equipamentos } \\
\text { aeroportuários. }\end{array}$ \\
\hline & $\begin{array}{l}\text { Existência de APP em um raio de até } \\
5 \mathrm{~km} \text { do eixo da pista. }\end{array}$ & $\begin{array}{l}\text { Existência de APP em um } \\
\text { raio de até } 10 \mathrm{~km} \text { do eixo } \\
\text { da pista. }\end{array}$ & $\begin{array}{l}\text { Inexistência de APP em um } \\
\text { raio de até } 20 \mathrm{~km} \text { do eixo } \\
\text { da pista. }\end{array}$ \\
\hline & $\begin{array}{l}\text { Necessidade de desvio de rios ou } \\
\text { aterro de lagoas. }\end{array}$ & $\begin{array}{l}\text { Pequenos córregos } \\
\text { próximos (até } 1 \mathrm{~km} \text { do } \\
\text { eixo da pista). }\end{array}$ & $\begin{array}{l}\text { Inexistência de massas de } \\
\text { águas impactadas. }\end{array}$ \\
\hline & $\begin{array}{l}\text { Vegetação nativa ocupando mais que } \\
90 \% \text { do sítio. }\end{array}$ & $\begin{array}{l}\text { Existência de vegetação } \\
\text { nativa no entorno (até } 1 \\
\text { km do eixo da pista). }\end{array}$ & $\begin{array}{l}\text { Não há observação de } \\
\text { vegetação nativa. }\end{array}$ \\
\hline Impacto Social & $\begin{array}{l}\text { Existência de residências e/ou } \\
\text { atividades comerciais/industriais no } \\
\text { sítio ou muito próximas ao sítio, } \\
\text { gerando necessidade de } \\
\text { remoção/desapropriação/ } \\
\text { desocupação. }\end{array}$ & $\begin{array}{l}\text { Existência de residências } \\
\text { e/ou atividades } \\
\text { comerciais/industriais } \\
\text { próximas ao sítio, que } \\
\text { eventualmente possam } \\
\text { gerar impacto. }\end{array}$ & $\begin{array}{l}\text { Não foram identificadas } \\
\text { residências e/ou atividades } \\
\text { comerciais/industriais } \\
\text { próximas ao sítio, não } \\
\text { gerando necessidade de } \\
\text { remoção/desapropriação/ } \\
\text { desocupação. }\end{array}$ \\
\hline
\end{tabular}

Tabela 3: Pontuação escala Likert - Disponibilidade de infraestrutura

\begin{tabular}{|l|l|l|l|}
\multicolumn{1}{|c|}{ Critério } & \multicolumn{1}{c|}{ Ruim (1) } & \multicolumn{1}{c|}{ Regular (3) } \\
\hline $\begin{array}{l}\text { Infraestrutura } \\
\text { básica }\end{array}$ & Infraestrutura básica não disponível. & $\begin{array}{l}\text { Infraestrutura básica } \\
\text { parcialmente disponível. }\end{array}$ & $\begin{array}{l}\text { Toda a infraestrutura } \\
\text { básica disponível. }\end{array}$ \\
\hline $\begin{array}{l}\text { Acessibilidade - } \\
\text { qualidade }\end{array}$ & Não existe acesso. & $\begin{array}{l}\text { Há necessidade de } \\
\text { melhorias no acesso } \\
\text { existente. }\end{array}$ & $\begin{array}{l}\text { O acesso é de boa } \\
\text { qualidade e atende à } \\
\text { necessidade de tráfego. }\end{array}$ \\
\hline $\begin{array}{l}\text { Acessibilidade - } \\
\text { distância }\end{array}$ & $\begin{array}{l}\text { Distância acima de 30 km do polo } \\
\text { gerador de demanda. }\end{array}$ & $\begin{array}{l}\text { Distância entre 20 km e } \\
\text { 30 km do polo gerador } \\
\text { de demanda. }\end{array}$ & $\begin{array}{l}\text { Distância abaixo de 20 km } \\
\text { do polo gerador de } \\
\text { demanda. }\end{array}$ \\
\hline
\end{tabular}


Tabela 4: Pontuação escala Likert - Operabilidade e confiabilidade

\begin{tabular}{|c|c|c|c|}
\hline Critério & Ruim & Regular & Bom \\
\hline PZR & $\begin{array}{l}\text { O sítio não compreende as } \\
\text { curvas do PBZR de acordo } \\
\text { com a classe esperada do } \\
\text { aeródromo. }\end{array}$ & $\begin{array}{l}\text { O sítio compreende } \\
\text { parcialmente as curvas do } \\
\text { PBZR de acordo com a } \\
\text { classe esperada do } \\
\text { aeródromo. }\end{array}$ & $\begin{array}{l}\text { O sítio compreende as } \\
\text { curvas do PBZR de } \\
\text { acordo com a classe } \\
\text { esperada do aeródromo. }\end{array}$ \\
\hline Risco aviário & $\begin{array}{l}\text { Há mais de um foco de } \\
\text { atração de aves no sítio ou } \\
\text { em sua proximidade. }\end{array}$ & $\begin{array}{l}\text { Foi identificado um foco de } \\
\text { atração de aves no sítio ou } \\
\text { em sua proximidade. }\end{array}$ & $\begin{array}{l}\text { Não há foco de atração de } \\
\text { aves no sítio nem em sua } \\
\text { proximidade. }\end{array}$ \\
\hline PBZPA & $\begin{array}{l}\text { Existem objetos, naturais ou } \\
\text { artificiais, que podem afetar } \\
\text { a segurança das operações } \\
\text { aéreas. }\end{array}$ & $\begin{array}{l}\text { Há soluções de contorno } \\
\text { para eventuais objetos que } \\
\text { podem se constituir em } \\
\text { obstáculos à navegação } \\
\text { aérea. }\end{array}$ & $\begin{array}{l}\text { Não há quaisquer objetos, } \\
\text { naturais ou artificiais, } \\
\text { que possam afetar a } \\
\text { segurança das operações } \\
\text { aéreas. }\end{array}$ \\
\hline $\begin{array}{c}\text { Desenvolvimento } \\
\text { urbano }\end{array}$ & $\begin{array}{l}\text { Não há compatibilidade do } \\
\text { planejamento urbano do } \\
\text { município com a inserção do } \\
\text { aeródromo no sítio. }\end{array}$ & $\begin{array}{l}\text { A inserção do aeródromo } \\
\text { no sítio requer ajustes no } \\
\text { planejamento urbano do } \\
\text { município. }\end{array}$ & $\begin{array}{l}\text { A inserção do aeródromo } \\
\text { no sítio é compatível com } \\
\text { o planejamento urbano } \\
\text { do município. }\end{array}$ \\
\hline $\begin{array}{c}\text { Ventos } \\
\text { Predominantes }\end{array}$ & $\begin{array}{l}\text { O sítio não acomoda a(s) } \\
\text { direção(ões) de pista } \\
\text { desejada(s) em relação aos } \\
\text { ventos predominantes. }\end{array}$ & $\begin{array}{l}\text { O sítio acomoda uma pista } \\
\text { no comprimento desejado, } \\
\text { porém sua orientação não } \\
\text { corresponde ao melhor } \\
\text { fator de utilização. }\end{array}$ & $\begin{array}{l}0 \text { sítio acomoda a(s) } \\
\text { direção(ões) de pista } \\
\text { desejada(s) em relação } \\
\text { aos ventos } \\
\text { predominantes. }\end{array}$ \\
\hline
\end{tabular}

Com relação ao critério Desenvolvimento Urbano (Tabela 4), por se tratar da escolha de sítio para um aeroporto regional, os especialistas e tomadores de decisão acordaram pela abordagem pelo aspecto da compatibilização com o planejamento urbano existente, atribuindo-se notas maiores aos sítios mais próximos da zona urbana, desde que conformes com o planejamento urbano do município.

Tabela 5: Pontuação escala Likert - Hidrografia e solo

\begin{tabular}{|c|c|c|c|}
\hline Critério & Ruim (1) & Regular (3) & Bom (5) \\
\hline $\begin{array}{l}\text { Topografia/ } \\
\text { Altimetria }\end{array}$ & $\begin{array}{l}\text { Existe grande variação de } \\
\text { altimetria no sítio. }\end{array}$ & $\begin{array}{l}\text { Existe variação de } \\
\text { altimetria no sítio que pode } \\
\text { ser ajustada sem grande } \\
\text { esforço de terraplanagem. }\end{array}$ & $\begin{array}{l}\text { Existe pouca variação da } \\
\text { altimetria no sítio. }\end{array}$ \\
\hline $\begin{array}{l}\text { Hidrografia/ } \\
\text { Drenagem }\end{array}$ & $\begin{array}{l}\text { O sítio possui características } \\
\text { hidrográficas desfavoráveis, } \\
\text { com necessidade de grandes } \\
\text { serviços de drenagem. }\end{array}$ & $\begin{array}{l}\text { As características } \\
\text { hidrográficas do sítio } \\
\text { requerem alguns serviços } \\
\text { de drenagem. }\end{array}$ & $\begin{array}{l}\text { O sítio possui } \\
\text { características } \\
\text { hidrográficas favoráveis, } \\
\text { sem necessidade de } \\
\text { grandes serviços de } \\
\text { drenagem. }\end{array}$ \\
\hline Pedologia & $\begin{array}{l}\text { Sítio com características } \\
\text { desfavoráveis quanto à } \\
\text { drenagem e capacidade de } \\
\text { suporte. }\end{array}$ & $\begin{array}{l}\text { Sítio com necessidade de } \\
\text { tratamento e adequação do } \\
\text { solo para implementação } \\
\text { da infraestrutura. }\end{array}$ & $\begin{array}{l}\text { Sítio com características } \\
\text { favoráveis quanto à } \\
\text { drenagem e capacidade } \\
\text { de suporte. }\end{array}$ \\
\hline
\end{tabular}

Após a definição da escala de avaliação, cada sítio potencial foi avaliado individualmente. Para apoiar essa avaliação, a prefeitura de Balsas organizou visitas técnicas e sobrevoo dos sítios. Assim, gerou-se uma matriz que pontuou cada área analisada de acordo com o critério observado. A Tabela 6 aponta a matriz com o resultado dessa pontuação. 
Tabela 6: Matriz de avaliação das áreas segundo os critérios estabelecidos

\begin{tabular}{|llllllll|}
\hline Impacto ambiental & 4,5 & 3,0 & 4,5 & 5,0 & 3,0 & 5,0 & 1,5 \\
Impacto social & 3,5 & 3,0 & 2,5 & 2,5 & 5,0 & 3,0 & 1,0 \\
Impacto arqueológico & 5,0 & 5,0 & 5,0 & 5,0 & 3,0 & 5,0 & 3,0 \\
Infraestrutura básica & 3,5 & 3,0 & 3,0 & 3,0 & 3,0 & 3,0 & 5,0 \\
Acessibilidade - qualidade & 3,5 & 4,5 & 4,5 & 4,5 & 4,0 & 4,5 & 4,5 \\
Acessibilidade - distância & 5,0 & 5,0 & 5,0 & 5,0 & 5,0 & 1,0 & 5,0 \\
$\quad$ PZR & 3,0 & 3,0 & 3,0 & 3,0 & 3,0 & 3,0 & 3,0 \\
\multicolumn{1}{c}{ Risco aviário } & 5,0 & 5,0 & 5,0 & 5,0 & 5,0 & 5,0 & 5,0 \\
$\quad$ PBZPA & 4,5 & 3,5 & 5,0 & 5,0 & 5,0 & 5,0 & 5,0 \\
Desenvolvimento urbano & 5,0 & 1,0 & 5,0 & 5,0 & 5,0 & 1,0 & 1,0 \\
Ventos predominantes & 5,0 & 4,5 & 5,0 & 5,0 & 5,0 & 5,0 & 5,0 \\
Topografia/Altimetria & 5,0 & 1,0 & 4,5 & 5,0 & 3,0 & 4,5 & 1,0 \\
Hidrografia/Drenagem & 5,0 & 1,0 & 5,0 & 5,0 & 1,0 & 5,0 & 5,0 \\
\multicolumn{1}{c}{ Pedologia } & 4,5 & 4,5 & 4,5 & 4,5 & 4,5 & 4,5 & 4,5 \\
\hline
\end{tabular}

\section{RESULTADOS}

Após a avaliação das áreas por critério, procedeu-se a uma avaliação global das mesmas. Para isso, calcularam-se as pontuações parciais de cada sítio multiplicando-se a avaliação das áreas (apresentada na Tabela 6) pelos pesos de cada critério (Figura 4). A Figura 5 apresenta o resultado da pontuação parcial de cada sítio em relação aos critérios considerados.

Figura 5: Pontuação parcial de cada sítio

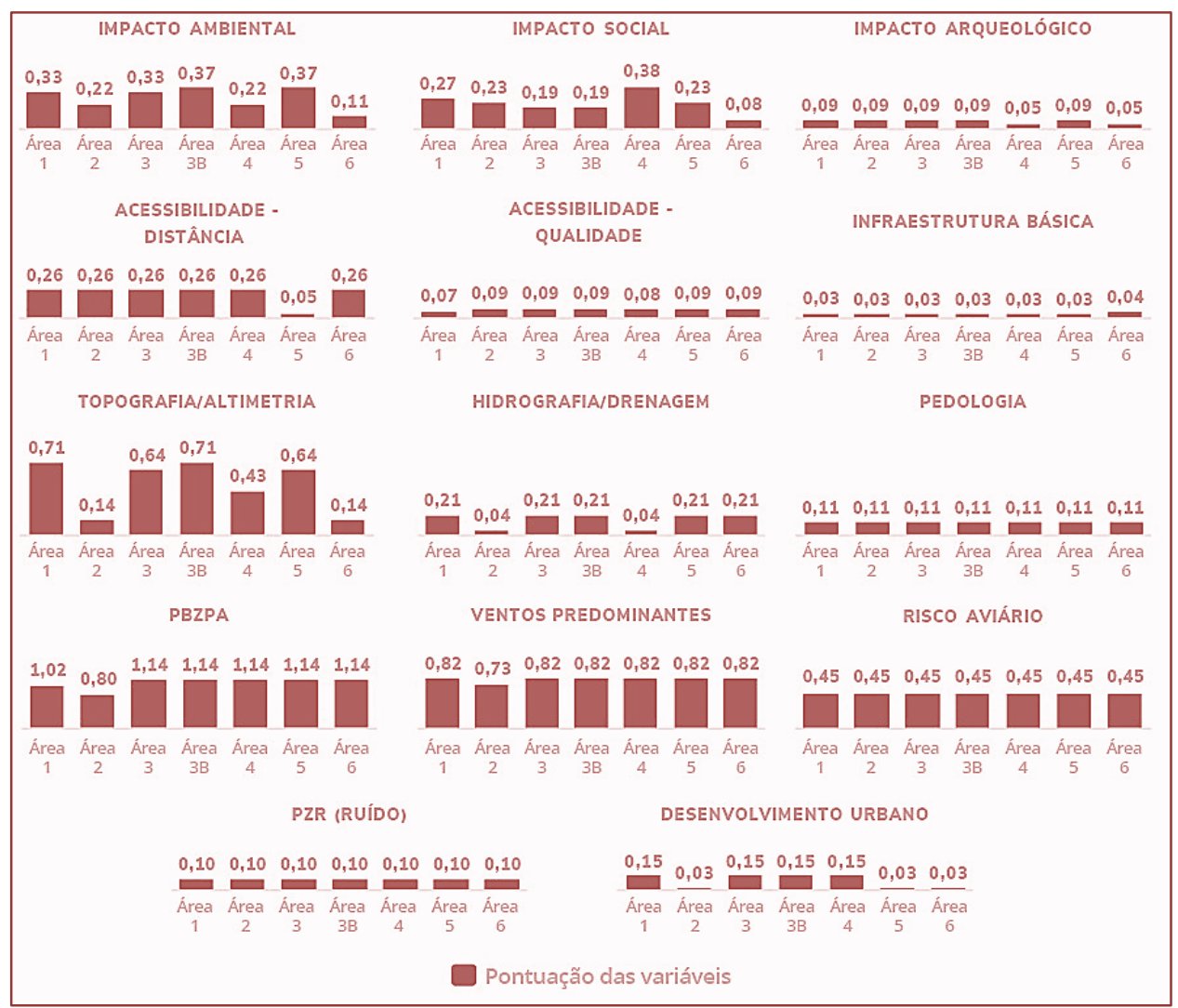


A pontuação final por sítio correspondente ao somatório das pontuações parciais e indica a aptidão de cada área potencial objeto dos estudos realizados. A Área 3B, que obteve a maior pontuação, a Área 1 e a Área 3 foram as indicadas como mais propícias à implantação do novo aeroporto, com base nos critérios considerados. A Figura 6 apresenta o resultado obtido para a pontuação final e uma hierarquização dos sítios potenciais.

Figura 6: Resultados da avaliação global dos sítios potenciais

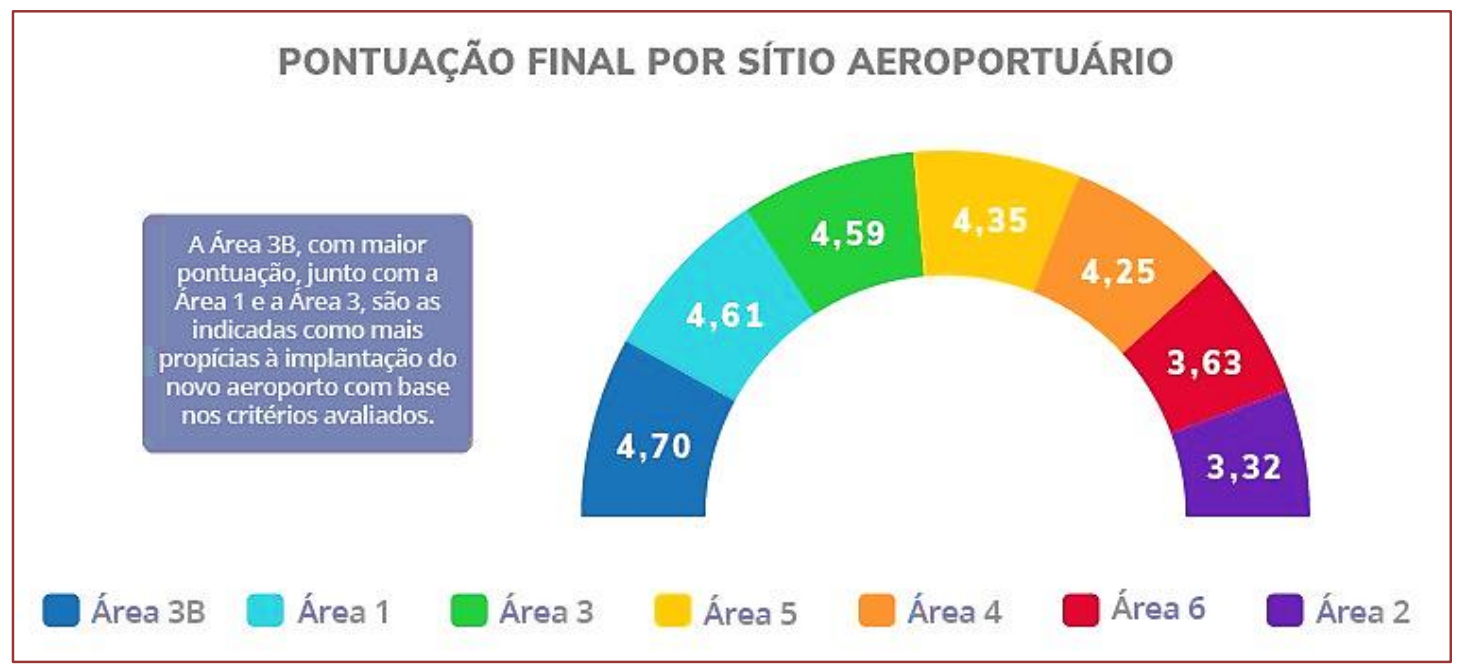

\section{CONCLUSÕES}

Este estudo demonstra que o uso de métodos multicriteriais mostra-se adequado ao apoio à tomada de decisão em problemas complexos, como o da escolha de um novo sítio aeroportuário. Dos instrumentos disponíveis, o método AHP é propício ao tratamento de problemas que envolvem variáveis de diferentes dimensões quantitativas e qualitativas. Esse método também possibilita lidar com múltiplos critérios conflitantes, inerentes ao processo de localização de um novo aeroporto, além de prover a participação dos decisores na escolha dos critérios e na estruturação hierárquica destes.

Foram apresentados 14 (quatorze) critérios para a aplicação do método, escolhidos levando-se em consideração as atuais normas e regulamentos brasileiros pertinentes, além da experiência dos técnicos envolvidos no estudo. Da mesma forma, foi construída uma escala Likert para esses critérios, a fim de executar a avaliação das potenciais áreas para o novo aeroporto.

Com relação a características intrínsecas do método AHP, vale fazer algumas observações relevantes. 0 método apoia-se na necessidade do estabelecimento consensual de critérios ou parâmetros de análise sobre os quais são feitas interpretações e julgamentos para subsidiar uma decisão final. Nesse sentido, deve-se observar que a seleção dos critérios ou parâmetros norteadores das análises pode variar qualitativa e/ou quantitativamente segundo o grau de qualificação, experiência e expectativas dos decisores envolvidos.

Também os julgamentos efetuados para a pontuação e hierarquização desses critérios, quando comparados entre si, estão sujeitos a consensos variáveis conforme essas mesmas qualidades dos decisores. Uma dada equipe técnica pode, portanto, optar por uma base de parâmetros que não contemplaria necessariamente os mesmos itens ou aspectos utilizados por outra equipe. Por outro lado, ainda que a mesma base de parâmetros seja adotada por equipes distintas, o processo de análise, julgamento e hierarquização dos critérios considerados, ou mesmo dos objetos de análise, pode levar a resultados finais diversos, dado que diferentes linhas de pensamento, entendimento, interpretação e conhecimento são fatores de peso e influência de graus variados entre os envolvidos.

Ainda, por conta de suas características específicas, o método fica sujeito a ponderações, embates e discussões em que a habilidade de argumentação pode se fazer presente, não necessariamente culminando no melhor resultado final. Portanto, a despeito de sua contribuição e adequação como ferramenta aplicável à seleção de sítios aeroportuários, é imprescindível evitar que a suscetibilidade do modelo a um grau de 
subjetivismo latente se sobreponha aos fundamentos embasados nos conceitos e conhecimentos técnicos necessários para obtenção do melhor resultado final. Para mitigar tais efeitos, foram organizadas visitas técnicas nos sítios, possibilitando-se assim uma avaliação bastante fidedigna das áreas. Também foram realizados diversos encontros entre os técnicos e tomadores de decisão, tanto para a escolha dos critérios de decisão quanto para a avaliação da importância relativa entre eles, considerando-se, ainda, caraterísticas locais que pudessem ser refletidas na seleção dos critérios de análise.

Em complementação ao método aplicado para o caso do Aeroporto de Balsas, recomenda-se a realização de análises de sensibilidade visando determinar a estabilidade do modelo às variações nos índices de importância relativa dos critérios. Sugere-se, também, a avaliação do impacto de eventuais mudanças de cenários políticos e estratégicos na decisão, conforme apresentado em Granemann e Gartner (1998). Outra evolução refere-se à utilização de métodos de análise multicriterial em conjunto com um Sistema de Informações Geográficas (SIG), como apresentado em Nóbrega et al. (2016). Nesse trabalho, os autores criaram mapas temáticos contendo dados de cada critério e utilizando-se da álgebra de mapas para localizar corredores propícios para a construção de ferrovias. Dessa forma, elimina-se o número discreto de áreas potenciais e trabalha-se com uma área contínua de possibilidades. Tal abordagem também poderia ser utilizada para a localização de sítios aeroportuários, podendose fazer uso dos mesmos critérios apresentados neste trabalho.

Embora o método AHP permita diversas abordagens diferentes, os critérios escolhidos e a forma de aplicação do método se adequaram ao caso avaliado neste trabalho. Ao final, recomendaram-se três áreas propícias para estudos mais aprofundados, como o levantamento de custos envolvidos na construção do aeroporto e estudos de viabilidade financeira.

\section{AGRADECIMENTOS}

Os autores agradecem à Secretaria Nacional de Aviação Civil (SAC), à prefeitura de Balsas (MA) e a todos os especialistas entrevistados que colaboraram na aplicação da metodologia.

\section{REFERÊNCIAS}

[1] ANAC (2011) Perigo aviário. In: Carta de Segurança Operacional (3 3 a ed.), Agência Nacional de Aviação Civil, Brasília, DF.

[2] ANAC (2018) Regulamento Brasileiro de Aviação Civil (RBAC) no 154 - Emenda noo 04. Agência Nacional de Aviação Civil, Brasília, DF.

[3] ANAC (2013) Regulamento Brasileiro de Aviação Civil (RBAC) no 161. Agência Nacional de Aviação Civil, Brasília, DF.

[4] Barcelos, J. A. (2001) Aeroporto e Meio Urbano: uma análise das legislações aeronáutica e urbanística em relação aos municípios de Campinas e Ribeirão Preto. Dissertação de mestrado. Universidade Estadual de Campinas, Faculdade de Engenharia Civil, Campinas, SP.

[5] Braga A. F. e Guedes E. P. (2008) Proposta de cálculo da acessibilidade em aeroportos com o uso de sistemas de informações geográficas. Anais do VII Simpósio de Transporte Aéreo (SITRAER), SBTA, Rio de Janeiro, p. 495-505.

[6] Brasil. Conama (1986) Resolução no 1, de 23 de janeiro de 1986. Diário Oficial da União de 17 de fevereiro de 1986, Brasília, DF.

[7] Brasil. Conama (1995) Resolução no 4, de 9 de outubro de 1995. Diário Oficial da União de 11 de dezembro de 1995, Brasília, DF.

[8] Brasil (2012). Lei no 12.725, de 16 de outubro de 2012. Diário oficial da União de 17 de outubro de 2017, Brasília, DF.

[9] Brasil. DECEA (2015) ICA 63-19 Critérios de análise técnica da área de aeródromos. Departamento do Controle do Espaço Aéreo, Brasília, DF.

[10] Brasil. SAC (2017). Projeção de demanda da aviação civil - Passageiros, aeronaves e carga - 2017-2037. Ministério dos Transportes, Portos e Aviação Civil, Brasília, DF.

[11] Brasil. SAC (2018). Plano aeroviário nacional 2018-2038. Ministério dos Transportes, Portos e Aviação Civil, Brasília, DF.

[12] Granemann S. R. e I. R. Gartner (1998) Seleção de financiamento para aquisição de aeronaves: uma aplicação do método de análise hierárquica (AHP). TRANSPORTES, v. 6, n. 1, p. 18-40. 
[13] IBGE (2018) Panorama: Balsas. Instituto Brasileiro de Geografia e Estatística, Rio de Janeiro. Disponível em:

[14] <https://cidades.ibge.gov.br/brasil/ma/balsas/panorama>. Acesso em: 20 dez. 2018.

[15] Likert, R. A (1932) Technique for the measurement of attitudes. Archives of psychology, v. 22, n. 140, p. 5-55.

[16] Merkisz-Guranowska, A.; Bieńczak M.; Kiciński M. e Zmuda-Trzebiatowski P. (2016) Location of airports selected quantitative methods. Scientific Journal of Logistics LogForum, v. 12, n. 3, p. 283-295.

[17] Migueis Pereira, A. C. (2017) Desapropriações e Remoções na implantação de projetos de infraestrutura: entre avanços e oportunidades perdidas. REVISTA PUBLICUM, v. 2, n.3, p. 134-165.

[18] Mim, H. (1994) Location Planning of Airport Facilities using the Analytic Hierarchy Process. Logistics and Transportation Review, v. 30, n. 1, p. 79-94.

[19] Nóbrega, R. A. A.; Vieira, R. R. T.; Berberian, C. F. Q; Dias Filho, N.; Masukawa, N.; Ferraz, C. A. M. e Quadro, E. A. T. (2016) Inteligência geográfica para avaliação de propostas de projeto de concessão de corredores ferroviários. TRANSPORTES, v. 24, n. 4, p. 75-84.

[20] Saaty, T. L (1980) The Analytic Hierarchy Process. McGraw-Hill, New York.

[21] Saaty, T. L. e Vargas L.G. (2013) Decision Making with the Analytic Network Process: Economic, Political, Social and Technological Applications with Benefits, Opportunities, Costs and Risks ( $2^{\underline{a}}$ ed.). Springer Science+business Media, New York. 


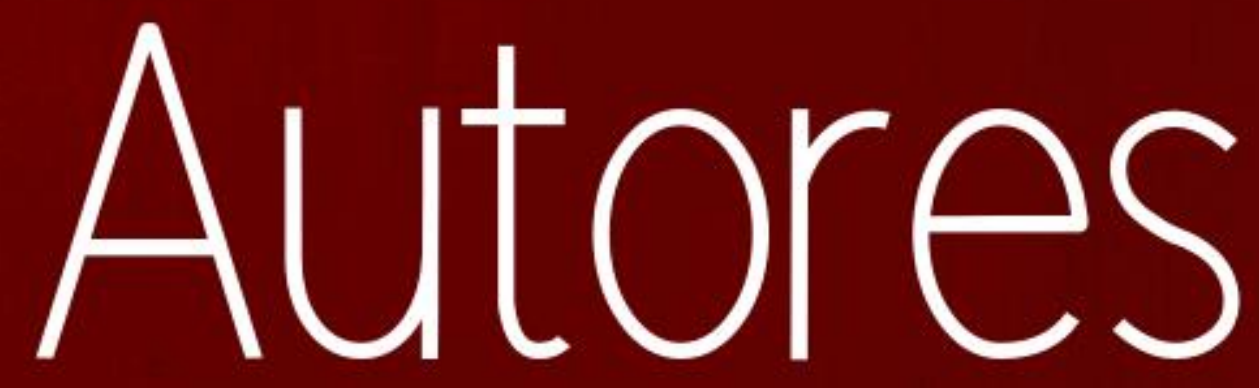




\section{ADOSINDRO JOAQUIM DE ALMEIDA}

Engenheiro Civil pela Universidade Federal de Santa Catarina - UFSC (2010). Possui mestrado (2013) e doutorado (2017), em Engenharia Civil pela mesma universidade, nas áreas de concentração Infraestrutura e Gerência Viária, e, Infraestrutura e Geotecnia". Atualmente, pesquisador do Laboratório de Transportes e Logística (LabTrans) e membro da equipe técnica do projeto de pesquisa inserido no Termo de Execução entre o Departamento Nacional de Infraestrutura de Transportes (DNIT) e a UFSC com enfoque na pesagem em movimento - WIM (Weigh In Motion) e é, também, professor do curso de Engenharia Civil do Instituto de Ensino Superior da Grande Florianópolis (IES/FASC) e da Universidade do Vale do Itajaí (UNIVALI). Tem experiência na área de Engenharia Civil, atuando principalmente nos seguintes temas: Infraestruturas de Transportes, estudo de materiais de pavimentação de estrada, estudo de comportamento reológico e de desempenho mecânico de concreto asfáltico nos ensaios fundamentais - Módulo Complexo e Fadiga, pesagens em movimento e dano aos pavimentos.

\section{AMIR MATTAR VALENTE}

Doutor em Engenharia de Produção pela Universidade Federal de Santa Catarina. Professor titular da Universidade Federal de Santa Catarina junto ao curso de Engenharia Civil na UFSC e no Programa de Pós-Graduação em Engenharia de Transportes e Gestão Territorial. Pesquisador de Desenvolvimento Tecnológico, nível 2 do CNPq. Coordenador Geral do Laboratório de Transportes e Logística da Universidade Federal de Santa Catarina - LabTrans/UFSC.

\section{ANDERSON SCHMITT}

Mestre em Engenharia de Transportes e Gestão Territorial pela Universidade Federal de Santa Catarina. Engenheiro Civil no Laboratório de Transportes e Logística da Universidade Federal de Santa Catarina - LabTrans/UFSC.

\section{ANDRÉ SOARES LOPES}

Mestre em engenharia e ciências sociais pelo Instituto Tecnológico de Tóquio (2007). Doutor em Engenharia pelo programa de Pós Graduação em Engenharia de Transportes pela UFC (2015). Interesses de pesquisa são: (1) Planejamento Integrado de Uso do solo e Transportes - LUTI, (2) Mobilidade Ativa e transporte não motorizado e (3) Morfologia Urbana, com ênfase em sintaxe espacial. Pesquisador da Universidade de Lisboa - Faculdade de Arquitectura - CIAUD.

\section{CAMILA BANDEIRA CAVALCANTE}

Arquiteta (UFC, 1999) com mestrado em transportes (IST/Lisboa, 2002). Atualmente, é pesquisadora de doutorado no no Programa de Pós-Graduação em Engenharia de Transportes (Petran/UFC), no Núcleo de Pesquisa PAMUS - Planejamento da Acessibilidade e Mobilidade na Urbe Sustentável. Atua como consultora em sistemas de mobilidade e planejamento urbano, além de ser professora dos cursos de arquitetura e urbanismo da Universidade de Fortaleza (UNIFOR), de especialização em mobilidade urbana da UNIFOR e da pós-graduação em engenharia de transportes da UFC.

\section{DIEGO MANOEL ENEDINO GONÇALVES}

Possui graduação em Engenharia Mecânica pelo Centro Federal de Educação Tecnológica Celso Suckow da Fonseca (2018). Tem experiência na área de Engenharia Mecânica, com ênfase em Métodos Numéricos, atuando principalmente no seguinte tema: opções reais, análise de investimento, transporte. Atualmente cursa o programa de pós-graduação no nível de Mestrado em Engenharia Nuclear, pela Instituto Alberto Luiz Coimbra de Pós-Graduação e Pesquisa de Engenharia (COPPE/UFRJ). 


\section{FERNANDA MATTOS DEUCHER}

Engenheira Civil formada pela Universidade Federal de Santa Catarina (2016). Mestre em Infraestrutura e Geotecnia pela Universidade Federal de Santa Catarina (2019). Desde 2019 trabalha como Engenheira Civil na Secretaria de Infraestrutura e Mobilidade do Estado de Santa Catarina.

\section{FRANCISCO ALTANIZIO BATISTA DE CASTRO JUNIOR}

Mestrando em Engenharia de Transportes e graduado em Engenharia Civil na Universidade Federal do Ceará

\section{GABRIELA CECCON CARLESSO}

Possui Graduação (2014) e Mestrado (2017) em Engenharia Civil pela Universidade Federal de Santa Catarina (UFSC), com Doutorado em andamento pela mesma Instituição, na área de Infraestrutura e Geotecnia. É Coordenadora do curso de Engenharia Civil da Universidade do Oeste de Santa Catarina (Unoesc) campus de Chapecó. Ministra as disciplinas de Estradas, Transporte e trânsito, Geologia e Mecânica dos Solos. Também orienta acadêmicos de Iniciação Científica, Estágios Supervisionados e Trabalhos de Conclusão de Curso. Atualmente é membro do Grupo de Pesquisa Inovação e Tecnologias em Engenharias, Arquitetura e Urbanismo (ITEAU, da Unoesc, certificado pelo CNPq). Entre 2014 e 2018, atuou como Pesquisadora no Grupo de Pesquisa Rodovias Verdes (UFSC). Tem experiência na área de Infraestrutura e Geotecnia, com ênfase, principalmente, em Pavimentação Rodoviária.

\section{GLICÉRIO TRICHÊS}

Possui graduação em Engenharia Civil pela Universidade Federal de Santa Catarina (1981), mestrado em Engenharia Civil pela Universidade Federal do Rio de Janeiro (1985) e doutorado em Infraestrutura Aeroportuária pelo Instituto Tecnológico de Aeronáutica (1993). É professor da Universidade Federal de Santa Catarina desde 1984. Professor Titular. Foi Coordenador do Programa de Pós-Graduação em Engenharia Civil da Universidade Federal de Santa Catarina (20052007;2007-2009; 2015-2018). Coordenador do curso de Engenharia Civil 2011-2013. Tem experiência na área de Engenharia Civil, com ênfase em Rodovias, Projeto e Construção, atuando principalmente nos seguintes temas: Dimensionamento de pavimentos, desempenho de pavimentos, comportamento dos materiais empregados na pavimentação e propriedades funcionais dos revestimentos asfálticos. Coordenador de Projetos de Pesquisa de Agências de Fomento e da Rede Temática de Tecnologia do Asfalto. Desenvolvimento de projetos de consultoria junto a empresas de engenharia consultiva do sul do Brasil e junto ao DEINFRA/SC e DNIT. Revisor de Periódicos Nacionais e Internacionais. Atualmente tem se dedicado a pesquisar temas relacionados com novos materiais, nanotecnologia aplica em rodovias e sustentabilidade dos empreendimentos rodoviários. Coordena do Grupo de Pesquisa Rodovias Verdes e é responsável pelo site www.rodoviasverdes.ufsc.br. Pesquisador CNPq, nível 1D.

\section{JOÃO VICTOR STAUB DE MELO}

Atualmente é professor do Departamento de Engenharia Civil da Universidade Federal de Santa Catarina (UFSC). Possui graduação em Engenharia Civil (2007), é Mestre (2011) e Doutor (2014) na área de concentração de Infraestrutura e Gerência Viária pela UFSC. Em 2015, concluiu o PósDoutorado (UFSC) com ênfase em pavimentação. Desde 2016 é professor permanente do Programa de Pós-Graduação em Engenharia Civil (PPGEC/UFSC) (conceito CAPES 5). Atua como pesquisador nas seguintes linhas: dimensionamento, desempenho e avaliação de pavimentos; misturas asfálticas especiais; comportamento reológico e desempenho mecânico de misturas asfálticas; comportamento reológico de ligantes asfálticos e nanotecnologia aplicada à pavimentação.

\section{JOAQUIM JOSÉ GUILHERME DE ARAGÃO}

Engenheiro Civil pela PUC-Rio (1977). Mestrado em Engenharia de Produção, pela PUC-Rio (1980), Doutorado pela Universität Dortmund, Alemanha (1987. Pós-Doutorados na University College of 
London (Direito Comparado dos Transportes, 1993-1995); École Nationale des Ponts et Chaussées, em Marne-la-Vallée, França (Parcerias Público-Privadas, 2002-2003), e na Technische Universität Berlin (Análise de impactos fiscais de investimentos em infraestrutura (2010-2011). É Pesquisador Nível 1D do CNPq

\section{JOSÉ DOS SANTOS DE MAGALHÃES}

Mestre em Pesquisa Operacional e Transporte Aéreo pelo Instituto Tecnológico de Aeronáutica. Engenheiro Civil / Planejamento Aeroportuário no Laboratório de Transportes e Logística da Universidade Federal de Santa Catarina - LabTrans/UFSC.

\section{KAIO MESQUITA}

Engenheiro Civil, Mestrando em Engenharia de Transportes com ênfase em Modelagem e Análise de dados com Big Data de transporte público. Pós Graduado em Data Science com ênfase em construção e gestão de banco de dados. Pós-Graduando em Gestão de Projetos.

\section{LEONARDO PERIM GUERSON}

Coordenador técnico de projetos de ITS no Laboratório de Transportes e Logística-LabTrans/UFSC. Mestre em Engenharia de Transportes e Gestão Territorial pela Universidade Federal de Santa Catarina.

\section{LISEANE PADILHA THIVES}

Possui graduação em Engenharia Civil pela Universidade Federal de Santa Catarina (1989), mestrado em Engenharia Civil pela Universidade Federal de Santa Catarina (2001) e doutorado em Engenharia Civil, área de conhecimento Vias de Comunicação, pela Universidade do Minho em Portugal (2009) e em Infra-Estrutura e Gerência Viária pela Universidade Federal de Santa Catarina (2009). Atuou na iniciativa privada como Engenheira de Obras Rodoviárias (terraplenagem, drenagem, pavimentação) e gerenciamento de Usina de Asfalto, Britagem e Pedreira. É professora Associada da Universidade Federal de Santa Catarina, Departamento de Engenharia Civil ministrando, na graduação, as disciplinas de Pavimentação e de Projeto Geométrico de Estradas. Atua na pós graduação (PPGEC/UFSC), ministrando as disciplinas de Reologia de Asfaltos, Fadiga de concreto asfáltico de Conservação e Restauração de Estradas. Tem experiência na área de Engenharia Civil, com ênfase em Rodovias; Projeto, Dimensionamento de Pavimentos e Construção, atuando principalmente nos seguintes temas: análise mecanicista de pavimentos, fadiga, deformação permanente, propagação de fendas, reologia de asfaltos, misturas modificadas com asfalto borracha e com polímeros e pavimentos drenantes.

\section{LUÁDYNA ALMEIDA BEZERRA}

Arquiteta e Urbanista formada pela Universidade de Fortaleza em 2019. Durante a graduação, participou do Programa de Monitoria Institucional, nos anos de 2016 e 2019, nas disciplinas de Projeto Arquitetônico e Urbanístico e Projeto Urbanístico. Atuou como aluna-pesquisadora no grupo de pesquisa "Análise Histórica Dos Planos Diretores De Fortaleza - Mapeamento Das Políticas Públicas", publicando artigos e participando de congressos, função que também desempenha atualmente. Enquanto profissional, atua em projetos de arquitetura e interiores, desenvolvendo habilidades em gestão e gerenciamento de projetos, concepção, maquetes 3D, renderizações, detalhamentos e acompanhamento em obra.

\section{LUCAS CÉZAR SANTANA FERREIRA}

Arquiteto e Urbanista, pelo Instituto de Ciências Juridicas e Sociais Prof. Camillo Filho, graduado em 2017. Possui graduação-sanduíche em Architecture Design na Deakin University - Australia, concluído em 2014. Tem mestrado acadêmico na área de Projeto e Planejamento Urbano e Regional, concluído em 2021, no PPG-FAU da Universidade de Brasília. Atualmente, desenvolve pesquisas 
sobre mobilidade, planejamento e gestão das cidades, com foco na aplicabilidade da Engenharia Territorial.

\section{MARCELO BAVIER MARCOS}

Coordenador de Autuação na Agência Nacional de Transportes Terrestres - ANTT. Mestrando em Engenharia de Transportes pela Universidade Federal do Rio de Janeiro.

\section{MATHEUS FELIPE MARCON}

Possui graduação em Engenharia Civil pela Universidade Federal de Santa Catarina (2013) e mestrado em Engenharia Civil pela Universidade Federal de Santa Catarina (2016), na área de Infraestrutura de Transportes. Tem experiência na área de Engenharia Civil, com ênfase em Rodovias; Projeto e Construção, atuando principalmente nos seguintes temas: concreto asfáltico modificado, comportamento reológico, módulo complexo, resistência à fadiga e deformação permanente.

\section{MOISÉS GOMES DE HOLANDA CUNHA}

Engenheiro Civil com ênfase em planejamento de transportes. Com experiência com pesquisa na área de planejamento integrado de transportes e uso do solo, bem como de modelagem da demanda. Com experiência acadêmica internacional em graduação sanduíche nos EUA, na UMKC em engenharia civil.

\section{RAFAEL CARDOSO CUNHA}

Mestre em Economia, Universidade Federal da Bahia. Especialista em Planejamento no Laboratório de Transportes e Logística da Universidade Federal de Santa Catarina - LabTrans/UFSC.

\section{REBECA FROÉS DE ASSIS}

Arquiteta e Urbanista pela Universidade de Fortaleza (2014-2019). Atualmente é pesquisadora de mestrado no Programa de Pós-Graduação em Engenharia de Transportes (Petran/UFC), onde atua como membro integrante do Núcleo de Pesquisa PAMUS - Planejamento da Acessibilidade e Mobilidade na Urbe Sustentável. Possui forte interesse em: Planejamento e Operação de Sistemas de Transportes; Pesquisa em Modelagem Integrada dos Transportes e Uso do Solo; Docência; Planejamento Urbano e Regional; Desenho urbano; Representação gráfica de projetos.

\section{RODRIGO RODRIGUES DE FREITAS}

Doutorando em Engenharia de Transporte (Universidade Federal do Rio de Janeiro - UFRJ/COPPE). Mestre em Economia Empresarial (Escola de Economia - Universidade Cândido Mendes), Graduado em Administração de Empresas (Faculdade São Paulo Apóstolo). Experiência profissional: Nas áreas de Risco financeiro, Análise de Investimento e Análise de commodities, atividades de consultoria em finanças, projeção econômica-financeira e planejamento em transporte com enfoque em aspectos de sustentabilidade, baixa emissão de carbono e consumo energético, projeção de dados econométricos e análises macroeconômica. Atividades militares como Oficial de Engenharia do Exército Brasileiro. Professor universitário nas áreas de ciências sociais aplicadas em gestão, economia e finanças. Atualmente trabalho no Centro Federal de Educação Tecnológica - CEFET-RJ Unidade Itaguaí. Membro do LabSim - Laboratório de Simulação do CEFET-RJ e do Laboratório de Transporte de Carga - LTC/COPPE/UFRJ.

\section{RONNY MARCELO ALIAGA MEDRANO}

Possui graduação em engeharia civil - ESCUELA MILITAR DE INGENIERIA (2006) e mestrado em Transportes pela Universidade de Brasília (2012). Doutor em Transporte pela Universidade de Brasilia (2016). Atuo profissionalmente como analista de transporte na prefeitura do Governo 
municipal de La Paz, Bolivia. Como assessor técnico na Empresa de Planejamento e Logística S.A. do Ministerio do Transporte do Brasil, com enfase no desenvolvimento do modelo de transporte do Plano Nacional de Logística Integrada. Como consultor em estudos de demanda para projetos ferroviarios, planos de mobilidade, planos de transporte público. Atualmente é professor do Curso de Engenharia de Transporte da Universidade Federal de Goiás.

\section{TEOTONIO KO FREITAG}

Coordenador de Gestão Estratégica do Ministério da Infraestrutura, Analista de Infraestrutura e Especialista em Gestão Estratégica.

\section{THIAGO DE SOUZA CARDOSO MAYRINK PAIVA}

Estudante do curso de Engenharia Mecânica pelo Centro Federal de Educação Tecnológica Celso Suckow da Fonseca Engenharia Mecânica do Cefet/RJ Itaguaí e membro do laboratório de simulação. Experiência profissional na indústria de óleo e gás, atuando no projeto e fabricação de equipamentos industriais: vasos de pressão com selo ASME, tanques API e trocadores de calor.

\section{VALTER ZANELA TANI}

Gerente de planejamento de transportes da Fundação de Amparo à Pesquisa e Extensão Universitária - FAPEU. Coordenador Técnico do Laboratório de Transportes e Logística da Universidade Federal de Santa Catarina - LabTrans/UFSC e do Centro de Excelência do iRAP no Brasil. Doutor em Engenharia de Produção pela Universidade Federal de Santa Catarina.

\section{VANESSA ESPÍNDOLA}

Engenheira Civil no Laboratório de Transportes e Logística - LabTrans/UFSC. Mestre em Engenharia de Transportes e Gestão Territorial pela Universidade Federal de Santa Catarina.

\section{WILLER LUCIANO CARVALHO}

Possui graduação em Engenharia Civil pela Universidade Federal de Goiás (1999), especialização em Planejamento e Gerenciamento de Recursos Hídricos (UFG), mestrado em Transportes pela Universidade de Brasília (2004) e doutorado em Transportes pela Universidade de Brasília (2011). Atuou profissionalmente como engenheiro de transportes na Companhia Metropolitana de Transportes Públicos da Região Metropolitana de Goiânia - CMTC, como gerente do projeto de transporte escolar rural no Centro de Formação de Recursos Humanos em Transportes da Universidade de Brasília - CEFTRU/UNB, e atualmente, atua profissionalmente como Professor Adjunto no curso de graduação em Engenharia de Transportes, da Universidade Federal de Goiás UFG.

\section{YAEKO YAMASHITA}

Engenheira Civil pela Universidade de Londrina; Mestre em Engenharia Civil pela Universidade de Tottori - Japão; Doutorado em Engenharia de Transportes - University of Wales - College of Cardiff ; Pós doutorado em Nagoya Institute of Technology no Japão. Professora da Universidade de Brasília, Pesquisadora PQ-1A do CNPQ - Conselho Nacional de Desenvolvimento Científico e Tecnológico 


\section{www.poisson.com.br contato@poisson.com.br}

@editorapoisson 